Portland State University

PDXScholar

Fall 12-4-2014

\title{
Early Childhood Educators' Perception of Oregon's Professional Development System: A Hermeneutic Phenomenological Study
}

Ingrid Anderson

Portland State University

Follow this and additional works at: https://pdxscholar.library.pdx.edu/open_access_etds

Part of the Pre-Elementary, Early Childhood, Kindergarten Teacher Education Commons Let us know how access to this document benefits you.

Recommended Citation

Anderson, Ingrid, "Early Childhood Educators' Perception of Oregon's Professional Development System: A Hermeneutic Phenomenological Study" (2014). Dissertations and Theses. Paper 2080.

https://doi.org/10.15760/etd.2078

This Dissertation is brought to you for free and open access. It has been accepted for inclusion in Dissertations and Theses by an authorized administrator of PDXScholar. Please contact us if we can make this document more accessible: pdxscholar@pdx.edu. 
Early Childhood Educators' Perception of Oregon's Professional Development System:

A Hermeneutic Phenomenological Study

by

Ingrid Mari Anderson

A dissertation submitted in partial fulfillment of the requirements for the degree of

Doctor of Education

in

Educational Leadership: Curriculum And Instruction

Dissertation Committee:

William Parnell, Chair

Ben Anderson-Nathe

Christine Chaillé

Jason Ranker

Portland State University

2014 
(C) 2014 Ingrid Mari Anderson 


\begin{abstract}
Since 2011, the state of Oregon has embarked on a comprehensive educational policy change to create a unified birth to twenty educational system. As part of the birth to age five early childhood and family investment strategy, mandated participation in Oregon professional development system is required for all early childhood educators working in Office of Child Care licensed programs. To date, research on early childhood educators' experience in professional development systems has focused primarily on experiences with regulatory systems. This hermeneutic phenomenological study explored how four early childhood educators made meaning of their experiences of professional engagement in Oregon's state professional development system.

As a researcher-participant, I conducted a two-part interview with these early childhood educators. First, we revisited the experience of the professional development journey in collage, followed by narrative semi-structured interviews. The researcher employed Dahlberg's (2006) concept of "bridling the experience" (p. 16) as a way to develop an understanding of early childhood educators' professional practice and the intersection between practice and professional engagement in Oregon's professional development system for childhood care and education. The collage and narrative dialogues illuminated the essence of each individual's experience. Experiences such as the intersection of personal professional self, acts of professional engagement, and the emotional nature of participants' work all emerged from the collage and interview process. Three essential themes emerged from the data interpretation and discussion, namely, (a) Personal and Professional Self: Intertwining Personal Experience and
\end{abstract}


Professional Identity, (b) Curves Ahead: Maneuvering Rivers, Roads, and Paths, and (c) The Journey and the System are Asynchronous: "You Guys Figure that Out, Good Luck." Through the emergence of essential themes, participants demonstrated that their experiences while unique also shared common characteristics of what it means to be an early childhood educator in Oregon living with policy in the classroom. It is now the turn of policy makers and program managers of Oregon's professional development system to recognize the strength and wisdom of the voices in the early childhood classroom. 


\section{Dedications}

For above all, love each other deeply, because love covers over a multitude of sins (1 Peter 4:8). To my beloved husband Gregory Baker, who has had the grace to joyfully live through my doctorial experience. Your unflagging love has made this journey possible.

In celebration of my parents Isabel and Gus who modeled through my childhood and beyond that curiosity creates a depth of opportunities to know the larger world and ourselves.

To Oregon's early childhood and education community, no voice is dearer than the ones who speak in the classroom. 


\section{Acknowledgements}

Hermeneutic phenomenology as a research methodology is a funny thing. It is not for the hurried or those who seek immediate clarity. It is for those who cultivate patience while actively awaiting meaning. As someone who works on cultivating a stance of active waiting, it was a bit of a struggle. Neither is hermeneutic phenomenology easy to describe as a first time researcher. It is only at the end of the research journey, that clarity emerges. It is then, that you say to yourself, "Ahh, the strands of my own and others experiences have woven themselves in a pattern where meaning has emerged." During the journey, however, doubt and confidence, frustration and enlightenment, darkness and vision all twined together.

In the vastness of trying to make sense of my research, there were guiding lights that reflected my thinking, my emotions, and my vision back to me. It was my advisor and colleague Dr. Will Parnell who paid attention and offered up a reflective frame of reference to support me through my academic journey. Will, thank you for your honest enthusiasm for every single one of my thoughts and ideas, as well as the strength to curb my keenness with good humor and honesty. To Dr. Christine Chaillé, thank you for the discussions that always pushed me to think about my thinking throughout our time together. Dr. Ben Anderson-Nathe, thank you as well for your insights into my research, you gave me such interesting platforms to launch from to new ways of knowing. I must also extend appreciation to Dr. Jason Ranker, who graciously joined my committee supporting my momentum forward. 
A special acknowledgement and appreciation for my friend and colleague Jean Barbre, who through 16 years of friendship has been an inspiration and sounding board for my journey in early childhood education.

I especially want to extend my deep appreciation for all the early childhood education professionals who contacted me and offered to participate in my study. A special debt of gratitude goes to the individuals who gave of their time and offered their professional journeys as a learning opportunity. Your insights into early childhood education humbled me. Thank you for telling your stories. 
TABLE OF CONTENTS

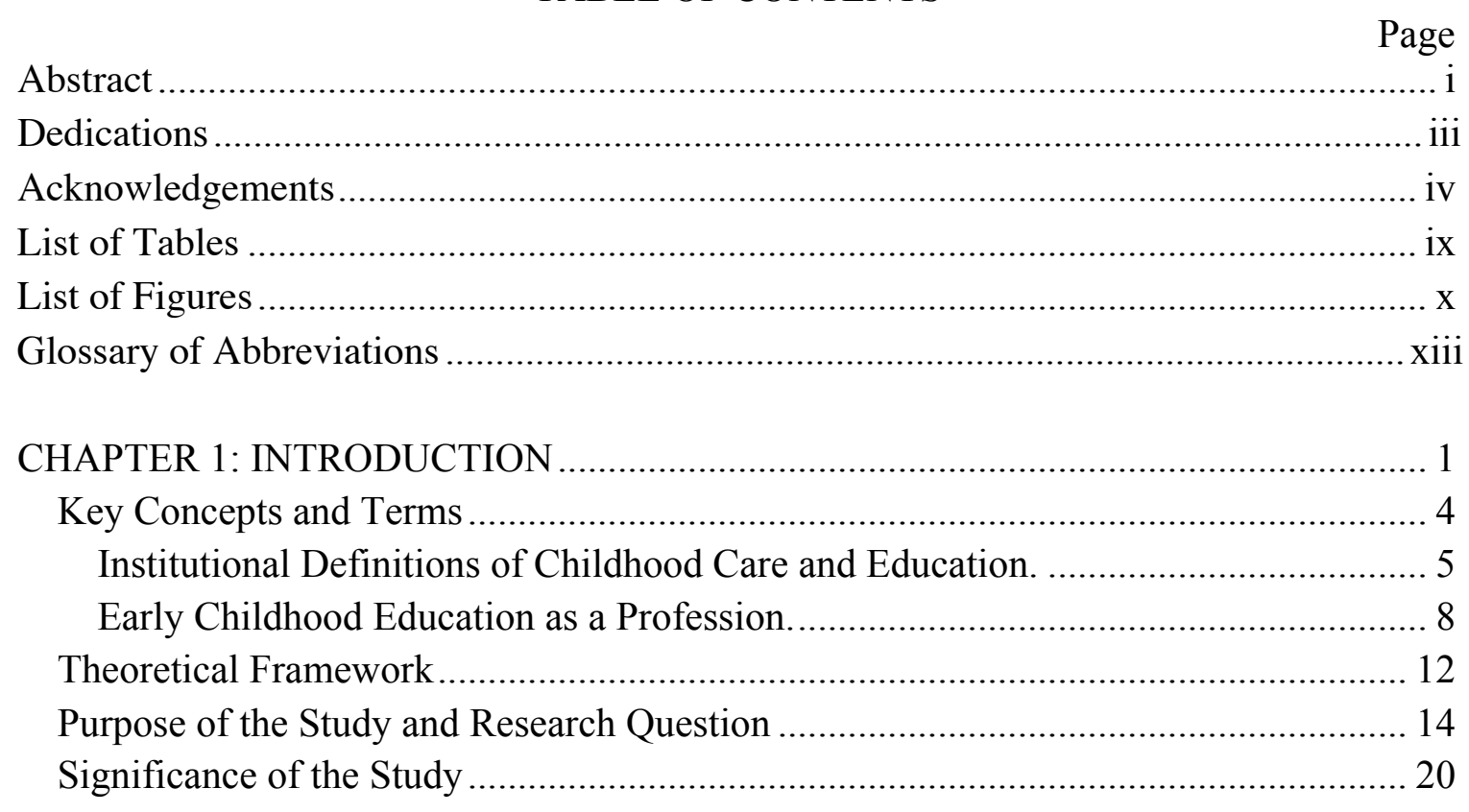

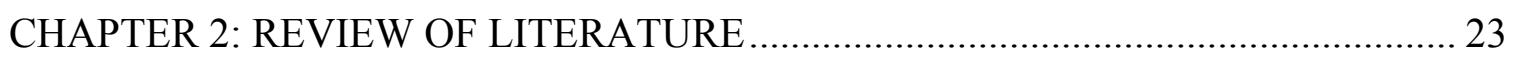

Professional Development Systems .......................................................................... 25

State and National Trends in Professional Development Systems .......................... 27

Formation and Enactment of Professional Development System Models................ 28

Strengths and Limitations of Professional Development Systems Models .............. 35



Concepts of Profession, Professionalism, and Professional Identity .......................... 40

The Early Childhood Education Profession............................................................ 40

Professionalism as a Cultural, Historical, and Political Construct .......................... 42

The Intersection of Professionalism and Professional Identity............................. 43

Construction of Professional Identity ........................................................... 44

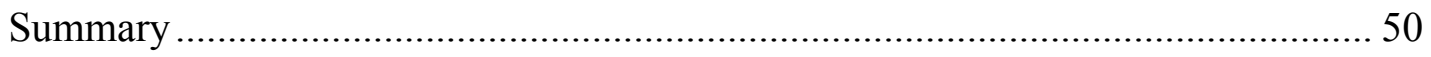

Professional Development and Professional Engagement......................................... 51

Professional Engagement Opportunities ............................................................. 54

Professional Engagement as a Function of Oregon's Professional Development

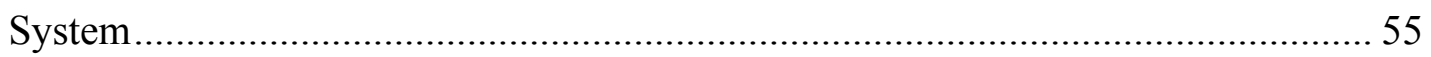

The Degree, Credential, and Certificate Pathway ............................................... 58

College Course Credit Pathway.......................................................................... 59

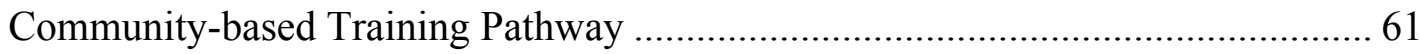

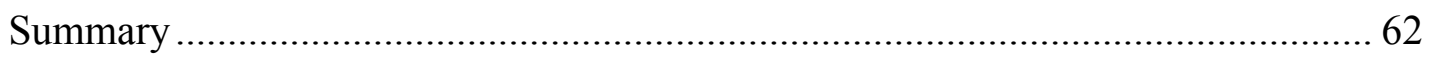




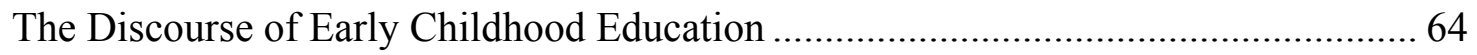

Conceptualization of Discourse of Early Childhood Education ................................ 64

Construction of Professional Identity and the Dominant Language Paradigm......... 68

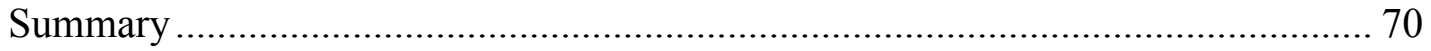

Expressive Language as a Way to Make Meaning of Professionalism ......................... 71

Early Childhood Educator Use of Reflective Practice.............................................. 73

The Intersection of Reflective Practice, Professionalism, and Mandated Professional

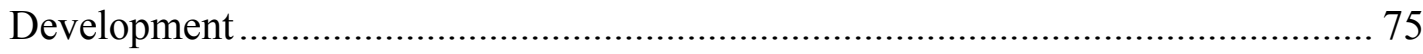

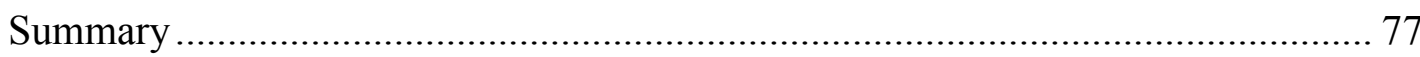

Implications of the Literature Review ................................................................. 78

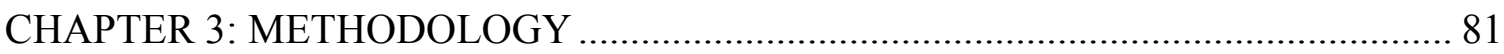

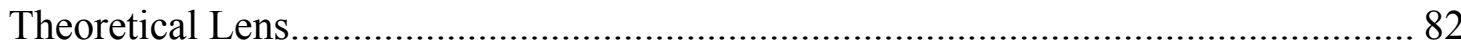

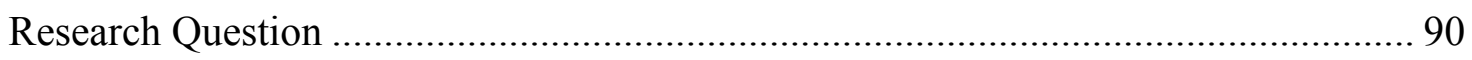

Recruitment and Participation.............................................................................. 91

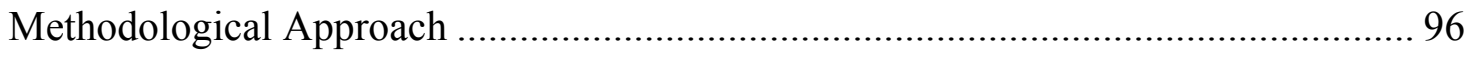

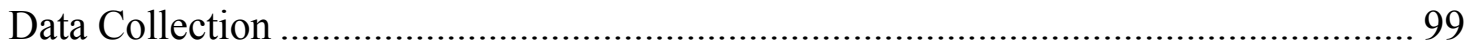

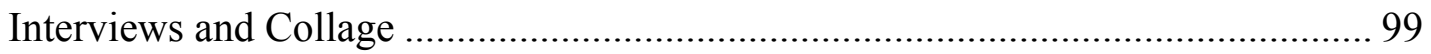

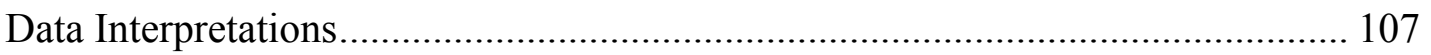

CHAPTER 4: RESEARCH FINDINGS AND DISCUSSION ……………………..... 110

Section One: Early Childhood Educators Professional Journeys ............................... 113

Carolina's Professional Development Journey ………………………................. 114

Ingrid's Experiences with Carolina's Professional Development Journey.............. 122

Linda's Professional Development Journey ……………………………............. 126

Ingrid's Experiences with Linda's Professional Development Journey ................... 132

Nora's Professional Development Journey.......................................................... 136

Ingrid's Experience with Nora's Professional Development Journey ..................... 144

Mira's Professional Development Journey ………………............................... 150

Ingrid's Experiences with Mira's Professional Development Journey..................... 159

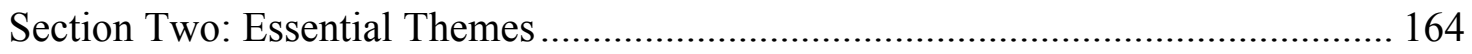

Personal and Professional Self: Intertwining Personal Experiences and Professional

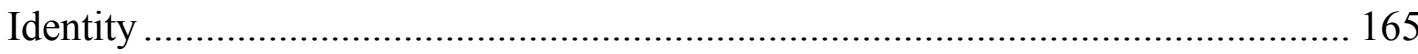

Curves Ahead: Maneuvering Rivers, Roads, and Paths. ........................................ 173

The Journey and the System are Asynchronous: "You Guys Figure That Out, Good

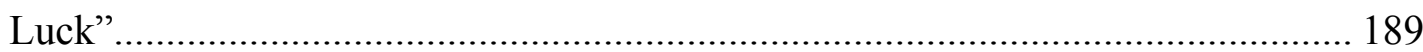

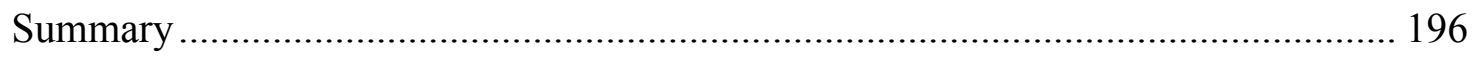


CHAPTER 5: REFLECTIONS, CONCLUSIONS, AND IMPLICATIONS................ 199

Situating the Essential Themes within Participants' Professional Development Journey

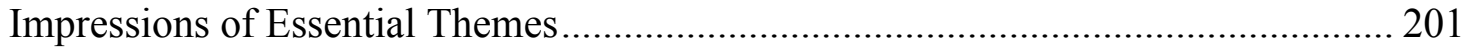

The Strength of an Intertwined Personal and Professional Self ............................ 202

Professional engagements and the development of pedagogical practices............ 204

The Unintended Consequences of Oregon's Professional Development System. .... 207

Reflections of Bridling the Experience...................................................................... 209

Implications and Recommendations for the Future Action ..................................... 214

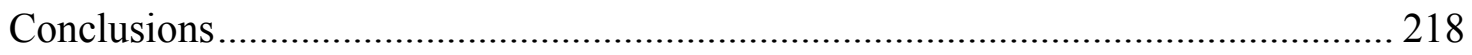

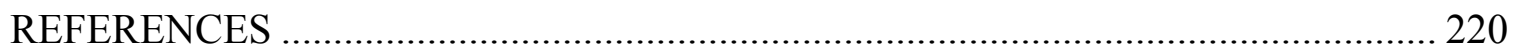

Appendix A Recruitement Materials .......................................................................... 233

Appendix B Support for Navigating Oregon's Professional Development System ....... 235

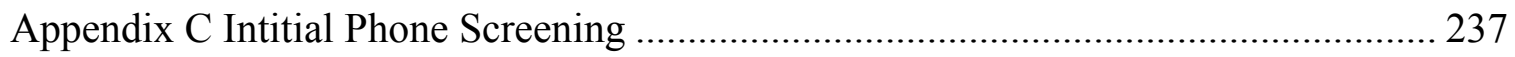

Appendix D Research Log................................................................................... 241

Appendix E Data Collection Timeline and Procedures ................................................ 242

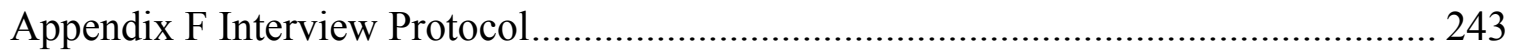

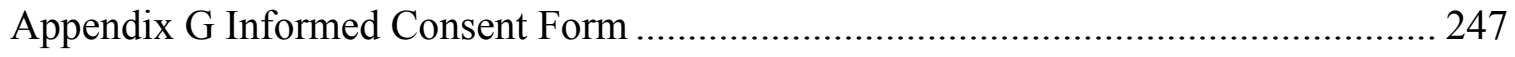

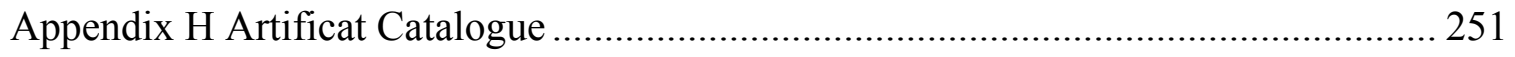




\section{LIST OF TABLES}

Table Page

1 Making Meaning of Professional Identity and Personal Experience ...............167

2 Identifying as an Early Childhood Education Professional ............................203

3 Identifying Experiences in Professional Engagement ..................................205

4 What Meaning Can Be Made of Experience? ..............................................207 
Figure

\section{LIST OF FIGURES}

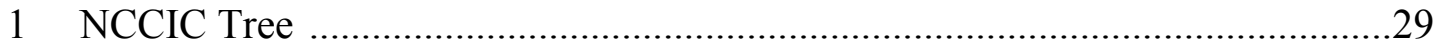

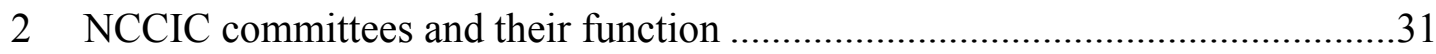

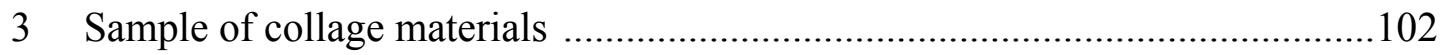

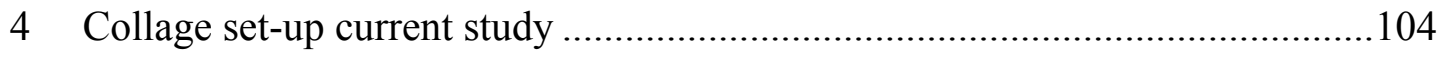

5 The floor where Carolina worked .............................................................. 116

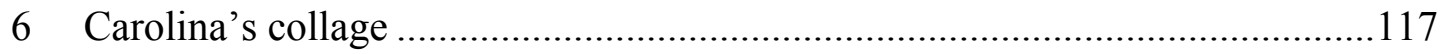

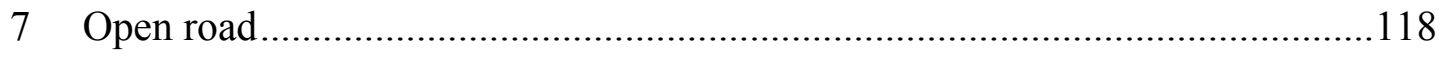

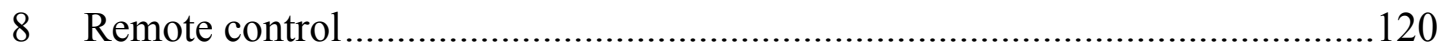

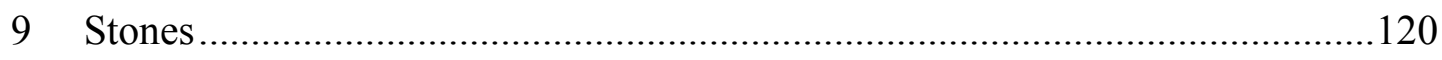

10 Ingrid's collage of Carolina's professional development journey ....................123

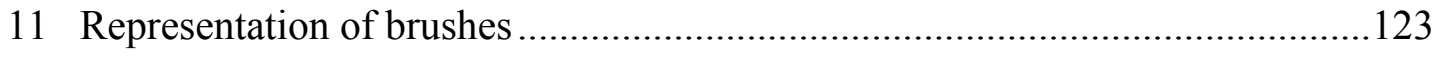

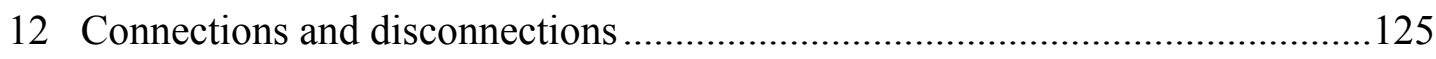

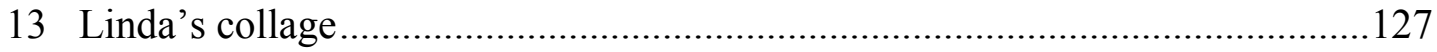

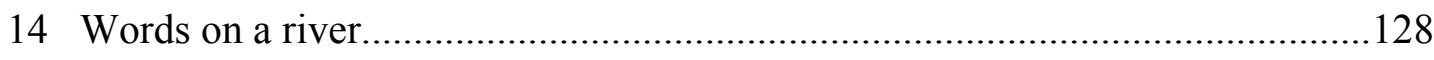

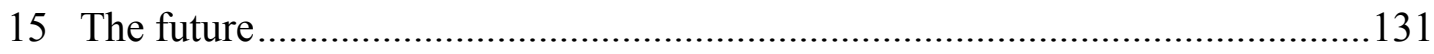

16 Ingrid's Collage of Linda's Professional Development Journey .......................133

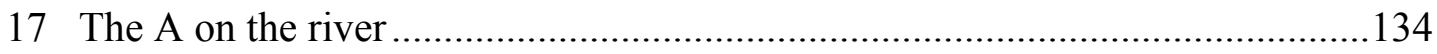

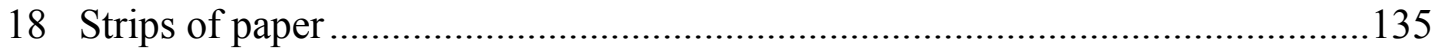

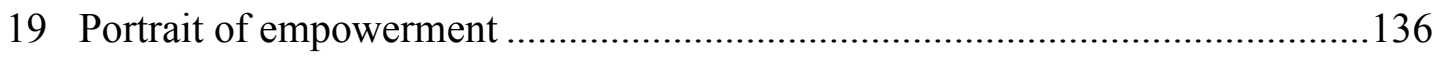

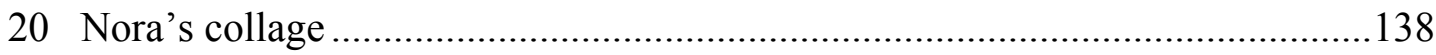




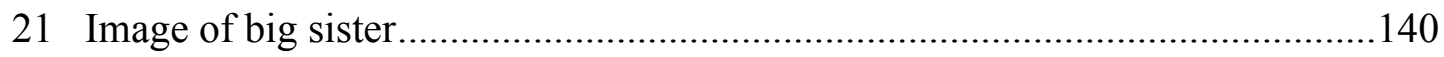

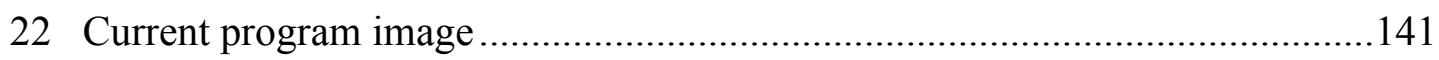

23 Ingrid's collage of Nora's professional development journey .........................145

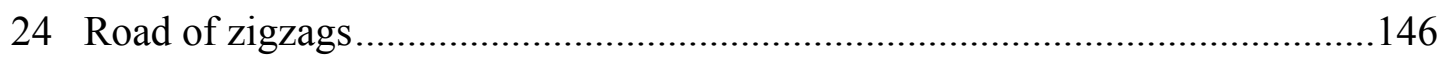

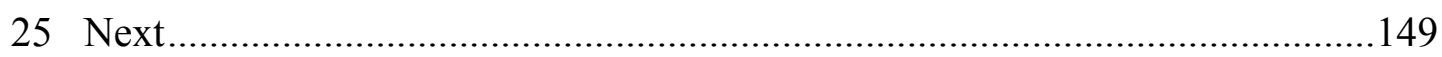

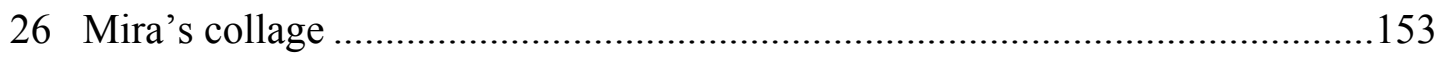

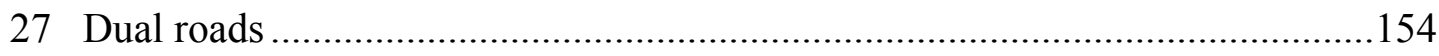

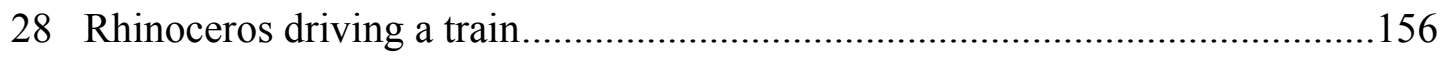

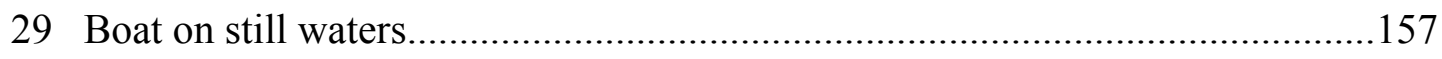

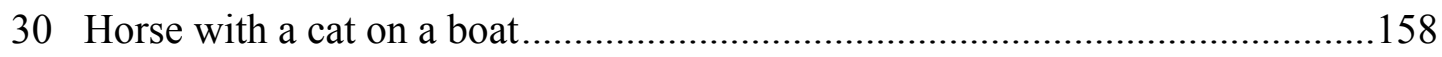

31 Ingrid's collage of Mira's professional development journey .........................160

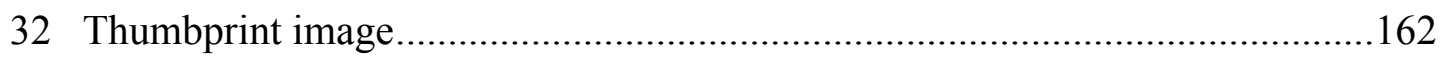

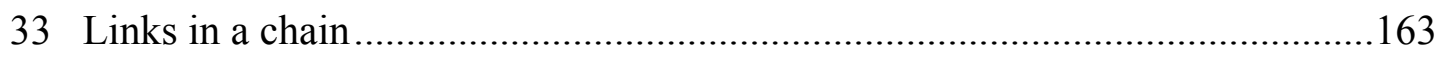

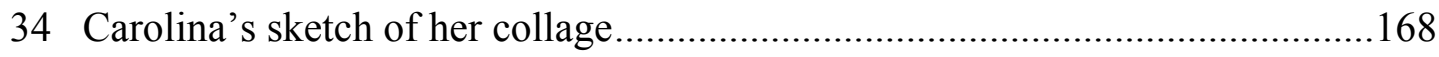

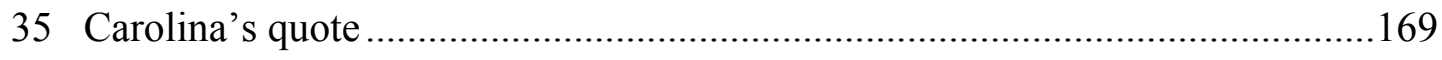

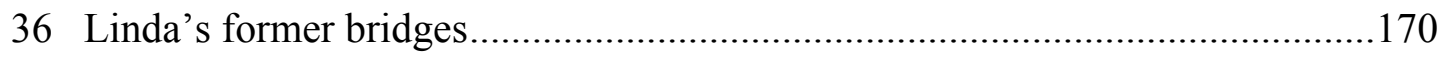

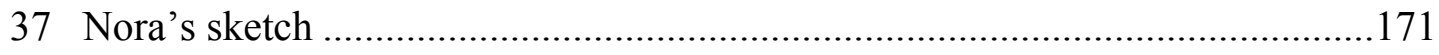

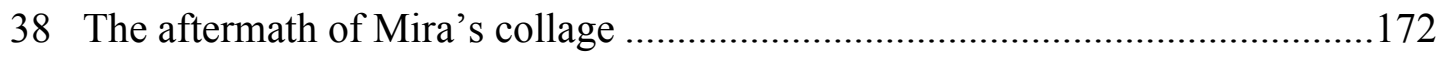

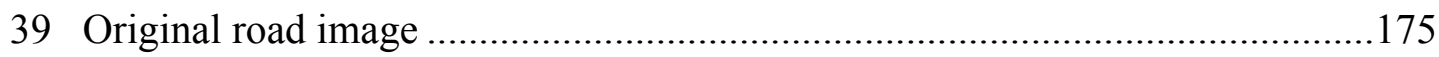

40 Participant's collage images of roads, rivers, and paths ...............................176

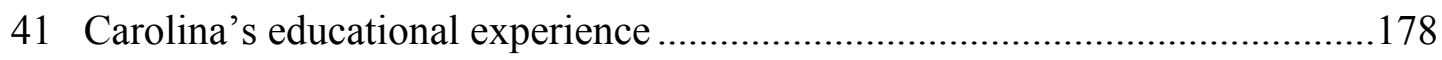

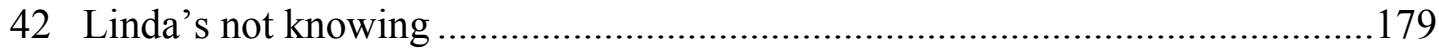




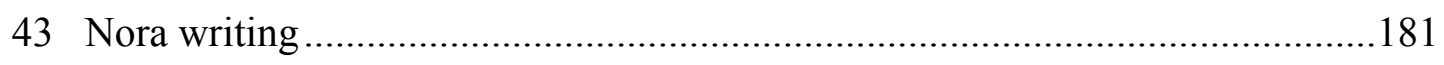

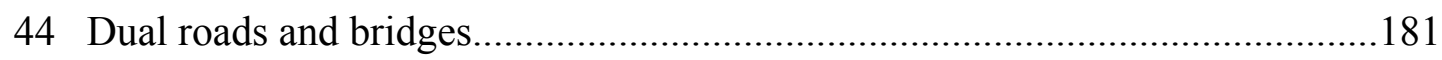

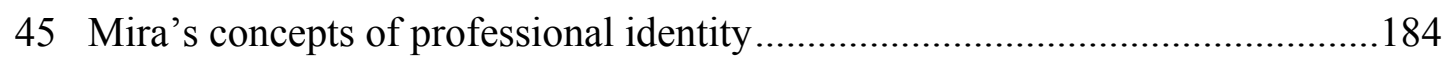

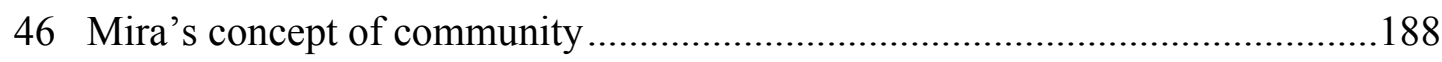




\section{GLOSSARY OF ABBREVIATIONS}

\begin{tabular}{|c|c|}
\hline CCD & $\begin{array}{l}\text { Child Care Division: housed at the Employment Department until 2013, } \\
\text { when it was moved to the Oregon Department of Education (ODE) } \\
\text { under the Early Learning Division (ELD) and renamed the Office of } \\
\text { Child Care (OCC). }\end{array}$ \\
\hline CCR\&R & $\begin{array}{l}\text { Child Care Resource and Referral: } 13 \text { programs located by geographic } \\
\text { area across Oregon to provide parent referral for care and professional } \\
\text { development opportunities for individuals who work with children, } \\
\text { tracks data for local level for care resource and referral programs to be } \\
\text { reported state and nationally. }\end{array}$ \\
\hline ELD & $\begin{array}{l}\text { Early Learning Division: formed through } 2011 \text { legislative action to align } \\
\text { all services statewide for programs serving children birth through five } \\
\text { and their families, reports to the Early Learning Council, a sub- } \\
\text { committee of the Oregon Education Investment Board (OEIB), chaired } \\
\text { by Oregon's Governor. }\end{array}$ \\
\hline NACCRRA & $\begin{array}{l}\text { National Association of Child Care Resource and Referral Agencies: a } \\
\text { national agency that provides information for parents of care resources } \\
\text { by geographic area, provides professional development for individuals } \\
\text { who work with children, tracks data for local and state childhood care } \\
\text { resource and referral programs, and was renamed Child Care Aware } \\
\text { (CCA) in } 2012 \text {. }\end{array}$ \\
\hline NAEYC & $\begin{array}{l}\text { National Association for the Education of Young Children: a national } \\
\text { membership organization that provides research, advocacy, policy, and } \\
\text { professional development opportunities for individuals who work with } \\
\text { children birth through eight years. }\end{array}$ \\
\hline NCCIC & $\begin{array}{l}\text { National Child Care Information Center: The national technical } \\
\text { assistance center for federal grantees that work with children birth } \\
\text { through twelve years and clearing house of resources and reports } \\
\text { profiling individual, state, federal programs or systems. }\end{array}$ \\
\hline $\begin{array}{l}\text { OCC } \\
\text { Licensing }\end{array}$ & $\begin{array}{l}\text { Office of Child Care: Licensing is the regulatory branch of the OCC that } \\
\text { monitors and enforces compliance in accordance with the OAR for } \\
\text { Registered Family Child Care, Certified Family Child Care, and Center } \\
\text { Based Programs in Oregon. }\end{array}$ \\
\hline OAR & $\begin{array}{l}\text { Oregon Administrative Rules: the legislative rules of the state of Oregon } \\
\text { that govern health and safety standards, including individual or } \\
\text { programs that work with children birth through twelve years. }\end{array}$ \\
\hline $\begin{array}{l}\text { (National) } \\
\text { OCC }\end{array}$ & $\begin{array}{l}\text { (National) Office of Child Care: located under the United States Health } \\
\text { Department, Administration for Children and Families, the (national) } \\
\text { OCC provides supports to states through the Child Care and } \\
\text { Development Block Grant funds, and supports low-income families with } \\
\text { stipends for care. }\end{array}$ \\
\hline
\end{tabular}




\begin{tabular}{|c|c|}
\hline OCCD & $\begin{array}{l}\text { Oregon Center for Career Development in Childhood Care and } \\
\text { Education, at Portland State University, Graduate School of Education: } \\
\text { provides leadership in the development and operation integrated and } \\
\text { statewide professional development standards and system, and } \\
\text { monitoring for the childhood care and education field, home of the } \\
\text { Oregon Registry and ORO. }\end{array}$ \\
\hline ODE & $\begin{array}{l}\text { Oregon Department of Education: the state education department } \\
\text { responsible for K-12 education oversight in Oregon, now responsible for } \\
\text { birth-twelve program, services, standards, and regulations. }\end{array}$ \\
\hline OregonAEYC & $\begin{array}{l}\text { Oregon Association for the Education of Young Children: the Oregon } \\
\text { chapter of NAEYC. }\end{array}$ \\
\hline $\begin{array}{l}\text { Oregon's } \\
\text { professional } \\
\text { development } \\
\text { system }\end{array}$ & $\begin{array}{l}\text { Oregon's professional development system for childhood care and } \\
\text { education: the partnership of state agencies funded by the Office of } \\
\text { Child Care, federal grants, and state dollars administered by the Office } \\
\text { of Child Care and funding the CCR\&R, OregonAEYC, OCCD, TRI. }\end{array}$ \\
\hline Registry & $\begin{array}{l}\text { The Oregon Registry: a career lattice programs that evaluates training } \\
\text { and education of individuals in OCC licensed programs or those } \\
\text { participating in having their training and education evaluated for Steps, } \\
\text { provides both scholarship dollars and education awards for individuals } \\
\text { who achieve designated Steps on the Registry. }\end{array}$ \\
\hline ORO & $\begin{array}{l}\text { Oregon Registry Online: A statewide database that stores all submitted } \\
\text { training and education for the childhood care and education field who } \\
\text { participate in the Oregon Registry Steps or in OCC licensed programs. }\end{array}$ \\
\hline (T) QRIS & $\begin{array}{l}\text { Oregon's (tiered) Quality Rating Improvement System: a system using } \\
\text { progressively higher program standards to evaluate and communicate } \\
\text { the quality of an Early Leaning and Development Program and to } \\
\text { support program improvement. }\end{array}$ \\
\hline RTT-ELC & $\begin{array}{l}\text { Race to the Top Early Leaning Challenge Grant: a federal grant of \$30 } \\
\text { million dollars awarded to Oregon in } 2013 \text { (an initial \$20 million and } 9 \\
\text { months later \$10 million) for four years to implement coherent, } \\
\text { compelling, and comprehensive early learning education reform for the } \\
\text { QRIS, childhood care and education workforce initiatives, family and } \\
\text { community access to care, enhancement of QRIS data systems, and } \\
\text { kindergarten assessment. }\end{array}$ \\
\hline TRI & $\begin{array}{l}\text { Teaching Research Institute: located at Western Oregon University, TRI } \\
\text { is responsible for the QRIS initiative and the central coordination of the } \\
\text { CCR\&R for OCC. }\end{array}$ \\
\hline TNRA & $\begin{array}{l}\text { The National Registry Alliance: a non-profit membership agency } \\
\text { comprised of state career lattice programs or Registries, works in } \\
\text { conjunction with NAEYC and the Office of Child Care to develop } \\
\text { national and state policy initiatives for individuals who work with or on } \\
\text { behalf of children excluding K-12 settings. }\end{array}$ \\
\hline
\end{tabular}




\section{CHAPTER 1: INTRODUCTION}

I am at my desk. The phone rings. An early childhood educator has called to ask for help navigating her own professional development trajectory in Oregon's professional development system for childhood care and education.

I am just so confused and frustrated. I don't understand how this works. What is the difference between the Oregon Registry and the Oregon Registry Online [ORO]? If I have a Step on the Registry, why are some of the classes I submitted missing from my Professional Development Statement? What counts anyways? How do I know how to get to the next Step? If ORO is part of the Registry, do I have to send my training to both to make sure it counts for licensing? Help me know what to do." (Personal communication, 2012)

This, and similar calls or emails, has occurred over 1,200 times in the last year as I provided guidance and technical assistance as the Oregon Registry Coordinator for the Oregon Center for Career Development in Childhood Care and Education (OCCD). OCCD is the home of the Oregon Registry, a system for tracking education experiences, credentials, workshops, and professional development for the 21,000 individuals working with or on behalf of children and youth in licensed programs in Oregon (Oregon Center for Career Development in Childhood Care and Education [OCCD], 2014). The Oregon Registry is part of Oregon's professional development system for childhood care and is part of a statewide framework funded by the Office of Child Care to provide leadership in the development and operation of an integrated standards-based statewide professional development system (OCCD, 2012).

I can attest to the confusing nature of navigating Oregon's professional development system from my years as an administrator working with preschool and 
school age programs in Oregon. The information that I needed to navigate the system was often unclear and sometimes contradictory. The connection between agencies designed to support me in my professional journey felt like a web of information in each agency with enough information to be helpful, but never enough to solve my problem. In fact, I never filled out my own Oregon Registry application or received the $\$ 500$ Education Award because it was just too complex and time consuming.

I took the position as Coordinator of the Oregon Registry, in part, to gain access to the state professional development system as an insider. It is a role that I embraced as an opportunity to work from within our state's professional development system to affect change. I came to understand that my own experiences mirrored those of others who are working their way through the state's professional development system. However, to truly understand the structure of the experience, I was interested in the others' encounters with the same system. My own challenges made me wonder if studying the experiences of individuals working in Oregon's childhood care and education community could provide insight into changing our state's professional development system. I decided to illuminate what meaning can be made of early childhood educators' experiences navigating Oregon's professional development system as the central theme of my research.

While many individuals and groups provide services and education for children in Oregon, my focus was on exploring a specific sub-set of individuals engaged in navigating a specialized system in the childhood care and education field. The experiences of the childhood care and education community that navigates Oregon's 
professional development system constantly offered an opportunity to mount a research study designed to understand and highlight the experiences of childhood educators actively engaged in navigating the existing structure. My purpose in conducting this study would be to give a voice to early childhood educators who experience the processes associated with navigating the state professional development system. By bringing the features of these experiences to light through research, it would become possible to reflect on professional development system accessibility. As my research prioritized the meanings that early childhood educators attach to their experiences, I also sought to recognize the effects of institutional discourse on the accessibility of the professional development system to early childhood educators (Fenech, 2010).

This study is presented in five chapters. This chapter provides an overview of the study, an explanation of key concepts and terms, the purpose of the study and research questions, and the study's significance. The chapter also introduces hermeneutic phenomenology as the study's theoretical framework. Chapter 2 contains a literature review focusing on early childhood educators' professional identity formation through the participation in early childhood education in societal, political, and institutional professional development systems. Further, Chapter 2 sets the stage to support an understanding of complexity of the relationship between early childhood educators and their perceptions of the professional development system. Research methodology is described in Chapter 3. Chapter 4 starts with teachers' experiences and collage representations in interviews as well as my own meaning-making collage representation and reflections on the interview. Then a discussion of emerging essential themes 
concludes the chapter. Chapter 5 begins with the insights that grow out of data relating to early childhood educators' experiences with Oregon's professional development system. Chapter 5 then concludes with recommendations for professional development system agencies, enactment of policies, and future research.

\section{Key Concepts and Terms}

The use of language and discourse plays a significant role in the identification of roles of individuals who work with or on behalf of children (Langford, 2008). Several definitions exist to represent early childhood education professional development (Katz, 1977; National Association for the Education of Young Children [NAEYC] \& National Association of Child Care Resource and Referral Agencies [NACCRRA], 2011b; Oregon Administrative Rules [OAR], 2011). Language usage remains a point of tension in determining who defines the early childhood education profession (Parnell, 2010). Therefore, the experiences of the early childhood educator in navigating the professional development system reflect two journeys (Ord, 2010). The first journey involves what Dalli (2008) believed is the complex defining of professional status due to diversity in the early childhood field. The second journey incorporated what Ord (2010) identified as the process that educators must navigate and make sense of while navigating institutional discourses (i.e., the language of governmental policy and ideology used to describe and define state systems).

In framing early childhood educators' experiences within Oregon's professional development system, I found the need to work with two sets of key concepts and terms. The first set includes institutional key terms and the context in which they are used when 
early childhood educators interact with Oregon's professional development system. The second set circumscribes terms and concepts linked to early childhood education as a profession in the context of discussions within professional and early childhood research groups as to what it means to be an early childhood professional (Dalli \& Urban, 2010). Due to the complex nature of the key terminology, rather than employing a tradition listing of terms in alphabetical order, I chose to narrate the complicated definitions, bringing them to light in a contextualized interwoven fashion.

\section{Institutional Definitions of Childhood Care and Education.}

Oregon's educational framework was realigned in 2011 to be a birth to twenty system, encompassing birth through college graduation (Executive Order No. 11-02, 2011). Within the state education system, there exist overlapping age categories for those who work with and on behalf of children. At present, the birth to twenty system is separated into three distinct funding categories, birth to five years of age, kindergarten through twelfth grade (K-12), and college. The Oregon Department of Education (ODE) has oversight for public funding and programs for early childhood and K-12 educational programs that are linked to specific federal statutes for service delivery. The Office of Child Care (OCC) supports, regulates, or monitors programs for individuals who work with or on behalf of children from birth through 12 years of age in care and education outside of the K-12 education system. Childhood care and education as a term is used by OCC and its funded agencies to delineate roles and responsibilities from K-12 systems. The term Oregon's childhood care and education workforce identifies both (a) those engage directly with children, and (b) the structures and mechanisms (in other words, 
systems) that support individuals connected to the adults who work with children. These adults include education professionals, professional development providers, state agencies, professional organizations, and higher education (OCCD, 2008).

Currently, Oregon's professional development system for childhood care and education is housed in the OCC. The OCC recently relocated to the Oregon Department of Education where it is now a department under the newly formed Early Learning Division. Until 2013, the OCC, formerly known as the Child Care Division (CCD) was housed at Oregon's Employment Department as part of the workforce development unit. The OCC holds a unique role in housing and funding both the state's professional development system and the division's regulatory body. As a regulatory agency OCC is responsible for enforcing minimum health and safety standards, including minimum professional development requirements. OCC regulates what it terms "child care" in the form of family child care homes and center-based programs. Position titles are standardized in licensed child care programs, regardless of the age of children. Position titles in licensed center-based child care programs are listed for early childhood educators as Aide 1, Aide 2, Teacher, or Head Teacher (OAR, 2011).

As the leader of the state's professional development system, OCC funds a variety of agencies that are designed to address quality issues in early childhood education. The OCC vision is to "highlight the importance of child care in developing and maintaining a diverse, multi-skilled workforce" (Oregon Employment Department Child Care Division [OED CCD], 2011). Oregon's professional development system for the childhood care and education workforce is one of the systems within OCC's structure designed to 
support quality care. This system is comprised of OCC-funded agencies that are designed to support Oregon's licensed childhood care and education profession. Over the past decade, Oregon has based its professional development system model on the National Child Care Information Center (NCCIC) framework, known as the NCCIC Tree. With the 2011 alignment of the birth to twenty system, Oregon's professional development model has expanded to include the goals from National Association for the Education of Young Children's (NAEYC) policy report Workforce designs: A policy blueprint for state early childhood professional development systems (LeMoine, 2008). This system was adopted to guide the policy actions of the OCC (LeMoine, 2008). The key stakeholders of Oregon's professional development system for childhood care and education, those who enact policy decisions, are the Office of Child Care, the Child Care and Resource and Referral Network (CCR\&R), Western Oregon University’s Teaching Research Institute (WOU), and the Oregon Center for Career Development in Childhood Care and Education.

The current initiatives funded by the Oregon Employment Department Child Care Division (OED CCD) are Oregon's Quality Rating and Improvement System (QRIS), housed at WOU, the CCR\&R located at non-profits and community colleges in 13 regional areas, and OCCD, which is housed at Portland State University. These three agencies, along with OCC, provide the majority of technical assistance to individuals and programs connected with Oregon's childhood care and education quality initiatives. These quality initiatives form the foundation of Oregon's professional development system. 


\section{Early Childhood Education as a Profession.}

NAEYC identifies that "the field of early childhood education include[s] individuals who provide direct services to young children (from birth through age 8) and their families, as well as those who administer the programs in which these individuals work and who provide professional development for these individuals" (NAEYC, 2011). The early childhood field represents a multiplicity of environments, program types, and educational philosophies (NAEYC, 2012a). The differences between early childhood programs lead to asynchronous environments and goals for children.

The complexity of the early childhood environment, with the diversity of interactions between early childhood educators and children, also varies greatly from the relationship between teacher and student found in the K-12 grade system (Mozére, 2012). This complexity of interactions is referred to in this paper as the multiplicity of early childhood education, the concept that early childhood environments are complex and layered in the interactions between and among children and adults based on environments, program types, and educational philosophies. Further, the complexity of early childhood environments' is comprised of highly individualized daily experiences between adults and children (Rinaldi, 1998). The difference between early childhood and K-12 system environments and a lack of understanding of early childhood's differentiated structure is cause of much tension in bridging the systems (Ailwood, 2003; Copple \& Bredekamp, 1991; Dalli \& Urban, 2010). 
generally self-identify their work as preschool teacher, provider, early childhood teacher or educator, after school provider, or caregiver, among others. Early childhood research primarily uses the terms infant teacher, preschool teacher, practitioner, early childhood teacher or educator (Dana \&Yendol-Hoppey, 2005; Katz, 1995; Moloney, 2010; Osgood, 2012; Ortlipp, Arthur, \& Woodrow, 2011; Parnell, 2010). I am defining early childhood educator as individuals who provide direct services to children from birth through eight years of age in the early childhood community. I am replacing the institutional discourse terms workforce and field with the term early childhood community. The term early childhood community conveys a level of connection and interdependence between members of a group that can construct meaning together. This construction of meaning together is at the heart of open dialogue between participants of a community (Cadwell, 2003). All study participants are early childhood educators, however I will refer to them as participants to distinguish their specific role in this study from the generalized use of the word early childhood educator found in the literature and used to represent the larger early childhood education community (Feeney, 2012; Katz, 1995; NAEYC \& NACCRRA, 2011a; Osgood, 2012).

Definitions of the early childhood education profession are contradictory in both early childhood research and professional literature (Caulfield, 1997; Dalli \& Urban, 2010; Feeney, 2012; Taggart, 2011). The debate and implication of defining the profession is threaded throughout Chapter 2. In the literature referring to the early childhood profession, Feeney (2012) referred to a profession as "an occupation that serves the public welfare and that requires specialized educational training in some 
branch of education or science" (p. 6). NAEYC identified early childhood education as a workforce and as a profession, which includes a series of skills, attributes and dispositions that are required for a member of the profession (1997). The demographics of the profession according to NAEYC and the National Association of Child Care Resource and Referral Agencies (NACCRRA) are

those working with young children (infant, toddlers, preschool, and school-age children in centers, homes, and schools) and their families or on their behalf (in agencies, organizations, institutions of high education, etc.), with a primary mission of supporting children's development and learning. (NAEYC \& NACCRRA, 2011a,p. 5)

Thus, I define the early childhood profession as early childhood educators working in an early childhood community with a specific focus that requires specialized knowledge and skills. Professionalism is the embodiment of enacted behaviors that demonstrate a set of skills, professional values, and ethics that guide early childhood educators in their daily practice. Professionalism is enactment every day of the services early childhood educators provide for children, which are known as professional practices. One clearly defined element of professional practice is professional development, defined as, a "continuum of learning and support activities designed to prepare individuals to work with and on behalf of young children and their families..." (NAEYC \& NACCRRA, 2011a, p. 4).

The act of professional engagement encompasses participation in all aspects of professional practice, including but not limited to participation in an early learning community, professional development activities, and navigation of Oregon's professional development system. Perceptions of professional experiences can impact early childhood 
educators' sense of professional identity. Early childhood educators' personal attributes, values, morality combined with professional ethics are the foundation of professional identity (Feeney, Freeman, \& Pizzolongo, 2012).

The professional growth patterns of early childhood educators that contribute to their professional identity are identified by Katz (1995) as having four distinct phases: survival, consolidation, renewal, and maturity. These four phases identify the capacity for professional engagement based on experience over time. Survival and consolidation focus on the relationship between the early childhood educator and the educator's classroom. Early childhood educators in these two phases work on identifying how to be effective as a teacher of young children. Renewal marks a turning point where early childhood educators start to look beyond their classrooms into the larger professional development system, and start to seek connections between their own professional practice and others in the field. At this stage, early childhood educators are "particularly receptive to experiences in local, regional, and national conferences and workshops, and they profit from membership in professional associations and participation in their meetings" (Katz, 1995, para. 10). In the final phase---maturity---early childhood educators are able to reflect on their beliefs from a place of security in their professional identity.

After careful consideration and adoption of Katz (1995) early childhood educators' stages of professional development theory, I chose as subjects early childhood educators working with children three to five years of age in licensed center-based programs, and who are in the renewal stage of development. For the purpose of this 
study, early childhood educators in the renewal stage of professional development are generally identified as having a professional development stance of openness to exploration of state or system models of professional development. Early childhood educators in renewal offered a perspective on Oregon's professional development system that is unique and distinctly different from that of new teachers with limited experience, and from that of mature teachers with extensive experience. Early childhood educators in the renewal stage are likely to reflect on professional development systems and connections to professional development practices for the first time.

\section{Theoretical Framework}

My personal interest for this study was in understanding participants' experiences with Oregon's professional development system. In particular, I was most interested in how participants make meaning from their experience and the connections between their meaning and how they see themselves as professionals within Oregon's professional development system. Specifically I refer to the messages embedded in institutional discourse about the early childhood profession in a state context, and what those messages convey to the early childhood education community. In the literature on professionalization of early childhood educators, two foci manifested themselves as lenses for the interpretation of early childhood educators' experiences. These were critical social theory and the discipline of phenomenology.

While both are mentioned in this paper, I was attracted to phenomenology as it offers a way to study participants' point of view of their experiences. Governmental policy focuses on the implementation of Oregon's professional development system, and 
fails to take into account early childhood educators' experiences or to use those experiences to impact professional development system policy. "Phenomenological research, unlike any other kind of research, makes a distinction between appearance and essence, between the things of our experience and that which grounds the things of our experience" (van Manen, 1990, p. 32). Since I sought to make meaning of participants' experiences, phenomenology offered an approach consistent with my intent.

In looking at participants' navigation of Oregon's professional development system, it became important to shift from the outward appearance of what it might be like to traverse such a system to the inward essence of what it must have felt like from a first person point of view. The concept of essence is fundamental to phenomenology. "Phenomenology shows that everything is experienced as something, i.e., everything has its own style. An essence is, simply, a phenomenon's style, its way of being, and thus the essence cannot be separated from the phenomenon that it is the essence of..." (Dahlberg, 2006, p. 18). Nor can experience be separated from perception, created by the feelings that are assigned to how the world is seen (Dahlberg \& Dahlberg, 2003). Further, in illuminating the essence of a phenomenon, Dahlberg and Dahlberg (2003) stated, "Perception is a dynamic relationship, made up of both subject and object. The subject perceives the world, and the world presents itself to the subject. It is within this relationship that meaning arises" (p. 35). If research is built upon participants' experiences in Oregon's professional development system, the reader should come away from engagement with this research with an understanding of what it is like to traverse the system from the participant's point of view. 
For the purpose of a hermeneutic phenomenological study, the act of reflecting on an experience and the co-construction of meaning of Oregon's professional development system represented a way of being both a researcher and a participant. Thus, I situated myself as a researcher-participant. The practice of a researcher-participant acknowledged my role in living inquiry (Merleau-Ponty, 1962; Springgay, Irwin, \& Kind, 2005). In this study, I position myself as a researcher-participant in acknowledgement of: (a) the role I hold at OCCD as the Coordinator of the Oregon Registry, (b) the methodological process employed as co-protagonist to make meaning of my participants' experiences through collage, and (c) how, as a researcher-participant, I created collages (described in detail in Chapter 3) as a way to support meaning to emerge from participants' experiences with Oregon professional development system. The role of researcher-participant thus offered a way of defining the multiplicity of my roles in my hermeneutic phenomenology study.

\section{Purpose of the Study and Research Question}

The intention of a state professional development system is to support individuals and agencies who work with or on behalf of children and youth (Kagan \& Kauerz, 2012). The NAEYC (2011) identified best practices for statewide professional development systems as inviting early childhood educators to collaborate in building their own professional practices. However, stakeholder messages about participation, navigation, and reflection of professional aspirations from the state agencies that administer the state professional development system should be laid out clearly with easy-to-follow steps. Unfortunately this is not the case in most states, according to S. Rudisill, Director of the Office of Child Care Administration for Children and Families, U.S. Department of 
Health and Human Services (personal communication, July 19, 2012). Building collaborative partnerships between state programs and agencies requires compromise as state agencies negotiate the realignment of services.

While change in professional development systems tends to happen over time, Oregon is charting a fast-paced course of change based on the election of an educationoriented Governor. In Oregon, one of the Governor Kitzhaber's first legislative actions focused on the coordination of a seamless system to support access to high quality services for children and families (Executive Order No. 11-02, 2011). In particular, the intent of early childhood policy is to improve the quality of support provided for children and their families by strengthening the quality of early childhood programs (OED CCD, 2011). Oregon has undertaken a massive restructuring of its educational system. Focused on the organizing of birth to five services under one division, the Early Learning Council is charged with the alignment of Head Start, child care assistance, scholarships, licensed child care facilities, early learning guidelines and standards, grants, early intervention, home visiting, training and education, school readiness initiatives, and licensing (Pham \& DeMoe, 2012). The focus of the realignment is to create a system that supports the 40 percent of Oregon children and their families that are exposed to a "well recognized set of socio-economic, physical or relational risk factors that adversely impact their ability to develop the foundations of school success" (Early Learning Council S. B. 909 Report, 2011, p. 4). The realignment of supports for families provides a strong motivation on behalf of the Governor to enact change, regardless of the disruption it causes to current organizational structures in childhood care and education. 
This major restructure causes anxiety for early childhood educators who believe that the state's existing childhood care and education system is already complex and difficult to navigate (OED CCD, 2008, 2009, 2010). The director of Oregon's largest CCR\&R agency, designed to provide professional development and technical assistance for the childhood care and education field, stated, "Providers have difficulty in navigating the professional development system. The addition of new requirements has further eroded their feelings of confidence that they can be successful on their own, without technical assistance” (J. Lemieux, personal communication, February 15, 2011). The complexity of the work, and the need to negotiate a multiplicity of environments in early childhood education, leaves very little time for early childhood educators to advocate for change (Mozére, 2012). Osgood (2012) noted that uncertain professional identities in early childhood educators occur when they feel disenfranchised from policy decisions that affect their classroom practice. Furthermore, the complexity of the professional development system alienates the very early childhood educators who are trying to engage and to enhance their professional practice working with, or on behalf of, children and families.

None of these changes acknowledges the magnitude of functions already performed by early childhood educators when engaged in the state's professional development system. The changes to the current licensing requirements and voluntary programs of the OCC are causing stress in the lives of early childhood educators who work in licensed programs. The Child Care Division (now OCC) conducted a series of customer service surveys in 2008, 2009 and 2010 with licensing registered family, 
certified family, and center-based programs. The 2008 report stated "a general lack of clarity exists among providers [early childhood educators] about which agency or program to access when they need assistance" (OED CCD, p. 3). The surveys found that family child care programs had limited knowledge of the interconnectedness between OCC Licensing, OCCD, and the CCR\&R. "More than 50 percent of providers [educators] reported that they were not affiliated with a professional organization" (p. 11). While a significant percentage of family child care providers express an interest in professional development activities, there is significant confusion on how that is defined. "These findings indicate that the professional development system needs to be more intentional in communicating with providers about the professional development... while about 65 percent of providers completing the survey said they know about the Oregon Registry, many of them are not aware of the step they have achieved" (p. 11-12). In contrast, the OED CCD Certified Child Care Center Survey (2010) found that center-based programs readily identify components of Oregon's professional development system. The survey found that "awareness among child care providers [educators], including center directors and their staff, is high about the Oregon Registry; however, awareness still greatly exceeds participation" (p. 3). When participants were queried about changes to Oregon's professional development system, they said that they would like to see easier access to forms, paperwork, and opportunities for input and sharing. Currently, 20 percent of individuals working at licensed center-based programs actively engage in the Oregon's Registry and Education Awards, indicating a low level of engagement for Oregon's professional development system (Western Oregon University 
[WOU], 2013a, 2013b).

The results of the survey highlighted the importance of exploring early childhood educators' experiences with Oregon's professional development system. After reviewing the survey, center-based programs demonstrated greater knowledge of Oregon's professional development system than did licensed family child care. Knowledge of Oregon's professional development combined with demographics of center-based programs in the Portland Metro area confirmed that early childhood educators in centerbased settings would be the best group from which to draw a purposeful sample.

The design and approach of this hermeneutic phenomenological study (detailed in Chapter 3) was to collect participants' experiences engaging in the professional development system and "bridle the experience" (Dahlberg, 2006, p. 16). The act of bridling an experience invites the researcher to create space to allow meaning to come forward. One of the fundamental strengths of bridling an experience is the acknowledgement that experiences are intertwined with perceptions. The act of bridling, therefore, creates a space where reflection can occur. Dahlberg and Dahlberg posed that reflection creates "elbow-room that is needed if we are to make clear what is going on in the encounter between ourselves and the world" (p.47). As a researcher-participant I am using "bridling" a practice when working to make meaning from the narrative and collage of participants' professional development journey. Thus the act of "bridling" allows meaning to come forth from participants' a/r/tographic experiences. A/r/tography is a form of arts-based research that combines participants' experiences with active participation in an arts medium (Springgay et al., 2005). The introduction of an art 
medium into the participant's experience is said to "create opening, displace meaning, and allow for slippages" (p. 898). Seamon (2012) called the act of taking a double look at the data through narration and art as "crosshatching" (para. 1). The combination of art with narration enhanced understanding in phenomenological studies (Seamon). This concept is expanded in Chapter 3.

Meaning making happened when the participants engaged in collaging and then participated in a semi-structured narrative interview of their professional journey. An early childhood educator's journey referred to the participants' experiences and the events, people, and situations that intersect with Oregon's professional development system. Meaning making was revisited when the experiences were bridled as the researcher created pedagogical documentation by examining the visual records in the form of written notes, audio recordings, and photos of the participants' collaged responses. The research was phenomenological in nature and drew its data directly from the words and other expressions of participants as they engaged the professional development system.

Pedagogical documentation provided a construct to look at the many possibilities that encompass participants' experiences (The Reggio Emilia Australia Information Exchange [REAIE], 2011). "It [pedagogical documentation] values what regulatory modernity finds problematic: complexity and multiplicity, subjectivity and context, provisionality and uncertainty" (Dahlberg, Moss, \& Pence, 2007, p. 24). Pedagogical documentation in a hermeneutic phenomenological study provided a scaffold for what van Manen (1990) stressed as the exploration of meaning rather than the identification of 
problems or development of solutions. Beyond the interpretation of the participant experience, a hermeneutic phenomenological study offered the opportunity to be both attentive to how things appear and to let the experiences of early childhood educators speak for themselves (van Manen, 1990). Van Manen stated that "there is no such thing as uninterpreted phenomena...moreover, even the 'facts' of the lived experience need to be captured in language" (p. 180-181). In making space for reflection and allowing participants' experiences to be interpreted, the research question that focused my study was this: In the renewal stage of their professional practice, what meaning can be made of early childhood educators' experiences navigating Oregon's professional development system? Informing this primary question were the following open-ended research questions.

- What have been the experiences of early childhood educators in identifying themselves as early childhood education professionals?

- How do early childhood educators identify their experiences of professional engagement?

\section{Significance of the Study}

Technical assistance for early childhood educators navigating the professional development system is focused on one-to-one support. All the surveys commissioned by the OCC show that technical assistance and support focuses on solving early childhood educators' problems of Oregon's professional development system engagement, primarily by answering questions and addressing barriers for early childhood educators who have the knowledge to navigate professional development system programs and 
services. One ongoing issue in Oregon is that a system that works with individuals often duplicates services and fails to recognize systemic problems at such a micro level. The alignment of early childhood state agencies and programs in Oregon is designed to address the issue of duplicate services, lack of efficiency in service delivery, and differences in licensing requirements (Early Learning Council S.B. 909 Report, 2011; Office of the Governor, 2011b). However, no coordinated efforts have been made to figure out how and why early childhood educators have difficulty finding their way in the system entry points provided by the state.

A survey of the literature indicates that a small amount of research exists dealing with the relationship between regulatory agencies and professional practices (Bown \& Sumsion, 2007; Fenech \& Sumsion, 2007; Novinger \& O’Brien, 2003). Still, little research focuses on early childhood educators' actual perceptions about navigating professional development systems (Bown \& Sumsion, 2007). The research that does exist is mostly cited in studies from Great Britain due to the initiatives to support the professionalization of early childhood education in that country (Day, Kington, Stobart, \& Sammons, 2006; Osgood, 2006, 2012) and for Australia (Ailwood, 2003, 2008; Bown \& Sumsion, 2007; Fenech, Sumsion, \& Shepard, 2010). Questions of early childhood educator experiences in navigating professional development systems made up of various stakeholders are not addressed in the literature. There is some research in navigating regulatory agencies (Menmuir \& Huges, 2012; Ortlipp et. al., 2011; Osgood, 2006). Designed by stakeholders to increase child outcomes, professional development systems based on child performance lead to uncertain messages about empowerment for 
early childhood educators. The absence of studies of early childhood educators' experiences in navigating professional development systems creates the risk of broadcasting a message that a particular professional development system is unresponsive to the needs of the early childhood community (Osgood, 2012).

Therefore, the significance of this study rested in bringing to the foreground the voices and professional development experiences of early childhood education professionals, from whom little has been heard. The complexity of the relationship between individuals and their perceptions of the professional development system is predominately unobservable, multidimensioned, and context-dependent. The reflective early childhood educator, therefore, is the best voice for articulating that complexity. To situate an early childhood educator in the context of their environment is to explore aspects of their lived experiences or lifeworld. It is important to note that the lifeworld is the entire contextual experience for an individual.

Chapter 2 looks at the literature as a way of situating early childhood educators in their multidimensioned environments. A next important step is looking more deeply into the literature to see what other scholars have determined with respect to early childhood educators' experiences of professional development systems. 


\section{CHAPTER 2: REVIEW OF LITERATURE}

This chapter presents a review of the literature relevant to early childhood educators' process of navigation through professional development systems. To understand how participants experience Oregon's professional development system in particular, I reviewed both the institutional and the early childhood research literature. First, I reviewed the institutional terminology and discourse relating to formation and enactment of professional development systems nationally, and, then, specifically in Oregon. Second, in a review of qualitative research studies, I explored the themes of profession, professionalism, professional development, professional engagement, and professional identity. After reviewing these two strands, I discovered two additional foci emerging from the literature.

The first of these is the role of discourse in early childhood education, and discourses' effects on early childhood educators' interpretation of professional development systems. The second strand revealed reflective practices as a way to frame and make meaning of experiences in navigating Oregon's professional development system. Chapter 2 is divided into five sections: professional development systems, the construction of professional identity, professional development structures, the discourse of early childhood education, and early childhood educators' reflective practice.

The literature review began with an exploration of state and national trends in professional development systems. The review then explored the formation and enactment of professional development system models. How professional development systems engage the multiplicity of public and private agencies that operate independently 
of each other under a shared state system was the next focus of the review (McCabe \& Sipple, 2011). I discussed the strengths, limitations, and the purpose of professional development systems against the social and political perceptions of what early childhood educators are able to know and do. Finally, I reviewed how the disconnection between early childhood educators and the professional development system can lead to the destabilization of professional identity, and I explore such findings (Day et. al., 2006).

Next, I discussed the different definitions of the early childhood education profession. I investigated the concepts of professionalism and professional identity in phenomenological studies. Early childhood education phenomenological studies highlighted conversations about the early childhood educators' perceptions of the value of education versus experience and how those perceptions align and contrast with societal values (McCabe \& Sipple, 2011; Osgood, 2012). Furthermore, early childhood educators' perceptions of their own professionalism were defined by the beliefs they hold about education and experience (Osgood, 2012). Looking at professional identity and professionalism through qualitative research gave insight into early childhood educators' perceptions of the role of education and experience in the societal and political landscape, and into how identity frames these perceptions about professional engagement within professional development systems.

Continuing to build an understanding of early childhood educators' concepts about professionalism and professional identities, I identified connections between teacher preparation and ongoing professional development through professional development and professional engagement. The discussions in the literature identified 
beliefs held in the field about early childhood educators' engagement as a result of participation in early childhood educator preparation programs, and participation in ongoing professional development activities (Moloney, 2010; Webster-Wright, 2009). This discussion included the impact of quality improvement policy and regulatory practices as a way to engage early childhood educators in increased professional development.

To prepare for the interpretation of participant experiences in Oregon's professional development system through patterns and themes, the final two sections of the literature review focused on the role of discourse in early childhood education and reflective practices as a way for early childhood educators to use expressive language to make meaning of experiences. Together, these sections provided a foundation to make meaning of the complexity of the relationship between individuals and their perceptions of the professional development system that is predominately unobservable, multidimensional, and context-dependent. Chapter 2 situates aspects of the lifeworld of early childhood educators as a foundation for the looking in on the specific phenomenon of early childhood educators making meaning of their experiences of professional engagement in Oregon's professional development system.

\section{Professional Development Systems}

The demand on the field of early childhood is becoming greater and more complex (Dalli \& Urban, 2010; Osgood, 2010). Growing demands for accountability through increased public awareness, the view of parents' rights as consumers, and demands of policy makers push conversations about accountability to the forefront of 
current discourse (Dalli \& Urban, 2010; Moloney, 2010). Policy formation has a significant impact on early childhood educators’ professional identity (Fenech \& Sumsion, 2007; Kelchtermans, 2005; Woodrow \& Press, 2007). As policy and research intersect in early childhood education, national attention is focused on improving the quality of early childhood programs, both in regulatory and professional development systems. While regulatory systems are not identified in a professional development system, they are firmly intertwined with the professional development system. In Oregon, this is identified through the OCC licensing. Embedding regulations, in particular minimum health and safety standards, into professional development systems impacts the view of professionalism in early childhood education, tying professionalism to a narrow definition of professional competencies.

Over the past fifteen years, numerous publications have referred to changes in practice and policy (Sachs, 2001; Saracho \& Spodek, 1993; Webster-Wright, 2009). Camp (2009) and Gable and Halliburton (2003) cited policy recommendations from the National Institute of Early Childhood Professional Development, the Early Childhood Education Goals Panel, From Neurons to Neighborhoods, and the NAEYC platforms as impacting changes to the field of early childhood education. Osgood (2006) identified the change in education as double-sided. On one side, increased awareness of the importance of early development in children leads to the promise of greater funding and educational opportunities. On the other, increased regulations and constraints further remove early childhood educators from the historical holistic care structure based on nurturing environments. 


\section{State and National Trends in Professional Development Systems}

State professional development systems are gaining national prominence as both state and federal policy makers see these systems as a way to influence quality in early childhood education (Kagan \& Kauerz, 2012). In turn, national policy influences state initiatives through two major sequential initiatives designed to support consistent structuring of professional development system components across multiple states. The National Child Care Information Center (NCCIC) developed the first widely adopted professional development system models for states, known as the NCCIC Tree (Kagan \& Kauerz, 2012). This model has gradually transitioned into the National Association for the Education of Young Children's Workforce Design: A Policy Blueprint for State Early Childhood Professional Development Systems (LeMoine, 2008). Workforce design is the cornerstone of NAEYC's early childhood workforce system initiative.

The Early Childhood Workforce Systems Initiative's (ECWSI) purpose is to assist states in developing, enhancing, and implementing policies for an integrated early childhood professional development system for all early childhood education professionals working with and on behalf of young children. Integrated policies intentionally promote the building and support of an efficient cross-sector system that decreases duplication of efforts and increases accountability and sustainability. (NAEYC, 2012b, p. 1)

The Early Childhood Workforce Systems Initiative is gaining traction as it mirrors many of the requirements of the Race to the Top Early Learning Challenge Grant (RTT-ELC). Much of Oregon's current professional development system is modeled after the NCCIC Tree and the NAEYC early childhood workforce system initiative. The connection will continue to grow stronger with the 2013 award of $\$ 30$ million for Oregon to implement the RTT-ELC Grant over the next four years. The influence on my research study is 
minimal while the RTT-ELC grant is in the pilot stage in 2013. However, statewide rollout is scheduled for the middle of 2014 and will have significant impact on the early childhood community.

The funding of RTT-ELC will restructure Oregon's professional development system, increasing educational attainment requirements for early childhood educators and focusing on increasing measurement of adult and child interactions (D. Woods, personal communication, March 11, 2013). Due to the narrowing of the professional development system requirements, early childhood educators may need to change their practices regarding professional development, educational attainment, and classroom interactions to meet new professional development system requirements. Additionally, early childhood educators who choose to participate in ongoing professional development activities and who work in OCC-licensed programs are now mandated to participate in Oregon's professional development system. Professional development system models have a significant impact on early childhood educators who engage in professional activities in Oregon. Understanding the components of a professional development system provides a framework for exploring early childhood educators' experiences.

\section{Formation and Enactment of Professional Development System Models}

NCCIC defines a comprehensive professional development system for early care and education as accessible and based on a clearly articulated framework (2009). Embedded in the professional development system is a continuum of professional development [what NCCIC refers to as training] and ongoing supports, accompanied by defined pathways that are tied to licensure or increased qualifications, credentials and 
degrees. Figure 1 shows the model, known as the NCCIC Tree, with outlined elements of Oregon's professional development system. Oregon adopted the NCCIC Tree as a framework for its professional development system for individuals in programs that serve children birth through twelve years of age.

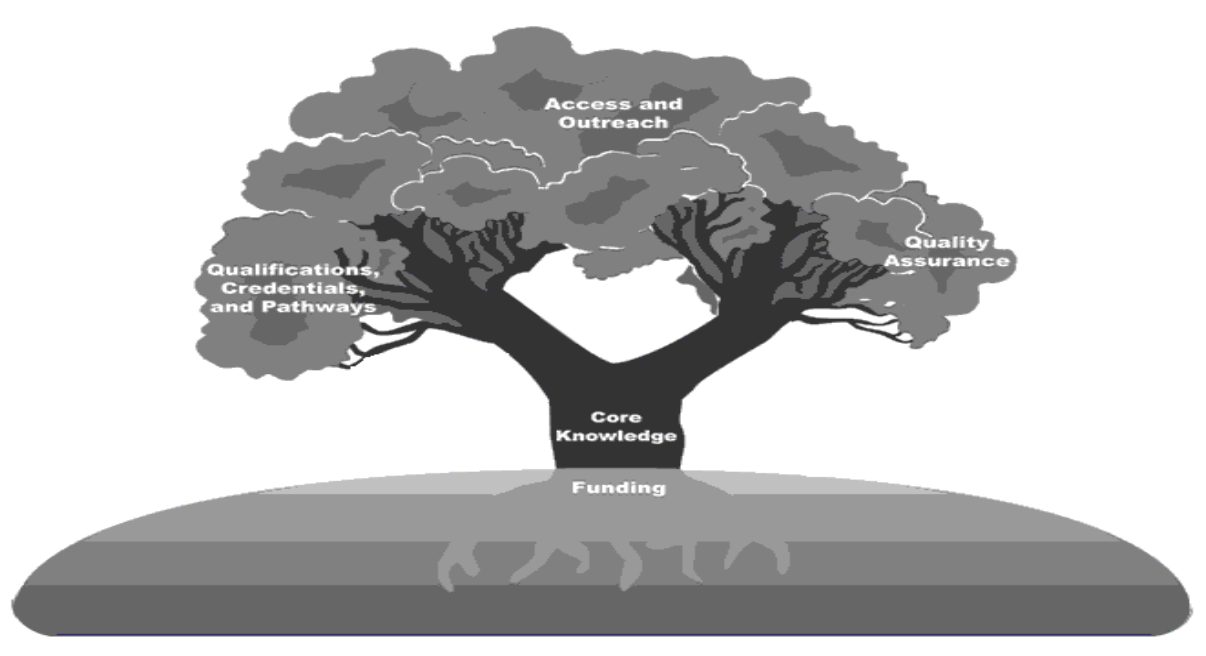

Figure 1. NCCIC Tree

Housed in the OCC, the professional development systems can be categorized in "five broad interconnected elements, growing from the 'roots' of funding to the extending 'leaves' of access and outreach to the overarching system-level issues of infrastructure, governance, and financing" (NCCIC, 2009, para. 1). Each of these broad interconnecting elements is made up of detailed elements that support the professional development system.

A key element of a professional development system is its core body of knowledge (NCCIC, 2009). A core body of knowledge defines (from a state system perspective) the body of skills and knowledge that early childhood educators are expected 
to have mastered. Oregon's Core Body of Knowledge has ten core knowledge categories. The demonstration of core competencies is embedded within the Oregon Administrative Rules (OAR) for OCC regulatory licensing and the Oregon Registry. Early childhood educators who work in licensed programs must meet the requirements of the OARs. The OARs have minimum professional development requirements in the form of position qualifications and annual requirements for continuing education. Additionally, individuals may elect to have their professional development and education evaluated for a Step on the Oregon Registry. Oregon Registry Steps reflect milestones of professional development or education achievement by linking degrees, credentials, certificates, college course credit or community-based training to one of 12 steps of education or professional development achievement connected to a progression of knowledge in the field. The Core Body of Knowledge and the Oregon Registry Steps are identified in the state as foundational documents for defining core competencies in the childhood care and education field.

Figures 2 outline the elements of the NCCIC model and the corresponding components in Oregon. Early childhood educators in Oregon directly experience or interact with the Oregon Programs listed in the figure if working in an OCC-licensed program. Currently, participation in policy recommendations informing the professional development model is limited to participation in a series of interwoven committees, including Access and Outreach, Qualifications, Credentials and Pathways, and Quality Assurance, that the state uses to make its decisions. Each committee is designed to create a different access point, or to study and remove barriers to accessing the state 
professional development system.

\section{NCCIC Committees' Functions \\ Access and Outreach \\ - Online databases of training and education opportunities. \\ - Training calendars: Published lists of trainings with short descriptions, locations, dates, and times of training sessions.}

- Directories of college degree programs.

- Career development advising: The process of informing individuals about entry and continuing education requirements for professional roles in the field and helping them assess current qualifications, identify education resources, and plan career advancement, while paying attention to cultural and linguistic frameworks.

- Continuum of individual and group supports:

- Orientations to the early childhood regulations, standards, or programs.

- Mentoring and coaching programs.

○ Peer support groups.

- Leadership development.

○ General skills and education supports (e.g., bilingual education, literacy, etc.).

- Multiple professional development delivery methods:

○ Onsite, community-based, and higher education/campus-based delivery.

- Mobile units.

- Distance learning.

- Courses as modularized workshops (i.e., credit-bearing courses that are developed into a set of related workshops).

○ Internships, assistantships, and apprenticeships.

o Hotlines, warmlines, help desks.

- Technical assistance.

- Public engagement efforts/initiatives.

Qualifications, Credentials, and Pathways

- Preservice requirements: Minimum qualifications that staff are required to have prior to assuming their positions.

- Continuing education requirements: Ongoing trainings that staff are required to obtain to remain in their positions.

- Career lattice: Levels of mastery connected to a progression of roles in the field.

- Credentials: Documents certifying that an individual has met a defined set of requirements, usually related to skills and knowledge, and may include demonstrations of competence.

- Pathways leading to qualifications, degrees, and credentials:

- Articulation agreements.

○ Training registries: Databases that track all completed personnel training.

- Credit-bearing workshops and training series.

- Credit for prior learning: Systems by institutions of higher education for granting credit for learning through life and/or work experiences.

Oregon Programs
Oregon Registry Online
Training Calendar
Articulation Brochure
Housed as Child Care
Resource and Referral
and Community College
Limited but expanding
Yes
DHS Orientations
Limited
No
No
Oredentials
No
Yncomm. Colleges
Yes
Yes
Yes


Figure 2 continued

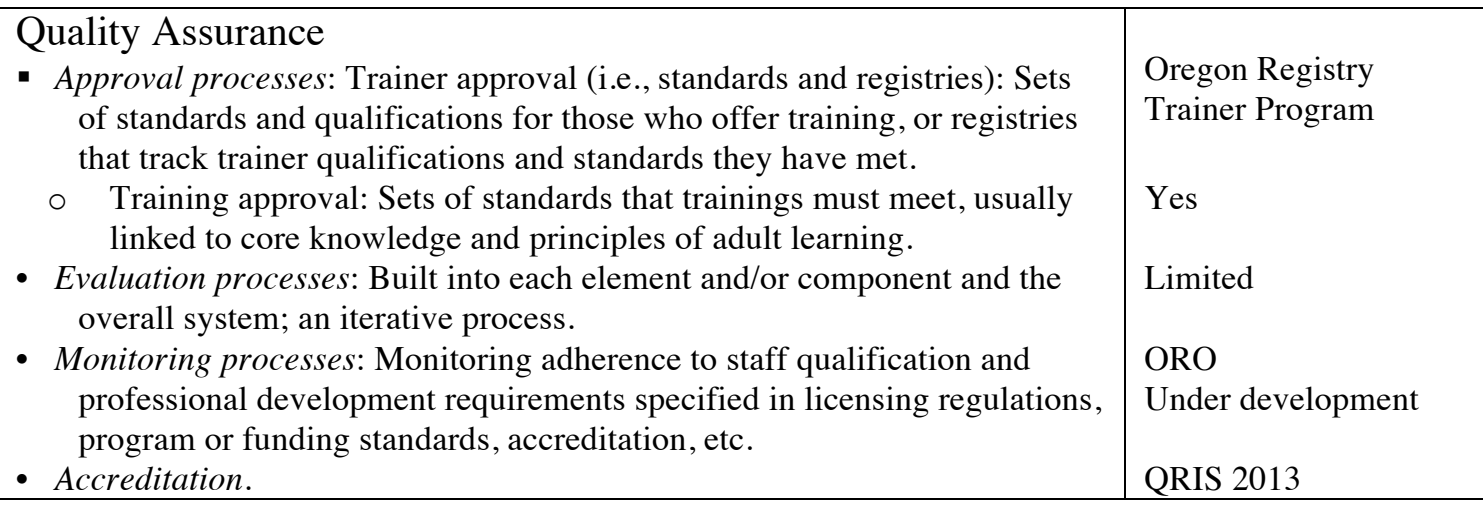

Figure 2. Oregon's NCCIC Committees and their functions, adapted from NCCIC Committees' Functions, NCCIC 2009).

Funding initiatives are encouraged in the NCCIC model (2009). To encourage participation beyond the mandated requirements of tracking and documenting professional development activities for OCC licensed programs, there are financial aid and scholarships, compensation, retention initiatives, and program quality awards. Through public and private partnerships, Oregon is able to fund financial aid, scholarships, and program quality awards. The NCCIC structure remains in place as the state continues to expand its vision for a professional development system consistent with NAEYC Workforce Design Model.

The NAEYC Workforce Design was built to provide a political scaffold that extended the NCCIC model into legislative action. While NAEYC does not have the only model for building a professional development system, it is the model adopted by Oregon. The evolution of the professional development system reflects the shift of early childhood education to the political arena (Kagan \& Kauerz, 2012). The goals of the 
political policy model was outlined in an issue brief by the National Governors Association (NGA) who prepared their recommendation in conjunction with NAEYC (Demma \& LeMoine, 2010). The issue brief outlines recommendations for best practices for building an early childhood professional development system. The recommendations include: "coordination of early childhood professional development policies, implementation of research-based standards for early childhood professional development, ensuring access to professional development opportunities, and gathering and using data on characteristics of the early childhood workforce to improve professional and program quality" (Demma \& LeMoine, p. 1). S. Rudisill (personal communication, July 19, 2012), Director of the Office of Child Care Administration for Children and Families, U.S. Department of Health and Human Services, stated that at the national level the money is following a research-based model. This poses a challenge for the NGA, which points out in its issue brief that there is "a lack of research-based professional development standards" (Demma \& LeMoine, p. 3). What is made clear in the NGA issue brief is that courses and seminars that do not lead to credentials and degrees are not as effective for the development of professional competencies for early childhood educator learning.

The NAEYC Workforce Design model identifies six policy making principles, "Integration, quality assurance, diversity, inclusion and access, and compensation parity" (LeMoine, 2008, p. 11). To support the restructuring of the professional development system for childhood care and education, OCC has implemented three major initiatives designed to align and track quality in OCC-licensed programs. The first initiative is 
housed at OCC, the Oregon Registry Online. ORO was developed as statewide database to capture all professional development activities for childhood care and the education workforce. In 2011, OCC required that all individuals who work in OCC-licensed programs submit their annual requirements for 15 hours of college course credits, workshops, conferences, or other professional development activities to ORO (OED CCD, 2011). In addition, individuals who choose to participate in the Oregon Registry Pathways to Professional Recognition have their data stored in ORO.

The second major initiative currently underway is the revision of the OAR for licensed child development programs. The OCC seeks the alignment of OAR between all facility types to increase professional competencies and annual professional development. The third initiative, designed to start in 2013, is the development of Oregon's Quality Rating Improvement System funded through the RTT-ELC grant. The QRIS is a voluntary program improvement system for licensed facilities that ties performance to both program and individual compensation (WOU, 2013a; 2013b).

All three of the OCC's current initiatives fit into the NAEYC Workforce Design model. The initiatives directly affect early childhood educators in licensed programs. ORO, the state's data collection initiative, requires that all early childhood educators who work in licensed programs submit their annual mandated professional development hours to ORO. The new QRIS ties funding for programs and individuals to performance measures. The ongoing revisions to the OAR reflect mandated changes that must be followed by early childhood educators who work in licensed programs. While regulatory impacts are slated for 2014, the pilot of the QRIS is currently happening in Multnomah 
County. The enactment of new professional development system programs impact early childhood educator experiences as they engage in a changing professional development system.

\section{Strengths and Limitations of Professional Development Systems Models}

The strengths and limitations of professional development systems are reflected in literature that addresses what Osgood (2006) identified "a top-down professionalization agenda" for professionalizing early childhood education in the political arena (p.9). While literature on early childhood educators' experiences in professional development systems is limited to qualitative studies of experiences in regulatory systems, there is an emerging body of early childhood research literature that discusses the impact of political policy on the professionalization of early childhood.

In many ways, the early childhood education community lacks the professional infrastructure of fields such as nursing, social work, or K-12 education. Due to the ambiguous definitions of the early childhood profession, a tension exists between the values held in the early childhood education community and what the government envisions ought to be available or valued in terms of curriculum, standards, qualifications, training, and career structures (Osgood, 2012; Sachs, 2001). In addition, impacting state professional development systems is the pull between the role of education and the role of regulations, which on one hand is restricting and on the other does not provide enough requirements for quality (Moloney, 2010). This tension is heightened even more by the complex nature of state agencies, the overlapping functions of which create frustration on the part of providers. 
Many individuals and organizations seek to shape the early childhood profession in our state. The array of agencies participating in defining Oregon's childhood care and education field highlight that the framework encompasses research, practice, professional development, and educational policy. Each stakeholder group in the system has its own social norms, agreements and assumptions about the needs of young children (Curtis et al., 2011). The OCC, The Office of the Governor, the Oregon Legislature, and the Children's Initiative each operate within a sphere of influence that is able to enact policy change in the early childhood community. The OCC is Oregon's lead agency for federal Child Care and Development Block Grant funds. The division is responsible for regulating licensed programs in Oregon and for contracting for services to support the state's early childhood professional system.

Through political action, the Office of the Governor and the Oregon Legislature pursue the alignment of the birth to twenty system of education to achieve better results, including the improvement of child outcomes for birth to twenty education. The Office coordinates educational and social services for the bottom 40 percent of children and their families, and it eliminates duplication of services impacting budgets thereby creating greater efficiency in government (Executive Order 11-02, 2011). The Children's Institute, a non-profit advocacy group, seeks to influence Oregon's educational policy, and outlines beliefs about what constitutes early childhood education. The overarching goal of current policy is to increase school readiness for children through academic outcomes in early childhood education (Early Learning Council S. B. 909 Report, 2011). 
The demands on the field of early childhood are becoming more complex as school readiness becomes a focus. Growing demands of accountability, in the form of child outcomes, are fed by an increase in public awareness of the need for school readiness and parents' consumer demands (Moloney, 2010). Additionally, government policy in early childhood education is said to have a "myopic focus on cognitive benefits" (Zigler \& Styfco, 2003, p. 15) of high quality programs. This holds true in Oregon, where the Governor's first legislative actions focused on early childhood policy and were designed to improve quality and to support children and families success by strengthening the quality of early childhood programs (Office of the Governor, 2011a). The current preoccupation with school readiness measured through academic achievement in early childhood education has created a political agenda that has a significant impact on the early childhood community (Parnell, 2010; Sachs, 2001). In a quest for academic certainty at kindergarten entry, the policy agenda is focused on key targeted areas of early childhood professionalism (Osgood, 2012; Webster-Wright, 2009). The concept of a "professional in every setting within a predetermined timescale meeting the target becomes the overriding concern, rather than whether or not the concept [of discreet individual as professional] represents professional more broadly" (Osgood, 2012, p. 51). Driving policy in Oregon are program targets that convey beliefs about early childhood learning and child outcomes (WOU, 2013a, 2013b). Policy outcomes can have far-reaching unintentional impacts. The development of the new QRIS and its vision for professional development and professional competencies are based on what policy makers believe are best practices and what the state educational 
framework can support (WOU, 2013a, 2013b). However, within the early childhood community, a theoretical division remains between concepts of education and care (Osgood, 2012). While government policy struggles with the close relationship between education and care, administration policy and programs continue to compartmentalize the many dimensions of the early childhood community (Osgood, 2012).

To understand the external forces impacting early childhood educators, it is important to identify the underlying structure of early childhood education. McCabe and Sipple (2011) spoke of early childhood education as being an assortment of services and programs delivered by a multiplicity of public and private agencies that operate independently of each other. "This merger of public and private, system and nonsystem, caregiving and education, and home versus institutional care individualized early childhood programs and educators into the forefront like no other current policy issue of our time" (McCabe \& Sipple, p. e2). One of the greatest divides of expectations is in the intent of early childhood education. Government funded early childhood education focuses on school readiness as measured by performance-based testing. The structure of federally funded programs is being used as the model for all programs. It is a fundamental source of tension in a market economy where the majority of early childhood programs are funded by parents.

\section{Summary}

My research study explored early childhood educators' experiences in Oregon's professional development system. Early childhood educators' professional identities are influenced by state professional development systems. Further, policy mandates continue 
to constrict and define professional engagement. Kelchtermans (2005) linked educational reform to increased vulnerability in those who educate children. As early childhood educators become advocates for their own professional identity, they are becoming increasingly aware of the limitations that they face within the professional development system framework. This recognition of a disconnection between their own professional identity and a system-imposed value of identity is destabilizing (Day et al., 2006).

Currently, the OCC is enacting a series of initiatives and mandates to unify early childhood education in the state of Oregon. The complexity of early childhood education is often lost within the framework of professional development systems that focus on the overarching structure of regulation and quality indicators. Professional engagement in the social and political landscape is made more complex by Oregon's mandate that all early childhood educators in licensed programs must participate in the state's professional development system (OED CCD, 2011). Regulations further shape the daily lives of early childhood educators with the constraints of regulatory systems, and create an ever-narrowing sense of acceptable knowledge and practice (Fenech \& Sumsion, 2007).

Policy and regulatory changes to early childhood education will force early childhood educators to change their professional practices to continue participating in Oregon's professional development system. Ever narrowing requirements for early childhood educators by the professional development system can minimize connections that early childhood educators make between their professional practices (Fenech, Sumsion, Robertson, \& Goodfellow, 2008). The topic of what constitutes 
professionalism emerged from the literature focused on government regulation of early childhood education (Dalli \& Urban, 2010; Fenech \& Sumsion, 2007; Osgood, 2010). Discussions on professionalism and the construction of professional identity within the context of social and political structures begin to acknowledge the complexity of early childhood educator's experiences within society.

\section{Concepts of Profession, Professionalism, and Professional Identity}

The struggle to define professionalism and how professional identity connects to a profession is found throughout the literature (Dana \& Yendol-Hoppey, 2005; Katz, 1995; Moloney, 2010; Osgood, 2012; Ortlipp et al., 2011). A profession is referred to in the literature as a set of specialized knowledge and skills (Caulfield, 1997; Feeney, 2012). Osgood (2010) stated that professional practice defined is a broad construct, apolitical, and applicable to many fields. However, she went on to say that professional practice always must be situated in the "cultural, historical and political specificity in relation to early childhood" (p. 121). It is within the cultural, historical, and political framework or societal construct that a literature review was conducted to examine the concepts of profession, professionalism, and professional identity.

\section{The Early Childhood Education Profession}

Defining the early childhood education profession is difficult. Debates in the literature focus on defining attributes of a profession (Feeney, 2012; Osgood, 2012). For the purpose of this study, the early childhood profession encompasses early childhood educators working in an early childhood community with a specific focus that requires specialized knowledge and skills. This definition is supported by NAEYC (1997), which 
stated the early childhood education field needs to includes skills, attributes, and dispositions that connect a group of individuals together with a shared scope of work to strengthen it as a profession (NAEYC, 1997). Feeney (2012) noted that early childhood education, while meeting many requirements of a profession, lacks the unified platform at the state and national level necessary to be considered a profession. In the literature, the lack of a national platform was also cited by others in the United States and abroad (Feeney; Dalli \& Urban, 2010; Osgood, 2012). Institutional systems, such as Oregon's professional development system and NAEYC, call early childhood education a workforce as a way to categorize those working with and on behalf of young children (OED CCD, 2011; LeMoine, 2008; NAEYC 2012b). However, the early childhood community is unable to define a community-unifying concept of professional.

Furthermore, Oregon's Governor Kitzhaber has a plan for changing the early care and education landscape (Curtis, et al., 2011). An unclear definition of the early childhood education profession, its professionalism, and the early childhood educator's professional identity all contribute to an unclear starting point for early childhood education realignment. Instead, the realignment of Oregon's professional development system is starting with child outcomes. A focus on child outcomes is what Osgood (2012) identified as concepts of evidence-based research that drive policy platforms of "top down" reform from policy maker to early childhood educators. Key stakeholders include government departments, advocacy groups, and legislators. However, the voices of early childhood professionals are not reflected in current state early childhood policy discussions. Osgood (2006) stated that policy initiatives provide early childhood 
educators with attention and funding, which represents "an attractive and seductive opportunity to raise the status and prestige of ECEC" (p. 9). She went on to say that this model creates a "double-bind," pitting the culture of care and nurturing against "externally proscribed regulations and standards" (Osgood, p. 9). The realignment of regulations and standards, coupled with child outcome measurements, imposes further restrictions on early childhood educators' practice in the classroom.

\section{Professionalism as a Cultural, Historical, and Political Construct}

The purpose of early childhood education is bound up in a multilayered, multidimensional conundrum of cultural, historical, and political beliefs about what young children should know and be able to do in preparation for school. At the heart of school readiness is what Apple (1993) suggested,

What counts as knowledge, the ways in which it is organized, who is empowered to teach it, what counts as an appropriate display of having learned it, and-just as critically - who is allowed to answer all of these questions are part and parcel of how dominance and subordination are reproduced and altered in society. (p. 222)

Many of the expectations about professional competency emerge from beliefs about teacher education and credentialing in the K-12 system (Barnett, 2011). Early childhood education is often measured against education, social work, and nursing as a basis on which to compare and contrast the attributes of a profession (Dalli \& Urban, 2010; Feeney, 2012). I have defined professionalism as the embodiment of enacted behaviors that demonstrate a set of skills, professional values, and ethics that guide early childhood educators in their daily practice. The literature continues to grapple with a single definition of what professionalism looks like in practice. 
This debate impacts the nature of early childhood education and the identification of who should define early childhood educators' professional identity (Osgood, 2006; Parnell, 2010; Sachs, 2001). Parnell (2010) acknowledged that professional identity in early childhood education has traditionally been negotiated through societal values. Osgood (2006) contended that middle class societal messages about early childhood educators' professionalism could not be separated from the requirements of regulatory agencies or compliance to quality standards within the state professional development system, which educators and with that of the system they navigate. Since professionalism is confused with quality and regulatory compliance, the intersection of these messages can clash with early childhood educators' definition of their own professional identity, and how they choose to enact their concept of professionalism.

\section{The Intersection of Professionalism and Professional Identity}

While professionalism as a term for early childhood education is defined as part of the societal construct, the construction of professional identity happens at the individual level for early childhood educators (Lazzari, 2012). The early childhood educators' construction of their professional identity overlaps with societal construction of professionalism in early childhood education much like a Venn diagram in the literature (Caulfield, 2007; Feeney, 2012). Constructs of professionalism identified by Feeney for early childhood educators (2012) include communication and relationships, work ethic, moral and ethical behavior, and advocacy. The literature is clear that professionalism as a set of actions and beliefs is prescribed through society constructs, such as NAEYC, regulatory agencies, and policy structures (Dalli \& Urban, 2010; 
Feeney, 2012; Hardwood, Klopper, Osanyin, \& Vanderlee, 2012). In the other circle of the Venn diagram, professional identity is the cross section of early childhood educators' personal attributes, values, morality combined with professional ethics (Feeney et al., 2012). In the intersection of the Venn diagram, early childhood educators make meaning between their professional identities and societal constructs for professionalism.

Tensions emerge in the disconnect between the self-identification of professional identity and the societal construct of professionalism that requires early childhood educators to navigate state professional development system standards in order to claim professional recognition, legitimacy, and credibility. Dalli and Urban (2010) spoke of professionalism and quality being intertwined in the political arenas. This conversation leads to confusion in the political area linking the concepts of child outcomes to early childhood professionalism.

\section{Construction of Professional Identity}

The construction of a professional identity in the early childhood community is found woven throughout the qualitative research involving phenomenological, heuristic, and discourse analysis studies (Dana \&Yendol-Hoppey, 2005; Katz, 1995; Moloney, 2010; Osgood, 2012; Ortlipp, et al., 2011; Sachs, 2001). Much of the literature focuses on individuals' perceptions about what it means to be an early childhood educator and how these perceptions connect to self-identification as a professional (Harwood et al., 2012). A significant portion of the research has been generated in Australia and Great Britain, and researchers in New Zealand, Sweden, and the United States have contributed to the conversation (Osgood, 2012; Parnell, 2012a; Sumsion, 2001; Taguchi, 2007; 
Woodrow, 2007). Conversations throughout the literature circle back to early childhood educators' struggles to develop a professional identity within the larger societal context. It is easy to mistake this struggle as a binary argument between the early childhood educator's professional identity and societal or political expectations. However, the multiplicity of purposes found in early childhood education programs cannot be made simple (Osgood, 2012).

The importance of the voice of the early childhood educator emerged from studies by Osgood (2012), Dalli and Urban (2010), and others (Hsu, 2008; Parnell, 2010; Sumsion, 2003). Power inequality between early childhood educators and the formal structures of government regulation and control have emerged as a theme in the literature (Apple, 1993; Apple \& King 1977; Langford, 2008; Parnell, 2010; Webster-Wright, 2009). Also having emerged as a theme is the issue of measureable child outcomes and who defines school readiness (Cohen, 2008; Goelman \& Guo, 1998; Fenech \& Sumsion, 2007; Krieg, 2010; Osgood, 2006). These themes of unequal power and quality as measureable child outcomes present a narrow point of reference for what early childhood educators should be able to know and do within a governmental framework.

Within the multiplicity of types of early childhood programs, the development of professional identity is measured in broader terms. Concepts of a vocation emerge from the literature focused on early childhood educators' perception of professional identity (Hardwood et al., 2012; Osgood, 2012; Taggert, 2011). Osgood (2012) spoke to the choices individuals make to pursue careers in early childhood education. She believed that early childhood educators' motivation comes from one of two sources. First, it is a 
personal choice that is made positively and proactively. Second, it is a fallback position, a position that happens to be easily available or open to us as educators. Throughout the literature, there is an acknowledgement of the dichotomy of the choice and fallback position (Osgood, 2012; Sachs, 2001).

When asked to define why they chose their profession, many early childhood educators speak of their connection to children or the worthiness of the work (Dana \& Yendol-Hoppey, 2005; Moloney, 2010; Osgood, 2012; Sachs, 2001). Furthermore, some identified the lack of career options and the accessibility of early childhood as field, since it requires limited professional training. Specifically, Osgood (2012) spoke to early childhood educators' beliefs that there are limited career choices and the work of early childhood is closely aligned to maternalism, which is an option for most young women. When early childhood is chosen as a profession, Torquati, Raikes, and Huddleston-Casas (2007) identified three viewpoints of early childhood educators: as a career/professional, as a stepping stone, and as a personal calling. Those who choose the work, a attitude of choice, to serve the greater good, have a highly personalized construct of what it means to be an early childhood professional, grounded in the feelings and attitudes about the job as part of their professional identity (Moloney, 2010,p. 168). Individuals who do not feel that they have a choice in a career or that their choice is limited show a lack of interest in developing an internal framework for professional identity (Osgood, 2012).

Several studies cited that once early childhood educators start working, they quickly realize the disconnection between their projections of classroom life versus its reality, and they must adjust their thinking (Dana \&Yendol-Hoppey, 2005; Hardwood et 
al., 2012; Mevawalla \& Hadley, 2012; Osgood 2012; Sumsion, 2001). These studies discovered that early childhood educators have altruistic motives for working in the early childhood community, and that the reality of the hard work, identified as both physical and emotional, was unexpected (Osgood, 2012, p. 77). Many providers indicated that they were unprepared for the energy that was needed to sustain a commitment to the field (Mevawalla \& Hadley, 2012; Sumsion, 2001). Early childhood educators who remained struggled to reconcile the fit between "who I am and what I do," directly related to emotionality of the work (Osgood, 2012). Much of this emotionality was connected to perceptions about their work formed in childhood (Dana \& Yendol-Hoppey, 2005; Osgood, 2012; Sumsion, 2001). Early childhood educators who came to their work with longstanding expectations from childhood struggled the most with reconciling their personal and professional self (Osgood, 2012; Sumsion, 2001).

The literature establishes that emotional connections to children are vital to providing an environment that supports children's development (Ailwood, 2008; Parnell, 2010; Rinaldi, 1998). The emotionality of the work took early childhood educators by surprise as it extended beyond their engagement with children extending into time required in support of the community and colleagues (Katz, 1995). Very often the emotionality of their work reinforces personal attributes that foster a professional belief on the importance of nurturing young children (Hargreave, 1998; Osgood, 2006). Mozére (2012) identified early childhood educators as "wonderful people who invent many arenas to imagine how to share and how to create, but because they are not connected (as part of macro-politics in institutions that may be useful), their realm of 
efficiency, of action, their energy and their power of action are necessarily limited" (p. 6). Mozére (2012) clearly captured the disconnection between what early childhood educators valued as the care and nurturing of young children, and what Dalli and Urban (2011) called the larger societal or political construct which focuses on quality and professionalism.

Policy stakeholders view altruism as a professional value for an early childhood educator to be a weakness (Osgood, 2012). However, the literature establishes that an emotional connection to children lies at the heart of a caring, engaged professional (Dana \& Yendol-Hoppey, 2005; Osgood, 2012; Sumsion, 2001). Early childhood educators also recognize the tension when seeking to advocate for themselves and their programs, although they often lack the skills or experience to do so, further reinforcing stakeholder views that emotionality should be subjugated to factual realities of performance (McCabe \& Sipple, 2011; Osgood, 2012). The tension, in part, emerges from early childhood educators' growing sense of urgency to change societal perceptions of the field (Dana \&Yendol-Hoppey, 2005).

Emerging research also speaks from a postmodern, post-feminist perspective of the power differentials between the field and the policy makers (Moloney, 2010; Osgood, 2012). This power differential often assumes that, since early childhood educators are grounded in a viewpoint of nurturing, they lack the skills needed to enact educational change (Ailwood, 2008). Further, policy makers mistake the multiplicity of early childhood education as a lack of shared vision by the early child community rather than a position designed to meet parental needs for services (Osgood, 2012). However, as a 
review of the literature in professional identity formation reveals, many voices are contributing to the empowerment of early childhood educators and their professional identity formation.

Empowerment through actions, such as collective bargaining and other collaborations, can create tension between early childhood educators and Oregon's professional development system (Curtis et. al., 2011). In other words, society and the political structure are not prepared for a female-dominated field to rise up and define the terms. These actions challenge political and societal assumptions of a docile workforce (Osgood, 2012). Parnell (2012b) described the disequilibrium of crisis points as a tool of empowerment for change. However, minimum efforts are being made within the current political agenda to create shared meaning of the professional identity of early childhood educators (McCabe \& Sipple, 2011).

The dilemma unfolds between the day-to-day experiences of having to act concretely, spontaneously and autonomously in ever-changing, uncertain situations which, to a large extent, are determined by factors beyond the practitioners' control, and the pressure that arises from increasing socio-cultural and socio-economic expectations to produce predetermined outcomes in this complex work context. (Dalli \& Urban, 2010, p. 5)

Oregon's adoption of the QRIS model supports professional development outcomes that define what it means to be a professional. Financial incentives are being tied to performance measurements both in child outcomes and in educational attainment. Osgood (2009) terms financial incentives as a concept of rescuing the early childhood educator from under-funding, lack of direction, and neglect. While state professional development systems are designed to increase quality, they firmly define the concept of 
professionalism, sometimes with unintended consequences for early childhood educators (Menmuir \& Huges, 2012; Osgood, 2012).

The push for professionalism as defined by a prescribed series of skills, along with the narrowing of what is accepted as professional preparation and practice, is taking its toll on the early childhood community. Osgood (2012) stated that low professional status in the broader community and high demand roles, combined with poor pay and working conditions, is forcing early childhood educators from the field. Day, Kington, Stobart, and Sammons (2006) spoke to the pressure educators feel when there is a disconnection between the system and the individual. Referred to as "colliding worlds" by McCabe and Sipple (2011), they caution that the outcome is yet to be seen in how the "complex reality" of early childhood education will be handled by politicians and interest groups (p. e20).

\section{Summary}

Early childhood educator professional identity cannot be explored without identifying personal, societal, and political messages about the early childhood profession. Parnell (2010) acknowledged that socially constructed images of early childhood educators influence the effectiveness of educational implementation. Evident in the literature is the discussion of the personal and professional self as being enmeshed in professional role conception in the field of education (Day et al., 2006). Moreover, the debate of education versus experience as the valued attribute is leaving much of the early childhood community behind as the concept of developing a professional identity over 
time in the workplace is taking a back seat to education in professional development systems (Moloney, 2010).

The experiences of early childhood educators, therefore, are often over simplified in the social and political context of professionalism (Demma \& LeMoine, 2010). In reality, early childhood educators' experiences are reflected in the complex nature of early childhood education, which is situated in a rapidly changing landscape (Cohen, 2008). Phenomenological research of professional identity can demonstrate the influence of experiences on professional identity formation, and lay a foundation to explore the experiences of early childhood educators in identifying themselves as early childhood education professionals.

\section{Professional Development and Professional Engagement}

Historically, early childhood education has been an extension of women in the home who care for children (Ailwood, 2008). Parnell (2010) reflected that there are societal norms of "longstanding traditional beliefs children should stay home" (p. 2). These societal norms are identified as the concept of middle class mothering which, according to Osgood (2012), have remained fixed in society's eye, while the construct of early childhood has changed. Early childhood education is now tied to legislative platforms, performance standards, and school readiness. Early childhood education has become important in the eyes of society and politics. As public school education platform and performance measurements push into preschool, the perception that early childhood education fills a need is driving new policy decisions (Moloney, 2010; Ortlipp, et al., 2011; Osgood, 2012). 
Part of the disconnect between early childhood education and education in K-12 grades is in the expectations of the role of the educator. Mozére (2012) clearly identified the disconnect between educational systems engaged in a theoretical construct of a "dyadic pattern of one child/one adult" (p.5) and the multiplicity of early childhood education. The education system was designed to create measurable child outcomes, in the form of performance measurements on test and other formal survey tools. However, the realities of early childhood environments are grounded in interactions between and among children, and early childhood educators, which is very different from the K-12 education system (Barrett, 2011; Lubeck, 1996). The very complexity of early childhood education reveals learning through the discovery of serendipitous moments found in the multiplicity of the early childhood environment (Mozére, 2012). Rinaldi (1998) further emphasized "the scholastic institution-infant-toddler center or preschool-is viewed as a 'living organism' that pulses, changes, transforms, grows and matures” (p. 118). However, conceptions of serendipitous moments and learning as a developmental process towards emergent learning have no place in a performance-based model that looks for child outcomes in formal education.

What was once embraced by the early childhood community - that an experienced early childhood educator in a nurturing, creative and loving environment can support healthy child development - is devalued in the new social order that defines early childhood by child outcomes (Osgood, 2006). Through legislative policy and action, professionalism is coming to be defined by an ever-narrowing construct. The rise of education as a pathway to professionalism has removed one of the last existing positions 
held by early childhood community, namely, experience matters. In the eyes of the early childhood community, experience is part of the professional identity that early childhood educators can stake a definitive claim on as meaningful and valued by employers (Dumbrajs \& Keinonen, 2011). In a field that traditionally has had low status, low compensation, and has been predominantly populated by women with limited professional development, experience provides a common thread (Moloney, 2010, p. 168). Furthermore, the field is diverse, consisting of the early childhood individuals who differ in their preparation, qualifications, employment situation, and status (Moloney, 2010). Experience can be seen as a unifying factor that transcends the multiplicity of early childhood programs. It is the one shared construct that acknowledges, regardless of education or preparation, that all early childhood educators experience professional growth patterns (Katz, 1995).

In the confusion between professionalism and quality, education policy reforms seek to develop and implement an academic or developmental model of early childhood education (Dalli \& Urban, 2010). These education models gain popularity when states link financial compensation to educational policy reforms, like QRIS. When a QRIS system also links state professional development systems to individual financial compensation for educational attainment, there is a further increase in participation (WOU, 2013a, 2013b). If compensation or professional development access is not equalized for all early childhood educators at a facility or even in a community, then an incentives-based model can drive a wedge between those with access to professional development system programs and services and those who do not have such access. An 
unintended consequence of uneven access is the widening gap between those with education and those without.

To further complicate early childhood education, policy models confuse professionalism with professional status. Professional status is a nebulous term that creates a series of forced choice rankings by qualifications in Oregon's educational system (OAR, 2011). Early childhood does not fit the mold of K-12 education and, therefore, does not adapt well to the professional status model. The early childhood model's lack of unified requirements and standardized language, and the fact that much of the field is privately funded, all serve to give early childhood the appearance of a disjointed system. The differences in early childhood professional practices reflects in how early childhood educators' engage in professional development activities and enact their practice not only among programs but even between individual early childhood educators (Dumbrajs \& Keinonen, 2011).

\section{Professional Engagement Opportunities}

Menmuir and Huges (2012) stated that a depth of knowledge and reflection on practices are hallmarks of a sense of professionalism. The NAEYC stated that specialized education and professional preparation in early childhood is critical to establishing a professional identity (Zigler, Gilliam, \& Barnett, 2011). Teacher preparation and ongoing professional development each play a role in shaping professional identity. There is a growing consensus that teacher preparation programs and ongoing professional development are needed for all early childhood educators to support their work with young children (Camp, 2009; Darling-Hammond, 2012; Gable \& 
Halliburton, 2003). However, there exists a debate in the literature about the role education plays in the formation of professional identity. Some scholars believe that professional identity is the result of early childhood educator teacher preparation programs, while others believe that professional identity is formed as the result of being a field practitioner, benefiting subsequently by ongoing professional development. Hsu (2008) summarized a continuum of beliefs, encompassing teacher preparation as the study of theory and practices as everything that happens in a real setting. This is most often identified in the literature as the gap between theory, seen as abstract, and practice, seen as concrete (Bown \& Sumsion, 2007; Goelman \& Guo, 1998: Osgood, 2012; Sumsion, 2003). The gap between theory and practice may be seen in the number of early childhood educators who choose community-based activities as opposed to formal education as a way to document professional development activities (OCCD, 2013). Professional Engagement as a Function of Oregon's Professional Development System

There are debates in the literature over how different types of activities are defined as professional engagement (Torquati, Raikes, \& Huddleston-Casas, 2007; Webster-Wright, 2009). Furthermore, the powerful institutions that regulate licensed care and control funding offer their own definition of what professional engagement means (Osgood, 2006; Sachs, 2001). Information regarding beliefs about professional recognition and experiences with the state professional development system are reinforced when program participation is mandated. Early childhood educators are subject to accountability pressures from external agencies, yet the requirements for the 
work are often inconsistent (Moloney, 2010). In exploring early childhood educators' professional engagement, it is important to identify the professional pathways for early childhood educators in the professional development system. Voluntary professional engagement activities are entangled with mandatory requirements for professional development both in early childhood educator preparation and as part of OAR. There are defined roles and responsibilities of early childhood educators working in licensed programs. Nevertheless, requirements are contradictory and confusing, offering early childhood educators multiple unequal pathways to meet regulatory qualifications (OAR, 2011). For example, early childhood educators may become teacher qualified with a year's experience in the classroom or 30 units of early childhood education or a degree in early childhood, to name a few options.

Early childhood educators who work in licensed certified child care programs in Oregon are required to take 15 hours of professional development annually. The intent of mandated professional development in licensed programs is to meet state regulations for minimum training hours. Copple and Bredekamp (1991) and Katz (1996; 2008) acknowledged the importance of keeping skills current as an identifier of professionalism. However, Ettlings (2006) cautioned of the moral obligation that comes from mandating professional development, citing the ethical responsibilities of individuals who deliver professional development, and stresses the importance of emotional safety in these settings.

In Oregon, the childhood care and education field connects all professional development activities to Oregon's Core Body of Knowledge. The Core Body of 
Knowledge is the basis for the training and education essential for on-going professional development in the childhood care and education profession (OCCD, 2008). There are ten specific core knowledge categories that make up the Core Body of Knowledge Diversity: Families \& Community Systems; Health, Safety \& Nutrition; Human Growth \& Development; Learning Environments \& Curriculum; Observation and Assessment; Personal, Professional and Leadership Development; Program Management; Special Needs; and Understanding and Guiding Behavior. These ten categories are embedded in the Oregon Registry Steps. Oregon Registry Steps measure professional development against three pathways for professional recognition of professional development (OCCD, 2009). These pathways provide a way for childhood care and education professional to group and measure their professional development activities. The pathways include: a Degree, Credential, and Certificate Pathway; a College Course Credit Pathway; and a Community-Based Training Pathway that may be combined with College Course Credit (OCCD, 2009). The Oregon Registry's twelve Step pathway was implemented in 2005 to acknowledge the variety of professional development that early childhood educators had in the Oregon's Childhood Care and Education field. The Oregon Registry Steps offer an increasing time requirement. Step 1-7 are between 20-120 hours of professional development workshops. Steps 7.5, 8, and 8.5 are between 200-400 hours, and Step 9-10 are between 600-800 hours. Step 11 is a Master Degree and Step 12 is a Doctorate (OCCD, 2009). However, in the effort to increase quality in childhood care and education through the implementation of QRIS, there are increasing requirements to achieve higher Steps (WOU, 2013a, 2013b). 


\section{The Degree, Credential, and Certificate Pathway}

Early childhood educators have a variety of opportunities to prepare to work with children. Formal education programs range from certificate and credential programs to advanced degrees. NAEYC states that preparation programs should include specialized knowledge about child development, families, pedagogies, and developmentally appropriate practice to plan a culturally relevant and inclusive curriculum that supports and challenges young children (NAEYC, 2009). Certificate programs range from trade schools to community college certificate programs. Credentials can include those from the Council for Professional Recognition (CDA) to state teacher credentials. While Degree preparation programs are generally identified as Associate Degrees, Bachelors Degrees, Masters Degrees, and Doctoral Degrees.

Within the literature focused on early childhood educator professional preparation, there is debate on the ability to measure the benefit of educational attainment on child outcomes (Hsu, 2008). Barnett (2011) in his work for NAEYC, acknowledged that the correlation between different educational pathways and child outcomes is difficult to measure due to the variety of variables used in this type of study. However, the literature does speak to both strengths and gaps in early childhood educator preparation programs (Brownlee \& Berthelsen, 2005; Goffin, 1996; Krieg, 2010). A theoretical foundation to early childhood educators is cornerstone of many preparation programs (Camp, 2009; Gable \& Halliburton, 2003; Torquati et al., 2007). Knowledge of theory is foundational to framing and interpreting classroom experiences (Camp, 2009). A foundation or core knowledge of concepts is mandated by many professional 
development registries, which acknowledge degree and certificate pathways with far greater frequency than community-based professional development only (National Registry Alliance, 2012). While studies are inconclusive about the correlation between degrees and child outcomes, the literature consistently identifies that qualifications are critical to shaping professional identity that affects domains of "self-esteem, self-belief, job satisfaction and belonging” (Moloney, 2010, p. 184). The majority of degree, credential, and certificate programs have practicum components.

However, while programs share commonalities, there continue to be significant differences among program requirements for early childhood education. Since the expectations in early childhood preparation programs are divergent, they fail to provide a common standard (Camp, 2009; Cochran-Smith \& Lytle, 1990). Feeney (2012) identified common standards as a baseline of best practices for the early childhood profession. Kwong and Kwong (2000) spoke to concerns about preparation programs that are based solely on theory. Theory-based programs are rapidly expanding as online degree, credential, and certificate programs continue to grow. Kwong and Kwong's research showed that early childhood educators struggle with the transition of theory to practice without a bridge that demonstrates theory in practice. Their research was supported by Fleet and Patterson (2001), who acknowledged that educating children requires classroom experiences in order to construct meaning from theory.

\section{College Course Credit Pathway.}

While degrees, credentials, and certifications are granted by a variety of institutions, college course credit is strictly associated with regionally accredited colleges 
and universities. Within the focus of the college and university pathway, there is identified coursework. Coursework and degrees that received automatic acceptance to the Oregon Registry include studies in early childhood education, child development, human development, elementary education, human ecology, home economics, family and consumer studies, child and family studies, education, special education, special education early intervention (OCCD, 2013). All other submissions of college course content must be found within the Core Body of Knowledge if they are to be recognized by Oregon's professional development system.

College or university studies represent one of the most significant investments early childhood educators can make on behalf of their professional competencies (Osgood, 2012). The amount of time spent in college or university classes far exceeds the hours spent on an individual professional development activity. There is a recognition that specialized knowledge is available in these settings that creates a depth of understanding (Caulfield, 1997). This professional expertise is identified as one of the hallmarks of a professional (Feeney, 2012). Goodfellow (2004) spoke to the opportunity college degrees offer in supporting reflective practices of early childhood educators. While college and or university studies offer distinct advantages in the depth of study, they still remain out of reach for many early childhood educators. The demand for college scholarships for early childhood education exceeds the availability of funding (OCCD, 2012). This holds particularly true in the Oregon Community College system. Camille Preus, Commissioner of the Oregon Department of Community Colleges and Workforce Development, stated that access to community college classes is limited by 
the fact that many colleges are enrolled at or beyond capacity (personal communication May 18, 2011). Barriers to accessing college courses affect the early childhood education community in significant ways. When there are significant barriers to college preparation, many early childhood educators seek community-based training to meet their professional development needs.

\section{Community-based Training Pathway}

Professional development in community settings also plays a role in early childhood educator professional engagement (Webster-Wright, 2009). Spodek, cited in Fleet and Patterson (2001), noted that the term "professional development" is difficult to define. Several definitions exist to represent early childhood education professional development (NAEYC \& NACCRA, 2011b; OAR, 2011). In Oregon, community-based professional development is offered by individuals or agencies in settings that include classrooms, distance, self-study, webinars, or hybrid options. Oregon accepts community-based professional development that is both regulated by the Oregon Registry Trainer Program (ORTP) and professional development that is exempt from regulation. Professional development that is exempt only needs to document attendance providing that professional development regulated by the ORTP follows a best practices model based on NAEYC standards. General characteristics of professional development programs and best practice models are defined by empathizing critical thinking and reflective practice, providing baseline knowledge of professional practices, and offering opportunities for learning by doing (Hsu, 2008; Katz, 2006, 2008; NAEYC \& NACCRA, 2011a). Webster-Wright (2009) found that the treatment of knowledge in professional 
development system activities is defined by the dominant discourse. In Oregon, almost a third of all professional development is taken in settings exempt from best practice standards (OCCD, 2014). The continued gap between regulated and exempt professional development activities creates an unequal quality of professional development activities continuing to widen the skills gap in the early childhood field.

Webster-Wright (2009) stated that, when it comes to professional development, much of the literature focuses on concepts of "training" or "developing" or on content being "delivered" (p. 713). In Oregon, 75 percent of ongoing professional development activities are found in workshops, conferences, or online single session activities (OCCD, 2012). There is increasing recognition that one-shot professional development activities do not lead to sustained changes in practice (S. Rudisill personal communication, July 19, 2012). The importance of coaching and mentoring is gaining national prominence as research shows that ongoing professional development contacts are shown to yield sustained changes in actions, defined in the literature as spirals of engagement over time (Fleet \& Patterson, 2001). In other words, educators experience concentrated periods of study followed by periods of application, which yields sustained changes in practice based on learning. Professional development can also impact early childhood educators' professional beliefs and focus their practices (Hsu, 2008).

\section{Summary}

Professional development activities are recognized as a foundation for professional competency (Osgood, 2012). Professional development activities encompass college or university studies, degree, credential, and certification programs, 
and community based training. Each type of professional development activity offers strengths and limitations. One continued global concern is that lack of a national standard for professional development activities. Fenech, Sumsion, and Shepard (2010) cautioned that until we address the diversity of qualifications, the early childhood education field is diminished. The very diversity of expectations creates uncertainty that disempowers professional recognition.

This research study focuses on experiences of childhood educators by exploring the importance of framing professional development activities in the voice of educators. Mozére (2012), addressing the subjugation of early childhood educator experiences in the political system, stated,

In the end, there is no space for heterogeneity, only the expertise. It is important to recall that expertise means judging. Experts' judgments decide what is good or evil, what is right or wrong. That is why expertise is so strong, because, when actions, situations, and behaviors are judged to be appropriate, they can be relied on. (p. 6)

Thus, although the state has the capacity to impose universal standards of automated practices, it can fail to engage early childhood educators in meaningful explorations of their professional experiences.

Professional engagement in the social, political, and educational landscape is made more complex by Oregon's mandate that all early childhood educators in licensed programs must participate in the state's professional development system (OED CCD, 2011). The reality of professional engagement in ongoing professional development or educational attainment in professional development systems is much more complex than meeting the mandates of required hours. The continuum of beliefs about the purpose of 
professional development, educational attainment, and how early childhood educators connect their practice to the professional development system is reflected in their engagement. Beliefs provide insight into how early childhood educators value the professional development system.

\section{The Discourse of Early Childhood Education}

There is a multiplicity of terms and definitions used to describe early childhood education. Kagan and Kauerz (2012) spoke of that "practice and literature are awash with various definitions of systems generally and with different labels for and definitions of early childhood systems specifically" (p. 8). The defining of what is early childhood education is an untidy process with competing platforms seeking to define what it means to be an early childhood educator (Kagan \& Kauerz, 2012). Gee (2011) acknowledged the power of language not only to communicate and cooperate but also to create advantages and define institutions. This section explores two ways language is used in early childhood education settings. The first is the conceptualization of the discourse of early childhood education in the literature. The second is the examination of language to reveal its underlying meaning.

\section{Conceptualization of Discourse of Early Childhood Education}

Early childhood education researchers make abundant use of the term "discourse" (Langford, 2008; Osgood, 2006; Ortlipp et al., 2011; Woodrow \& Press, 2007). Within the examination of language, there are both theoretical approaches and methodological approaches to examining discourse as a way to identify the underlying meaning of language. The theoretical approach, in early childhood education, highlights power 
variances between individual educators and with that of the system they navigate (Dana \& Yendol-Hoppey, 2005; Novinger \& O’Brien, 2003; Taguchi, 2007). The analysis of discourse, as a methodological approach, may focus on the structure of language or its intent (Gee, 2011). For the purpose of surveying the literature in relation to how early childhood educators create their professional identities, this section focuses on power differences between individual educators and the system they navigate.

In early childhood education professional development, significant time and resources are dedicated to determining what it means to be an early childhood education professional in relation to what early childhood educators need to know and be able to do (Lobman \& Ryan, 2007). Joining in the conversation about early childhood educator competencies are political, social, and education stakeholders (McCabe \& Sipple, 2011). A significant amount of the conversation by Oregon's stakeholders occurs outside of early childhood educators' domain of access, leading to a separation of regulations from classroom practice (Novinger \& O'Brien, 2003). Furthermore, the work of Foucault has been cited as a way to bring to the surface how power is enacted, and this idea has emerged as a theme in the literature (Cohen, 2008; Goelman \& Guo, 1998; Fenech \& Sumsion, 2007; Krieg, 2010; Osgood, 2006).

Skattebol (2010) spoke to the historic use of scientific discourse as bringing "status and credibility to the feminized field of early childhood education" (p. 75). Of primary interest to political and social stakeholders is the traditional "mapping" of children's development and achievement (p. 75). This creates a focus on the importance of achievement through measurable outcomes based on academically-based school 
readiness models of early childhood education (Osgood, 2012; Webster-Wright, 2009). Taguchi (2007) concurred, stating that the use of discourse highlights through language the power structure of masculine and feminine knowledge, with masculine knowledge represented by the achievement language and feminine knowledge connected to language about the development of children.

Postmodern, post-feminist theorists Ailwood (2008), Osgood (2012), and Sumsion (2003) indicated that early childhood educator identity and maternal identity speak to the alignment of messaging that emphasizes preparing children to be responsible citizens. The concept of raising citizens follows from an identified role of early childhood educator as a mother figure responsible for the moral development of children. Langford (2008) further stated that the message of developing young children as citizens of the world is in direct contrast with the significance that society places on early childhood educators' value as educators of young children.

However, in an analysis of early childhood textbooks, Langford (2008) found that the concept of a "good ECE [early childhood educator] focuses primarily on the personal qualities of passion, happiness, inner strength, caring and alertness to an individual child's needs and interests" (p. 82). In other words, the perceptions of masculine evidence-based knowledge that emerges as standards in the structure of professional development systems and rules in regulatory practices comes into direct conflict not only with maternal values, but with the way in which early childhood education is presented as a professional practice. Terminology in early childhood education speaks to a feminine notion of nurturing (Harwood et al., 2012). However, the language of regulation speaks 
to health and safety mandates (Novinger \& O'Brien, 2003). Additionally, system language speaks to learning outcomes and achievement (Early Learning Council S. B. 909 Report, 2011).

The disconnection of language in early childhood education creates multiple realities and values with little intersection. The gap between "accepted" language in the early childhood education system and descriptive language used by providers does not appear to be closing. The National Governors Association claims, "Too few early childhood providers and educators, however, possess even the basic knowledge of child development" (Demma \& LeMoine, 2010, p. 4). This claim is hard to dispute because of the lack of standardized requirements for the preparation and education of early childhood educators who leave the field without a measureable baseline for qualification.

Further, the language of the early childhood community is feminist in nature, and does not translate into a discourse that is readily understood by governmental systems (Osgood, 2012). However, educators do speak of creating an emotional connection to children as a value (Lobman \& Ryan, 2007; Skattebol, 2010). Lobman and Ryan (2007) highlighted early childhood educators' beliefs that beyond a theoretical knowledge, attributes were "internally located" primarily in the form of a connection to children (p. 375). Ortlipp, Arthur, and Woodrow (2011) identified this connection to children as a "discourse of care" (p. 67). The focus on personal attributes does not appear to be valued in "technicist discourse" (p. 67) of educational bureaucracies. The gap between discourse and language is observed in the difference in language used by the early childhood community to describe their daily practice and the language used by the professional 
development system. Understanding the possible difference in language usage provides support for reflecting on early childhood educator's experiences in Oregon professional development system.

\section{Construction of Professional Identity and the Dominant Language Paradigm}

Professional identification is being shaped by the use of language in the political arena (Parnell, 2010). Terms such as “workforce," "provider," and "training” represent politically charged words (Moloney, 2010; Sachs, 2001). Parnell (2010) stated that images of the early childhood educator reflect a view of a non-professional in the eyes of parents, teachers, children, and society. Osgood (2006) further pointed out that advocates of the professional agenda believe that professionalism could lead to a strengthening position and increase respect for those who work in ECEC [early childhood education and care], but concerns abound that a process of professionalization could be used as a means of control and provide increasing domination to those in power. (p. 5)

Bown and Sumsion (2007) cautioned that the rise of the regulatory body will lead to adverse effects on early childhood educators through the limiting of pathways available for finding work in early childhood education.

Increasingly, the use of professional identification by state regulatory agencies and federal programs escalates separation from the intention of early childhood education. The new QRIS framework, along with OAR, defines professionals as "providers" or "teachers" (OAR, 2011; WOU, 2013a, 2013b). Each comes with its own meaning and conveys different types of intentions for professional practice. Osgood (2006) stated that an examination of language to expose its underlying meaning in the construction of identity reveals beliefs about the dominant paradigm. Further, early 
childhood educators" "ways of being come from the active engagement and negotiation of the discourse through which they are shaped and positioned" (Osgood, 2006, p. 7). As Curtis and Carter (2000) contended, "Early childhood education behaves as if it has lost its way, following current trends, rather that cultivating a vision for ourselves" (p. xii). Langford (1998) confirmed in her discourse analysis research that a "significant number of early childhood graduates do not choose to use and do not have the discourses to defend their profession" (p. 92). This lack of a strong narrative voice often results in the early childhood education community being relegated to non-professional status (Osgood, 2012).

The narrative voice of early childhood educators rarely comes through in the literature outside of phenomenological, narrative, or action research. It is difficult, therefore, to identify the early childhood educator's perceptions of professional practice and meaning making from those experiences. Langford (2008) spoke to early childhood educators' self-perception through their use of discourse. Early childhood educators' sense of agency is affected when reconciling the discourse of every day professional practice with that of the system in which they navigate (Fenech et al., 2010). Fleet and Patterson (2001), and Moloney (2010) described that a sense of agency creates selfauthorship of professional identity.

Beyond the societal and political discourse of early childhood education, a language used by early childhood educators to describe their professional practices does exist (Osgood, 2012; Sumsion, 2003). While more informal in nature than "technicist discourse" (Ortlipp et al., 2011, p. 67), early childhood educators have their own unique 
discourse in defining their practice. Analysis of early childhood educators' discourse can be found in professional identity formation. Fenech and Sumsion (2007) stated that early childhood educators who have a strong sense of self and their practice are not swayed by technicist discourse. Rather, these early childhood educators use their own reflective practice to define themselves outside of the labels of governmental systems.

Early childhood educators' discourse informs emerging patterns of thinking, and shows individuals' conceptions of engagement that either align with existing systems through the language of these systems or are rejected as an expression of individuality (Fenech \& Sumsion, 2007). The impact of personal reflection on professional identity is revealed as a autobiography that shapes professional subjectivity (Osgood, 2012). Osgood (2012) went on to identify the notion of subjectivity as a way to identify the construction of the professional self that gives us a reference point for the process of selfreflection on professional practices.

\section{Summary}

Beyond the debate over the usage of terms and definitions to describe early childhood education, norms exist on how language is employed in the daily lives of the early childhood education system. The discourse of early childhood educators and the early childhood education system rarely align (Skattebol, 2010). Early childhood educators' discourse reflects the multiple realities of the profession (McCabe \& Sipple, 2011). However, the social and political nature of professional development systems focuses on child outcomes (Ortlipp et al., 2011). The narrowing of state professional 
development systems and the language used to support them both limits and diminishes the perceptions of what can and should happen in early childhood education.

Situating early childhood educators within the professional development system landscape requires an examination of how language is used in the early childhood field. The discourses of early childhood education ground us in the framework of early childhood educators' experiences. Van Manen (1990) stated that experiences are situated in a contextualized environment within the lifeworld. Therefore, the discourse found in very complex and convoluted early childhood education professional development systems lays a foundation for study of early childhood educators' experiences, namely, of educators who are frequently defined by the language of the regulatory system (Bown \& Sumsion, 2007; Fenech \& Sumsion, 2007; Novinger \& O’Brien, 2003) and wish to define themselves differently. Defining oneself requires the strength to listen to one's own inner voice and to question external messages including how one is defined.

\section{Expressive Language as a Way to Make Meaning of Professionalism}

Messages about how we are to experience our world have a profound influence on what we believe to be true. How early childhood educators make meaning from those messages is part of reflective practice. Parnell (2011) suggested that teacher reflection is located in "praxis (the intersection of theory and practice)" (p. 118). The study of teacher reflection is found throughout educational qualitative research. In the context of this study, early childhood educator reflective practice offers a way to explore experiences in navigating Oregon's professional development system. When connected to phenomenology, reflective practice acts as a catalyst to delve into an experience of a 
phenomenon (van Manen, 1990). Van Manen (1990) went on to explain that phenomenology "is the progress of humanizing human life and humanizing human institutions to help human beings to become increasingly thoughtful and thus better prepared to act tactfully in situations" (p. 21). The act of slowing down to examine the experiences of early childhood educators with Oregon's professional development system provides an opportunity to connect the state system to its constituents.

Dewey (1934) provided a framework to think about reflective practice. Dewey believed that reflection is a meaning-making process for learners that deepens a learner's understanding. Understanding comes from connecting reflection to "life experiences" (p. 305) supporting learners to build and connect new meaning as they engage in the world. Schön (1983) spoke of reflective practice as a type of conversation.

In this reflective conversation, the practitioner's effort to solve the reframed problem yields new discoveries which call for new reflection-in-action. The process spirals through stages of appreciation, action, and reappreciation. The unique and uncertain situation comes to be understood through the attempt to change it, and changed through the attempt to understand it. (p. 63)

Schön further stated that many of our daily actions, recognitions, and judgments stem from our foundational knowledge, which is the foundation of practice. However, unexamined knowledge creates gaps in our thinking, and brackets experiences within its limitations. When time is taken to contemplate the inherent patterns of living in our work, our choices are visible. The practice of reflection, therefore, draws from the critique of the original phenomenon (Schön, 1983).

Early childhood educator reflection is a way to make meaning of experiences, and phenomenology is a lens with which to focus the experience in the hands of the early 
childhood educator. Parnell (2012b) shared that "reflection on action leads to a metacognitive process, which grows us into our critical inquiry stance and how we navigate our experiences" (p. 120). One of the greatest growth opportunities that emerges from reflective practice is the ability to think beyond the concentric circles of our daily lives. Reflective practice offers an opportunity to "become something more than we were before" (Parnell, 2012b, p. 131). Reflection moves profession practice forward, supporting individuals in developing their own theoretical framework for how to act and exist in their personal and professional identity.

\section{Early Childhood Educator Use of Reflective Practice}

Examining reflective practice for underlying assumptions about early childhood education provides insights into the experiences of early childhood educators. An analysis of early childhood educators' experience through their discourse offers insight into professional identity creation (Ortlipp et al., 2011). Curtis and Carter (2000) shared that by "looking closely, we can see influences of cultural patterns and more about ourselves, our preferences, our biases and our blind spots" (p. xiii). Parnell (2010) urged close attention to the language we use in the construction of our professional image. Osgood (2012), and Bown and Sumsion (2007) agreed that the role of "others" defining early childhood is a slippery slope that fractures the field. Hsu (2008) echoed "teaching, especially young children, can be said to be a skill and art-a life-oriented. Life is reality, you cannot fully know about it without experiencing it” (p. 270). Reflective practice scaffolds the power of the early childhood educators' visions for their own professional practice, and how it is nested into a larger societal context. 
Emerging language and thought patterns show educators' beliefs about selfidentity in the broader social, political, and educational context. Reflection offers a way of constructing knowledge about self in a broader context. Out of the many ways of knowing, comes the concept of "learning-as-participating" (Sfard, 1998, p. 6).

Additionally, knowledge is defined as participatory and sense making in experiential learning (Ernst, 1993; Phillips, 1995). Fosnot (1996) spoke of the need to create coherence and meaning from knowledge. At the heart of reflection is the dialogue of the learner, focused on capturing and scaffolding learners' desires to understand more (Warash, Curtis, Hursh, \& Tucci, 2008). Saracho and Spodek (1993) stated that early childhood educators construct their own pedagogical knowledge base through daily experiences. The engagement in reflective practices supports early childhood educator thinking, thereby making them active participants in their own learning (Curtis \& Carter, 2000).

The act of owning experiences emerges when early childhood educators engage in reflective practice. Fleet and Patterson (2001) spoke to the importance of reconceptualizing previous practice when engaging in reflective practice. This idea of owning experience in reflective practice makes us responsible to changing practices when awareness occurs. Anderson-Nathe (2008a) claimed that it is an individual's "knowledge and the ability with which the professional responds [that] defines the professional self" (p. 20). Beyond understanding, reflective practice is a call to action. Early childhood educators who engage in in reflective practice clarify their own professional practice. Tennant and Pogson (1995) contended that autonomy occurs in learning when three 
characteristics are present: the freedom to choose without outside influence, the ability to reflect objectively, and the focus or concentration on meaning making. In other words, reflective practice as part of professional learning is a tool of self-empowerment for early childhood educators.

Parnell (2010) spoke to the importance of early childhood educators' responsibility for creating their own self-image. Self-care also emerged as a skill that helping professionals needed to practice (Anderson-Nathe 2008A; Osgood, 2012). Carter and Curtis (2000) discussed reflective practice as an act of self-care and identity confirmation. In an initial review of research by Bown and Sumsion (2007), Osgood (2006, 2012), and Sumsion (2001), it seemed necessary to ask early childhood educators to share part of their identity formation. Identity formation and its relationship to professional engagement are highlighted time and again in the literature (Fenech et al., 2010; Osgood, 2012: Sachs, 2001). The documentation of the professional identity formation process is important to uncovering the beliefs behind professional engagement actions. Osgood (2012) explored the concept that early childhood educators with an alternative construction of self had greater self-efficacy. Further, Osgood (2012) stated that "bringing subjective experiences from autobiographies" leads to a "greater authenticity in their pedagogical practices and a sense of professionalism" (p. 152). In other words, providing early childhood educators opportunities to connect their personal and professional selves leads to higher levels of self-efficacy and professionalism.

The Intersection of Reflective Practice, Professionalism, and Mandated Professional

\section{Development}


When engaging early childhood educators in reflective practices, there is an ethical responsibility to create time and space for these educators to engage in meaningful, rich reflection (Tennant \& Pogson, 1995). In hermeneutic phenomenology, it is a delicate balance to capture what is considered the prereflective experience (Ajjawi \& Higgs, 2007). There is need to acknowledge that research interviews may have emotions attached to experiences of professionalism, professional identity, and professional engagement. Early childhood educators express feelings of uncertainty when diverse expectation for what early childhood educators are able to know and do lead to an uneven knowledge base for the field (Sachs, 2001). Uneven knowledge can be between programs, systems, and individuals. Care must be taken in engaging early childhood educators in accessing their prereflective experiences, to hold those experiences gently, and not impart or correct any assumptions made based on an uneven knowledge base between the participant and the researcher. Nor can the act of not knowing be discounted for the emotional vulnerability that affects professional identity (Anderson-Nathe, 2008a). Further compounding the concept of professional identities are the economic and educational differences that drive such perceptions (Osgood, 2012). An underlying fear exists for early childhood educators that if they align with the K-12 education system, this will eventually force elementary education standards onto early childhood education, thereby decontextualizing development from learning and debasing it (Ortlipp et al., 2011).

In Oregon, state funded preschools may follow Washington State and require Oregon Teacher Standards and Practices Commission's (TSPC) credentials for all early 
childhood teachers (P. Deardorff, personal communication October 1, 2013). Early childhood educators fear that, in the future, their current positions will no longer be available to them, leading to further unease with state systems for education (Ortlipp et al., 2011). Professional identities cascade into and become beliefs about learning that are reinforced by the very systems early childhood educators must navigate. Day et al., (2005) spoke to these very factors destabilizing professional identity. State and national curriculums de-professionalize early childhood education communities when systems remove decision-making autonomy from early childhood educators themselves (Ortlipp et al., 2011).

\section{Summary}

Reflective practice is a way of being as an educator. Reflective practice also provides opportunities for contextual experiences, and it focuses on the core of the experience to draw meaning from the phenomenon (Parnell, 2012b). Reflection offers a way through the unknown to making meaning from experience (Anderson-Nathe, 2008b). Through meaning making, early childhood educators can to internalize their perceptions of their professional selves, supporting a strong core of who they are as early childhood educators.

Through reflective practices, early childhood educators then must determine how they make meaning of societal, political, and educational messages, and they must determine if they will accept or reject the professional development system as a way to make meaning in their professional practice. Researchers who study early childhood educators' perceptions of self through empirical research find that early childhood 
educators need to navigate and make sense both of external and internal messages about professionalism (Bown and Sumsion, 2007; Fenech et al., 2010; Osgood, 2012: Sachs, 2001). Therefore, looking in on educators' experiences and making meaning of them can affect and change the structure of professional development systems.

\section{Implications of the Literature Review}

Every day, early childhood educators navigate the complex world in which they have situated themselves. Working in licensed programs connects early childhood educators to the state professional development system and its requirements. In a profession that is loosely defined but tightly regulated, early childhood educators must make their meaning of societal, political, and educational messages.

The process of creating a sense of professional self is further compounded by the enmeshed nature of early childhood educators' personal and professional self-perception as caring, nurturing individuals (Day et al., 2006). These perceptions are reinforced both in early childhood education preparation and in ongoing professional development. Langford (2007) called this self-perception as the cultivation of the "good identity" (p. 333). The adoption of the good identity in early childhood education often keeps educators from questioning or challenging the professional development system that has such a pervasive and dominating power over their professional lives (Ailwood, 2003; Novinger \& O’Brien, 2005; Woodrow, 2007).

The constraints of regulatory systems and the rise of professional development systems create a narrowing of the field of professional practices in early childhood education (Fenech \& Sumsion, 2007). This narrowing of what it means to be an early 
childhood educator generates an ever-increasing vulnerability for early childhood educators, allowing them to be buffeted by changing political climates (Kelchtermans, 2005). As long as the discourse of early childhood educators and the early childhood education system fail to align, there will be confusion in the profession (Skattebol, 2010).

A lack of a shared vision between early childhood educators and the professional development system is a loss for everyone. While much of the literature dichotomizes the issues of early childhood education, nurture versus outcomes, experience versus education, or professional development versus formal education, the reality is somewhere in the gray area in the middle. The strongest system emerges from a shared community of practice between early childhood educators and the state professional development system they must navigate. Hsu (2008) and Webster-Wright (2009) stressed the importance of interactions in communities of practice in making meaning from knowledge. When communities of practice come together to make meaning, hooks (2010) called these "genuine conversations," and refers to the importance of authentic, engaged dialogue and natural opportunities for reflection that emerge from the process. Fleet and Patterson (2001) stressed the importance of reflection as a way to reconceptualized previous practice. Hooks (2010) echoed this in the idea that shared communities provide the most meaningful learning opportunities.

The importance of prereflection and reflective practice is to access and make meaning from experiences. In making meaning, early childhood educator's authentic voice counters institutional discourse that drives policy decisions. The thinking, reflective early childhood educator is the best voice to articulate the complexity of the 
early childhood environment. Both Mozére (2012) and Rinaldi (1998) spoke to the connection between experience, time, and culture as relational. Against this backdrop of complexity in the childhood education environment, I seek to illuminate early childhood educators' experiences as they engage with Oregon's professional development system. 


\section{CHAPTER 3: METHODOLOGY}

An emergent world asks us to stand in a different place. We can no longer stand at the end of something we visualize in detail and plan backwards from the future. Instead, we must stand at the beginning, clear in our intent, with a willingness to be involved in discovery. The world asks that we focus less on how we can coerce something to make it conform to our design and focus more on how we can engage with one another, how we can enter into the experience and then what comes forth. It asks that we participate more than plan. (Wheatley \& KellnerRogers, 1996, p. 73)

Chapter 3 presents the methodological focus of the study. It gathers the theoretical lens of phenomenology, the research question, the research paradigm as hermeneutic phenomenology, and the research design as pedagogical documentation of the researcherparticipant and participant interview process. To situate the study in the orientation of hermeneutic phenomenology, I started with a discussion of the theoretical lens of phenomenology as a philosophy. My theoretical lens supported my decision to employ the specific structure of collage. Collage became an a/r/tographic way to engage participants in the hermeneutic phenomenological process as discussed in the methodology (Springgay et al., 2005). For a study focused on early childhood educators making meaning of experiences of professional engagement using Oregon's state professional development system to explore their practice, phenomenology offers a unique mode of inquiry.

Phenomenology is a form of qualitative research. Van Manen (2011a) spoke of the orientations of phenomenology, often identified as branches.

We may distinguish several phenomenological movements and traditions such as transcendental, existential, hermeneutical, linguistical, ethical, and experiential or practice phenomenology. This list of orientations is not necessarily complete. But 
these are designations that seem to recur throughout the philosophical and phenomenological literature. (van Manen, 2011b, para 3)

The primary attribute of phenomenology remains the intentional study of an experience or phenomenon studied from a "first person point-of-view" (Smith, 2011). Two branches of phenomenology roots are discussed in Chapter 3 as a way to provide some (not all) history, lineage and context to my methodological choices. Transcendental phenomenology is discussed providing historic references for the roots of descriptive phenomenology. This study is anchored in the interperavist orientation of hermeneutic phenomenology. The orientation of hermeneutic phenomenology provides insight into the role of language in interpretations, especially through the arts (van Manen, 2011c). As a qualitative researcher-participant, I found great value in what Merriam (2009) formulated as the "understanding of how people interpret their experiences, how they construct their worlds, and what meaning they attribute to their experiences" (p. 5). Therefore, hermeneutic phenomenology, with its focus on the lived experience, provided a way to investigate participants' personal learning journeys (Ajjawi \& Higgs, 2007) in navigating Oregon's professional development system.

\section{Theoretical Lens}

Phenomenology has its roots in the work of German mathematician Edward Husserl. Husserl described phenomenology as the conscious meaning made from experiences to represent a belief about an object or experience (1913). Originating as a philosophy, the term phenomenology has come to represent many approaches to making meaning of experience. Patton (2002) saw it as a complex interweaving of philosophy, 
paradigm, methodology, and approach to qualitative analysis. Van Manen (1990) argued that it is not positional discourse, nor a method for theorizing one truth; rather it is an attitude to the experiences in which meaning can be made (p. 298). Husserl (1913) himself believed that the "bracketing of natural attitudes" or the removal of personal values would expose the essence of the experience. In his footsteps followed Moustakas (1994), who believed that the researcher sets aside their experiences, leading to a "fresh" interpretation (transcendental phenomenology) of the phenomenon.

The form of phenomenology labeled transcendental began as a scientific approach to description, having much in common with the positivist frame of reference (Kakkori, 2009). Van Manen (2001b) concurred stating that transcendental phenomenology is a "rigorous science" (para 3), comprised of withdrawing any subjectivity from the researchers experience of the phenomenon. In transcendental phenomenology, experiences should be examined by setting aside the researcher's beliefs. The act of removing oneself from the experience supports the epoche of the experience in becoming visible. This suspension of judgment positions the researcher to know the experience, and to eliminate methodological doubt from the interpretation.

Kakkori (2009) noted that as Husserl continued to reflect on the philosophy of phenomenology, he came to argue for the incorporation of theoretical deduction into the once-believed "purely" scientific process. However, at the heart of his phenomenological approach remained the concept that the examination of the experience required strict methodological application to remove the researcher from the research by rigorously bracketing the researcher's experience, thus enforcing its positivist essence free from 
researcher's bias (Anderson-Nathe, 2008b; Groenewald, 2004). This concept of removing researcher bias was designed to avoid the conceptual presumptions identified as reductionism or the cyclical process of coming to the pure starting point of the investigation (Groenewald, 2004; Kakkori, 2009). Therefore, in this reductionist view, researchers must not only bracket the experience, but any relationship that the researcher has to the experience must be fully set aside as well so the interpretation of the experience is not tainted.

In contrast, hermeneutic phenomenology places the researcher in a central role. Within the theoretical framework of hermeneutics, the interpretation of language for meaning and context comes at least in part from the author's point of view (Gadamer 1962; Heidegger, 1962; Patton, 2002). Hermeneutic phenomenology, as an orientation of study methodology, provides an interpretation of a narrative that is rich in description (Gadamer 1962; Heidegger, 1962; Patton, 2002). Different from the positivist form of transcendental phenomenology, the hermeneutic experience allows researchers to interpret an experience and explore its meaning (Kakkori, 2009). Van Manen (1990) explored hermeneutic phenomenology as a dynamic interplay of research activities as interpreted by the researcher who maintains a strong relation to the topic. Ricoeur (1976) influenced this belief in van Manen's work. Van Manen (2011c) spoke of

Ricoeur's hermeneutic phenomenology examines how human meanings are deposited and mediated through myth, religion, art, and language. He elaborates especially on the narrative function of language, on the various uses of language such as storytelling, and how narrativity and temporality interact and ultimately return to the question of the meaning of being, the self and self-identity. 
In turn, van Manen (2011c) linked the work of Ricoeur to Heidegger (1962) and Gadamer (1975) and the importance of every form of human awareness as interpretation in this orientation of phenomenology.

The experience is situated in the context between the individual and the environment (Anderson-Nathe, 2008b). Therefore, essence is represented in two different contexts within phenomenology. In transcendental phenomenology, essence is seen as part of a bracketed experience where its interpretation is bound by the postpositivist viewpoint. More recently, in hermeneutic phenomenology, the essence of the experiences is embraced as part of the relationship between the participant, researcher, and the meaning that is made from the participants' point of view of their experiences (Dahlberg, 2006). This focus becomes part of the context in which individuals assume meaning and position their view of the world.

Van Manen (1990) identified this contextual relationship as a lifeworld. "The lifeworld is the site for pre-reflective engagement between self and environment, the location of the sense of wonderment that characterizes pre-theoretical human experience" (Anderson-Nathe, 2008b, p. 28-29). Van Manen (1990) contended “our lived experiences and the structures of meaning (themes) in terms of which these lived experiences can be described and interpreted constitute the immense complexity of the lifeworld" (p. 101). In other words, phenomenology seeks to set aside the reflective experience, offering up the essence of the experience, and make meaning from it in the interplay between the individual and the researcher. It is important to note that the lifeworld is the entire contextual experience for an individual, all aspects of their 
experiences. However, this research study focuses on one specific encounter in the lifeworld, namely participants' experiences of Oregon's professional development system.

Due to the interactive nature between the researcher and the study of the experience in hermeneutic phenomenology, care must be taken in situating the subjectresearcher roles. Van Manen (1990) urged the researcher to pay attention to the "speaking of language" (p. 111). He went on to say that "the world is our home, our habitat, the materialization of our subjectivity" (p.112). This gives rise to the role of the researcher-participant. In that statement, we can see the merger of our own hermeneutic experience as researcher-participants into the study of the phenomenon. For example, in this study I am the researcher-participant having experiences with participants' experiences. The layering of phenomenological exploration encompass both the exploration of participants experiences, my experience of their professional journeys, and my own meaning making from both acts. In the end, I am completely entwined in the layered levels of meaning making.

However, as researcher-participants, we are cautioned always to remember that within the understanding of the phenomenon, we may know too much rather than too little. A danger always exists in beginning interpretation before the question has been fully explored (Dahlberg, 2006; Van Manen, 1990). In other words, time for reflecting on the experience prior to interpretation is critical. Dahlberg and Dahlberg and Dahlberg (2003) spoke of the role of self-reflection in phenomenological process as a way to "loosen the intentional threads" that exist as part of the human consciousness, providing a 
chance to discover inauthentic perceptual conclusions. To loosen the intentional threads, I must let go of my preconceptions about the profession in which I work and listen to the experiences of participants.

Hermeneutic phenomenology focuses on the "pre-reflective experiences and feelings" (Ajjawi \& Higgs, 2007, p. 616). A key aspect of participants' experiences was to see if they connect their professional journey with Oregon's professional development system. Three hermeneutic phenomenological studies looked in on early childhood educators' sense of professional engagement in professional development settings (Fenech \& Sumsion, 2007; Osgood, 2006; Sumsion, 2001). From these studies, the concepts of institutional discourses, profession, professionalism, professional development, professional engagement, and professional identity were established as strands in the literature (Bown \& Sumsion, 2007; Hsu, 2008; Parnell \& Iorio, in press; Sumsion, 2001). The identification of these themes provided me with an anchor to which to attach my own research proposition.

A way of understanding oneself in relation to professional engagement is formed as early childhood educators participate in the experiences available within the current professional development system. To fully support the participants' experiences and the meaning that I will make from those experiences, I used Dahlberg's (2006) concept of "bridling the experience" (p. 16). Dahlberg used the metaphor of a rider bridling a horse to convey the relationship between the researcher-participant and the data collected from the participants' experiences of the phenomenon. Bridling therefore is a practice that supports allowing the participant's point of view to unfold, and supports the researcher- 
participant waiting for meaning to emerge from spending time with the phenomenon rather than making assumptions about the experience (Dahlberg, 2006). Bridling both supports the meaning of the human experience and creates a slowing down of understanding, minimizing quick decisions about the meaning of an experience (Dahlberg, 2006).

In the literature on bridling, Ellett (2011), and Vagle (2009) shared what it means in phenomenology to "bridle the experience" (Dahlberg, 2006, p. 16). The original work on bridling by Dahlberg (2006) spoke of awaiting meaning that still had one foot in concepts of transcendental phenomenology. As Dahlberg's thinking evolved, so has the clarity with which she speaks to the relationship between the researcher and the research (2011). In particular, clarity is given around the act of pre-understanding, or the frame of reference researcher-participants take to be aware of themselves, as researchers, within the phenomenological process. Vagle (2009) concurred, stating that "Dahlberg's bridling of the phenomenon is the process by which the researcher-participant takes an open stance, scrutinizing his or her involvement with the phenomenon" (p. 585). Ellett (2011) described bridling as a process of looking back and forward. It is a process where the researcher-participant's own "thoughts and experiences" (p. 6) connect with participants meaning making. Vagle called this the "giving-finding" (p. 586) of meaning from the phenomenon, a continual tending towards understanding. As a researcher-participant, I engaged in the "positional, textual, and constitutively reflective" (p. 592) process. In Chapter 4, I illustrate the process of waiting for meaning through multiple revisits to the narrative interviews and collage. 
From a theoretical perspective, when choosing to situate this study in hermeneutic phenomenology, I had to decide as to which approach would best illuminate the experiences of the participants. Participants stated that navigation of Oregon's professional development system is complex and difficult (OED CCD, 2008, 2009, 2010). Reflection on the complexity of the relationship between participants and their perceptions of the professional development system was predominately unobservable, multifaceted, and context-dependent. The narrative and collage format provided the structure for illuminating the experiences of participants; a format that Seamon (2012) has termed "a crosshatching" (para. 1) between narration and an art-based form to deepen meaning, in this case $\mathrm{a} / \mathrm{r} /$ tographic representations of the experience through collage. Beyond interviews, I needed a way for participants to engage with a complex subject (Bamberger, \& Schön, 1983). An art medium, such as collage, supports inquiry into experiences through an "artistic and aesthetic means" or a/r/tography (Springgay et al., 2005, p. 898). The benefit of $\mathrm{a} / \mathrm{r} /$ tographic experiences is that they supported the "active participation of doing and meaning making" (p. 899) through the arts. Collage serves as a way to bridle the experience. A/r/tography is a way to look at participants' experiences with an openness to explore representation of the phenomenon through collage. As someone who engages in Oregon's professional development system on a daily basis, I needed a process that would cause me to pause and support my reflections on participants' experiences. The act of collage both by participants and myself as researcher-participant supported living inquiry as identified by Merleau-Ponty (1962) 
who inspired Springgay, Irwin, and Kind (2005) to “rupture open” (p 899) living inquiry and connected it to a/r/tography.

As a researcher-participant, using a hermeneutic phenomenological approach was critical to understand the lenses through which I viewed and interacted with the participants. Dahlberg and Dahlberg (2003) spoke to the importance of practicing "the ability of consciousness to, so to speak, make a 'loop' and instead of being directed out into the world it becomes directed to itself. Thus, supporting consciousness as its own intentional focus" (p. 48). Embedding consciousness as its own intentional focus, I worked to cautioned myself to give the phenomenon the time it needed to "breathe" before overlaying any meaning making. As a researcher-participant, I took care to engage in a dialogue between the participants' experience and the meaning that is made from the experience by collaging about their collage and writing up my experience of their interview at a later time once the initial interview and collage experiences were completed.

\section{Research Question}

In order to examine the phenomenon of meaning making by early childhood educators navigating Oregon's professional development system, I posed the following research question as restated here: In the renewal stage of their professional practice, what meaning can be made of early childhood educators' experiences navigating Oregon's professional development system? Informing this primary question are the following open-ended research questions.

- What have been the experiences of early childhood educators in identifying 
themselves as early childhood education professionals?

- How do early childhood educators identify their experiences of professional engagement?

Before exploring the methodological approach and tools utilized in this study, I describe the context and explanation of the recruitment of participants.

\section{Recruitment and Participation}

In identifying participants in a phenomenological study, it is essential that the participants have experience with the phenomenon (Anderson-Nathe, 2008b). Therefore, I employed a purposeful selection method for its ability to provide "information-rich cases for detailed study" (Ajjawi \& Higgs, 2007). To narrow the purposeful selection of individuals engaging in Oregon's professional development system, I used a selection criteria that included (1) years in the profession, (2) stage of professional development, and (3) current employment in a licensed center-based program in the Portland metro area. The state professional development system has multiple mandated components for those working in the 2,400-licensed center-based early childhood programs and provided a baseline of participation. Four female participants were selected from licensed centerbased programs serving children three to five years of age in the Portland Metro area. For the purpose of the study, the Portland Metro area was identified as Clackamas, Multnomah, and Washington Counties in Oregon. This participant population was identified in Chapter 1 as having the greatest potential knowledge about Oregon's professional development system (OCCD, 2012; OED CCD, 2010). 
For selection, early childhood teachers needed between three and five consecutive years' experiences in teaching children three to five years of age. Using Katz' (1995) stages of early childhood educator professional growth patterns and professional development needs, years three through five correlated to the stage of "renewal" (para. 9). Renewal is identified as a stage where early childhood educators will start to seek connections in their professional development activities, including joining professional organizations or participation in local, state and regional conference. It is typically characterized as the stage where early childhood educators start to connect their classroom practice to the larger early childhood education community. For the purpose of the study, participants in this stage of professional development would have a greater likelihood of having recent or first time experiences connecting to Oregon's professional development system.

Then, I recruited participants through Oregon's professional development system partners, specifically, the Oregon Association for the Education of Young Children (OregonAEYC), its affiliate Metco, the tri-county chapter (Clackamas, Multnomah, and Washington Counties) of OregonAEYC, the Child Care Resource and Referral Network $(C C R \& R)$, the statewide organization, and the three CCR\&R, located in the metro area. OregonAEYC is a statewide membership organization that participates in state professional development system activities and offers technical assistance to individuals interested in participating in Oregon's professional development system through professional development activities. The CCR\&R is a stakeholder in Oregon's professional development system and is funded to provide technical assistance and 
professional development activities specifically designed to support early childhood educators in navigating Oregon's professional development system.

Both the CCR\&R and OregonAEYC support early childhood educators at the individual and non-center-based level. Individual engagement was important because I sought individual educators engaged in the professional development system regardless of the culture of professional participation at the program or facility level. Additionally, individuals who interacted with OregonAEYC or the CCR\&R would have baseline knowledge of professional organizations and supports.

The initial recruitment of participants was posted through OregonAEYC and the CCR\&R system in the tri-county area using flyers, websites, and Facebook (Appendix A). After the first two months of recruitment yielded a limited number of responses, postings to additional early childhood listserv were added. Recruitment materials approved by the Institutional Review Board (IRB) outlined the study content, time commitments, and contact information for participants (Appendix G). Information about engaging in Oregon's Professional Development System was available to all individuals who inquired about the study (Appendix B). Contact information was linked back to a specific phone number or email account setup for the study.

I conducted an initial phone screening with all individuals who contacted me expressing an interest in participating in the project (Appendix C). The initial phone screening typically lasted fifteen minutes. At the outset of the initial phone screening, I identified my dual role as a researcher-participant and as coordinator of the Oregon Registry. Additionally, I clarified how my work role would remain separate from my 
role as a graduate student. I identified that I would not provide direct evaluation of Oregon Registry Step application, scholarships, or education awards. I asked participants if they would like to continue with the initial phone conversation. In the initial phone screening, the call was used to obtain basic demographic information, including verification of working with children ages 3-5 years, a minimum of 21 years of age, and Portland Metro area location. If the participant met the baseline demographics, I asked a series of five questions about the participant's professional status within the early childhood community, including:

1. Are you currently working in a Child Care Division/Office of Child Care licensed center-based program?

2. Are you currently working with children, ages 3-5 years of age?

3. How long have you worked with this age group?

4. Are you familiar with Oregon Professional Development system for childhood care and education professionals?

5. Can you name two or more agencies or programs in Oregon's professional development system that you participate in?

If participants met the demographics, I provided details about the study and its methodological approach, including the ideas from a/r/tography, interview, and phenomenology.

Within the methodological approach to the study, I asked participants about their feelings about collage as part of the interview process. Participants were offered an opportunity to elect out of participation if they felt uncomfortable with the process. I followed the same procedure when identifying the data collection mechanism of recording and transcribing their interview. As part of the study, I offered to meet 
participants in a private studio space. Not all study participants chose this option; however, all participants chose to work in a private space with the collage materials. I encouraged them to bring any photos or paper representations of their experiences in early childhood education to incorporate into their collage based on the prompt, "Tell me about your professional journey in early childhood education." After each series of questions, I asked participants about the questions they had regarding the study, and asked if they wish to continue. At any time the participants' answers excluded them from the study, I thanked them for their time and offered resources about Oregon's professional development system.

As part of the initial phone interview, I notified participants that their information remained confidential and separate from any aspect of the professional development system itself. Contact information was made available about professional development advisors in the state professional development system to all participants. From the screening of the initial phone interview, I selected four participants and two alternates. I deemed four participants necessary in order to gather sufficient data based on previous studies (Bown \& Sumsion, 2007; Fenech \& Sumsion, 2007; Novinger \& O’Brien, 2003). A minimum of four participants offered a baseline of in-depth experiences, in case participants voluntarily withdrew or asked to discontinue. No participants withdrew from the study. During the recruitment process, I heard from 19 individuals. All but six were screened out during the initial phone interview. In Chapter 4, participants' professional journeys are presented in greater depth to introduce their collage and narrative experiences. Collecting the data from more than four participants 
posed difficulty in the management of time and resources when collecting the rich, dense data that is needed as a foundation for hermeneutic phenomenology (Ajjawi \& Higgs, 2007).

\section{Methodological Approach}

Hermeneutic phenomenology, adapted from by the work of van Manen (1990) and Dahlberg (2006), formed the methodology for my study. The primary attribute of phenomenology is the intentional study of an experience or phenomenon researched from a "first person point of view" (Smith, 2011, para. 4). As a qualitative researcherparticipant, I found great value in what Merriam (2009) formulated as the "understanding of how people interpret their experiences, how they construct their worlds, and what meaning they attribute to their experiences" (p. 5). Further, hermeneutic phenomenology was suitable for interpreting the pluralities of early childhood educator experiences due to its rich descriptive nature (Gadamer 1962; Heidegger, 1962; Patton, 2002). First, in the initial review of the literature, I came to see the power of language, and the use of terminology as an indicator of ways of thinking about self and others through institutional discourse. The identification of meaning and context in the use of language - the hermeneutics study of the language - was a focal point in the literature review of early childhood educators who frequently define themselves by language classifications using the language of the regulatory system (Bown \& Sumsion, 2007; Fenech \& Sumsion, 2007; Novinger \& O’Brien, 2003). I knew I needed a methodology that supported the understanding of experience and addressed the themes that would emerge from the use of 
institutional discourse in describing phenomena (Dalli, 2008; Langford, 2008; Katz, 1977; Parnell, 2010).

Second, I came to realize that a hermeneutic phenomenological study provided the best platform for the participants' experience to take center stage. This research study focused on creating a collective consciousness of what it is like to navigate Oregon's professional development system from an early childhood educator's point of view. However, I had experiences in Oregon's professional development system, too. I needed a phenomenological orientation that would keep me from making assumptions as researcher-participant. Therefore, it became apparent that the act of bridling participants' experiences supported a practice of slowing down and "actively waiting" for meaning within a phenomenon, and this act became fundamentally important to my study (Dahlberg, 2006, p. 16). To provide the space for participants to delve into their experiences, and to give them time with these experiences, I employed collage and semistructured narrative interviews.

Phenomenology traditionally seeks to illuminate participants experience to create a connection for reader to relate to the essence of the experience (van Manen, 1990). Openness is critical in hermeneutic phenomenological interviews as it supports the participant's presentation of the experience (Laverty, 2003). Several tools were employed to support the participants' presentation of their experiences. During the collage process, three prompts were placed in the collage areas. With the semi-structured interview that followed, a narrative frame was used to present primary questions followed by open-ended prompts to support the structure of the participant in staying "as close to 
the lived experience as possible" (Laverty, 2003, p. 19). The semi-structured narrative interview format placed participants' experience at the center of the interview and supported their meaning making for the experiences though long uninterrupted narratives of their experiences. The narrative conversation using the collage as a prompt limited my role to that of recorder of the experiences, minimizing my directing the experience through interview questions, and leaving the essence of the phenomenon open and unaltered (Laverty, 2003). Dahlberg and Dahlberg (2003) encouraged letting "things present themselves in all of their multiplicity" (p. 44). When we make room for experiences to present themselves, we allow them to show their multiplicity of possibilities (Dahlberg \& Dahlberg, 2003).

Two intertwined experiences were at the foundation for this Chapter. In one context, I wrote as a member of the early childhood community whose own participation in the state professional development system is part of my meaning making. As a researcher-participant, I sought to reconcile (a) my personal beliefs about early childhood educator empowerment and (b) the tension those beliefs create when I must act in an official capacity as an administrator of the state professional development system with early childhood educators. In the second context, I sought to enact changes in our professional development system by examining others' experiences.

It therefore became of primary importance to build into my study a practice of "bridle the experience" (Dahlberg, 2006, p. 16) with participants engaged in Oregon's professional development system. The importance of allowing the experience to unfold and meaning to be constructed and then co-constructed is particularly critical when a 
researcher-participant has great familiarity with the subject. Waiting for meaning prevented the assumptive practices that may be present when aspects of the experience are known. Since the data collection and data analysis outlined a research process which intended to give voice to participants' experiences as a way to make meaning and mirror the state professional development system interactions with early childhood educators, it was necessary to put safeguards in place to preserve the essence of the experience.

\section{Data Collection}

Data collection is at the heart of research (Merriam, 2009). A nested system of inquiry builds on itself. Decisions on what to collect and how to analyze data nests within the fundamental research question, which, in turn, nest within the methodological approach. For example, to capture and interpret participants' experiences in Oregon's professional development system, contextually rich data is collected. This collection of rich or dense data of the phenomenon being investigated is a primary aim of hermeneutic phenomenology research (Ajjawi \& Higgs, 2007).

Further, this research study profits from me, as researcher-participant, taking a pedagogical viewpoint of listening in order to make meaning (Parnell, 2011). I collected contextually rich data and layered meaning making through multiple modalities of interviews, written notes, artifacts, and audio recordings. I tracked all research activities by using a Research Log (Appendix D). Data was collected from September 2013 through February 2014 (Appendix E).

\section{Interviews and Collage}


In this research study, the interview served two specific purposes. "First, it is used as a means for exploring and gathering narrative (or stories) of lived experience. Second, it is a vehicle by which to develop a conversational relationship about the meaning of the experience" (Ajjawi \& Higgs, 2007, p. 619). After the phone screening, a single two-part interview was conducted with each participant. The interviews were recorded and transcribed. The first part of the interview consisted of the introduction to the collage materials, primarily paper. Located with the collage materials were three prompts that were first reviewed in the phone screening for qualifying participants. This set up focused the participants on self-identifying their professional journey as part of their experiences with Oregon's professional development system. The participants were then given time to work on a collage that supported the collection of rich, dense data. The semi-structured narrative interview followed. The collage supported what van Manen (1990) recognized in hermeneutic phenomenology as opportunities for participants to explore their meaning making of the experience and to preserve the first person point of view. The interviews were scheduled to last between 60 and 90 minutes. Instead the interviews lasted between 90 and 120 minutes. The additional time was incorporated into both the collage process, with most participants spending approximately 45 to 60 minutes on the collage, and 45 minutes in the interview that explored their experiences with Oregon's professional development system.

In choosing to use collages as part of the interview process, the research literature reminded me that challenges existed in collecting rich, dense data when asking participants to reflect on standards-based systems without an activity or tool to bring 
forth the meaning (Bown \& Sumsion, 2007; Fenech \& Sumsion, 2007; Novinger \& O'Brien, 2003). In a review of research literature that utilized similar approaches, I discovered three studies in which early childhood educators explored experiences with a standardized context (Bown \& Sumsion, 2007; Fenech \& Sumsion, 2007; Novinger \& O'Brien, 2003). In these research studies, regulatory structure played a large role in the data; to contextualize experiences with the regulatory system, all three studies employed interviews. Further, one study used collage as an interview tool to create a dialogue between the participant and the research material as ways to see into the experience and to expand on depth of the interview (Bown \& Sumsion, 2007).

Bown and Sumsion (2007) went on to say that a visual or textual inquiry process in methodology offered a "multi-dimensional approach to understanding the lived experience of teachers that transcended traditional methodological and disciplinary approaches" (p. 34). Bown and Sumsion (2007) captured a participant's reflection of their professional experiences with Australia's regulatory system in a series of panels using photography, artifacts, texts, and visual art media. Following their lead, I defined collage as an art medium that uses various forms, materials, and objects pasted over a surface as seen in Figure 3. 


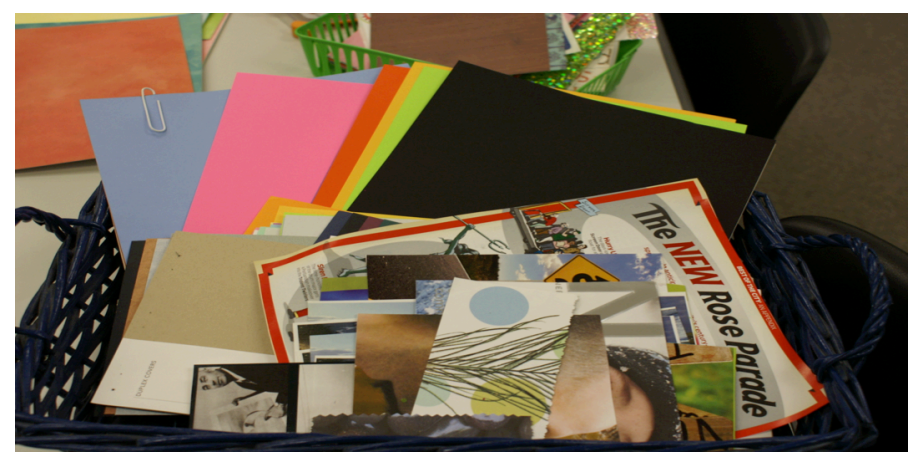

Figure 3. Sample of collage materials.

In making space for reflection and to allow participants' experiences to speak for themselves, combining platforms such as collage with a semi-structured narrative interview provided rich, contextual meaning from the participants' narratives and collage. Fundamental to the data collection were the voices of the participants, in particular their feelings about their experiences. The importance of situating participants' feelings as part of their professional development journey was documented by Osgood (2012) and Sumsion (2001). The benefit of the arts in expressing feelings is also well documented in art therapy research (Malchiodi, 2011; Mignot, 2000). Malchiodi (2011) explained that the use of art creates a unique mental image that gives voice to internal images and feelings. Mignot (2000) spoke to the engagement of self when using art-based medium as a way to narrate and assign meaning to a topic. With the support of collage, the narrative interviews could be extended and deepened.

The process of collage was also used by the researcher-participant as a tool to bridle the participants' experience, discussed in detail in the data interpretations section of Chapter 3 and shown as part of the research-participant dialogue with the narratives 
and collage in Chapter 4. The importance of making space for meaning to emerge from participants' experiences was aligned with my phenomenological orientation. I implemented a research design based on a collage arts medium to enhance the two-part single interview process as the primary source of data generation. To support understanding, I used the semi-structured interview protocol to guide the process (Appendix F).

The interview set-up was design as follows. Participants were welcomed to the interview location. While arrangements were made for use of private studios throughout the Portland metro area, two participants elected to use the studio spaces available at their work. All participants had access to the same materials, in particular, a wide variety of paper collage materials and tools. An introduction to the study was made and the informed consent document was reviewed (Appendix G). Each participant received a copy of the informed consent form before the study was started, and was reminded that a participant could stop at any time. I then explained the concept of collage as a way to tell a participant's story of their experiences. Very intentionally, I shared that there was no expectation about the look of the collage; rather, collage existed as a tool of the interview. A basic introduction to collage proposed that an advantage of collage was ability to move objects around. So, all of these materials could come together and be organized in a way that supported participants in telling their story. While participants were encouraged to bring personal artifacts to the interview to explore their story of their professional development journey in early childhood education, three chose to do so. Personal artifacts provided an opportunity for participants to include material in their 
collage that had personal meaning to them. Participants had the ability to choose from different cardstock bases as a foundation for photos, texts, and paper elements. Materials and tools included magazines, images, sharpie markers, scissors, color paper, printedpaper, and glue. The setup of the materials was similar for each interview (Figure 4).

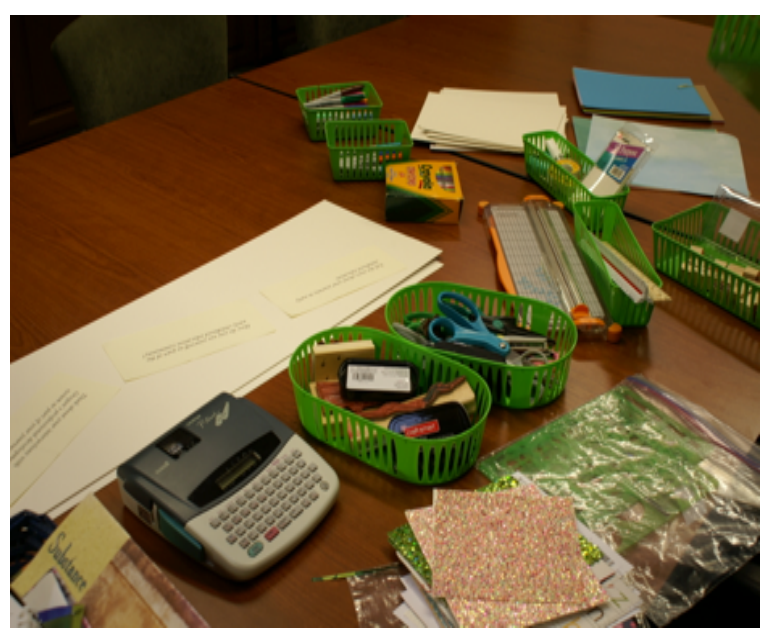

Figure 4. Collage setup for current study.

The three prompts on the table that helped to focus the participants were, "Tell the story of your journey in early childhood education," "Think about your actions as part of Oregon's professional development system as part of your journey," and "How do you see yourself as part of the early childhood community." Once participants received a tour of the materials and felt they had the information they needed to begin the collage process, I excused myself from the room to give them privacy and time for personal reflection without my immediate presence. After leaving the room, I remained within a reasonable distance to answer questions that might arise.

When participants indicated they had completed the collage, I returned to the room. Each location had multiple surfaces on which participants could work. The 
narrative semi-structured interviews took place either at a separate table or in an area separated from the collage materials. I started the interviews with a general question, "How was the process for you?" as a way to open the conversation and connect with the participant. I followed the opening question with the prompts laid out on the table. As part of the process, I brought up the prompts if the participant did not circle back to them. To extend participant responses, I asked, "Can you tell me more about..." and, "How did that make you feel?" or "Thinking back, are there particular experiences that changed your thinking?" When participants had responded to the three main prompts, I concluded with the question, "Is there anything else you would like to add?" to close the interview. Prior to the participant leaving the interview, I took photos of the collages and thanked the participants for their participation. Each of the four participants offered to leave their collage with me at the end of the interview. Taking advantage of this offering, I took the collages with me and offered to return them at the completion of the study.

As part of the research process, I reflected on the participants' experience through the process of collage. I created own collages were created using the same materials accessible to the participants. I created one collage in response to each participant's collage and interview of their experiences with Oregon's professional development system. My collages were designed to provide both space to expose my own in understanding of their experiences and served a dialogue between their meaning and mine, engaging in an exploration of each experience's essence. My collage served as part of my data interpretation as described later in this chapter. 
Field notes in this study were subdivided into two parts. The first part consisted of recording the responses to the prompt and notes that I took during the interview, which were kept in a bound journal. My notes, sketches, and representations of the participants' experiences during the interview narrative were captured in a section of my journal. Each entry was dated and cross-referenced with the artifact records. Vagle (2009) called for researchers to engage in reflective commentary throughout the research process to support the giving and finding of meaning. To capture my thoughts throughout the process, I made reflective notes at the completion of each interview. Then, I spent a minimum of 20 minutes writing my experiences alongside of the participant's experiences as a way to begin bridling the experiences of the interview process (Dahlberg, 2006). My researcher-participant notes were later kept in a locked file cabinet in my home office.

Multiple collected artifacts included data, such as initial screening notes, the collage, digital photos of the collage and other visual markers, and researcher-participant reflections. The initial screening of participants and notes were one set of artifacts. Photo images of collage, room arrangements, images or representations of experiences were another. Photos were taken of the collage space before and after the process. While no photos were taken of participant faces, three participants encouraged me to take photos of their hands with their collages. All collage or visual representations that I made in response to the interviews were catalogued in the same fashion as the participants. Digital photos were stored in a locked folder on my research computer. I catalogued all artifacts and recorded them (Appendix $\mathrm{H})$. 
Each interview was audio recorded. The audio recording began when the participant invited me back into the room at the completion of their collage. The audio recording concluded at the end of the final prompt. All audio recordings were time and date stamped. Each audio recording of the interview was transcribed verbatim. Only I, as researcher-participant, had access to the transcriptions, coded with participant pseudonyms and date. This data was stored in a password-protected file on my computer (along with the interview transcriptions and digital photos of the collage). I stored all hard copies connected with the project in a locked cabinet in my home office.

\section{Data Interpretations}

Merriam (2009) stated that phenomenological data interpretation seeks the essence of the phenomenon. In hermeneutic phenomenology, Dahlberg (2006) identified the act of bridling the experience as a way to be as researcher-participant in phenomenology methodology. In taking a pedagogical posture of what Parnell (2010) terms reflective listening, there were opportunities, as Dahlberg (2006) suggested, that allow for the essence of the experience to emerge. Much of what is studied of early childhood educators' hermeneutic phenomenological research is based on meaning making of a phenomenon (Osgood, 2012; Parnell, 2012b; Sumsion, 2001; Taguchi, 2007; Woodrow, 2007).

As part of this hermeneutic phenomenological research study, I needed to reflect on my own meaning making and experiences through the process. The story of participants' professional development journey through collage was presented in narrative; first the participants' and then followed by my own experience of each 
participant's experience. The essential themes emerged through a process of actively waiting for the essence of each experience to illuminate itself. In my active waiting practice, I employed a number of actions. I started by listening to the recorded interview, following the participant's narration of their professional development journey and reflecting on their collage. Over a period of weeks, I continued to listen to each narrative, engaging in what Ellett (2011) described as bridling by looking back and forward on the experience. Sometimes I would listen to the narrative following along with the transcript, others times I would listen and add notes to my journal. Dahlberg (2006) reminds us that "as researchers, we stand and fall with our own and others' language ability" (p. 17). This reminder prompted me to be attentive to the words, and descriptions that participants use to make meaning of their experiences and how they represented their experiences visually.

Beyond the review of written content of the interview, there was a visual component represented in the form of collage. La Jevic and Springgay (2008) shared visual journals [maps] as a way to provide spaces to reflect on experiences that are messy, uncomfortable, and complex. As I listened to the narration, I combed through magazines for images that capture my response to each professional journey and collaged my response to each participant's experience. My collage reflections became a dialogue with each participant's experience. The repetitive process of listening and slowing down the conscious course of understanding made “-room” (Dahlberg \& Dahlberg, 2003, p. 47) for my responses to the participants by bridling their experiences. Then, my collage could authentically become about participants' experiences with the professional 
development system. The original experience, therefore, remained as represented in the collage and participant narratives. My collage and narrative experiences came to reflect meaning from the participant's and my own discoveries of their experiences. Parnell and Iorio (in press) shared that this method of collage dialogue leads to a "drive towards the experience's meaning" for both the participant and the researcher-participant (p. 26).

Part of the process of phenomenological research is a loop of revisiting data. Dahlberg and Dahlberg (2003) stated that looping folds the experience back in on itself, rather than letting it be directed out of the phenomenon. Van Manen (1990) concurred, calling on researchers to "determine the universal or essential quality of a theme....to discover aspects or qualities that make a phenomenon what it is and without which the phenomenon could not be what it is" (p. 107). The act of identifying essential themes, therefore engaged the process of looping back for constant comparison of emerging perceptions against the essence of the experience. In spending time with individuals' experiences, I came to make connections between what Anderson-Nathe (2008a, 2008b) called the individual first-hand accounts of experience. This was done through the process of collages, the recorded and transcribed interviews, and my notes. After spending several months reflecting on the narratives of individual participants' experiences, I began to see strands of meaning emerge. Then, I went through a looping process of addition and deletion of participants' experiences to see what emerged. This looping process yielded strands, which became themes, clear in their unique content. Reflecting again through the looping process allowed other themes to recede back into the strand of individual experiences. Essential themes emerged from content that 
remained as a shared differentiated experience, sufficiently exceptional across contexts to prominently demonstrate in the research findings.

\section{CHAPTER 4: RESEARCH FINDINGS AND DISCUSSION}

Chapter 4 explains how participants expressed their engagement in Oregon's professional development system. Experience with Oregon's professional development system could take many forms for the four study participants. The literature review in Chapter 2 provided context for the professional development system and activities of engagement participants might experience (Ailwood, 2003; Kagan \& Kauerz, 2012; Novinger \& O'Brien, 2005; Woodrow, 2007). In this hermeneutic phenomenology, the study of each participant's unique journey was explored for essential themes relating to their experiences in the Oregon professional development system.

Phenomenological themes are not objects or generalizations; metaphorically speaking, they are more like knots in the webs of our experiences, around which certain lived experiences are spun and thus lived through as meaningful wholes. Themes are the constellations that make up the universes of meaning we live through. By the patterns and light of these themes we can navigate and explore such universes. (van Manen, 2011a, para. 2)

Collage and interview were used as a way to make visible participants' thinking. While essential themes emerged, the participants' stories remained unique. As the interviews with collage unfolded, participants' experiences became intertwined between their personal and professional identities. Both Sumsion (2001) and Osgood (2006; 2012) stated that early childhood educators often experience a merger of person and profession in their work with children. The collages revealed a deep connection between personal and professional identity. In the interviews, participants treated their collages as 
extension of their experiences as early childhood educators. During the interviews, the collages acted as "art and words that are not separate or illustrative of each other but instead, are interconnected and woven through each other to create additional meaning" (Springgay et al., 2005). My own experience of intertwining came from my role as a researcher-participant in a study that both reflected on my meaning making of the four participants and my own struggles with Oregon's professional development system. For both the participants and myself, the intertwining between personal and professional became evident during this study.

Chapter 4 is presented in two sections. Section One lays out the narrative interviews, collages, and meanings of the four early childhood educators and the researcher-participant. The section provides the foundation for the research questions presenting the participants' and researcher-participant's experiences. Section Two then gathers the participants' experiences through essential themes connected to the research questions.

In Section One, the participants' experience of their professional development journey through collage and interview is presented as a narrative. Participants' experiences started with their narrative of their experiences through interview and collage. Careful attention was paid to each participant's descriptions of their experiences and how they represented their experiences visually. Elements that related to participants' engagement in the professional development system are presented in their own words. Images of the collage that were specifically identified by participants as 
meaningful representations of their experience are present throughout each narrative. These narratives were drawn directly from interviews with each participant.

Following the participants' narratives are my own reflections of their experiences as a way of bridling (Dahlberg, 2006). My collages of bridling each participant's experience emerged from an iterative process of listening to the interviews, looking at the collages, and reading the transcriptions. Over a period of weeks, as I listened to the narration, I started to seek images that captured my response to each professional journey and collaged my response to each participant's experience. My collage reflections, therefore, became a sort of dialogue with each participant's experience. Additionally, for continuity, my collages followed the same pattern with individual elements such as reflecting size, use of imagery, incorporation of participants' words in my meaning making that disclosed a certain experience embedded within my narrative.

Section Two explores the emergence of essential themes. Van Manen (1990) described essential themes as "structures of the experience" (p.79). However, in hermeneutic phenomenology, the researcher-participant must never lose sight that "themes are intransitive" (van Manen, p. 87). The essential themes emerged from the looping and revisiting data as I did for the participants' experiences, thus identifying where experiences tangled. Out of the looping process, essential themes emerged from the knots of the participant's experiences with Oregon's professional development system. The work for me as researcher-participant then became an act of continuous consciousness to direct the experience back on itself. Identifying essential themes, therefore, engaged the process of looping back for constant comparison. What emerged 
as knots on the web of participants' experiences were insights into the impact of the professional development system on these participants' lives (van Manen, 2011a). While no thematic formula can completely unlock the mystery of the experience, they provide a foundation for making sense of the experience (van Manen, 2009).

In Section Two, illumination of essential themes provided a way for the knots of the experience to be highlighted. Then, I identified the themes that seemed particularly revealing from the participants' threaded and differentiated experiences. Essential themes came to the foreground when knots of experiences were threaded together sufficiently for weaving a narrative of shared experiences.

\section{Section One: Early Childhood Educators' Professional Journeys}

The four early childhood educators in this study participated in an initial phone screening followed by an interview. The phone screening provided basic demographic information about the participants, primarily identifying that they were in the renewal stage of early childhood educator professional growth patterns (Katz, 1995). The second interview focused on participants' experiences through collage and interviews. Leavy (2009) identified that "visual art can jar people into seeing something differently" (p. 220). Thus, collage was used as a way to deepen and focus the interviews.

To guide the collage process, written prompts were placed on the table with the collage materials. These prompts were, Tell the story about your journey in early childhood education, Think about your interactions with Oregon's professional development system as part of your journey, and How do you see yourself as part of the early childhood education community? Participants were invited to bring objects that 
could be incorporated into their collage. A variety of materials were provided to support the development of paper collages. Each participant had access to the same materials during the collage process. As researcher-participant, I bridled each participant's collage and interview with a collaged response as a foundation of my subsequent narrative. Individual acts of bridling participants' experiences are expanded upon in my response to each participant's experience.

The following narratives of the professional development journeys are represented in images and words. Drawn directly from the participant interviews, the collage is presented at the beginning of each narrative. Direct quotes from interviews are interspersed with photos of collage objects that were specifically identified by participants as a meaningful representation of their experience. This data is integrated into the each of the four professional development journey narratives; indentation and single spacing indicate the direct words of the participants and their thoughts. The block quotes include quotes to honor the words of the participants. Also participants' words are always presented in quotes to impart their voices clearly. The interpretation of the experience by the researcher-participant follows each participant's collage and narrative interview following the same format. As a researcher-participant, my images are taken from my collage of participants' experiences. The quotes in my section as researcherparticipant emerged from my own journaling and note taking of the interviews.

\section{Carolina's Professional Development Journey}

I interviewed Carolina on a Wednesday. She came to me through a posting for the research project on a list serve. After the initial screening, Carolina expressed an 
interest in the study and met the required criteria. Carolina had briefly taught kindergarten before moving to Oregon and starting work for a government-funded education program. Shortly after moving to Oregon, she started a graduate program, upon completion of her Master's, she moved to a corporate-licensed, center-based program in the Portland Metro area. Carolina requested that her interview take place in a studio space located within her center. Her employer provided release time to participate in this interview. At the time of her interview, Carolina was completing her fifth year as an early childhood educator in Oregon.

Carolina's self-description of her state of mind was "overwhelmingly excited." At the time of her interview, she was in constant motion as we reviewed the informed consent form. Multiple times she expressed her desire to "get started." As I showed Carolina the materials that I had brought to support the collage, she touched and picked up objects, while asking questions, "where are the scissors?" and "where did you find these images?" When I went to leave the room, Carolina asked me to remain, because she “might need something." At first I was hesitant, but on quick reflection I realized that I did not want to reject requests from participants that would change their comfort level and the possibly the telling of their experiences. In the end, I stayed. Sitting as quietly as I could, I wrote in my journal. Carolina appeared to forget me as soon as she started on the collage. She actively spoke to herself, quickly flipping through multiple images, discarding them on the floor around her as she searched for images, words, or concepts that would reflect "what she had been thinking about in preparation for this meeting" (Figure 5). 


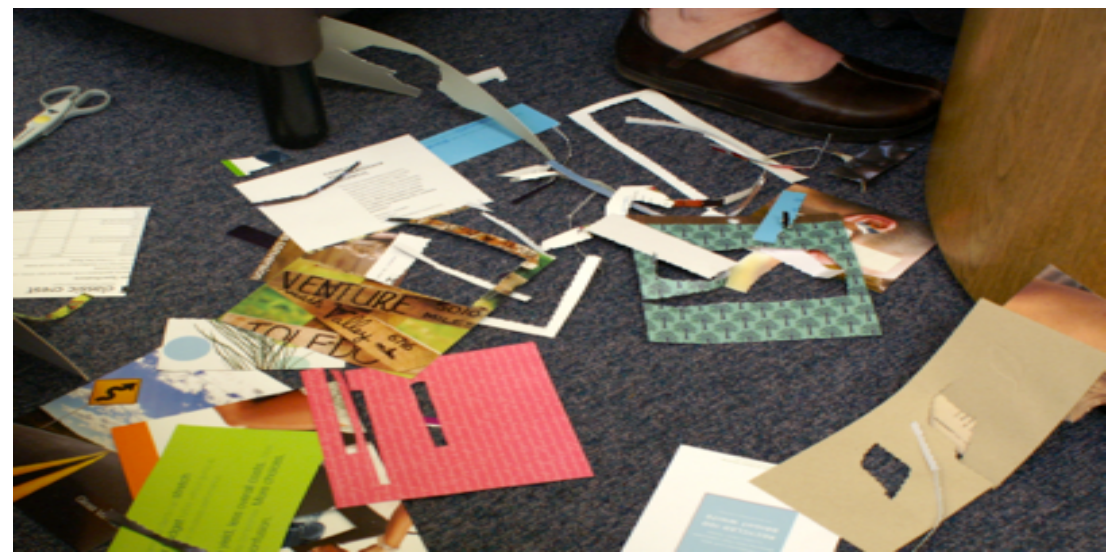

Figure 5. The floor where Carolina worked.

At one point, she pulled out her journal and quickly drew a sketch of her concept that guided the placement of her collage materials (See Figure 34 in Section Two of the chapter). When Carolina engaged me during the collage process, it was to send me out of the room to retrieve a book that she wanted from her classroom. She later transferred a quote from the book to her collage. The quote read,

It is not the critic who counts; not the man who points out how the strong man stumbles, or where the doer of deeds could have done them better. The credit belongs to the man who is actually in the arena, whose face is marred by dust and sweat and blood; who strives valiantly; who errs, who comes short again and again, because there is no effort without error and shortcomings; but who does actually strive to do the deeds; who knows great enthusiasm, the great devotions; who spends himself in a worthy cause; who at the best knows in the end the triumph of high achievement, and who at the worst, if he fails, at least fails while [daring greatly].... (Roosevelt in Brown, 2012, p. 1).

Carefully Carolina made a space for the quote in the center of her collage. She pulled out the label makers and added the words, "DARING GREATLY" in capital letters to finish the quote above. It struck me how carefully and precisely she smoothed the label onto the collage. 
About 45 minutes had passed when having given a quick final review of her images and words, Carolina put down her collage and turned to me (Figure 6).

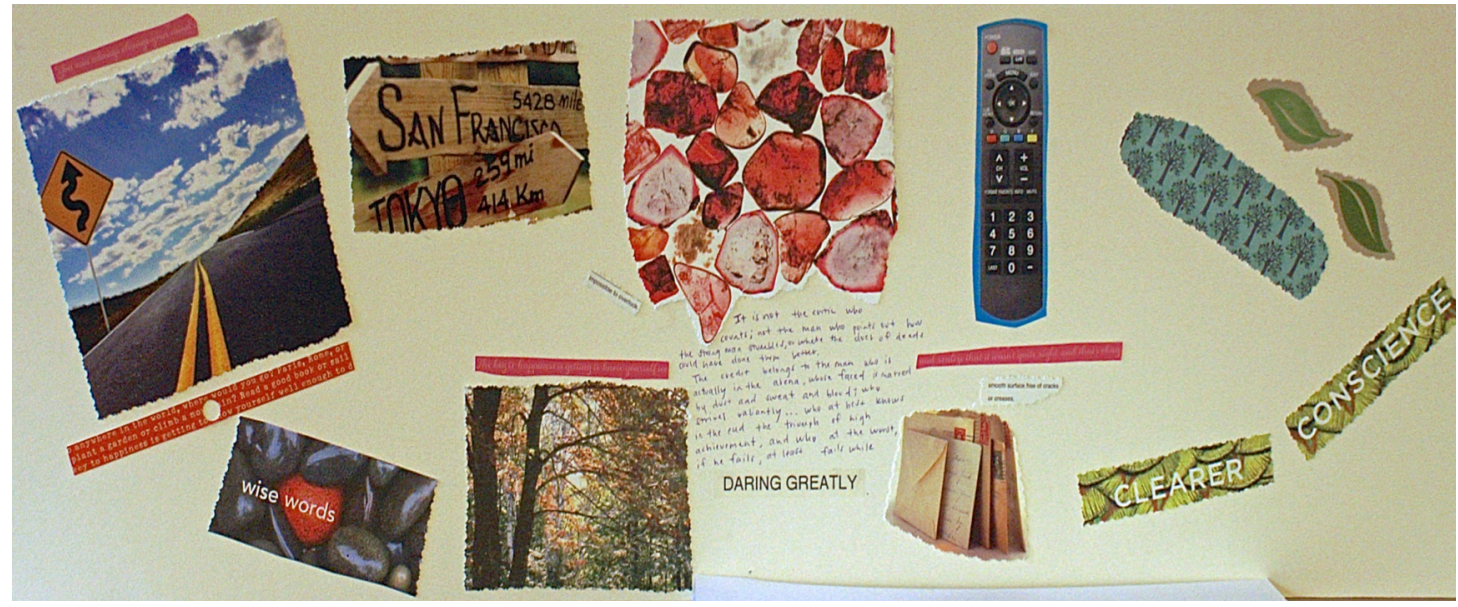

Figure 6. Carolina's collage.

I just want you to know that I didn't like that it was this white thingie [collage base] because I wanted it to be something that represented the ability for making a circle. I think a lot of this is cyclical and not linear, but in the beginning I thought it was linear. I think that's how my brain thinks: That I want to follow this linear path and then I realize that actually it doesn't go in a line, it goes in a circle. It comes full circle, so I made it a circle even if you can't tell.

Over the next hour, Carolina and I discussed her collage and her experiences of her professional journey. I started with the question, "How was the process of collage for you?"

I remember doing a collage for a class and I loved it. So I think pressure [time limitation of interview] is good actually because it makes you think. Sometimes too much time, you just don't even need it and you can go crazy in it. In the end the pressure that I had made me figure it out, come to it quicker than I would have. What was the question again?

I repeated the prompt.

The collage was kind of hard, cause you have your story in your head and then you're confined to the images but at the same time that is the cool part. It's like 
life you don't always have what you want to work with but you have to make it work with what's there.

"What surprised you?" I asked. Carolina started to build momentum with her answer, speaking faster as her words, tumbled out.

I think maybe just the thing that surprised me is the parts of your story that you forget about. I guess because you're just going, you're moving, propelling really fast right down the lane of whatever this is. It's nice to be given a chance to stop for a minute and think about your story and think about pieces of it and ways that you haven't if you're not constantly journaling and reflecting. Which you can't always be doing.

Then Carolina started her narrative of her professional development journey

[indicating the circular path she would take with her finger] with a photo of the open road and a quote, "you can always change your mind" (Figure 7). Carolina then expressed,

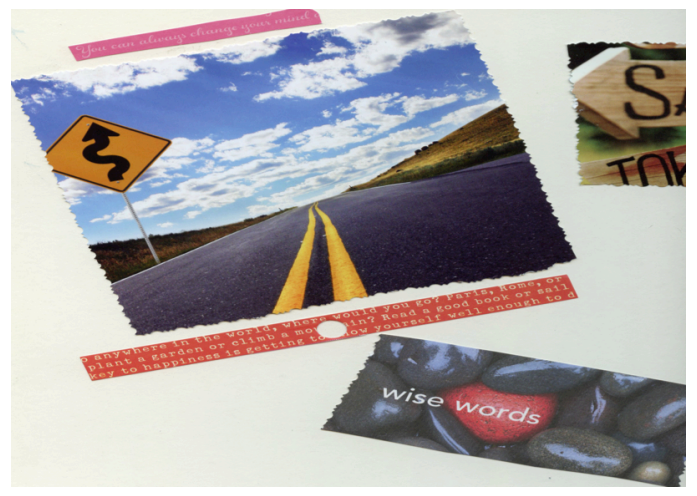

Figure 7. Carolina's open road.

Some of the pictures are probably just going to be obvious, like the open road, but in the beginning when I graduated from undergrad I feel you're so naïve and you don't really know. Not that you don't know and there's awful things coming, but [rather] you just don't know yet what's happening. You have this open road in front of you and you can always change your mind is what it says. I feel you don't really know what to believe in and that's sort of the sweet part. The hard part is that you're asked to go out into the world and be this person and say what your teaching philosophy is. But, I feel you don't even have one yet because you're... you don't even know what side of the whatever you stand on because you have 
never been faced with having to really think about those issues or actually know people in those situations.

Carolina came back to this place of not knowing in several instances in her collage. As she started her journey as a new teacher, aspects of not knowing caused her to recall feelings of uncertainty.

I got a teaching job teaching kindergarten and I was really excited. It was really wonderful in many ways, but I quickly learned, there were things I was quickly faced with and things I didn't agree with... not agreeing with that but not really feeling confident enough to disagree yet, especially in the beginning I feel like you have to have a voice. You have to feel like you have your voice to voice it.

As Carolina continued sharing her experiences, she expressed her growing

frustration in finding her voice. Her professional development journey clearly conveyed this sense that she did not agree with how others were teaching around her but did not have the tools yet to identify and covey her philosophy of children. Carolina continued pointing to the remote control (Figure 8).

It was my first job here in Oregon, during which time I started to learn that there was a bigger system that I was a part of and that I didn't agree with a lot of the aspects that I was being asked to do. I felt like they were asking me to do this job but then they weren't, they weren't. There were so many other things that they were asking me to do that I couldn't really do the job they wanted me to do. I was busy doing all of the $\mathrm{x}, \mathrm{y}$, and $\mathrm{z}$ of the paperwork aspect, which I understand why that's in place but I felt like there was so many bigger pieces that I didn't agree with. This got in the way of the things that I really did agree with. And then there are the things that I felt like children deserve... I think I picked the image of the [remote control], I don't have a TV and I don't ever understand how to work a remote control. I think that's why I picked it because when I pick up remote controls I'm so not attuned to them that I never really know how to work them even though they're simple and I think that's how I felt at [my job] a lot. There were a lot of things that they wanted me to do that I just couldn't wrap my brain around because I thought it was more important to be with the children than filling out like carbon copies of a million things.... 


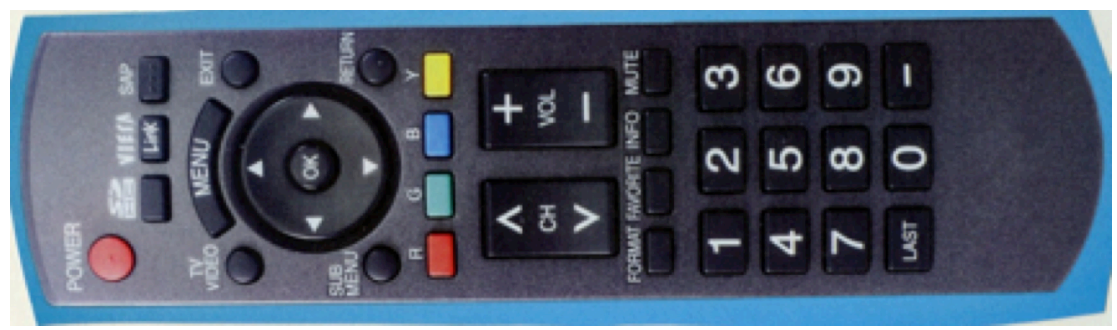

Figure 8. Remote control from Northcut (n.d.). Reprinted with permission.

Carolina went on to say how her experiences as a student in graduate school helped her to frame her beliefs about children. The experiences gave her a voice. With a clearer vision for herself, she came to see that she needed to work in a place that matched her belief systems. In finding her present place of work, she felt that she works in a place that matched her philosophy of what children are capable of doing.

As Carolina started to mature in her practice, she found that she was able to start to frame the density of education systems. For her, the photo representation of the complexity of Oregon's Education system required a layered image (Figure 9).

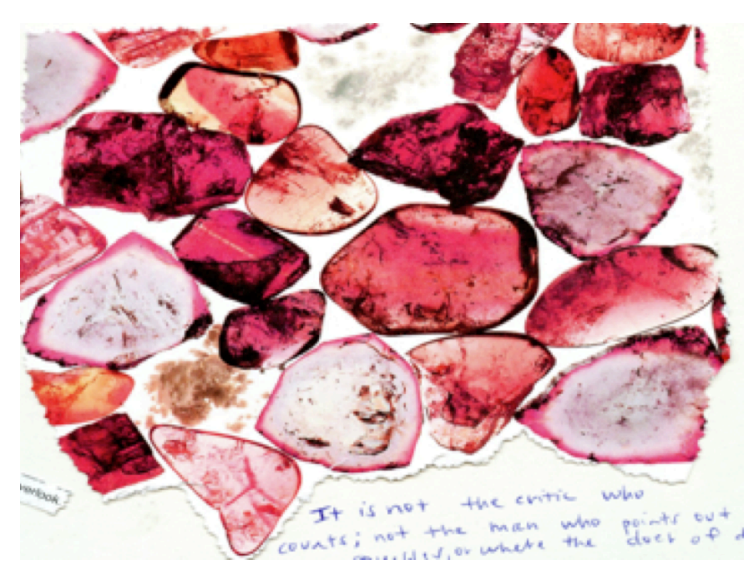

Figure 9. Stones.

This picture here of the stones kind of ties into that [Oregon's professional development system], just that in education I have learned and believe that there 
are many issues of all sorts. I feel it's even hard to explain, my words aren't going to do it justice, but to me this picture represents the layers of complexity for issues in education, that some are really easy to see through and some are so foggy that you cannot see through them and you may never see through them, you may never come to a-I don't even know if I'm making sense. But there's so many, I mean, so many, a million, all the issues, all the things to think about, all of the fights we're fighting, all the controversial issues and whatnot. So that's my stones and gems image, that's what that represents. And I have these words here "impossible to overlook." That's how I feel a lot of people I know can look and overlook a lot of things.

Then Carolina shared the importance of early childhood educators' voices in decisionmaking processes for Oregon childhood care and education community.

We must take our voice to the people who are making the decisions and I think the people who are making the decisions make a lot of them, but not here [in our program]. Here, we are making the decisions. [Our Director] is making the decision. She's in our group, but up there [in the professional development system] I feel like the people who are making the decisions aren't in the arena as he's saying [pointing to the quote from Daring Greatly]. They're on the sidelines, not waking up at night. And they don't really know what it's like to be in the arena. And so I think that's hard, to have decisions be made by people who may not know the exact ins and outs.... well I always thought that when you're making a really big decision about a law or a No Child Left Behind or whatever, that's fine, but you should live it. So if you're going to implement a law that says all teachers should have to have all students have all their children read $\mathrm{x}, \mathrm{y}$ and $\mathrm{z}$ by $x, y$ and $z$ month of the year or whatever, you personally should have to experience it for a year. Because I think if a lot of people in that role had to do a lot of the things they're asking us to do they would think twice about the way they're asking us to do it.

When reflecting on what she wanted from Oregon's professional development system, Carolina gestured to the words "smooth surface free of cracks and creases." As she continued, she expressed her feelings about the amount of work that goes into being an early childhood professional. As Carolina reflected, she expressed how motherhood has changed her focus again. Carolina finished her interview by sharing about motherhood 
I don't know how to give the same amount of attention to this one piece of my life that I'm so excited about, which is here. I don't know how to give it the same amount of attention that I could before. So now your time is divided up. So trying, trying to figure out how to be this person you are and act on these things that you believe in while having, I hate to blame time, but having not the same amount of time to think about it and to act on it. And then having that time also be occupied with wanting to do these other wonderful things in the world.

At the conclusion of Carolina's interview, she rushed out to take up her new role as mother. I sat among the scattered papers, cutouts, and general disarray of Carolina's creative efforts to create visual markers of her experiences. I was slightly overwhelmed by the passion and the volume of the experiences Carolina shared.

At the end of our interview, after Carolina left, and as I picked up the studio space, I thought about Carolina's experiences. Before I left the space, I sat down and captured my thoughts for about 25 minutes. When I arrived home, I sat and listened through the interview while looking at her collage. During this first review of her interview, I just listened.

\section{Ingrid's Experiences with Carolina's Professional Development Journey}

Over the course of the next month, I continued to listen to Carolina's interview. I sent it for transcription. After the transcription arrived, I sat down with Carolina's collage, the transcription, and her words to collage my experience of her journey. Over the next weeks as I listened to Carolina's recorded interview, read the transcription, examined her collage, and took notes of my impressions, I thought deeply about picturing my experiences with Carolina's professional development journey (Figure 10). 


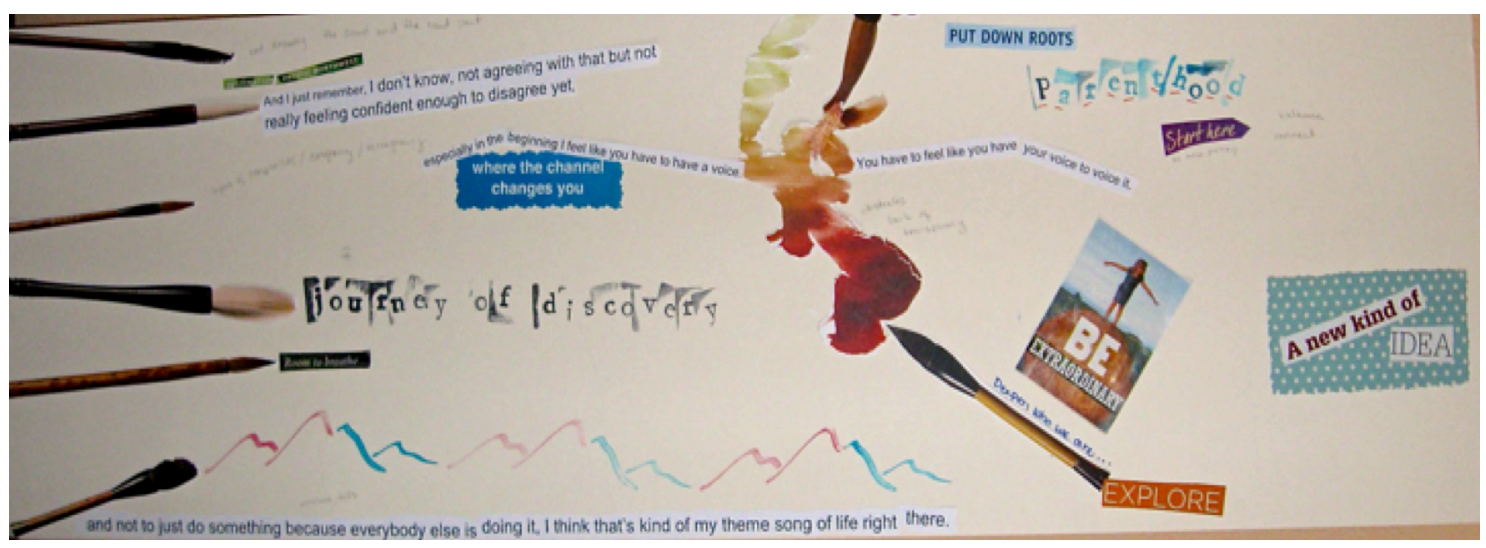

Figure 10. Ingrid's collage of Carolina's professional development journey.

Thinking on her interview, I was struck by the strands of Carolina's experiences.

I wanted to find a way to represent her professional development journey that captured these strands and the act of "daring greatly." As I looked for images, I found a series of brushes. Thinking about the property of brushes, the ability of different brushes to create different effects, began to feel like a metaphor that would reflect my experience of Carolina's professional journey.

Each brush then became a strand of my experience of Carolina's journey (Figure 11). Overall, eight brushes were incorporated into my collage and helped me to address the concept from my initial notes of "finding and losing ourselves." The six brushes, from top to bottom, connect to the strands of:

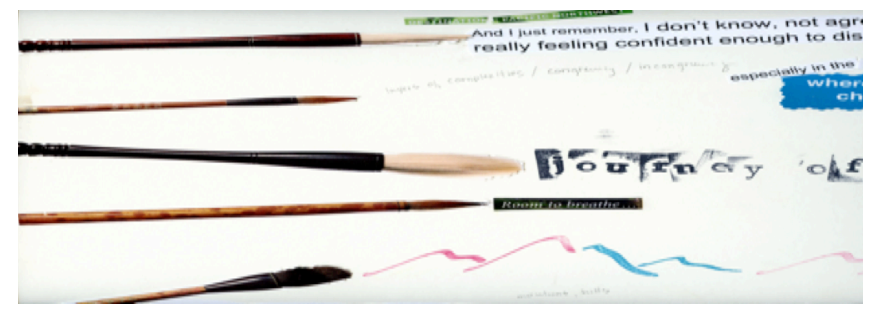

Figure 11. Representation of brushes. 
- Brush \#1: concepts of not knowing, the sweet and the hard part of starting a career in early childhood education.

- Brush \#2: concepts of being a new professional as Carolina's quoted, "and I just remember, not agreeing with that [the policy for children on outside play] but not really feeling confident enough to disagree yet."

- Brush \#3: the layers of complexity that emerge when Carolina, struggle to find her path in early childhood. The congruency and incongruences that Carolina started to recognize as she sought to align her personal beliefs with the program beliefs. The image that follows these words, "where the channel changes you" represents the internal struggle that I heard Carolina express in her interviews. This brush is particularly small to represent the feelings that I heard emerge as a new educator to find one's own voice, as Carolina said, "especially in the beginning."

- Brush \#4: This is the thickest brush, capable of the broadest strokes. After this brush, I stamped the words "journey of discovery." Throughout the strands of "finding and loosing ourselves" that Carolina expressed, I responded to each cycle to her "overwhelmingly enthusiastic" vision. To me, Carolina's passion in describing her experiences made each strand of her professional development journey an act of discovery.

- Brush \#5: "Room to Breathe" was a very personal statement that connected with my own experiences with feelings about "my place in the world and how she feels lost sometime - is also how I feel," too. I 
purposefully left space after this statement to indicate that space needs to be carefully guarded to allow time to reflect upon our professional practice and just be.

- Brush \#6: “... and not just do something because everyone else is doing it, I kind of think that's kind of my theme song of life right there." I see this quote from Carolina as the place in which she is in her professional journey. For me the mountains represent the ups and downs of becoming strong in who she is as an early childhood educator. The mountains lead to concepts of who she is now as moves beyond the renewal stage of her professional development into maturity.

In addition to the first six brushes, I added two more based on other emerging qualities of Carolina's experiences (Figure 12).

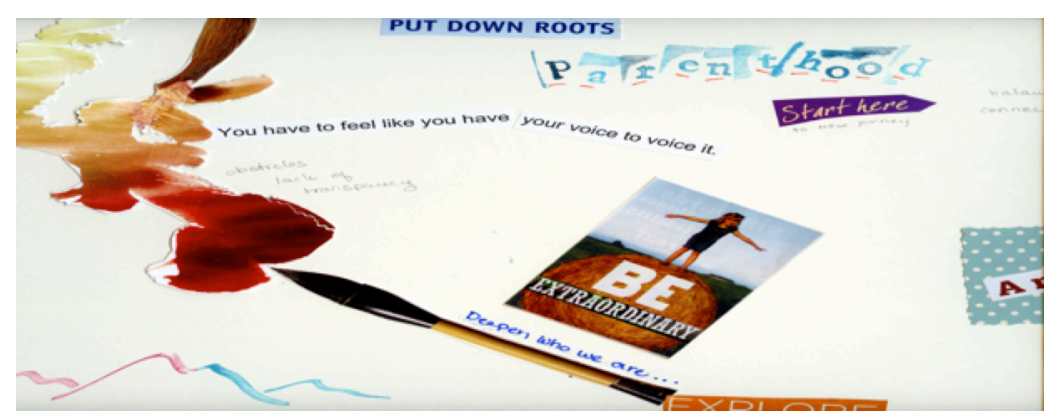

Figure 12. Connections and disconnections.

The seventh and the eight brushes speak of the changes that occurred in Carolina's professional journey between feeling that she did not have a voice and her observation that you "have to have your voice to voice it." The paint spill represented the emotional cost of being "lost and found." The color change represented the differences 
of the emotional cost of finding one's self and one's voice. What struck me about Carolina's experiences, at her crisis points, was where she lost herself as an educator. The act of finding herself was following in each instance with a surge of energy and change in her professional journey demonstrating her actions "daring greatly."

\section{Linda's Professional Development Journey}

Linda and I had worked in the same location when she was starting her professional journey, four years prior to the selection of my research participants. When she saw my study information, she contacted me and agreed to participate. During the phone interview, I confirmed that Linda was in her fifth year as early childhood educator. When we sat down, it had been three years since we had last seen one another. Linda expressed her excitement in creating her collage, sharing, "I do a lot of collaging at my house." As I left the room, Linda was already examining the materials. There was a window in the door of the multipurpose space where she worked.

Over the next hour, as I periodically checked in the window to see if Linda was ready for me, I saw her standing over the materials, always looking at what was in front of her and thinking. After an hour, I tentatively knocked on the studio door. Linda beckoned me in, sharing "I am just gluing everything down now and am almost ready"

(Figure 13). I came into the room and had a seat. When I asked, "How was the process of collage for you?" Linda responded,

Different, talking through different ideas with myself or just trying to make a picture. I was really was challenged. I thought that this would be an easy process, since I just finished some collages at home, so, I don't know why this one was such a struggle for me. I had to do a lot of thinking while trying to get my ideas out there and answer these questions [gesturing to the prompts on the table]. 


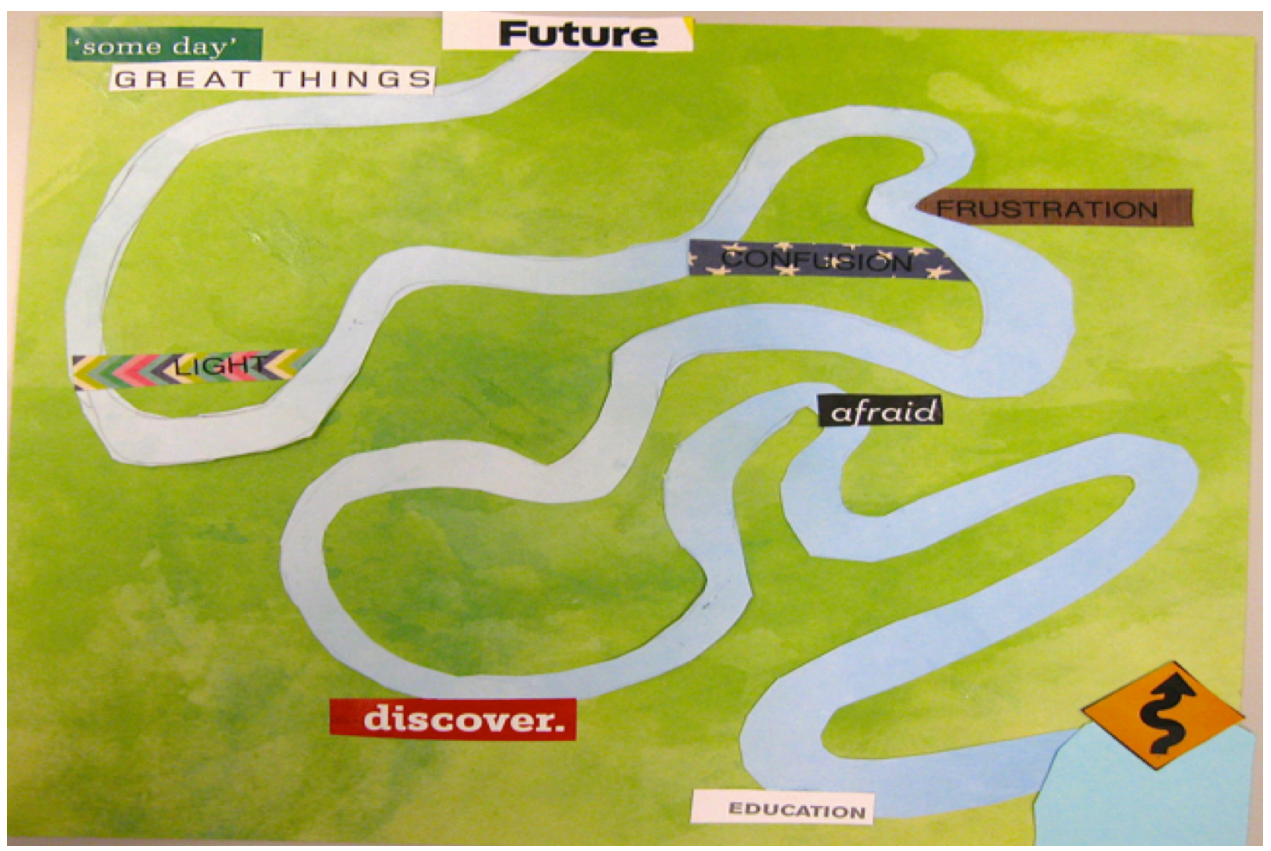

Figure 13. Linda's collage.

She pointed out a place where glue was on the collage. "I originally had a bridge here, you can see where the glue was, because in my head, it's my path but then it didn't fit with the river, so it's gone." Linda stopped and then tried to express a few other thoughts, but they were incomplete. To move the interview forward and support Linda, I asked the next prompt, "Can you tell me about your collage?"

Linda started her interview of her professional development journey by equating her professional development journey to her life,

This is the river, the river to my career... I don't know if we really even call it my career, my passion, so, it doesn't really have an end to it because it's also my life so I don't really know where one begins and one ends.

Beyond the metaphor of the river, her intertwining of career, passion, and life were very evident as she wove back and forth between events and their connections of how she saw 
herself today. Settling in, Linda started speaking slowly at first, appearing to be gathering her thoughts.

I was debating on starting with a tree and a seed, because I knew, I think, my entire life that I would go into education. From playing with the kids down the street, or from being a teacher... a friend of mine gave me a note that I wrote to her once in the eight grade and it's from math and it's really horrible but I said I don't know why I need to learn... why I need to know any of this [eighth grade math]...I'm going to be an elementary school teacher. Really, I also knew that I wanted to go into it [teaching] because I wanted to make it, fun. Like the thing that I saw in movies, of people loving school and getting something from it.

As Linda continued speaking, she spoke of being afraid after completing a

Master's in Education. As she spoke, she traced the river with her finger (Figure 14).

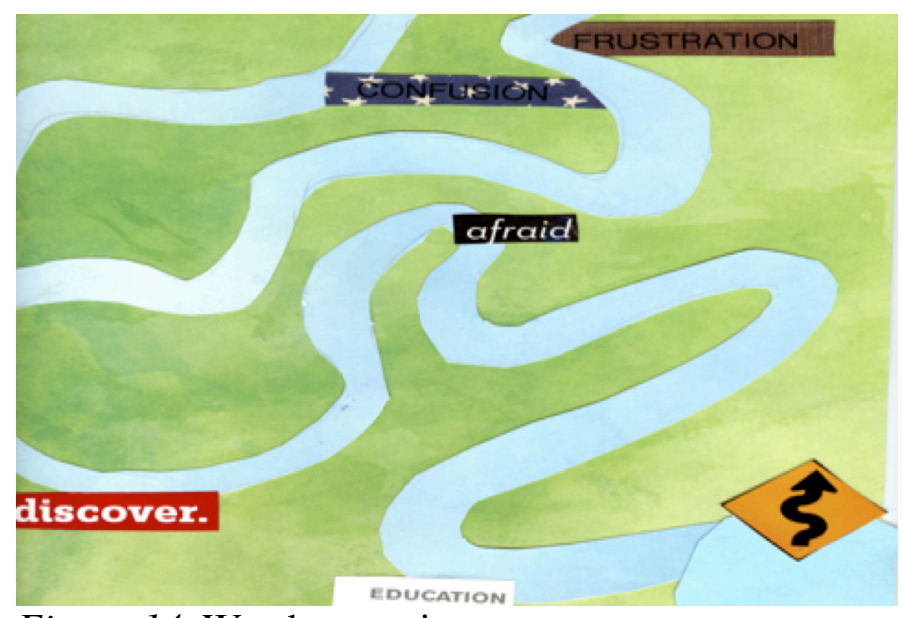

Figure 14. Words on a river.

So there's education and then in each bend [pointing to the bends in the river between the words "education" and "afraid" on her collage], there was going to represent some kind of change in the flow. So we'll kind of go with graduation and kind of being afraid of what follows because there's no real path or, after you graduate, here's your job. It's gonna be just like what you did for the last four years in school [Linda shakes her head no here]. So it's a very scary kind of time of just trying to feel different fields out. 
As Linda started her exploration of education, she began to reflect "and then we go into kind of a discovery and maybe a calmer, a little bit of a calmer time." Linda pauses here, to take a breath. Linda took her finger and pointed to the word "discovery" on her collage. She started to speak of finding early childhood education.

So to be honest with you I did not know that there was such a large difference between elementary education and early childhood education. And so when I was thinking about that I was thinking--that's kind of my discovery part--I was thinking there's this whole other field that's available to me that I didn't really know existed whenever I said to myself I'm going to be a teacher and work with young children. There's kind of that discovery piece and then we keep on going but it's very confusing and frustrating. Some things don't really align even though you have this certificate that says early childhood education. But, there's still some things maybe that are missing for me that are at one part. Because what I found for myself is that I felt like my education prepared me for an elementary classroom and not, not... [early childhood]. Why they would be so different, I don't know.

Linda turned back from her collage and went on to explain that there are many regulatory differences, that early childhood has different rules. "Then I was trying to feel my way out in this early childhood education and figuring out what licensing is. So, I thought maybe someone should have prepared me, myself for this in my graduate study." As Linda spoke of rules of early childhood education, she pondered the role of education in licensed programs.

I find it very funny that early childhood education was underneath the Employment Department and why it wasn't underneath the Education Department? [It was] something I never understood, when they were talking about this, but now, now it's changed.

Linda continued to express her learning to make sense of early childhood education.

I didn't see myself going into the early childhood education part of things so that played into it whenever I was afraid and in the world of what am I going to do, and still wanting to work with children, and then realizing that there is this other 
door that's available to me that still pertains somewhat less into the things I put my time into studying. Just trying to think [about what I do with my education], my professional life is playing into my decisions. That is a way I think I'll think of it. When one door closed, the elementary school, another one opened and that's when I started to maneuver and manipulate.

This concept of maneuver and manipulate was expanded as Linda spoke of teachers moving between early childhood and k-12 education. She questioned whether teachers who study early childhood education find their place in a K-12 world. Mostly Linda connected concepts of maneuvering and manipulating as a way to actively engage in her practice starting to make her mark as a teacher in her educational practices. Much of engaging in her practice came from a theme of making it "okay for children," as she said,

[Children need] more opportunities to explore, learn hands on, to be. I'm a big fan of the project-based learning and I think that's a really great and empowering way to learn. Kids are very capable of doing things and comprehending things, so I don't know why we give them story problems when we could give them real problems---mathematical problems, or political even, things that are really happening.

Her insights took on deeper meaning based on her own sharing of her education experiences. Linda shared that she often moved schools, had few friends, and had difficulty reading. School became such a struggle that she dropped out of high school and did not graduate. When she was 19 , she took a job with children who experienced the same struggles she had. It was at that time that Linda decided to formally work with children. She worked to earn her GED and then started to take classes at the local community college.

I got my first A in a poetry class at PCC [in all my schooling]. And while some things really turned around, it was amazing, it really was. Because, then, if you 
look at my record from PSU, it's like all A's. But it was just that, it was that taste of knowing that this was achievable and actually it became easier because once we were starting to do things that I was interested in.

When Linda spoke of the needs of children, she spoke from her own experiences.

So I really wish that there were hundreds of thousands of little schools. Little schools everywhere to work with little groups of children. Out in the community, that would be my ideal wish. I think that a lot of kids come to school with a lot of baggage. They come and there's no control over that [their baggage], so if I had my magic wand I would wish that they could just come happy and no fears and no, no worries about what's happening at home. I think that that would make it easier too, to learn. I guess that would be my biggest issues because I do think that small learning is the best way to go. You can really check in with somebody. And I think it's probably easier to deal with those issues that are happening at home when it's a small number. People don't get lost in the system.

As we concluded the interview, Linda asked if her interview gave me what I

needed. I assured her that it was her journey and the telling of her story was what I had

hoped for. Linda shared that completing the collage led to discoveries (Figure 15).

Pointing to the words on her collage - 'someday' GREAT THINGS." She commented,

Well this is the light toward the future. I'm currently happy where I am. There's more to come. I guess the light is that good things are happening and not that any of these things [pointing to twist and turns in the river] were necessarily bad, but I don't know. I have more of an understanding of how things work, the system. Where I am there's no end [pointing to the river], but it's more, we'll go with light-hearted feeling. It's just we're on a good part of the river right now.

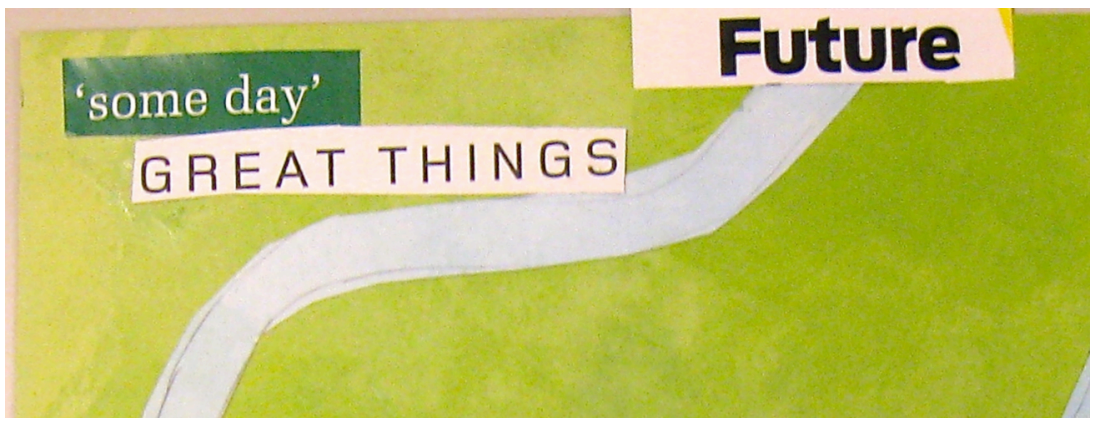

Figure 15. The future. 
As I said goodbye to Linda, once again I was struck by the emotional honestly she shared. It reminded me how carefully I needed to hold each participant's experience and how careful I must be in sharing their professional development journeys. I thought back to Osgood's (2012) writing of the fusion of personal and professional self in an “emotional profession" (p. 152). I began to write my reflections on the interview with Linda.

\section{Ingrid's Experiences with Linda's Professional Development Journey}

There was a vulnerability in Linda's experiences of her professional development journey. As I read the script and listen to the audio, I was concerned about how I would hold such intertwining of personal and professional self. Linda's story touched a chord in me. I reflected over many weeks on how to handle my meaning making for her experiences with care. Two items I included very deliberately in my collage were the color of the collage paper and her river. During the interview, I asked Linda what made her pick such a lovely interplay of blue and green. She responded, "I looked over the colors. I really, I really like this one, darker blue, but I was, it's almost too beautiful to use is what I came to." Linda then chose the lighter green color. When I started my collage, I purposefully selected the dark blue/green color as a way to value Linda and the beauty I saw in her story. The second deliberate action I took was to transpose her river onto my collage. I thought long and hard before I took this action. In the end, it was the vulnerability in how Linda shared her experiences that made it essential for me to leave the essence of her represented experiences intact as an image on my collage (Figure 16). 


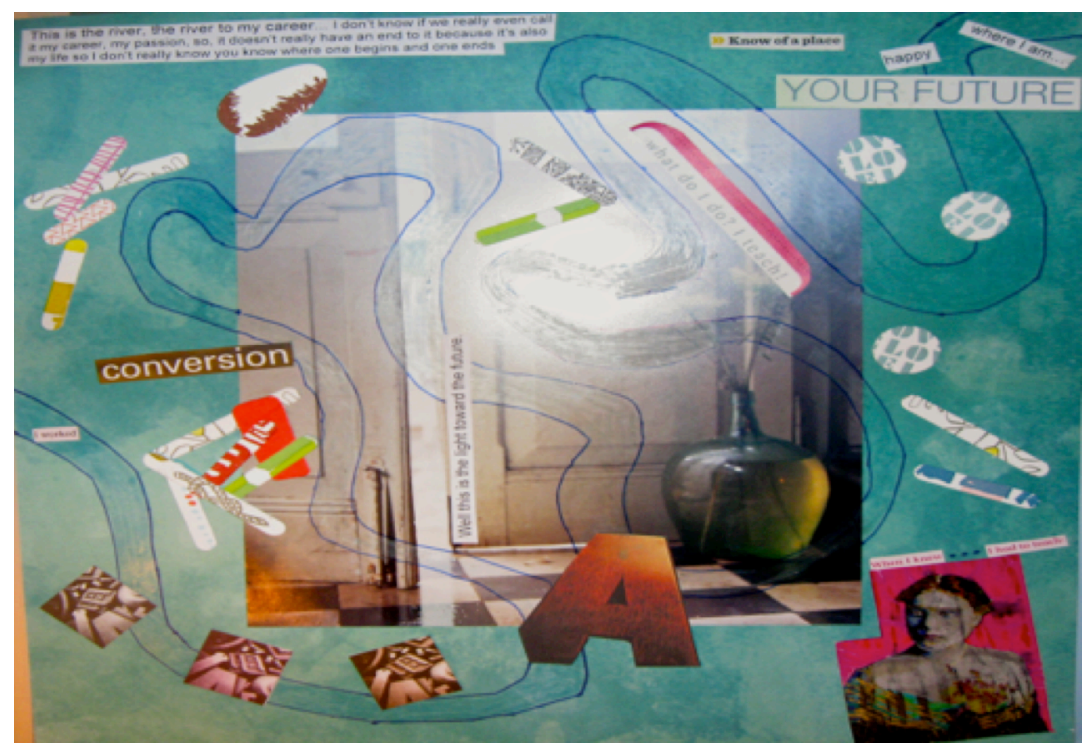

Figure 16. Ingrid's collage of Linda's professional development journey.

At the center of my collage is an image of an opening door with light spilling into the interior. This image represented all of the "befores," "transitions," and "afters" that Linda wove into her interview. Along one of the doors were the words from Linda's interview, "This is the light towards the future." This image also connected the action of stepping through a door to the three positive words on her collage "Discover," "Light," and "Some day great things." I saw these words as Linda's tools for combating her dark words of "Afraid," "Confusion," and "Frustration."

Embedded onto the river were a series of images in sepia tones that graduate to a full color "A." I selected these images to illustrate how education challenged and changed in Linda's life, from her struggles in school and dropping out to her first "A" (Figure 17). The grade which changed Linda's belief in her ability as a learner. She stated, "I got my first A in a poetry class at PCC. And while some things really turned around, it was amazing, it really was." Linda's act of self-empowerment and success 
then led to her pride in receiving "all A's in her work at PSU." It was what Linda called "that taste of knowing that this was achievable" that supported Linda in conceptualizing herself as an empowered learner.

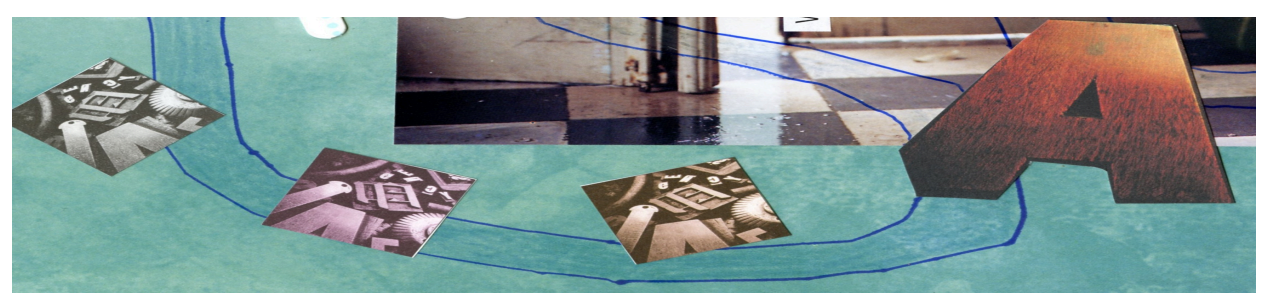

Figure 17. The A on the river.

Throughout the collage, I layered strips of paper. Following the image of the river one sees the strips of paper (Figure 18). At first, the paper strips were layered as multiple overlapping pieces. Following the river, these strips appeared less entangled and gradually disappeared. For me, the strips of paper represented the barriers Linda spoke of in her journey. The strips finally start to break up at the point of conversion where Linda started to recognize her own power. 


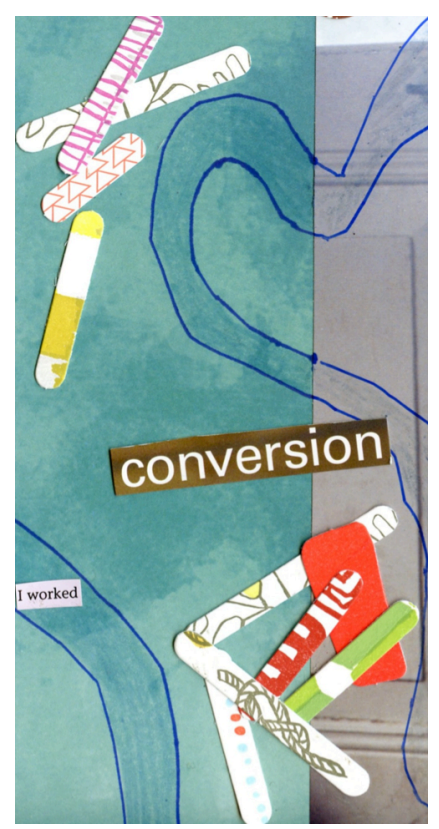

Figure 18. Strips of paper.

As Linda started to "maneuver and manipulate" her passion, I saw her claim her vision for herself. This was represented in the portrait of the bottom right of the collage. The intensities of the color pink in the background spoke to me of Linda's strength in her conviction to become an educator. The portrait itself showed a distressed image, speaking to me of the dark words that she represented on her collage, and personal cost it took to move into the light (Figure 19). "I guess the light is that good things are happening" as Linda pointed to the place where the word light is cut out and placed just past the last sharp "u shape" bend on the river. 


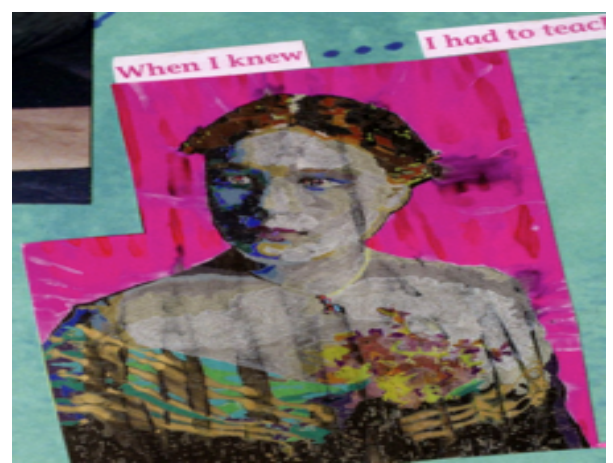

Figure 19. Portrait of empowerment.

Linda's disconnections and reconnections remained a theme throughout her experiences. In listening to her professional development journey, there were times during her retelling that an almost innocent view of the world had me concerned about the dark times overwhelming her. As Linda made the final tracing of her river of her passion, she spoke of the coming of the light. Her fingers spread out to sweep the last gentle curves to word light and to the final words on her collage. To reflect in her hope for herself, I placed the words where the river runs off the page with Linda's own word, "know of a place - happy - where I am - future."

\section{Nora's Professional Development Journey}

Nora and I had not seen each other in two years. I was surprised to see her on campus and was pleased that she was thriving and close to graduation. When she asked what I was doing I told her about my work and graduate school, she shared that she was working at a local preschool. Knowing a little of Nora's work history, I asked if I could call her to participate in my research. She said yes. After the initial phone conversation, I confirmed that she did meet the criteria with three years' experience in licensed early childhood center-based facilities. Nora had a background working at a local arts based 
facility and clay studio. She had worked in environments with young children since she was 15 years old.

Nora and I met on a Tuesday afternoon in the Remida spaces on the Portland State University campus. I looked forward to interviewing Nora because she had arts experience and in our phone interview she indicated that collage was one of her favorite media. Nora's open enthusiasm for the project had me excited to start the process. After reviewing the interview structure, I watched for a minute as Nora started to sort materials by texture in a very deliberate way.

At the end of the collage process, I sat down with Nora. A drawing captured my attention; Nora had sketched out a visual concept of her journey. Nora explained, I make a sketch, I had to, because otherwise I was going to put things down and be, oh wait, pull this up, that wasn't supposed to go there. It's good to have a roadmap of what you think you want to do.

Nora went on to say, "As you can see I was going to throw in a bunch of the other stuff along the way and I didn't have time! So I just made the buildings," as she pointed to the three buildings that were a focal point of her collage. I asked how she decided to create her distinct images. She replied, "When I first sat down I was thinking about squares and then I decided on a road." Nora labeled her collage with the names of the programs [represented in block shapes] in which she had worked (Figure 20). These names were covered in the collage images to protect Nora's anonymity. All program names in Nora's interview are pseudonyms. 


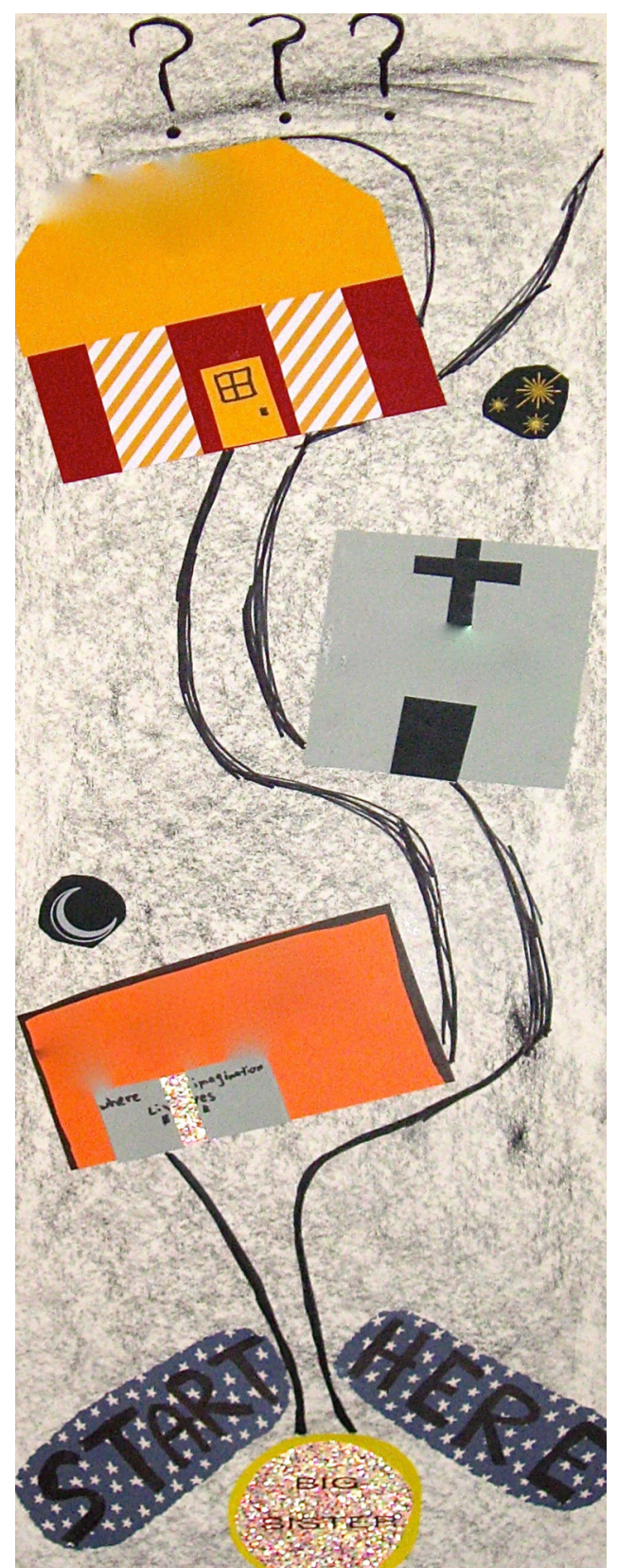

Figure 20. Nora's collage.

Nora shared that she had deliberately colored her background with the side of a black crayon to make a background pattern. "I just can’t deal with a whole big blank 
white space. It's not as inviting to me." Nora started the introduction of her collage by explaining her experience.

It was really fun. I really enjoy looking for materials and just handwriting stuff. I really liked how big I made it and having this big piece of paper to map things out was really fun. Yeah. I had a good time. It was interesting thinking about how I would like to organize my journey, because I [wanted to] talk about materials, or specific experiences and instead I just zoned in on these three big places. I made the buildings instead of specifically the interaction with this child or teacher or whatever.

Nora explained that her journey started with "A pathway, a pathway into the unknown."

She continued on to share that being a big sister made her "really good with kids." Nora went on to connect her experiences together, "Because I always think of my starting point in education as being at the Orange CDC and starting there, but as far as my interest in children and childcare and doing all of that, that started way back when my sister was born." Nora revealed over the course of the interview that her journey was intertwined with responsibilities to her sister (Figure 21). She shared,

Well I became a big sister when I was 10, which was crazy. I mean it's just, you're already so old and now there's this small being in your life and you all of a sudden have all of this responsibility for that child. 


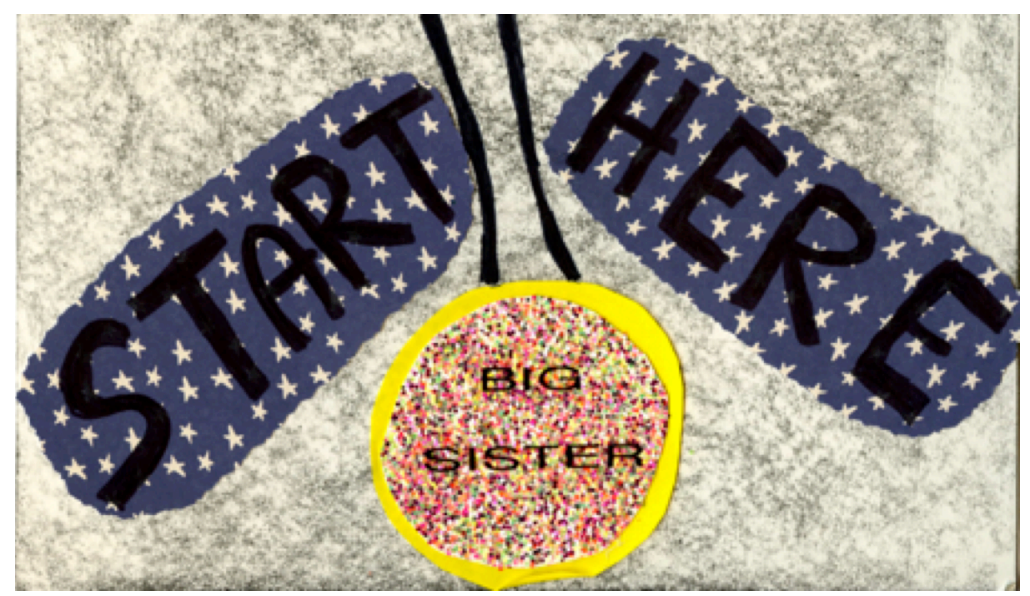

Figure 21. Image of big sister.

A sense of responsibility led to Nora's first job at a local program that had studio spaces and was a licensed early childhood program. Nora started volunteering at 15 years of age, was hired at 16 years old, and worked there until she was 20 years old.

Working at Orange CDC was really personal for me, I felt at that time in my life I didn't really feel like I had a home anywhere and it felt like the Orange CDC was my home. I always felt really welcome there and so that was just a very personal place for me.

Nora took a pause in the conversation and looked at her collage. After a minute, I offered a prompt to Nora about what she learned working at that place.

Nora seemed to refocus herself and started to speak about how she came to see children.

I found everything I know and believe about early childhood from there. I know that whole foundation of respect for them and really listening to the child's ideas and what they're making and not imposing your own idea of what you should make in the clay studio or what you think their idea is and just being open with kids. It really taught me how interested I was in documenting kids work, too. In my last year or so I was there, I was really pushing documentation in the studios and had all these systems in place to try to get people to document more kids 
work. I was trying to get more places to display it in the program and making their work visible.

While Nora was at her program, she transitioned from the studio to work in the licensed center-based program part time with children from three to twelve years of age. She spoke of working with children and hearing their stories during the creative process.

[I would be] sitting down, and [asking] what are you making and then the stories that would come out of that were just phenomenal. I would never have thought of any of these things. I've got to get this down and I feel like a lot of people who don't know about education in the street are just thinking, "oh yeah kids making stuff." Whatever. It doesn't matter to them and I felt like their stories were really powerful to me and they [children] definitely jumpstart my creativity too.

Nora explained why she left her program and went to work in another agency,

The different education styles [at the new job] and how jarring it was to suddenly be in this place where children weren't as respected as they were in my previous job. I was really getting sick and mad about it.

As we looked over the collage together, she shared that the image of this Gray

Block CDC was represented in black and gray, a stark contrast to the images of the other programs images that are full of color, pattern, and texture (Figure 22).

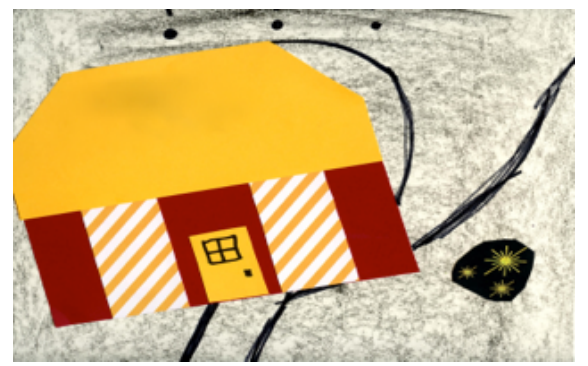

Figure 22. Yellow roof CDC.

Nora made a decision to leave the program. She went to a well-known early childhood center and asked, 
Do you need anyone to work here? That's why I started working at Yellow Roof CDC. I really felt at home again, because these people have the same core beliefs about children and learning and environment that I do and really respect all these things.

Nora sat back with a smile. I paused for a moment in admiration. It takes a certain type of courage to knock on a door and ask for a job. When I picked up my train of thought, I asked Nora what core value resonated with her in her current program and she explained,

I want to keep experiencing how children form their ideas and where their stories come from. That's the most interesting part to me is when you're talking to a child about something, something they built or something they're working on, or even in pretend play it's like why did you even come up with these ideas.

As we continued, Nora expressed that other experiences were influencing her values. Since Nora is in school, she shared her thoughts about her college classes in early childhood education and the impact those have had in her thinking. I asked her about the importance of education versus experience, and which had a greater role in sharing her professional identity.

Experience, I think. I feel like my education has helped me develop those ideas but all of my beliefs about education came from experience at Orange CDC and seeing people interact. Watching local schoolteachers or watching other coworkers at the Orange CDC and being, oh wow, that's really cool. That actually works really well, I like that. I want to do that too.

I was curious how her current program viewed education and experience. As a response, Nora explained that her program decided to participate in the Quality Rating Improvement System in Oregon and one of the requirements is an Oregon Registry Step. I asked her about the process. Nora pulled out a file with her Registry Step and correspondence. She responded, “at Yellow Roof CDC, they were: here's this 
paperwork. You have to do it." I asked, “Did they tell you anything about it?' Nora continued to explain.

Not really. I haven't learned a whole lot about it. I have lots of questions about the Registry. I know I'm in it and I know I'm at Step 8 and I'm pretty sure that's a high step, but I'm not very clear on what those mean for me as a professional. What that shows other people who see that. So, that was not super clear.

When I asked Nora "And so, the stuff that you got, did you feel like it, did it tell you much?" She shared, "Sort of. I thought, well, it tracks your training, right, and I got that part. Then I thought, that's important and that's good to know that somewhere there's a database that has all my stuff." With a laugh she added, "because I'm not very good at tracking that myself." Then, Nora continued earnestly,

I did get a certificate. I actually brought it with me, because I thought, I'm just going to bring this since it has the other paperwork in it too that I want to look at, for the [education] award. [The paperwork] says congratulations; you're at Step 8! And, I remember I had done it before at [program name] too and I was at a much lower step. So, I thought, oh wow, I moved up. I think I've done it twice now.

I ask if she had any other questions about the Registry.

It was not super clear that I could go in and look at it [my training online]. And that would be nice. It'd be nice too if it had a big compiling of professional development things coming up in your area. A big database of stuff you could search. That would be really cool, I think, and helpful. That'd be really neat, cause then I could shop for classes.

Nora shared that she feels that she is "just learning" about being a teacher. I asked in her eyes what would that look like - to be a professional teacher - and she responded,

Someone with a lot of experience and a lot of confidence I think is what really defines that for me. Looking at [program name] at student teachers versus like the lead teachers. We're all working with children and doing all of these things, but it's like a confidence difference I feel like. That lead teachers have the confidence to just do what they've got to do and know where they're going" 
We both paused, looking at the collage. I traced the lines on the collage. Then to my unspoken prompt, Nora replied,

When I first sat down I was thinking about squares and then I decided on a road actually. I feel like the road... I feel like I don't have enough knowledge about where I'm going or how everything connects together yet to make a quilt or a circle or anything like that. It's still going off into the distance somewhere and maybe it'll circle back or maybe it'll all come together as something.

Nora trailed off. I sensed it was a good place to wrap up the interview. I thanked her for her time and expressed how much I appreciated her sharing her experience, to which she replied "Sweet!" To me, her reply summed up my experience interviewing Nora.

\section{Ingrid's Experience with Nora's Professional Development Journey}

Each collage response to a participant's journey started with a ritual. I would clear off my desk and lay out the collage materials on the ground around me. Once my environment was set up, I could then think about Nora's interview. Of all the interviews that I conducted, Nora spoke most extensively about her classroom experiences framed from the perspective of her work with children. I started my reflections by playing back the audio and I was surprised that our interview lasted 45 minutes. It had seemed to pass quickly. As I listened to Nora's voice and looked at her collage, I was struck by how Nora created strong visual images of specific blocks of time of her experiences.

Nora's blocking of her collage gave me the idea to block my response to Nora's collage experience by using a pattern (Figure 23). The pattern, which covered the whole collage background, is also a nod to Nora's distaste for "big white spaces." This idea also served to keep at the front of my mind, the breaks in connections that Nora experienced and shared from her childhood. However, Nora's personality, her beliefs 
about children and her positivity in living her life are acknowledged in the harmonizing of the background materials; celebrating Nora's positive view of how she sees the patterns of her life.

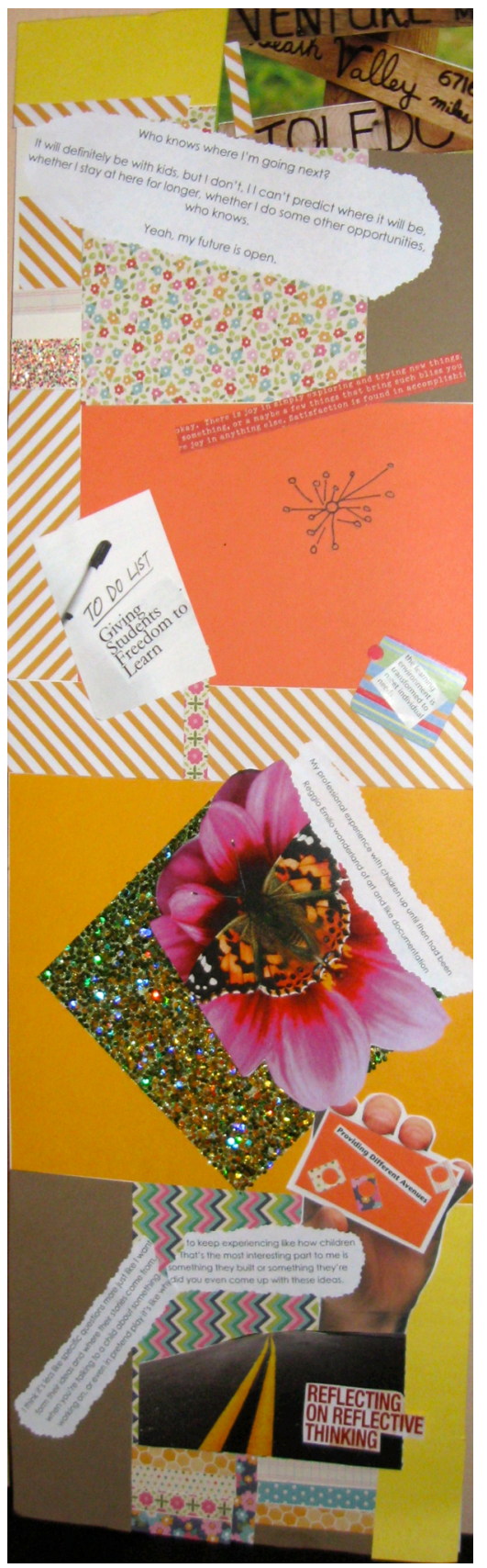

Figure 23. Ingrid's collage of Nora's professional development journey. 
As I started my collage of Nora's experience, I started with many strips of paper. These many small pieces were to me a way to imagine scaffolding the experiences in Nora's early life. The image of the road presented an image of a path that led to the curves of the zigzag paper (Figure 24). It was the only way I could capture Nora's early stories. I thought carefully about placing an image of Nora as sister on the collage. Finally, I decided that the complexity of experiences in the sister relationship, should only be reflected on Nora's collage. I made this decision because elements of Nora's story about her sister were known to me before the interview and I wanted to assure that the way Nora represented her sister was specific to our interview.

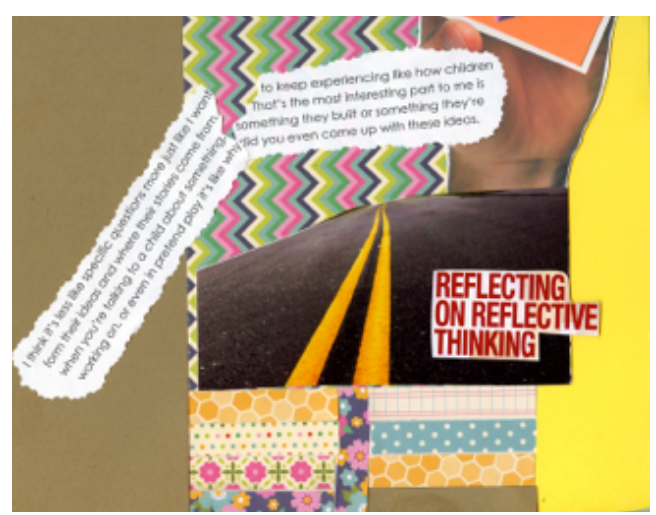

Figure 24. Road of zigzags.

Pattern played a large part in Nora's collage. My use of stripes, flowers, and geometric shapes came to symbolize the complexity of Nora's story that emerges from simplicity of her words. For example, the words that Nora used to describe her experiences were straightforward and direct. However the concepts behind them offered a picture of complex ideas about children as members of society. When I left the interview with Nora, my initial first impression was Nora's joy in working with children. 
However, as I continued to revisit the interview audio and especially transcript, I came to see a depth of thinking presented in the casual wording.

In revisiting Nora's story, I became impressed by her reflective practice as an early childhood educator. She happened to mention her age throughout the interview at different points in her life experiences. At 22 years of age, she exhibited a complexity of understanding far beyond her youthful image. When Nora spoke about her teaching practice, I had responded with a prompt about the questions that she had in her early childhood journey Nora voiced her thoughts,

That's the most interesting part to me [in working with children] when you're talking to a child about something, something they built or something they're working on, or even in pretend play it's like why did you even come up with these ideas.

Nora's fascination with children's thinking manifested itself in a physical response. Her eyes widened, her hands gestured, and her voice rose to form a question. Clearly, Nora had a physical response to her admiration for children's thinking.

In trying to create a visual representation of Nora's reflective practice I came across a series of quotes that I used on my collage, "reflecting on reflective thinking," "providing different avenues," "giving students the freedom to learn," and, "the learning environment is transformed to meet individual's needs." This is how I perceived Nora's reflections on her practice as an early childhood educator. With each part of Nora's journey, she spoke specifically and with precision about her respect for children.

Toward the middle of the collage is the bright sparkle of green glitter paper overlaid with a butterfly on a flower and Nora's quote that her professional experience 
with children up until then had been "[a] Reggio Emilia wonderland of art and like documentation." This highlighted the strong internal conception of self as artist that I heard through her interview. She made reference to how proud she was of the doors that she represented in her collage; the sparkle was such a way to express how she felt about her experience. Nora went on to explain that the sparkle represented all of the possibilities of place. I had a moment of nostalgia for my own beliefs about possibility of place. To me, possibility of place takes on different meaning depending where you are on your journey. There appeared to be freedom in Nora's possibilities of a future that was appealing to me. It was one of the reasons I captured the image of the road on Nora's collage. The act of traveling down a road, or as Nora claimed, "path," mirrored my own movement and the unknown that is to come after I graduate. However, I was struck with the differences of how possibility could be perceived at the start or middle of a journey. I wrote in my notes after the interview,

To be young, light of spirit, and full of possibility, to have a sense of self that is built on struggles, but built in such a way that it results in hope. Not to be worn by the cares of a life in the middle, of responsibility, and work. While possibility is not only for the young, it is harder to risk what is possible once your responsibilities have grown beyond yourself.

I debated if I should even incorporate that quote into my paper. After adding it and removing it, I decided to leave it in. I wondered if I could capture Nora's light spirit by reflecting back on her words again. My hope increased when I saw that my collage seemed to echo Nora's, starting with greater detail and trailing off into greater open space (Figure 25). 


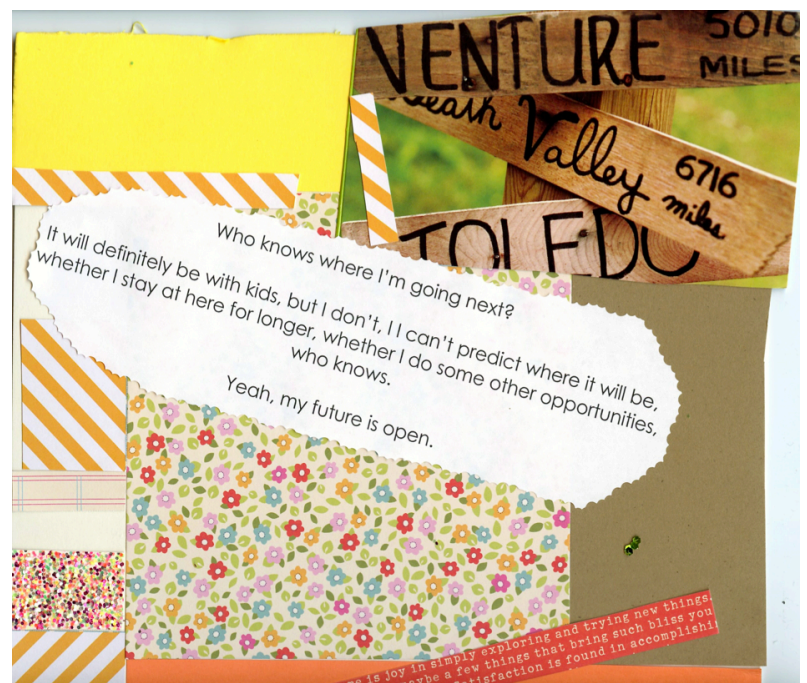

Figure 25. Next.

I wondered what caused my unconscious reflection of Nora's formatting of her collage. As I went back through the transcript, I could see that I was influenced by Nora's quote,

Who knows where I'm going next? It will definitely be with kids, but I can't predict where it will be, whether I stay at here for longer, whether I do some other opportunities, who knows? Yeah, my future is open.

I paused and remembered a moment of similar feelings in my own youth. Then, I found the image of the directional sign, "Venture 5010 miles." It seemed to summarize the possibilities of Nora's future. For me, it represented the cross-roads of possibility. The very last piece I taped onto my collage was from a quote, "There is joy in simply exploring and trying new things, something, or maybe a few things that bring such bliss to you." It made me think of Nora and her words, "It's still going off into the distance somewhere and maybe it'll circle back or maybe it'll all come together as something." 
A few weeks later, as I sat at my desk thinking about my collage of Nora's professional journey, I realized that I had not created any connection to the professional development system. I took some time to write on my thoughts on this discovery.

Nora spoke about the Oregon Registry. You could see her pride in moving up between the Steps. She even brought her certificate for a Step 8. For me, when she spoke of the wish that programs and services were connected to the Oregon Registry, ones that were already in place, such as the Training Calendar, myORO, and concept materials. It created an "ah-ha" moment for me. Individuals could find meaning and make personal connections to achievement without contextualizing the experience within Oregon's professional development system.

This would come to be an important reflection point as I moved forward to create essential themes.

\section{Mira's Professional Development Journey}

Mira expressed an interest in my research project while I was handing out flyers at a local association meeting. The experiences she shared of Oregon's Professional Development system were extremely frustrating to her and she was eager to provide feedback about Oregon's professional development system, in particular the Oregon Registry. Mira knew that I worked for OCCD before I even spoke at the local association meeting. She later shared that my connection to the Oregon Registry drew her to the interview, since she felt that my work there could be influenced by her experiences.

Given Mira's passion for sharing her experiences, it was particularly important to me that I clearly express how my research was distinctly separate from my work with the Oregon Registry. While Mira acknowledged this distinction, she still firmly believed that her experiences would resonate with me in the duality of my roles as a researcher and professional. She was right. 
Mira's academic degree originated outside of early childhood or any other education fields. Mira's first experiences with early childhood were as a nanny. She laughed a little as she reflected on her own naiveté.

I started as a short-term nanny for a tax accountant. I was planning on moving to Oregon, so this was a way to make that move. So I said to myself, 'I'll be a nanny because anyone can be a nanny.' Her children were 18-month twins and a kindergarten daughter. I had no idea how to care for those children. Luckily, the previous nanny wrote a five-page list of what to do. I must have read those pages 200 times. I would have it with me when I was trying to care for them. It turned out great. These children really changed my life.

After working as a nanny, Mira decided to go back to school. She went to school to become a high school science teacher. However, while seeking employment, she took a position in an early childhood program. Mira shared, "I went to get a job and guess who you get to work with if you don't have any education or experience? Babies. The smallest children, that was shocking to me." Mira was confounded by the absence of what she identified as basic developmentally appropriate practices, “just like why wouldn't you have things down for the children to play with?" Mira quickly discovered Montessori and now holds a Montessori diploma. As Mira explained,

I found Montessori through early childhood education. It's like you are looking for something that you don't even know you are seeking. Sometimes it finds you and you say to yourself, "Oh, it found me. Good, it was supposed to find me."

Once Mira discovered Montessori methods, she worked in a family child care setting before becoming a teacher/co-owner of her own Montessori program. She has five years with licensed center-based preschool and is still in the classroom.

Our meeting took place in a multipurpose space downtown. While Mira did not bring any artifacts to our meeting, she did bring a laptop for music and looking up quotes. 
After I left Mira to her collage, I could hear her music playing in the background. Mira took over an hour to create her collage. She systematically sorted through the materials, choosing visual images exclusively to represent her professional journey (Figure 26). I returned to the room. Mira paused to look around the work surface. As she saw the materials spread around the room, she started to pick them up. I respond to her action, “Oh, don't even worry about picking anything up. I will take care of it all." As we began, I asked about the experience of collage. Mira started with a laugh.

It was good. It was a challenge, like it definitely is challenging. It took me a minute... then I approached it not necessarily as like creating a work of art. I do not believe this is my masterpiece as in look at my beautiful art. It's more about my story. And so once I felt like it was my story and that I was telling a story and I'm not creating a piece of art, then I could relax a little bit. And then I thought, ok, well I had some themes in mind. [I] tried to find images that reflected some themes that I feel about my journey and how my interaction with the professional development system, you know how I feel about that. So it [the process] was satisfying, I felt really satisfied.

Mira paused and took a drink of water, then she continued.

It's funny because I really don't consider myself like an artist. Well I am a musician, it's just a different than being a visual artist is what I usually say. So collage, is definitely an experience in and of itself to push yourself into a place where you're asking, 'How do I use this material to represent what I'm trying to say?' I mean, you know, if I had, I probably could geek out on it more. But I think this is, I think, I definitely feel like I found a lot of what I wanted to find. 


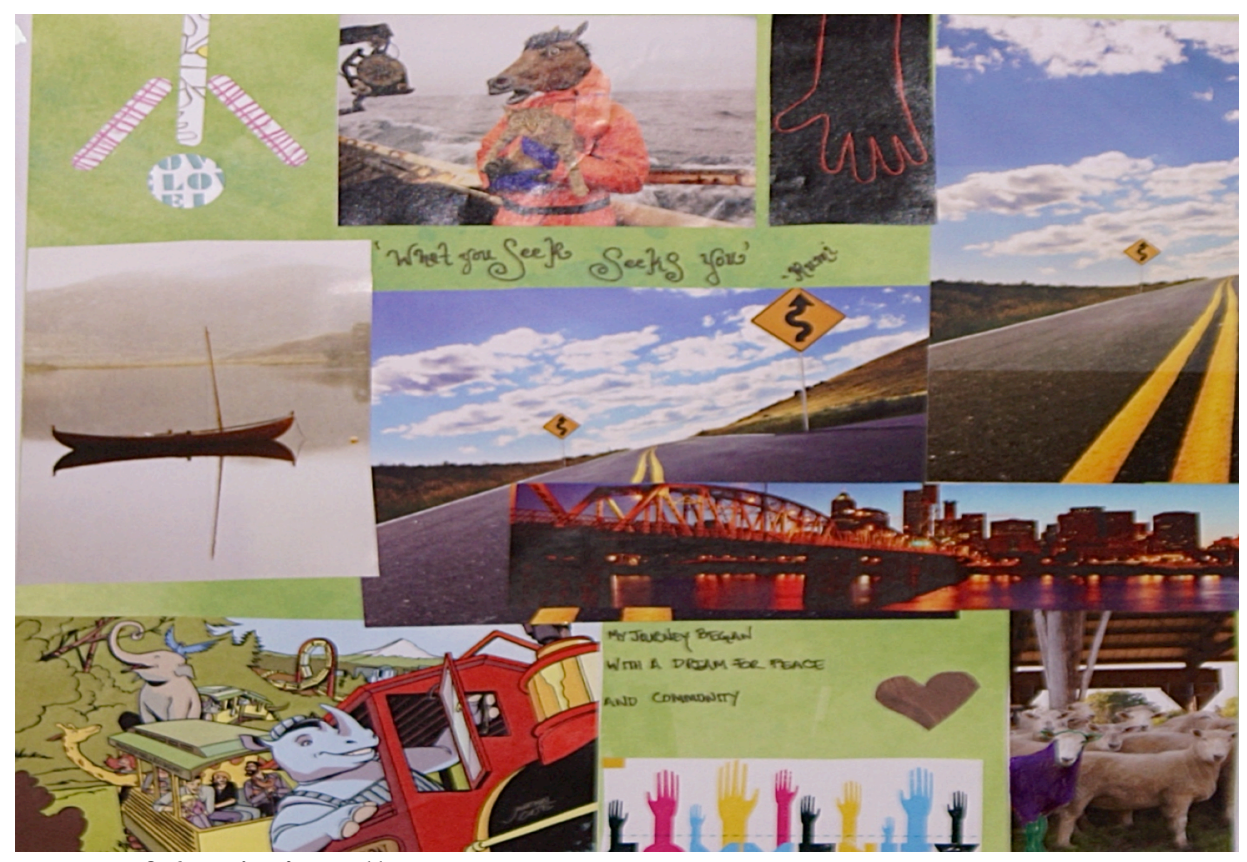

Figure 26. Mira's collage.

Mira gestured to the center of the collage, "I wrote a little haiku." A haiku, Mira explained, was used to express her emotions and a way to share "this is really coming from inside of me."

My journey begins With a dream for peace And community

As we moved into the intent of the interview, I had prepared a series of neutral responses to any feedback that Mira might be looking for as she shared her experiences with Oregon's Professional Development System. Based on her phone interview and our meeting at the association meeting, which seemed intense, I was prepared for an emotionally charged response to my prompts. Unexpectedly, our interview was surprisingly light hearted and full of laughter. 
We both smiled as Mira pointed to the picture of a rhinoceros driving a train. As we looked together, she seemed to become lost in thought. I prompt, "So was there anything that surprised you about the process?"

Well, I mean, I think feeling the pressure...I'm actually going to have to create something. It also surprised me how [much] less...I remember feeling very emotional and upset and unhappy and really angry, just all these negative emotions about my [Oregon Registry experience]. A lot about how I feel like I've been treated, and how my contribution is recognized formally with the professional development registry. And what surprised me honestly was that I had a hard time accessing those deep angry emotions, and so it felt really good that I've processed that in some way, and that I didn't need a vision board to help me process maybe a little bit. That was surprising. How mellow I am about it now, as in, wow that's different.

I heard the tone of Mira voice and saw that her body posture was in a relaxed state. Her emotions of past experiences were not present in her current interview. As Mira continued to talk, she reflected that an hour is "a good amount of time to think." Mira shared that it took several tries to layout her experience and appreciated that she could manipulate her images (Figure 27).

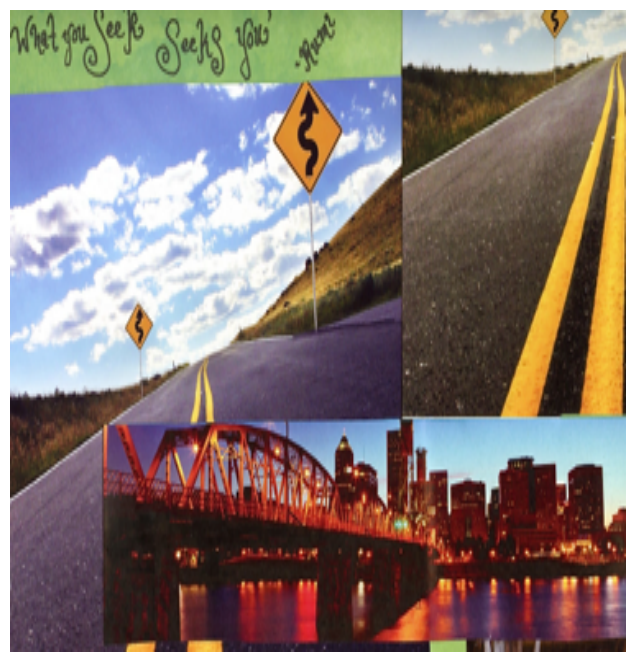

Figure 27. Dual roads. 
Mira eventually found a way to represent all the parts of her experiences. At first, Mira thought that her journey might be circular, then she thought it might be linear, and finally she settled on themes. She expressed that even expecting the process of collage as part of the interview, the process of visually representing her journey was a struggle to organize her journey in a cohesive collection of themes.

I had some themes in mind and tried to find images that reflected some themes that captured my feelings about my journey and how my interaction with the professional development system.

Mira continued that when she started to capture her experiences, they were "multileveled."

There are so many strands to human development and each one of those is a road, so I put the same image in twice because it's the same image---but it looks different---as if there's a different lens on each image. One is the early childhood road and [following the yellow line with her finger] this is the Montessori road [far right] and they're 1 kind of the same but they're also a little different, but they're both twisted. I have my Montessori road and then there's the ECE road but also I have my [personal] road and everybody else has their own road, too.

Later in the interview, Mira revisited the concept of roads.

I saw this, the image of the roads and I actually just cut out like one of the signs and I was just going to use that but then the more I kept playing with it, the more it's really the road that I want. I just kept thinking about the roads and how great these two images were to really articulate how alike the two pictures could look but so different with a little bit of a different lens. At the same time, I do believe we're reaching towards each other and then there's the bridge [between the roads.

Mira continued to expand on the thought of themes and why she chose her images. She pointed to the image of the train and smiled (Figure 28).

I definitely was drawn to like the images, the more concrete images as opposed to the more abstract. I felt like I wanted visual representation that was direct, something like not abstract rather something that everyone could look and see--Oh! That's a train with a rhinoceros driving it. 


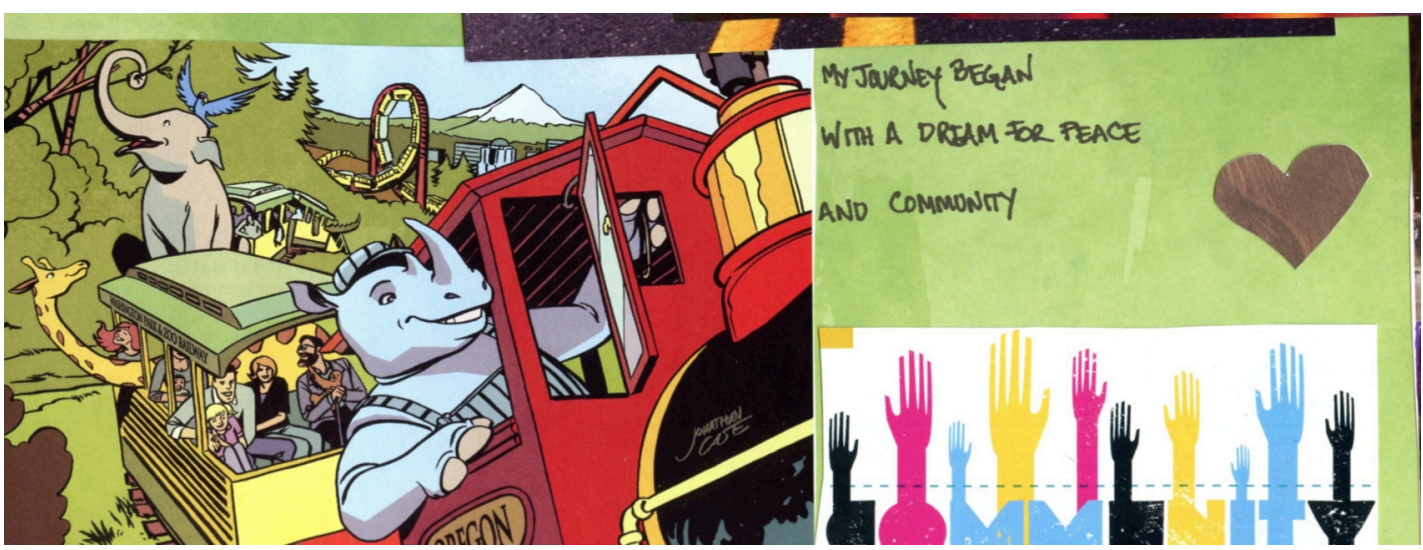

Figure 28. Rhinoceros driving a train from Case (2012).

This [pointing to the train] was one of my favorite images. I saw it right away. And feeling free, and feeling happy, and I really believe that this image brought me to the place where I am now. I'm still riding this awesome train and it's just that I'm doing something a little different.

Mira identified herself as the Rhinoceros. She expressed great satisfaction that the picture has so many elements that were contradictions, such as "Rhino and humans" or the fact the "train was a rollercoaster." Then these [images of the Rhino] were important in terms of the roads. Her acknowledgement of contradictions would emerge again in the interview.

For Mira, the image of the train also invoked a connection to Oregon. Mira says, "I just feel in many ways Oregon has like guided me professionally." Mira's went on to describe her sense of community in Portland as represented in three photos, one of the bridges that span the Willamette River and the other two of a single hand facing the bridge and a group of hands across the paper, also facing the bridge.

I've always been a person about community and there is an early childhood community here in Portland. This is intentional [pointing to the bridge and two 
sets of hands], this is like me and this is everyone else. We are for a long time like this hand[s] facing another direction. And, I don't want them to face that away because I do believe like that we're reaching towards each other and then there's the bridge. So the bridge is one of the reasons why I love this city and the metaphorical forming. I do feel like it's a good place to build bridges and to have community.

Mira shared that she wanted an image that expressed her sense of isolation (Figure

29). In many ways, this isolation was compounded by how her Montessori training was

accepted into the state professional development system.

I worked really hard to go through the Montessori training. I talked to people about using my Montessori training to get a Step on the Registry and no one ever said anything to me that this idea wasn't going to work or stopped me from thinking that this idea was the way that it was going to go, until I got my certificate back. And that felt really, really isolating because I thought, wow I worked so hard to get this education and I'm being told that it doesn't mean anything in this [the Oregon Registry]; that there's no way to measure it.

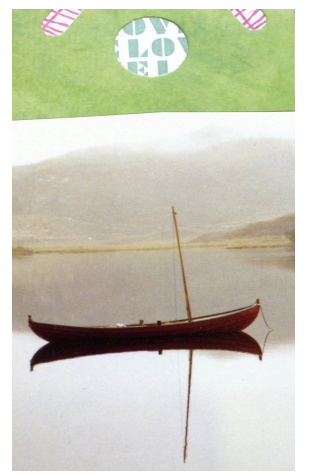

Figure 29. Boat on still waters.

She pointed to the image of the boat on still waters.

And that felt really isolating. I like this image because it's the reflection. I felt like it was a lot of layers, like it looks the same upside down and that it felt, just felt really empty and why like the boat, looking at it could be the same. That there wasn't any rationale, I really couldn't understand why there wasn't a place for my work to be recognized. 
She looked up at me and paused. Continuing on how she feels the feeling of separateness, Mira regained some composure and gestured to the strange juxtaposition of the horse with a cat on a boat (Figure 30).

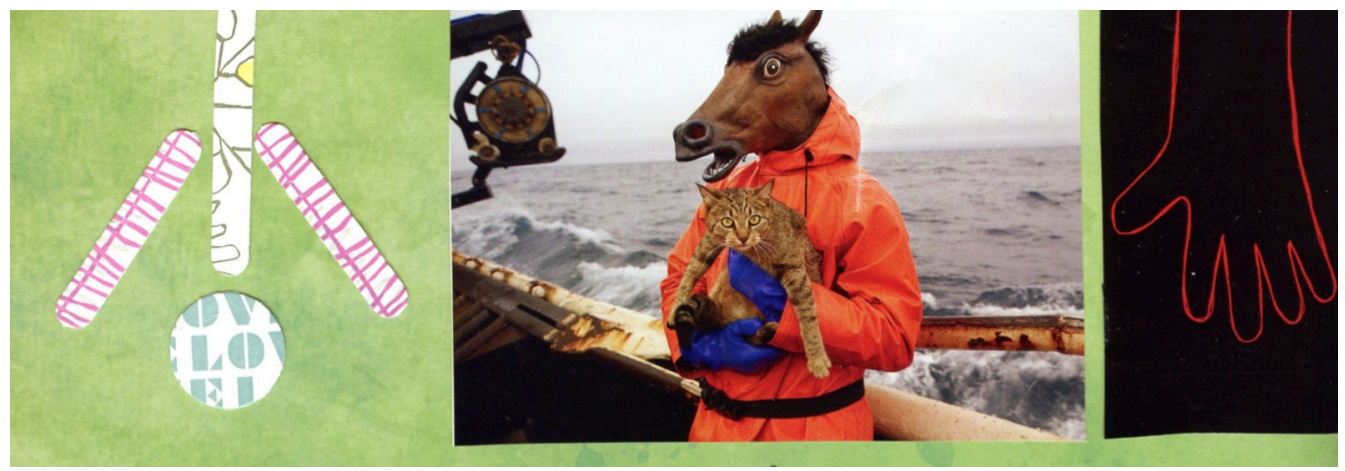

Figure 30. Horse with a cat on a boat from Arnold (2002).

I feel like that horse and you know, like what the hell? Excuse me, but what the fuck? Like, what is this? What is this horse? And the horse looks crazy and freaked out, and why is the horse holding a cat? And to me that's kind of like the minutia of, like, it does not make any sense to me. Well first of all, I feel like I am both of this image and this image is the Oregon Registry. That it's a horse in a raincoat on a boat holding a cat. You guys figure that out. Good luck. And I think coming from a Montessori program, I also feel that's how people look at me when I'm talking about things Montessori. People say, oh my god, you're like a horse in a raincoat on a barge holding a cat like that's, what is that? I don't even know what to do with that image.

Then, Mira described her experiences of "many strands" and of the difficulty that is faced when working in systems with limitations such as in the Oregon Registry and also in her Montessori training. Mira expressed the need to stand within her own pedagogy, constructed of self-experiences. The importance of her values came forward as Mira spoke about childhood care and education at a system level.

[A colleague] and I are looking at everyone that's on the Early Learning Council and [we think] what does a used car salesman know [inaudible] and who are these people? Why are they on the Early Learning Council? What qualifies [them] and 
where are the teachers that are still practicing? Just coming out of the classroom I feel is a shift in your perspective because you're not in it anymore. The practitioners are the ones who can speak eloquently about their craft because it really is especially for those teachers who've been in the classroom for so many years. They have some pretty important things to share. So it's important to give them a voice. So often I'm in my own little bubble, but even thinking about public school teachers or Head Start teachers or where [is the education] community?

Where's our collective voice because we all do this for the future.

Mira concluded her interview with a small smile and a wave as she left. I took a moment to breathe. As I began to write, I acknowledged Mira's prediction of her experiences and how they would resonate within me in my multiple roles as a researcher, professional, teacher educator and person who works with the Oregon Registry.

\section{Ingrid's Experiences with Mira's Professional Development Journey}

As with each of the interviews, I started by listening to the recorded interview, reflecting upon the words and images together. I continued to listen to Mira's professional development journey over the next few weeks and, I also took a few sessions to follow the words of the transcript as she spoke. Throughout this process, I jotted down items on sticky notes that came to the fore of the experience. Listening again, I started to comb through magazines and images that captured my response to Mira's professional journey. I continued on my own exploration of her experiences by listening to her interview as I collaged my reflections of her experience (Figure 31).

For some reason, throughout the process, I thought about Mira always seeing herself as apart from others. Mira's sense of apartness was reflected in phrases 'I'm doing something a little different" and "I also feel that's how people look at me." I wanted to acknowledge her sense of difference in the ways she was special and unique. I 
was excited when I found the thumbprint and bike chain images because I felt that both could help represent aspects of Mira's experiences.

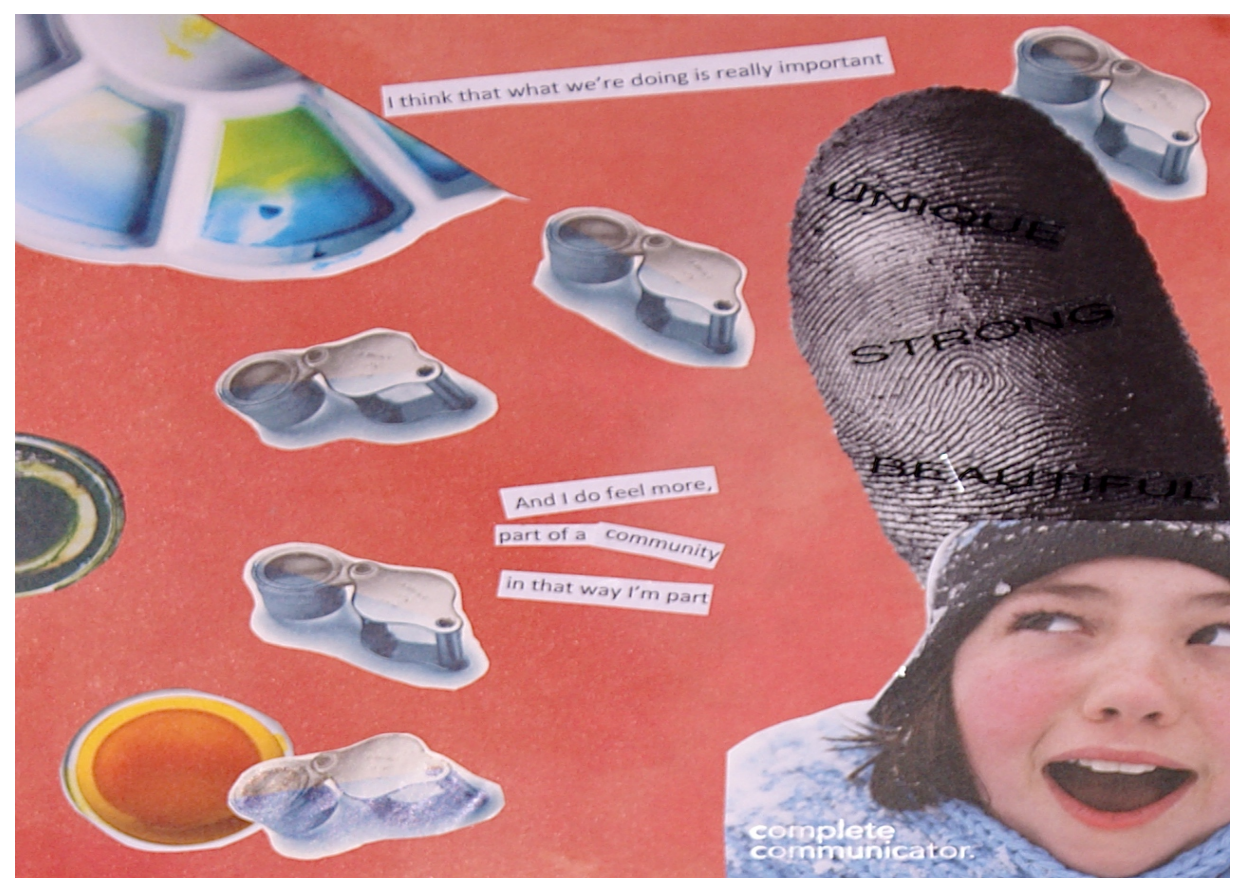

Figure 31. Ingrid's collage of Mira's professional development journey.

To honor Mira's experiences, I chose a piece of paper the same size as Mira's. I incorporated only graphic images, mirroring her experiences with the collage materials. Again as with each collage, I captured Mira's words on the collage itself. As I combed through the transcript, I looked for words to form a Haiku as Mira had created. The Haiku was one that expressed emotions. I saw this Haiku building from Mira words and forming a sentiment that I shared with her about early childhood education.

And I do feel more

Part of a community In that way I'm part 
With much of Mira's interview speaking to the isolation she felt, she also seemed to resolve the emotional disconnection that existed internally. Therefore, I attempted to communicate both a sense of looking in new directions and looking at life from a different angle in my collage. I chose the image of a girl looking up. Embossed on the image of the girl are the words "complete communicator." I spent some time deciding if I should leave those words on the image.

In the end, the words remained as a reminder of Mira's ability to communicate her experiences with depth and detail. I am struck by the strength that it takes to speak a powerful truth as Mira has done. Mira commented in reference to participating in this study, "It feels good to go beyond my house and beyond my small community and hopefully reach more people." As I looked at the image of the girl in the collage, I felt that the expression of the image captured the sense of humor that Mira brought to the interview too.

As well, emerging from the head of the girl is the image of a thumbprint (Figure 32). Each fingerprint is truly unique. The words that I associated with Mira's journey "unique," "strong," "beautiful" are captured on the thumbprint. Thumbprints always are unique with their ridges that form an intricate pattern. Harkening back, Mozére (2012) reminded us that the multiplicity of the early childhood educator's experience is defined by the complex and layered interactions. This notion was also manifest in Mira's experiences and was then characterized in the image of the thumbprint in my own collage of her experience. 


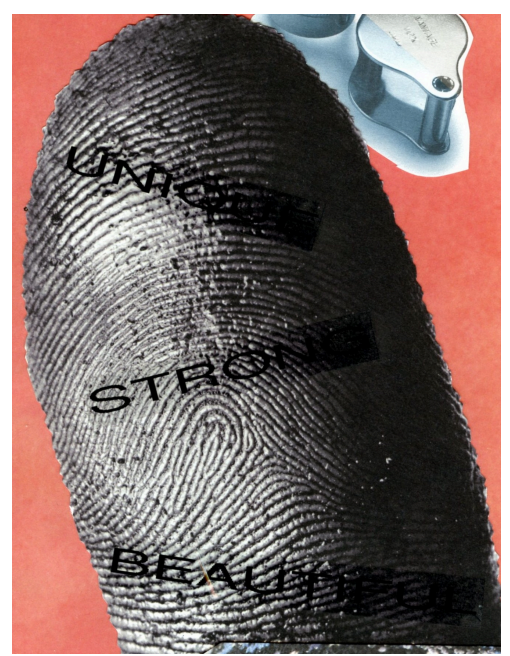

Figure 32. Thumbprint image.

Further, in looking at my reflections on Mira experiences, I wrote,

I worry so much that early childhood is so fractured and we're not working to come together and understand everybody. Also, I question that when these large state movements happen and huge systems are built there is so much of who we are and how we are and what we believe that gets left behind. And it's so important not to let that happen.

From this reflection, I represented the links in a chain on the collage as my expression of Mira's experience in the professional development system. Links in a chain for Mira and for the way that she represented all of the pieces of her professional self, separated for me for all of the fractures that I saw in Mira experiences (Figure 33). These links showed the fractures that can come together to form a chain, whole and strong. In reflecting on Mira's experiences and my links in a chain I wondered,

I can only think of how we might work to make the system better---Mira's story and tales of her journey and her experience in the professional development system changed her narrative of what it meant to be a professional and this was not to her benefit. 
As I read this, I am still moved at depth by her experience.

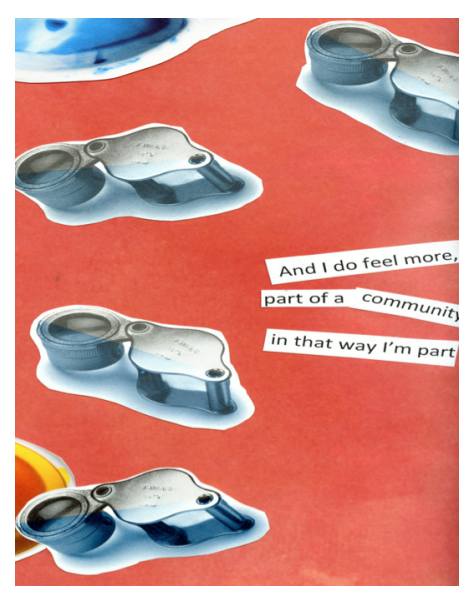

Figure 33. Links in a chain.

In looking back at my notes, I noticed a particularly important interaction between Mira and me at the end of her interview. Mira had asked why I was undertaking this particular project as part of my dissertation. I wrote my response after she left the room. My statements were written in my notes:

That's what I see of my work in this dissertation. It is to make a place for educators' voices because it's still your voice as practitioner and that's most important. And it's not that I'm framing it or trying to change the experience but trying to showcase the value and the strength of early childhood educator's voices. I have yet to hear anyone not speak incredibly eloquently about their practice and their profession, which just tells me how foolish we are in the way we go about normally gathering information and presenting it, because if we just listen to early childhood professionals, we can be incredibly humbled.

At the end of the day, such thoughts about Mira's interview stuck with me. In listening to participant's experiences through a hermeneutic phenomenological study such as I have done with Mira, I strengthen my resolve to understand how to support early childhood educators in navigating Oregon's professional development system, so that Mira's experiences are not the norm. 
As I closed out this section of interviews, collages, experiences and my reflective experiences of them, I found that a number of themes were emerging. The notes, thoughts, quotes, images, time, and so on took me toward a garden of themes and engendered a sense of van Manen's (1990) knots in the web of experiences. Those knots became the essential themes and give meaning and interpretation to the four participants' experiences and mine as researcher-participant that followed.

\section{Section Two: Essential Themes}

As I looked back on my notes, I saw a scribbled phrase I made in the margins after the final interview in which I wrote, "Each story has its own way of being." The comment became my touchstone as I embarked on bridling participants' unique experiences into essential themes. The use of participants' narratives, collage, and my interaction with these artifacts as researcher-participant became the foundation of my work on essential themes or knots. Using Dahlberg and Dahlberg's (2003) process of looping back, I visited and revisited the participants' experiences through constant comparison. Some strands tangled and revealed themselves as knots, while other strands, when examined closely, just unraveled into threads. The places where multiple experiences tangled and knotted led to my greatest discoveries. Embedded within the exploration of essential themes is the processed used to explain how themes tangled and knotted.

The collages and narratives illuminated an intertwined view of how participants connected personal and professional self together when discussing professional identity, professionalism, and professional engagement. The merger of personal and professional 
self was instrumental in understanding the primary research question. Therefore, the exploration of essential themes built from the two research sub-questions that explored the intertwining of personal and professional self as a way to clarify the study's primary research question. Together, these three essential themes provided insight into how participants navigate and engage as professionals as part of their experiences in Oregon's professional development system.

\section{Personal and Professional Self: Intertwining Personal Experience and Professional Identity as a way to Represent Experiences}

Throughout the interview Carolina, Linda, Nora, and Mira used descriptive, informal language to describe their experiences. In the first essential theme, the use of language offered insights into identity formation of early childhood educators (Curtis \& Carter, 2000). Day et al. (2006) explained that the process of creating a sense of professional self is further compounded by the enmeshed nature of early childhood educators' personal and professional self-perception as caring, nurturing individuals. Further, the use of language exposes the influences of culture, preferences, biases, and blind spots (Curtis \& Carter, 2000).

Part of the renewal stage is the act of refining who one is as an early childhood educator (Katz, 1995). Beliefs and values about early childhood education become the compass in which early childhood educators compare and contrast their classroom experiences to determine if there is an alignment of beliefs and values between themselves and the programs in which they work. The essential themes, therefore, started 
with the research sub-question, What have been the experiences of early childhood educators in identifying themselves as early childhood education professionals?"

Carolina, Linda, Nora, and Mira all clearly identified themselves as professionals through the imagery they selected for their collages and in their interviews. The initial interview questions were designed to introduce and acknowledge the collage experience, and it became a rich narrative process for participants to identify themselves as professionals with deep personal convictions. As a way to start the interviews, the questions (How was the experience of collage for you? and Was there anything that surprised you?) created an opening to connect professional identity and its emergence from personal experiences. The connection of personal and professional emerged through a series of actions that included clarifying concepts that led to the final collage. Each participant referred to collage as an act of representing self on paper. The participants worked through the collage process as a way to clarify their thoughts. Both the images selected and the layout of their collages clearly wove their personal experience to their professional practice (Table 1).

Table 1 offers examples from participants' interviews of personal experience and profession identity. It speaks to participants gathering of their personal experiences and expressing them as professional beliefs. Table 1 illustrates the personal nature of professional identity. Finally, as researcher-participant, I highlight my own reflections on participants' intertwine of personal and professional self.

Table 1

Making Meaning of Professional Identity and Personal Experiences 


\begin{tabular}{|c|c|c|c|}
\hline Participant & Personal Experience & Professional Identity & $\begin{array}{l}\text { Researcher-Participant } \\
\text { Bridling the Experience }\end{array}$ \\
\hline Carolina & $\begin{array}{l}\text { - "Opportunity to slow } \\
\text { down" } \\
\text { - "You have a story that } \\
\text { you need to tell" } \\
\text { - "A chance to stop for a } \\
\text { minute and think about } \\
\text { your story and think about } \\
\text { pieces of it" }\end{array}$ & $\begin{array}{l}\text { - "I feel like the people } \\
\text { who are making the } \\
\text { decisions aren't in the } \\
\text { arena" } \\
\text { - "In education I have } \\
\text { learned and believe that } \\
\text { there are many issues of all } \\
\text { sorts" } \\
\text { - I just couldn't wrap my } \\
\text { brain around because I } \\
\text { thought it was more } \\
\text { important to be with the } \\
\text { children than filling out } \\
\text { like carbon copies of a } \\
\text { million things...." }\end{array}$ & $\begin{array}{l}\text { - "I thought deeply about } \\
\text { picturing my experiences } \\
\text { with Carolina's } \\
\text { professional development } \\
\text { journey" } \\
\text { - "I purposefully left } \\
\text { space after this statement } \\
\text { to indicate that space } \\
\text { needs to be carefully } \\
\text { guarded to allow time to } \\
\text { reflect upon our } \\
\text { professional practice and } \\
\text { just be" }\end{array}$ \\
\hline Linda & $\begin{array}{l}\text { - "I had a lot of thinking to } \\
\text { get my ideas out" } \\
\text { - "In my head, it's my } \\
\text { path" } \\
\text { - "I was thinking about } \\
\text { that I was thinking, that's } \\
\text { kind of my discovery part" }\end{array}$ & $\begin{array}{l}\text { - "When one door closed, } \\
\text { the elementary school, } \\
\text { another one opened and } \\
\text { that's when I started to } \\
\text { maneuver and manipulate" } \\
\text { - "making it okay for } \\
\text { children" } \\
\text { - "I was trying to feel my } \\
\text { way out in this early } \\
\text { childhood education and } \\
\text { figuring out what licensing } \\
\text { is" }\end{array}$ & $\begin{array}{l}\text { - "For me, the strips of } \\
\text { paper represented the } \\
\text { barriers Linda spoke of in } \\
\text { her journey" } \\
\text { - "In listening to her } \\
\text { professional development } \\
\text { journey, there were times } \\
\text { during her retelling that } \\
\text { an almost innocent view } \\
\text { of the world had me } \\
\text { concerned about the dark } \\
\text { times overwhelming her" }\end{array}$ \\
\hline Nora & $\begin{array}{l}\text { - "I have been } \\
\text { brainstorming my ideas" } \\
\text { - "It's good to have a } \\
\text { roadmap of what you think } \\
\text { you want to do" } \\
\text { - "It was interesting } \\
\text { thinking about how I } \\
\text { would like to organize my } \\
\text { journey" }\end{array}$ & $\begin{array}{l}\text { - "I feel like my education } \\
\text { has helped me develop } \\
\text { those ideas but all of my } \\
\text { beliefs about education } \\
\text { came from experience at } \\
\text { Orange CDC and seeing } \\
\text { people interact" } \\
\text { - "I feel like a lot of } \\
\text { people who don't know } \\
\text { about education" }\end{array}$ & $\begin{array}{l}\text { - "I wondered if I could } \\
\text { capture Nora's light spirit } \\
\text { by reflecting back on her } \\
\text { words" } \\
\text { - "I saw that my collage } \\
\text { seemed to echo Nora's, } \\
\text { starting with greater } \\
\text { detail and trailing off into } \\
\text { greater open space" }\end{array}$ \\
\hline Mira & $\begin{array}{l}\text { - "Thinking about what I } \\
\text { had to say" } \\
\text { - "It comes from inside } \\
\text { you" } \\
\text { - "It's more about my } \\
\text { story" }\end{array}$ & $\begin{array}{l}\text { - "That felt really, really } \\
\text { isolating because I thought, } \\
\text { wow I worked so hard to } \\
\text { get this education and I'm } \\
\text { being told that it doesn't } \\
\text { mean anything in this [the } \\
\text { Oregon Registry" }\end{array}$ & $\begin{array}{l}\text { - "The words I associate } \\
\text { with Mira, 'unique,' } \\
\text { 'strong,' and 'beautiful'., } \\
\text { - "I am struck by the } \\
\text { strength that it takes to } \\
\text { speak a powerful truth as } \\
\text { Mira has done" }\end{array}$ \\
\hline
\end{tabular}

The act of organizing the telling of the professional development journey took many forms as identified in Table 1 . Toward the end of the collage process, I checked on 
each participant and each gave me permission to take some pictures of their work in completing their collages. These pictures of the collage layout and aftereffects became the foundation highlighting this theme's intertwining between personal experience and professional identity. My documentation of each participant's interaction with the collage during the interview process led me to the essential theme. Below are four specific examples of how each participant interview, supported by collage, expressed the connection between their personal experience and professional identity.

Carolina explained that she used a personal/professional journal as a tool to frame her practice. She brought her journal to the interview as a tool to reflect on her professional development journey. As she conceptualized her collage, pulled out her journal and drew the following sketch that guided her collage design (Figure 34).

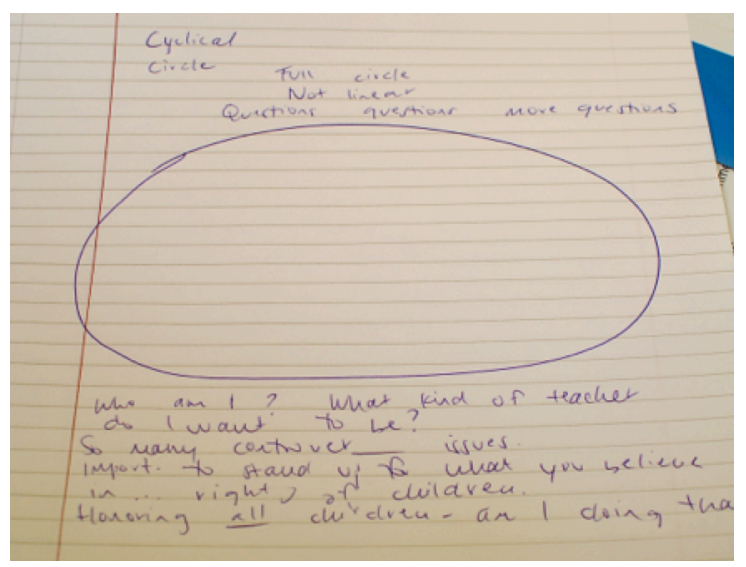

Figure 34. Carolina's sketch of her collage

When I looked closely at the collage, I could see Carolina's questions and reflections to herself.

- Who am I?

- What kind of teacher do I want to be? 
- So many counter [blank] issues?

- Important to stand for what you believe in... rights of children

- Honoring all children - am I doing that?

While Carolina did not outline her questions in her interview, their influence on her collage was apparent because she expanded on their meaning in her life through some of the themes of her interview. Carolina specifically represented the big idea of her questions through the quote from the book Daring Greatly (Brown, 2012). She indicated that her quote represented how she saw herself as an advocate for children everyday (Figure 35). The questions connected clearly illustrated how Carolina connected her personal and professional self through the act of internal monologues. Throughout her interview she connected her words to her collage images demonstrating the consistency between her internal beliefs and her spoken viewpoint.

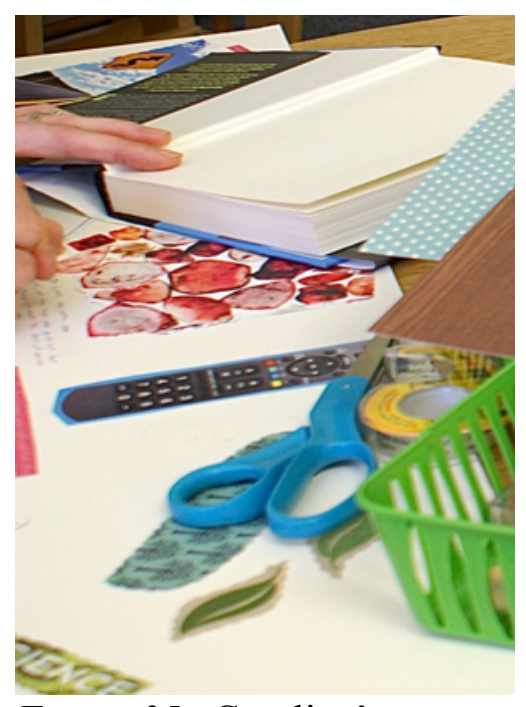

Figure 35. Carolina's quote.

Linda's demonstrated the alignment of her personal and professional self by revisiting and editing her collage. After developing the original collage, she returned to her images of bridges on a river and removed the bridges. The original placement of the 
bridges is indicated by the bars' place on the image (Figure 36). This shift from bridges over the river being Linda's journey to the river becoming her journey represented a significant shift in the way she clarified her experiences and then presented them in the interview. The act of adding and removing items to the collage seemed to echo Linda's sentiment that "I don't know if we really even call it my career, my passion, so, it doesn't really have an end to it because it's also my life so I don't really know where one begins and one ends." The precision in which Linda worked indicated the importance of representing her experiences accurately, thus highlighted the connection between her personal vision of her professional experiences.

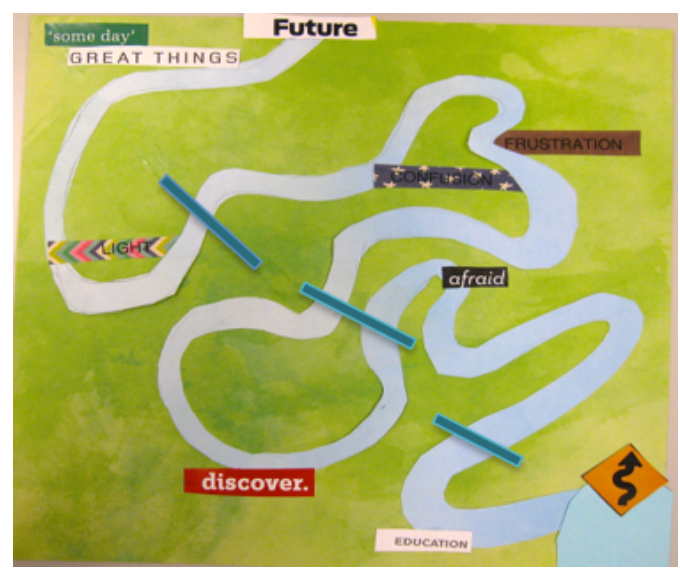

Figure 36. Linda's former bridge.

Nora made a sketch of her professional development journey (Figure 37). Nora explained that the materials and concept of who she was as a professional belonged together. "I did make a sketch, I had to, because otherwise I was going to put things down and be, oh wait, pull this up, that wasn't supposed to go there." The act of mapping out the process became a decision about organizing the journey around "specific experiences." As Nora spoke in her interviews, it became evident that her positive and 
negative associations with her professional experiences were reflected by the colors she selected. When Nora recognized how the colors she selected in the collage were about her feeling about the program she shared, “the color surprised me because I really didn't think about that until I was making it." Through the use of color, Nora illustrated her connection between her personal beliefs and professional self as she zoned in on three key areas that emotionally impacted her experiences as an early childhood educator.

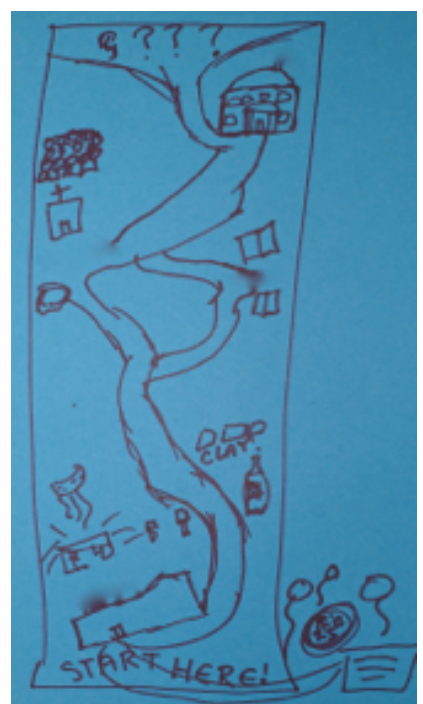

Figure 37. Nora's sketch.

Moreover, Mira saw the collage as a source of tension between her personal and professional self as represented in images. The use of images as themes became a way for Mira to create a concrete connection between how she felt and what she did as a professional. As Mira expressed how her thinking shifted, it opened up a place for her to align her vision for her professional journey. "It's more about my story. So once I felt like it was my story and that I was telling a story." Mira's themes all spoke to her emotional life as an early childhood educator. Her images represented her sense of being 
separate and isolated at many points in her professional journey (Figure 38). What struck me about Mira's collage was its use of images. In contrast to the other collages, where open space set off key experiences, Mira's collage showed many images. The multiplicity of images represented the experiences that Mira did not want to forget to value. Mira's professional experiences deeply affected how she represented her professional identity.

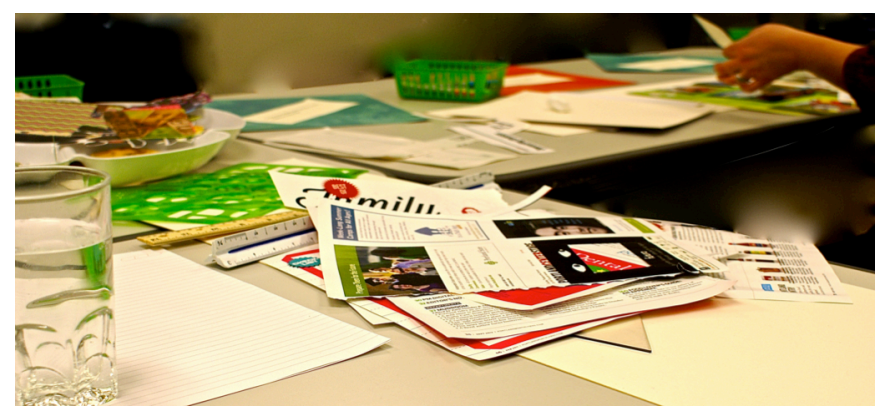

Figure 38. The aftermath of Mira's collage.

This theme taught me that for Carolina, Linda, Nora, and Mira, their personal experience and professional identity were intertwined. Personal experiences shaped professional identity in a way that made it difficult to separate personal from professional self. Revealing the intertwined nature of personal and professional identity provided a context to discover why personal experience intertwined and knotted in their professional identity formation.

At the beginning of the interviews, each participant identified that the act of collage was deeply personal highlighting the importance of the images and placement of materials during their interview process. The collage was the physical manifestation of participants' professional development journey. As a prompt the collage provided a 
place to make concrete the abstract experiences and emotions of personal experience and professional identity. The tangible output of the collage as part of the interview also provided an opportunity for me, as researcher-participant, to anchor my meaning making of their experiences in the interview. As I reflected on the interviews, anchored by collage, I was able to connect through the interview the importance of personal experiences in professional identity formation.

Throughout the interview participants' used a series of "I" or personal statements followed by a description of the feeling of representing their professional development journey. Then each participant selected images that represented an emotional connection to who they were as early childhood educators. The selection of images was a deliberate process that required careful place for accurate representation of participant as early childhood educator.

In reflecting on participants' professional journeys, Carolina, Linda, Nora, and Mira specifically described their experiences as an act of emerging from their sense of self. Finally each participant acknowledged the emotionality of their work by expressing their professional journey in emotional language. The use of collage connected the participants' professional journey to the emotionality of their work as early childhood educators, thus illuminating the strong connections between professional identity and personal experience.

\section{Curves Ahead: Maneuvering Rivers, Roads, and Paths}

As identified in the second essential theme, professional engagement encompasses participation in all aspects of professional practice, including but not limited to 
participation in an early learning community, professional development activities, and navigation of professional development systems (Katz, 1996, 2008). Depending on the length of experience in the renewal stage of professional development, they either saw themselves as growing or grounded in their practice. Each participant connected their professional practice to professional engagement in different ways. First, participants chronicled their journey from a new early childhood educator to the current stage of renewal. Second, participants identified their classroom community. Third, participants connected their practice to their connection with the early childhood field. The representation of rivers, roads, and paths came to be a way to provide insight into the second research sub-question, How do early childhood educators identify their experiences of professional engagement?

Carolina, Linda, Nora, and Mira described their experiences through collage and in their words as rivers, roads, and paths but also referred to the cyclical or circular nature of professional engagement. In reflecting on how each participant presented their professional journey, the essential theme of Curves Ahead: Maneuvering Rivers, Roads and Paths emerged. As I looped back for constant comparison of the data, I was struck by the frequency of images of rivers, roads or paths. When I was reviewing all images and transcripts, I had a jolt of surprise to see how each participant chose to represent their professional development journey with variations of the same photo image or its interpretation (Figure 39). 


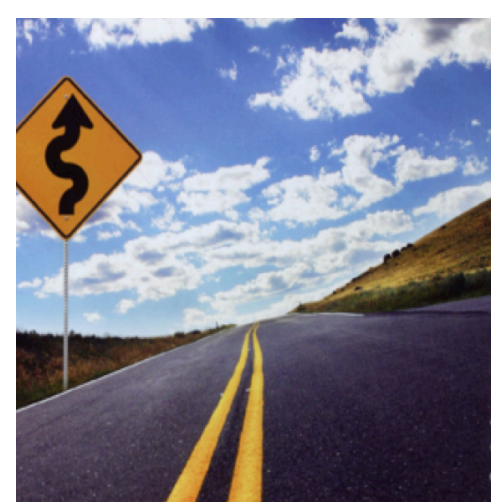

Figure 39. Original road image from Sims (2005). Reprinted with permission.

I wondered if the images of the road that I had selected had created some type of unconscious articulation of the journey as a road. So I carefully went back through the materials to see what other items might exist in multiples or if the images of the roads were the only one. I discovered that there were dozens of multiple images, such as constellations, beaches, flowers, trees, and people. None of those were touched. Curiously, I wondered what it was about the image or concept of the road and the "curves ahead" sign that created such resonance with Carolina, Linda, Nora and Mira. What came to fascinate me were the concepts of curves ahead that Carolina, Linda, Nora, and Mira saw as an essential image to show their growth as an early childhood educator (Figure 40). 

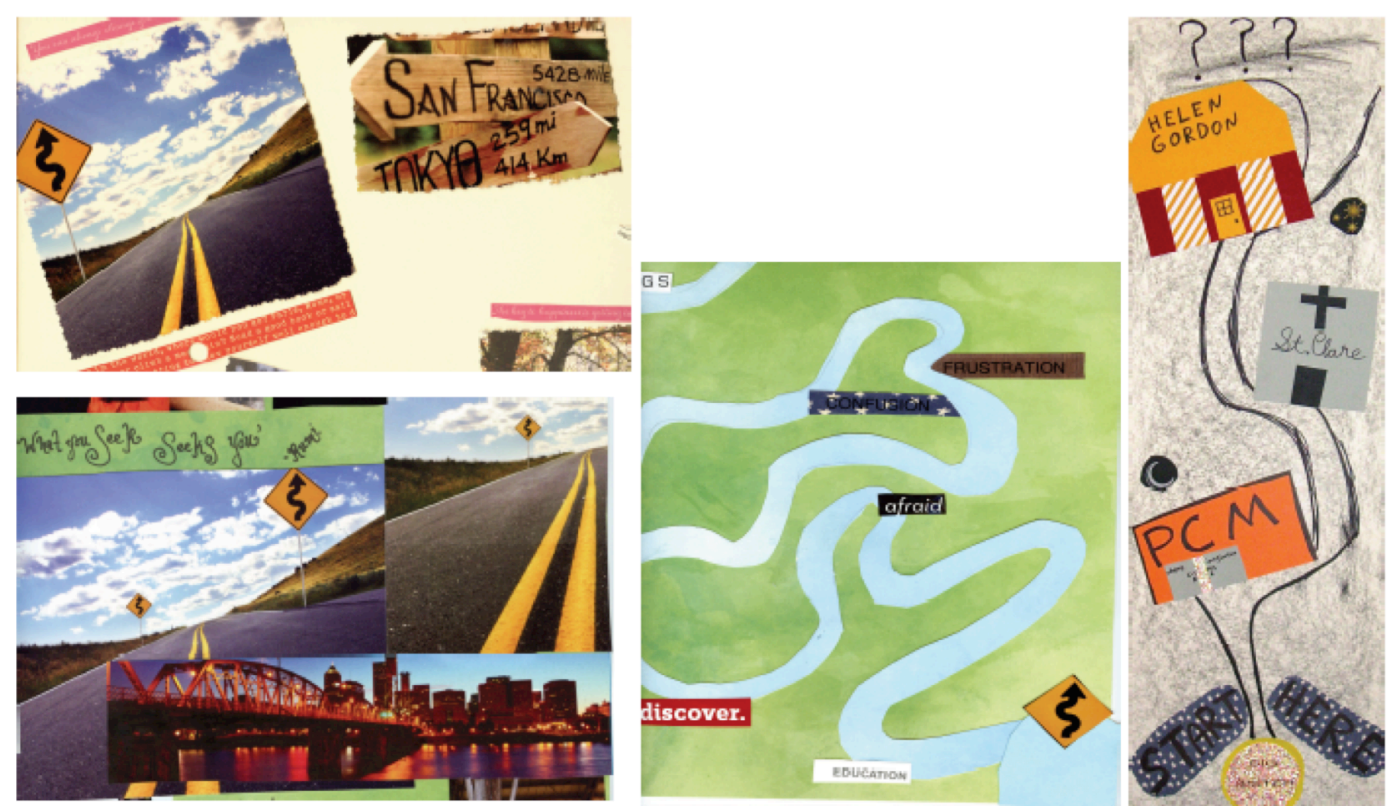

Figure 40. Participants' collage images of roads, rivers, and pathways.

Within the theme three strands emerged. Each strand highlighted participants' professional progression. First strand was "You just don't know what is happening yet": Becoming engaged in the early childhood profession through rivers, roads, and path. The second strand focused on "Learning in the classroom that I want to be in": defining professional engagement in the classroom. The third and final strand connected participants' to communities of practice with "It's a good place to build bridges": Defining professional engagement in the early childhood education community. Together these themes tangled to form the essential theme.

The first strand in the theme that emerged was focused on the concept of "You just don't know what is happening yet" : Becoming engaged in the early childhood profession through rivers, roads, and paths. The evolution of participants' journey illuminates how these participants built their sense of professionalism and their sense of 
professional engagement through their journey. In professional engagement, Carolina, Linda, Nora, and Mira presented their experiences as emerging from uncertainty they faced as new early childhood educators.

Carolina, as a new teacher, used an image of the open road to represent her sense of being naïve when she first started working in early childhood education. "I feel you're so naïve and you don't really know. Not that you don't know and there's awful things coming, but [rather] you just don't know yet what's happening." This is seen as Carolina went on to represent the concept not knowing in two specific types of professional engagement experiences. First, not knowing can represent discovery, "the sweet part" of discovering who you are. Second, not knowing can also represent uncertainty. Carolina points out that

The hard part is that you're asked to go out into the world and be this person and say what your teaching philosophy is. But, I feel you don't even have one yet because you're... you don't even know what side of the whatever you stand.

For not knowing to give way to knowing, an inner clarity must emerge. Inner clarity emerged as participants' started to articulate their professional beliefs. The transformation from not knowing to knowing appeared to be a bridge for participants to move from Katz's (1995) stage of survival to renewal.

Carolina came to identify experience as a way to reconcile her uncertainty. The transition of theory into long term sustained practice played a critical role in Carolina's development. The layering of experiences provided Carolina a way to start to compare and contrast her beliefs to the practices in the environment in which she worked. It surprised Carolina that a personal teaching philosophy would not be aligned with the 
program where she worked. Carolina went on to share that being new to the profession had its limitations. The act of not agreeing with a philosophy, "but not really feeling confident enough to disagree yet" represented a critical stage of self-awareness. Reflecting back on that time, Caroline came to understand the importance of finding "your voice" for children. Carolina felt that she needed additional help to clarify her

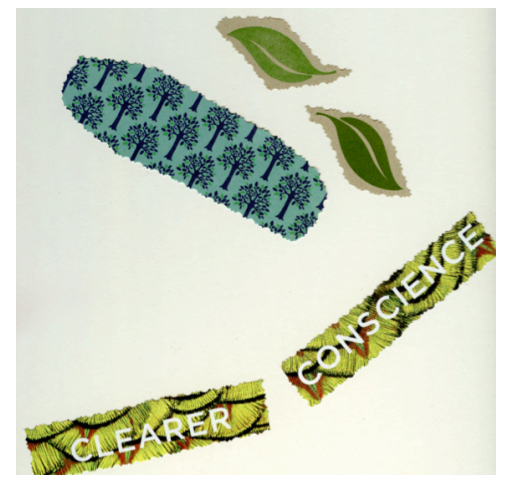

Figure 41. Carolina's educational experience.

personal philosophy. Carolina's mentioned how her Master's program "helped me realize what I believe in and what I want for children and the rights that I think they have." This was represented for Carolina in the green leaves and the words "clear conscience" that summarized her transition from not knowing to knowing (Figure 41). The sense of needing to find a voice was a theme of all participants as they struggled to develop a sense of how they engaged as professionals in their practice beyond the classroom.

Linda started her interview of her professional development journey by equating her professional development journey to her life as the "river of my career." Linda continued as she identified the process in trying to frame her experience. Even knowing 
from a young age that education was her path, Linda expressed her uncertainty starting out in her profession after completing school. Linda divided her not knowing into three distinct emotions, "afraid," "confused," and "frustrated" (Figure 42). When speaking of being afraid, Linda revealed, "So there's education and then in each bend [pointing to the bends in the river between the words "education" and "afraid" on her collage], there was going to represent some kind of change in the flow." While Linda's early experiences in education were traumatic, as her relationship with school evolved, so did its role in her life. Leaving the comfort of school then led to a sense of not knowing what was next. As Linda moved into finding work, there was a point of "discovery" of early childhood education.

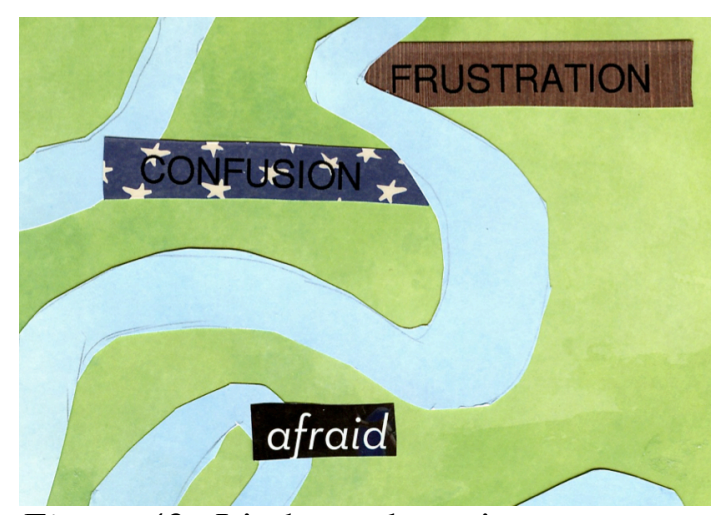

Figure 42. Linda not knowing.

When Linda entered the early childhood education field, she found that her challenges did not end. Her sense of "confusion" and "frustration" came from a sense of a lack of preparation for the early childhood classroom. It was only afterwards that Linda reconciled how she could find her place in the early childhood field. Her statement, 
"That's when I started to maneuver and manipulate," highlighted the transition to professional engagement beyond the classroom.

Nora looped the metaphor of the road to the beginning and end of her interview. The anchor for Nora's professional experiences was being a big sister. Nora's reference to the responsibility of caring for her sister was one of three places that she expressed uncertainty in in professional development journey. The first instance was becoming responsible for her little sister, and the sense of responsibility that she felt in caring for her sibling. While Nora did not specifically say that the years between 10 and 16 were a period of not knowing, she referenced her feelings when describing her first job: "I felt at that time in my life I didn't really feel like I had a home anywhere and it felt like the Orange CDC was my home." The experience of coming home to a job indicated the precariousness of Nora's physical home life. Nora found that professional education came from experiences and professional development in the classroom, "I found everything I know and believe about early childhood from there.” Finally, Nora revisited the concept of not knowing again as she moved into the next beginning of her life by graduating college. As Nora shared, she pointed to the images of the question marks (Figure 43). She shared, "maybe it'll all come together as something." For some participants, not knowing represented a place of uncertainty. I could see Nora perceived not knowing as more of an adventure than a concern. 


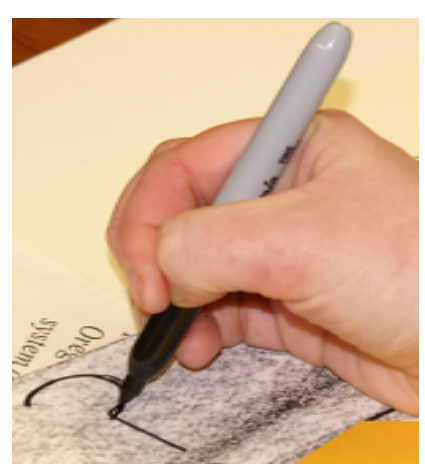

Figure 43. Nora writing.

Mira's representation of roads was presented in a different context from the other participants. Her representation of roads emerged from the two different roads that she presented on her collage. Multiple times during the interview, she would revisit the dual roads images, and use them to empathize aspects of her journey (Figure 44). Mira identified the dual roads image as a way to illustrate her sense of her unique journey in early childhood education. They were "multi-leveled" and "twisted." The dual roads represented, 1) stands of human development as a road, 2) the early childhood road and the Montessori road in general, and 3) "I have my [personal] road and everybody else has their own road, too." Mira's use of a parallel life was often used in the interview as a comparison between herself and other in their professional development journey.

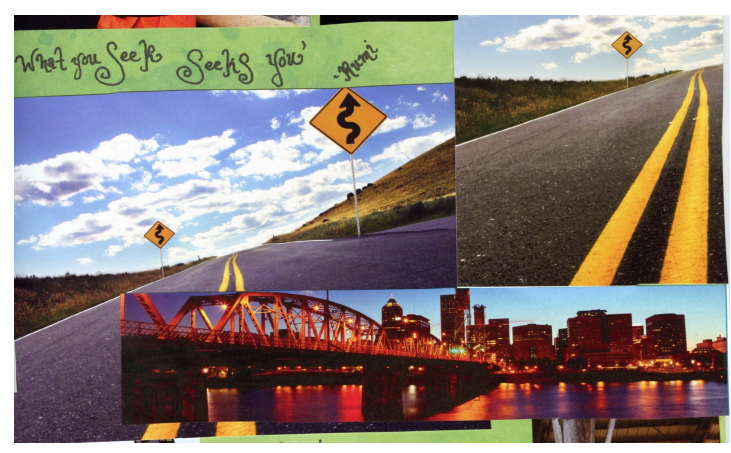

Figure 44. Dual roads and bridges. 
Mira identified her first professional experience as a nanny. In fact, Mira identified that she was a little lost on what to do next with her life when the opportunity to be a nanny presented itself. Mira continued revealing that once she shared working, her perceptions of what it took to work with children were immediately challenged. "I had no idea how to care for those children." Mira referenced the "five-page list of what to do" and reading it "200 times." She continued, sharing that she carried around those instructions like a safety blanket. It was at that time that Mira started reading books about early childhood seeking to understand how to work with the children in her care. "These children really changed my life." From that experience, came a sense of purpose, "I found early childhood education is what I was looking for...something that I didn't really realize. That actually is how I found Montessori.” It was Montessori that became Mira's anchor for early childhood education.

Carolina, Linda, Nora, and Mira characterized a sense of not knowing as they started their early childhood journey as feelings of uncertainty. Anderson-Nathe (2008a) stated that not knowing creates a state of emotionally vulnerable. Until participants were able to resolve uncertainty in their professional development journey, they were unable to engage in professional practices outside their own selves. As participants gained experience, their sense of professional engagement changed from a state of survival in the classroom to one where they could reflect on how they defined themselves as early childhood educators (Katz, 1995).

The second strand of rivers, roads, and pathways focused on "Learning in the classroom that I want to be in": defining professional engagement in the classroom 
connected professional practice to personal pedagogy. As participants emerged from this sense of not knowing, their acts of professional engagement expanded beyond their own internal meaning making and started to expand into the classroom.

Those who choose the work, a stance of choice, to serve the greater good, have a highly personalized construct of what it meant to be an early childhood professional, grounded in the feelings and attitudes about the job as part of their professional identity (Moloney, 2010, p. 168).

Carolina, Linda, Nora, and Mira explored the close connection between professional ethics and professional identity and its impact on professional engagement through their work in early childhood programs. When a program aligned with professional ethics and professional identity, the four participants expressed high levels of professional engagement. When programs they worked in clashed with professional ethics and professional identity, they felt disconnected. The lack of engagement was so strong that participants would rather leave the program than continue working in a program that did not align with their professional identity.

While working in Head Start, Carolina shared, "There's a system that doesn't agree with it [your philosophy about children], and every day you're sort of fighting against that system, that can be really hard." Nora also verified this theme in her work at Gray Block CDC. "It's not that they had bad intentions. They definitely cared about those kids and really loved them. But they couldn't address them on individual basis." Nora went on to say that she could not continue to work in an environment that failed to respect children. Linda expressed the need to be in an environment that matched her beliefs, moving from elementary education to early childhood. "I don't know why we 
give them story problems when we could give them real problems - mathematical problems, or political even, things that are really happening." Mira represented her concept of being "a little different" from others in her collage (Figure 45). The sense of being different from others led Mira to leave her program.

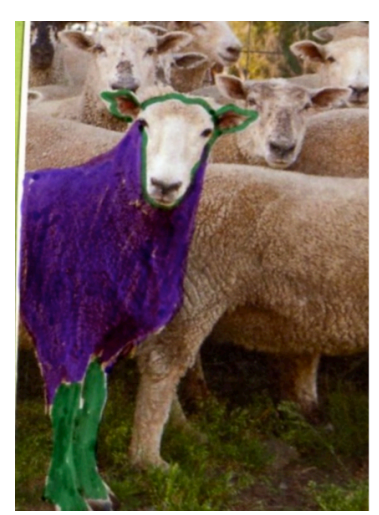

Figure 45. Mira's concept of professional identify.

Leaving positions was combined with a sense of loss, isolation, or frustration. Participants mentioned how their position failed to address the fundamental needs of children. Carolina explained how it started for her in her federally funded program. "I started to learn that there was a bigger system that I was a part of and that I didn't agree with a lot of the aspects that I was being asked to do." Mira was confounded by the absence of what she identified as basic developmentally appropriate practices, "just like why wouldn't you have things down for the children to play with?" Nora's example of “the director didn't really have a lot of experience either in any sort of childhood education" expressed her values about the standards that needed to be present in her work environment. The lack of respect for a child that was present when structured programs required whole group compliance rather than individualized support for children was a 
specific example. Linda spoke to K-12 schools failing to meet children's needs through large class sizes, "I do think that small learning is the best way to go. You can really check in with somebody." Nora stated, "How jarring it was to suddenly be in this place where children weren't as respected as like they were in my previous job.” Mira shared, "I went to get a job and guess who you get to work with if you don't have any education or experience? Babies. The smallest children, that was shocking to me." The concern for the fundamental rights of children in all four experiences was the catalyst for leaving former positions. These experiences represented turning points for the participants.

After facing experiences that clashed with a sense of professional identity - of who they were in the lives of young children-Carolina, Linda, Nora, and Mira all sought situations that would reinforce their professional values. The catalyst for change took many forms. Mira shared that she started an infant toddler program after her previous experiences with babies. "I could see that we needed something a little bit better for the youngest child." Nora sought out a program that aligned with her values and petitioned for a job there. "I said 'hello,' asking 'do you need anyone to work here? I would love to work here." Linda saw the work of the classroom as being to make sure every child's needs were met. Linda, who described her struggles in forming her professional identity, said that alignment of professional practice provided a chance to feel confident as a leader of children. "I'm learning in the classroom that I want to be in. I've been in various types of classrooms, but the one that I want to be in I can totally see that it's doable." Carolina proclaimed, "I thought it was more important to be with the children than filling out like carbon copies of a million things," and pointed to the image of the 
files on her collage. Carolina summed up the effect of working in a place that honors one's professional ethics and practice. "Now I feel like I'm in a place that supports what I believe in and that I think really makes the way you feel in a work environment significantly different."

Carolina, Linda, Nora, and Mira each connected the above concepts of their professional identities, grounded in their professional practice clearly throughout their interviews. When I read through the transcripts, it was clear participants' described their professional practices which grew into professional engagement. For each of the four, they formed the foundation of their perceptions of their work with children. Linda summed it up:

Well this is the light toward the future. I'm currently happy where I am. There's more to come. I guess the light is that good things are happening and not that any of these things [pointing to twist and turns in the river] were necessarily bad, but I don't know. I have more of an understanding of how things work, the system. Where I am there's no end [pointing to the river], but it's more, we'll go with light-hearted feeling. It's just we're on a good part of the river right now.

Illuminating how the participants in their renewal stage of professional development identified professional engagement has significant implications for both early childhood educator retention and integration into Oregon's professional development system. The connection between professional values and acts of engagement offered insights into participants' navigation of their professional development journey. The impacts of these actions are conveyed in Chapter 5 .

The third strand emerged as "It's a good place to build bridges": Defining professional engagement in the early childhood education community. As the four 
participants found work in programs that aligned with their professional ethics, they expanded their professional engagement beyond their classrooms or schools and into the greater early childhood community. Carolina, Linda, Nora, and Mira each illuminated their frame of reference about professional practice as grounded in their professional identity clearly throughout their interviews. When I read through the transcripts, participants' professional engagement stances tangled and knotted as themes because their professional practices emerged from connections between their self images as educators and their experiences with children. Carolina saw her role as one to "fight for the rights of children, every day you advocate in your classroom for children." Linda empathized the word "light" on her collage. Further, Linda summed up this belief as "every child deserves" a word she cut out to represent educational opportunities. Nora looked at the moon and stars on collage as a way to represent her role in "making space" for children's learning. She spoke to the importance of honoring children by observing and valuing their capabilities. She also believed in the importance of documentation, as a way to make children visible, thus debunking the myths that work with children is without meaning. Mira believed her purpose was to support citizenship through building peace, "because I really feel like peace is possible and that it's going to happen through them."

Beyond the work with children, Carolina, Linda, Nora, and Mira all mentioned the role of community participation as an act of professional engagement. The early childhood educators who participated in the study defined community as the classroom, the program community, or the larger community of early childhood professionals in 
Portland. Carolina shared that her program had control of their shared professional practice. Carolina also identified that a sense of community came from having control over decisions in the classroom and in the program. Nora also spoke to the importance of shared values as part of professional engagement in a community,

I'm very passionate about these things. I really want to be in this realm again. That's why I started working at Yellow Roof CDC and really felt at home again, because these people have the same core beliefs about children and learning and environment that I do and really respect all these things.

Mira represented the concept of community through a visual image (Figure 46).

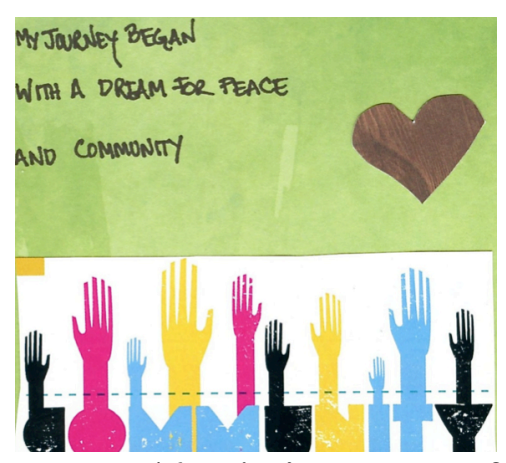

Figure 46. Mira's concept of community.

Linda concluded with how she wished the community would come together around education through small communities of practice or "little schools." Linda's statement was a clear indication that even without resources to enact change each participant was clear on what would make a better environment for children.

Engagement in an early childhood community was seen by the four educators as a way to connect and reaffirm professional practice reinforcing professional engagement.

In this theme, I learned that professional engagement takes many forms including what Carolina, Linda, Nora, and Mira identified as their own professionalism as 
represented in their metaphor of rivers, roads, and paths as a way to define their engagement in the classroom and the larger early childhood education community.

Professional engagement broadened to include participants' beliefs about professionalism that served as their moral compass when confronted with situations that challenged their professional identity or sense of professionalism and, therefore, affected their professional engagement.

Carolina, Linda, Nora, and Mira explored their sense of engagement in their past, present, and future work as early childhood professionals. The use of informal language only served to highlight their personal and professional values as connected to their professional identity. Mira highlights this notion,

So it's important to give them [early childhood educators] a voice. So often I'm in my own little bubble, but even thinking about public school teachers or Head Start teachers or where [is the education] community? Where's our collective voice because we all do this for the future.

The foundation for participants' interactions and perceptions of Oregon's professional development system is illustrated by their intertwine of personal and professional self.

The Journey and the System are Asynchronous: "You Guys Figure That Out, Good Luck"

Insight into the participants' intertwining of personal and professional self and acts of professional engagement as maneuvering the journey contextualized Carolina, Linda, Nora, and Mira's experiences within Oregon's professional development system. Building on the two previous essential themes led to the exploration of the primary research question: In the renewal stage of their professional practice, how do early 
childhood educators describe their experiences in navigating Oregon's professional development system? The participants all spoke extensively about their experiences as early childhood educators. They described their experiences with descriptive, informal language, which connected their emotions or feeling with events in their lives. The use of informal language contrasted with the discourse of institutional definitions. While their experiences in the professional development system were uniquely their own, there were knots in the web of their experiences that emerged as stands in this essential theme. The two strands were Being Separate from the Professional Development System and Navigating the Oregon Registry Steps. Each participant shared feelings about the intersection of Oregon's professional development system---as a whole as well as the Oregon Registry---with their lives. However, they did not seem to relate the system to their past, present, or future work. This was in stark contrast to the intertwining of their personal and professional selves that emerged from previous themes.

As a strand, participants identified Being Separate from the Professional Development System. The debate over the value of experience as a measure of competency is well documented in the literature (Moloney, 2010; Osgood, 2006; Torquati et al., 2007). The lack of a place to acknowledge the importance and value of participants' experiences within Oregon's professional development system is a potential disconnect. The concept that early childhood education is a life orientation, acknowledged as a skill and an art, provided insight into possible places of tension between participants and Oregon's professional development system (Hsu, 2008). Hsu reminds us that the experience of teaching must be lived and that there is danger in 
interpreting what early childhood means without experience. Defining early childhood educators becomes a slippery slope when these definitions are imposed by regulatory agencies (Bown \& Sumsion, 2007; Osgood, 2012). Comparing institutional discourse with Carolina, Linda, Nora, and Mira's experiences as laid out in the two previous essential themes led to the concept of asynchronicity between the professional development system's measurement of professional growth and the participants' professional journeys.

At a system level, participants identified the federal initiative, "No Child Left Behind," and several state initiatives, "the Early Learning Council," "Office of Child Care Licensing," and "the Oregon Registry Steps." These initiatives were explored at length in my review of the literature (Kagan \& Kauerz, 2012; LeMoine, 2008; NAEYC, 2012b; NCCIC, 2009). When referring back to the prompt "Think about your interactions with Oregon's professional development system," Carolina's sentiments reflected the participants' shared experiences. She explained that there were "layers of complexity for issues in education that some are really easy to see through and some are so foggy that you cannot see through them and you may never see through them.” All four participants believed there was a gap between the early childhood education community and the individuals at the state and federal level who made policy decisions.

The professional development system components were specifically identified as being different from participants' own lives. This is evident when Carolina said,

I think if a lot of people in that role had to do a lot of the things they're asking us to do they would think twice about the way they're asking us to do it. I always thought that when you're making a really big decision... you should live it. 
Carolina also referred to the feelings of an "us and them" divide that leads to a separation between policy makers and those who must live with their decisions. Carolina connected her beliefs to her image of policy makers. "They're on the sidelines, not waking up at night. And they don't really know what it's like to be in the arena." Being in the arena is about the direct work with children, in Carolina's eyes. She spoke of acting on what one believed and how actions should be tied to direct experience as early childhood educators.

When Linda spoke of her experiences, she also referred to the separation between systems and individuals. She specifically addressed how educational preparation and how the education system left her with a sense of separation. Linda also spoke of a sense that even the focus on elementary education as a system leaves children behind. She believed that there should be a sense of intimacy and connection in education. This is particularly important to Linda because, "People don't get lost in the system."

A lack of trust in policy makers was evident from the interviews. In my own notes is the comment, "All these views that arrive in education about how we enact education from people who know nothing about children... drive a lot of what I do." In each interview, the participants questioned aspects of practice that related to professional development policy. Mira demanded to know, "why are they [a used car salesman] on the Early Learning Council? What qualifies [them] and where are the teachers that are still practicing?" Carolina echoed this belief, "I think if a lot of people in that role [policy makers] had to do a lot of the things they're asking us to do they would think twice about 
the way they're asking us to do it." Linda questioned the vision of early childhood education in Oregon by saying, "I find it very funny that early childhood education was underneath the employment department." The participants clearly identified what they considered to be outside of early childhood education, even if they did not articulate the policy implications of such practices.

Mira spoke of separation from the system in the same way that Carolina did, seeing the professional development system as being outside of the arena. Mira framed her thoughts, "Just coming out of the classroom I feel is a shift in your perspective because you're not in it anymore." Mira goes on to echo the importance of the teacher's voice, "The practitioners are the ones who can speak eloquently about their craft because it really is especially for those teachers who've been in the classroom for so many years."

Each of the participants' voices expressed separation between themselves and Oregon's professional development system. Skattebol (2010) opined that as long as the discourse of early childhood educators and the early childhood education system fail to align, there will be confusion in the profession. This separation between policy enactment and the participants leads to the formation of asynchronous systems and a lack of trust.

Asynchronicities between personal experiences and professional development pathways is evident in Carolina, Linda, Nora, and Mira's journeys through their uses of rivers, paths, patchworks, circles, and so on. While aspects of Oregon's measurement of professional growth are defined in incremental measurements that are sequenced, as for example Oregon's QRIS or the Oregon Registry Step program, other aspects are not. 
Beyond the incremental measurements of professional growth, what is not as evident, is the asynchronous nature of Oregon's inconsistent larger professional development system. While participants could not always describe specifically how the system was asynchronous, they could identify a general disconnection between programs and services when they tried to navigate them as professionals. Linda explained that systems such as licensing were difficult to figure out. Carolina explained about the restraints of working with federally funded programs, "paperwork" as a barrier to being with the children. Mira shared that with all of her experience and her education, it was not the right type. The experiences of navigating asynchronous systems left a general sense of what Carolina identified as "cloudiness" of the professional development system.

The second strand that emerged in this essential theme focused on Navigating the Oregon Registry Steps. In looking back over the initial phone interviews, the participants were asked to name at least two components of Oregon's professional development system. All four participants had a Step in the Oregon Registry. The Oregon Registry Steps measures the depth and breadth of education as it relates to early childhood educators' education. Both the prescriptive nature of the Registry Steps and its formality lead to participants' confusion about their Registry Steps. Different feelings expressed in the interviews included such ideas as Mira's emotions about the lack of recognition of her training and education. These experiences led to belonging and resentment towards the Registry.

Carolina and Linda did not directly mention their Step 11 on the Oregon Registry once during the interview, although both shared that they each had that Step during the 
phone screening. A Step 11 is a Master's Degree and has a \$500 education award attached to its achievement, which both Linda and Carolina received. Linda and Carolina did measure their professional development during their interviews, however, as part of their ongoing practice. When asked, Linda saw professional development as "adding oil to your car" indicating a belief that professional development is an ongoing part of professional practice. Carolina saw professional development as part of education. Education was a way to make sense of the professional development system. Both Linda and Carolina's lack of connection between their education and Oregon Registry Steps provided insights into the lack of connection for them between educational attainment and Oregon Registry Steps.

When asked about the system aspect of the Oregon Registry, Nora expressed a lack of clarity about the system in which she achieved two separate Steps. Some of Nora's comments about the lack of understanding emerged from the presentation of the professional development system by her employer. When Nora pulled out her Oregon Registry paperwork during the interview, I asked if her employer had shared information with her about the Oregon Registry. She responded, "Not really. I have lots of questions about the Registry." Nora brought her Registry certificate, correspondence and other questions to our interview hoping to gain clarity on "what those [Oregon Registry Step] mean for me as a professional." Nora's attempt to gain clarity served to reveal another gap in the Oregon Registry Steps and the transparency of the program.

A lack of transparency both created perceptions about the Steps program and lack of understanding of what exactly was the scope and purpose of the Registry Steps. This 
confusion about the lack of transparency led to several suggestions from participants about what types of services the Registry could provide, for example, a training calendar and a way to see professional development training that was credited as professional development. Both services requested currently exist as part of the Registry Steps program and are accessible to early childhood educators, but were not evident to the participants. Registry Steps focus on college credits and degree achievements linked to childhood care and education. However, based on the participants' explanations of their professional growth, they did not connect their educational experiences to the Oregon Registry. Implications of participants' understanding of the Oregon Registry are discussed in Chapter 5.

In the end, in this theme I came to see Carolina, Linda, Nora, and Mira's experiences of professional identity, professionalism and professional engagement as asynchronous with the structured sequenced layout of Oregon's professional development system. Navigating the Oregon Registry Steps presented challenges of alignment when trying to connect to Carolina, Linda, Nora, and Mira's professional growth represented as Rivers, Roads, and Paths. The perceptions of state and federal systems as "foggy" or unclear are compounded by a sense of separation between the participants in the field and governmental structure.

\section{Summary}

Dahlberg and Dahlberg (2003) acknowledged that feelings, which create perceptions, are assigned to how we envision the world. Feelings then become entwined in the perception of how we experience a phenomenon. While the collage and interviews 
demonstrated a much larger experience of the professional journey, the essential themes emerged from my focus of the connections that Carolina, Linda, Nora, and Mira made as professionals and how their image of their professional selves connected to Oregon's professional development system. Their voices are woven into essential themes of individual experiences that provide insights into their acts of professional practice.

Carolina, Linda, Nora, and Mira never questioned whether they were professionals. While they each struggled to develop their voices as early childhood educators, their experiences with their classrooms, communities, and educational opportunities all refined who they were in the lives of young children. They reinforced their position as early childhood educators with strong beliefs about appropriate developmental practices for children. If fact, if they worked in a program that was incongruent with their belief system, they would rather leave than continue to follow what they identified as inappropriate practices. Education and communities of practice had to reflect their values of respect for children, children's capacity as learners, and children as citizen of the world. These acts of professional engagement were selfidentified as part of the participants' practice as early childhood educators.

Carolina, Linda, Nora, and Mira did not see themselves as engaging in a linear pattern of growth. Through their images of rivers, roads, and pathways, in their interviews and their visual representations, telling their professional journey jumped from past to present and back to past. When a particular experience resonated with one of them, that experience would emerge multiple times during the interview as a touchstone and as point of clarification for professional identity. 
In sum, the experiences of four participants in the renewal stage of professional development and the three questions about their professional engagement in Oregon's professional development system provided insights into how participants define professional engagement. There was an absence of descriptions of Oregon's professional development system as a meaningful connection for these participants in their experiences and collages. How participants make meaning of their experiences offers many lessons to those who work in Oregon's professional development system. Chapter 5 attends to each of the essential themes as a way to inform Oregon's professional development registry system and Oregon's policy. Ultimately, chapter 5 reflects on creating bridges between participants' professional identities and the system that seeks to engage them professionally. 


\section{CHAPTER 5: REFLECTIONS, CONCLUSIONS, AND IMPLICATIONS}

Chapter 5 begins with reflections on the essential themes that emerged from the participants' professional development journeys as told through narrative and collage. The combination of narrative and collage highlighted how alternative forms of representation supported accessing personal understanding (Sumsion, 2001). This holistic approach situated participants' experiences with Oregon's professional development system within the context of their lifeworld (van Manen, 1990). Essential themes and their meanings were illuminated from individual experiences allowing clarity to emerge from the hermeneutic phenomenological process.

Situating the essential themes within the participants' professional development journey follow and represent the places where multiple experiences tangled and knotted, leading to my greatest discoveries as a researcher-participant. Next I reflect on bridling the experience as a researcher-participant. Within this section, I reflect on my own role of being of and in Oregon's professional development system. The final two section presents my study's conclusions, its implications, and my recommendations.

\section{Situating the Essential Themes within Participants' Professional Development}

\section{Journey}

As stated previously, three essential themes emerged from the data interpretation and discussion, namely, (a) Personal and Professional Self: Intertwining Personal Experience and Professional Identity, (b) Curves Ahead: Maneuvering Rivers, Roads, and Paths, and (c) The Journey and the System are Asynchronous: "You Guys Figure that Out, Good Luck." As the central themes emerged, Carolina, Linda, Nora, and Mira's 
individual experiences in the renewal stage of professional development tangled to reveal the intertwining of their personal and professional selves as early childhood educators. The intertwined nature of personal and professional selves was central to understanding the implications of themes on Oregon's professional development system.

The role of personal motivation was explored as a way to learn about phenomenology as an act of making meaning as a researcher-participant. The personal motivation of the participants and me to engage in the study drove the narration of Chapter 4, as each individual shared their professional journey through narration and collage. The act of illuminating the essence therefore emerged from the repeated revisiting of participants' experiences through bridling (Dahlberg, 2006). The hermeneutic phenomenological process thus created understanding from the meaning of the experiencer, rather than from the essential structure of the phenomenon (AndersonNathe, 2008b, p. 29).

The lifeworld then served as a backdrop for a particular experience. The literature review in Chapter 2 specifically focused on elements of lifeworld experiences for early childhood educators from a reflective sense. These included (a) the professional development system and its structure, (b) concepts of early childhood as a profession, a professional experience, and a professional identity, and (c) Oregon's structure for professional development and professional engagement that all licensed early childhood educators must navigate. Beyond personal identification and Oregon's structural elements of the professional development system, a larger construct exists that influences the lifeworlds of early childhood educators. The discourse of early childhood education 
includes multiplicity of terms to situate different points-of-view of early childhood education that expose the underlying power structures in early childhood education messaging. In describing their experiences, participants' expressive language is often in direct contrast with the formal language of Oregon's professional development system. Expressive language becomes the tool for self-ownership of lifeworlds that reveal the essence of early childhood educators' experiences.

The experience of the professional development journey was captured in a/r/tographic collage, followed by semi-structured interview narratives. By asking Carolina, Linda, Nora, and Mira about their experiences with the professional development system through their professional journey, the essence of their experience as early childhood educators could be situated in their lifeworld of being an early childhood educator in Oregon. Through narrative and collage, Carolina, Linda, Nora, and Mira captured their previously unspoken need to be able to position themselves as early childhood professionals within Oregon's professional development system.

Each participant's narrative and college is followed by my own experience of their professional development journey. This format provided an opportunity for me to engage as a researcher-participant in a way that created a personal connection to their journeys. This connection was particularly important because the literature showed that the personal and professional selves of early childhood educators are intertwined (Sumsion, 2001; Osgood, 2006, 2012).

\section{Impressions of Essential Themes}


The participants expanded their professional development journeys well beyond the context of their experiences with Oregon's professional development system. Glimmers of their lifeworlds emerged as each participant provided a context for their professional development journey. The three essential themes knotted together to highlight the complexity of experiences in being an early childhood educator.

Though narrative and collage, the participants alluded multiple times to their metacognitive process of thinking about themselves in the context of their professional practices. Carolina, Linda, Nora, and Mira all identified themselves as professionals. Participants' experiences uncover their deep, reflective thinking about who they were in the lives of children and how they enacted their professional practice. Participants' revealed the complexity of values, beliefs, and ethics that are not acknowledged by the structure of the current professional development system.

\section{The Strength of an Intertwined Personal and Professional Self}

The debate continues statewide and nationally on what it means to be an early childhood education professional. However, Carolina, Linda, Nora, and Mira, never questioned if they were professionals in terms of the essential theme Personal and Professional Self: Intertwining Personal Experience and Professional Identity. Beyond the identification of self as professional, the participants revealed the intertwined nature of personal and professional selves. Participants expressed in their personal story narrative with collage as they described professional journey (Table 2). Their personal experiences therefore formed the foundation for who they were as professionals. Professional beliefs, values, and ethics emerged out of their meaning making of their 
lives. Strong convictions of professionalism led to an internal compass that steered Carolina, Linda, Nora, and Mira to that aligned to their professional values and create a deep sense of personal satisfaction in their personal lives.

Table 2

Identifying as Early Childhood Education Professionals

Research Sub- What have been the experiences of early childhood educators in Question identifying themselves as early childhood education professionals? Personal and professional self: Intertwining personal experience and Theme professional identity

- Indicating connections between professional identity and personal experience

- "You have your story in your head"

Variations - - "It's my path"

- "Start here"

- "It comes from inside you"

The role of collage in the participants' narratives was significant. Not only did collage use visual imagery to represent of their professional journeys, it also served as a touchstone for telling their stories. Multiple times during the interviews, each participant touched, traced, held, and used their collages as physical representations of their journey. The imagery they selected became the visual representation of their experience, and was deeply meaningful and personal to them. Hermeneutic phenomenology was used to explore experiences and carefully hold the uniqueness of each journey however the use of a/r/topgraphy and cross-hatching processes during collage revealed the deeply personal connection between their professional narratives and their personal selves through collage. 
The participants' collages and narratives demonstrated certain beliefs about their sense of agency as empowered early childhood educators. Much of their empowerment came from the knowledge of themselves in the broader context of their practice, whether it was school or community. While feelings of isolation, confusion, frustration, and anger were reflected in their narratives, their narratives and collages ended on themes of hope, contentment, new beginnings, and satisfaction with their current situation.

Collectively then, Carolina, Linda, Nora, and Mira's narratives and collages presented insight to the multiplicity of the early childhood field. Their experiences were a reminder that what is often portrayed as simple by society and policy makers - caring for and educating young children - is deeply complex and multi-dimensional. The importance of having been mindful of the multiplicity of the role of the participant is that it led to a greater understanding of how they constructed and enacted their professional identity.

\section{Professional engagements and the development of pedagogical practices}

In the discussion of professional engagement, as represented by the essential theme, Curves Ahead: Maneuvering Rivers, Roads, and Paths, the participants discussed the connections between their journeys and how their professional identities connected to various acts of professional engagement (Table 3). Professional engagement was identified in the classroom, school, and early childhood community. It included reflective practice, professional development, education, and experiences as early childhood educators. Professional engagement represented the enactment of beliefs, values, and ethics. 
Table 3

\section{Identifying Experiences of Professional Engagement}

\begin{tabular}{ll}
\hline Research Question & $\begin{array}{c}\text { How do early childhood educators identify their experiences of } \\
\text { professional engagement? }\end{array}$ \\
\hline Theme & Curves Ahead: Maneuvering Rivers, Roads, and Pathways \\
in the early childhood professional through rivers, roads, and paths. & - "I'm learning in the classroom that I want to be in": Defining \\
professional engagement in the classroom. \\
- "It's a good place to build bridges": Defining professional \\
engagement in the early childhood education community \\
\hline learning and environment that I do and really respect all these \\
things." \\
- "I've always been a person about community and there is an \\
early childhood community here" \\
- "Fight for the rights of children, every day you advocate in your \\
classroom for children" \\
- "I'm learning in the classroom that I want to be in"
\end{tabular}

Revealed in the narratives of Chapter 4, Carolina, Linda, Nora, and Mira's expressions of their professional development journey provided a vivid picture of their professional engagement. Professional engagement emerged as strong pedagogical stand of how they enacted their practice. Professional engagement was multi-dimensional and was driven by how participants saw themselves as professionals. Choices about professional engagement were influenced by beliefs about children. A deep and profound respect for children was embedded in their belief, values, and ethics. It is a common thread in the parlance of educators to speak of creating an emotional connection to children as a value of teaching (Lobman \& Ryan, 2007; Skattebol, 2010). This sense of professionalism also frames professional engagement activities. For Carolina, Linda, Nora, and Mira acts of honoring children reinforced the choices they made about their 
professional engagement, which in turn continued to drive a deeper connection with children. This spiral of professional engagement matched the cycles of professional development identified by Katz (1995). As the participants matured in their professional development journey, they left behind the uncertainty of their early years in the field and identified themselves as competent professionals. The stronger their own internal professional frame for reference, the less they required external validation of who they were as early childhood educators. Their sense of professionalism and professional engagement then became about how they might continue to stretch and grow their own pedagogical practices.

The participants' interests in finding caring communities of practice grew from their wish to find a place where they could draw strength and reinforce their pedagogical practices. Each realized the value of communities of practice when they worked in programs that did not share their values, beliefs, or ethics. Their ability to identify and act on their values, beliefs, and ethics to change their professional landscapes spoke to their self-awareness as early childhood educators.

Participants had the self-awareness to identify programs that did not align with their values. They also had skills and motivation to leave those programs and, in some cases, seek out better places to work where they and children were more respected. Additionally, they were introspective enough to recognize communities of practice that aligned with their values and know the alignment's worth to their personal and professional selves. This knowledge gave the participants a resiliency and a sense of peace that did not exist earlier in their professional journeys. 


\section{The Unintended Consequences of Oregon's Professional Development System.}

In the discussions of professional engagement, an absence of descriptions of interactions with Oregon's professional development system was identified in the essential theme The Journey and the System are Asynchronous: "You Guys Figure that Out, Good Luck.” The participants emphasized the lack of connection due to the asynchronicity of their professional journeys and the enactment of Oregon's professional development system. Two underlying threads in this theme were Being Separate from the Professional Development System and Navigating the Oregon Registry Steps. These threads emerged as a way to illuminate why a lack of personal connections occurred (Table 4).

Table 4

What Meaning Can Be Made of Experience?

\begin{tabular}{|c|c|}
\hline $\begin{array}{c}\text { Primary Research } \\
\text { Question }\end{array}$ & $\begin{array}{l}\text { In the renewal stage of their professional practice, what meaning can be made } \\
\text { of early childhood educators' experiences navigating Oregon's professional } \\
\text { development system? }\end{array}$ \\
\hline Essential Theme & $\begin{array}{l}\text { The Journey and the System are Asynchronous: You Guys Figure that Out, } \\
\text { Good Luck } \\
\text { - Being separate from the professional development system } \\
\text { - Navigating the Oregon Registry Steps } \\
\text { - Foggy Professional Development Systems }\end{array}$ \\
\hline Variations & $\begin{array}{l}\text { - 'It's not super clear" } \\
\text { - 'I was trying to feel my way out" } \\
\text { - 'I really couldn't understand why there wasn't a place for my work to } \\
\text { be recognized" } \\
\text { - "The layers of complexity for issues in education" }\end{array}$ \\
\hline
\end{tabular}

As soon as the interviews were concluded, it became visible through the images of rivers, roads, and pathways, that Carolina, Linda, Nora, and Mira did not see themselves as engaging in a linear pattern of growth. Both in their narratives and collage, 
their professional journeys were full of starts and stops that carried their professional development journey from past to present and back to past. These touchstones came in and out of focus during their narratives and places that held significant importance in professional identity formation. The commonality of these experiences were focused on resolving a pedagogical question of values beliefs or ethics either for personal clarification of who they were as an early childhood educator or how they fit with their community of practice. Carolina, Linda, Nora, and Mira saw building professional identity as separate from their engagement in Oregon professional development system.

The participants' experiences with the Oregon Registry spotlights the pitfalls of professional development systems components that exist separate from community of practice. As illustrated by Carolina, Linda, Nora, and Mira, reinforcing professional identity, professionalism, and professional engagement is strengthened by a sense of belonging to a community of practice. The personal work of defining oneself as an early childhood educator is shaped by cycles of experiences that refine values, beliefs, and ethics. Validating the Oregon Registry Steps did not increase a sense of professional engagement.

These feelings of separation carried into beliefs about the larger professional development system. As reviewed in the literature, the dichotomy between them (policy makers) and us (early childhood educators) is identified as embedded in the policy realm through the development of policies that shape the expected outcomes of the early childhood classroom (Early Learning Council S. B. 909 Report, 2011; Ortlipp et al., 2011; Skattebol, 2010). Equally highlighted by Carolina, Linda, Nora, and Mira was a 
sense of dichotomy between the difficult act of educating young children and their perception of policy makers' understanding of the early childhood field. Also, the professional development system offers no visual representations of how it exists as an entity, which would capture its own interconnectedness.

A lack of trust between the two groups further reinforces a sense of $u s$ and them. The outcome of this bifurcation of early childhood education leads to a participant's belief that state policy makers fail to acknowledge the multiplicity of early childhood field. While the acknowledgement of the multiplicity of early childhood education may occur in policy enactment, participants feel that is not communicated between the two groups. Further the complexity of the early childhood system led participants' to simple the professional development system, too. The unintended consequence of this bifurcation is that it leads to a perception that policy makers think of the early childhood field and profession as simple. The simplification of early childhood education prevented Carolina, Linda, Nora, and Mira from making meaningful and positive connections for the professional development system that was enacted to support their professional practice.

\section{Reflections of Bridling the Experience.}

Despite the strength of narratives and collages of Carolina, Linda, Nora, and Mira's professional development journey, it is neither possible nor desirable to generalize their experiences across the early childhood field. Neither is it recommended to develop a statewide course of action to address their experiences with Oregon's professional development system. However, the participants' professional development journey 
offered up the opportunity to make our own meaning of their experiences and to see ourselves reflected in their stories and experiences, perhaps bringing greater understanding to our own journeys. To further delineate my own role as a researcherparticipant both within this study and within my larger role of being in and working for Oregon's professional development system, I have now outlined both the study parameters in greater depth and my own reflections on my role.

This study was situated within a phenomenological paradigm. This paradigm acknowledges the relationship between me as researcher-participant and the participants' own worldview (van Manen, 1990). It acknowledges that participants seek to make meaning of the lived experience. Such a position intertwined me, as researcherparticipant, and the four study participants in dialogue where the meaning made by the participants informed how I made meaning from their experience. In phenomenology, the structure of first person experiences leads to the internal construction of beliefs that create the lens through which individuals navigate their lifeworld (Smith, 2011; van Manen). The exploration of meaning is important to a phenomenological researcher rather than the identification of problems or development of solutions (van Manen, p. 23). Researchers in hermeneutic phenomenology cannot claim generalizations of findings from a participant's specific experiences of the participant. Rather, they can see patterns and themes that emerge from both the participant's meaning and their own meaning making of the participant's experience. It is the ability to see oneself in another's experiences that is the strength of phenomenological research.

The conceptual framework used to examine the data drew on the findings of other 
hermeneutic phenomenological studies that look at early childhood educators' experiences in professional development engagement, and engage in the "giving-finding" (Vagle, 2009, p. 586) of meaning from the phenomenon in the process of building understanding. The concepts of self-identification of engagement, professionalism, sense of agency, and self-concept were drawn from other hermeneutic phenomenological studies (Anderson-Nathe, 2008a, 2008b; Hsu, 2011; Parnell, 2011; Sumsion, 2001). These concepts were used as a lens through which I engaged when reflecting on my impressions of the narratives and collage.

In hermeneutic phenomenology, the researcher-participant is bringing meaning forward from others' experience, specifically, constructing and layering the meaning of others' experiences to create new understanding. As part of the selection process and in the informed consent document, I clearly indicated how my roles as a researcherparticipant and as an employee of the Oregon Center for Career Development in Childhood Care and Education are unique, and where these roles do and do not overlap. I have included clear statements in the participants' informed consent documents of how and where the data and my interpretations (bridled experiences) will be used. Such actions on my part have lead me to draw conclusions and formulate implications from this research. Following, I reflect on my bridling the experience as a member of the professional development system.

Just as Carolina, Linda, Nora, and Mira struggled to articulate the intertwining of their personal and professional self, I also struggled. Indeed at the start of this study, I acknowledged that my personal experience matched what other early childhood educators 
experienced in the professional development system. My wonderings of why educators struggled led to this research. Over the course of this study, I have doubled my years of working for the Oregon Center for Career Development in Childhood Care and Education. I still struggle with what meaning can be made from interactions with Oregon's professional development system.

While I better understand the limitations of the system now, it does not stop me from feeling the experiences of our state's early childhood educators through my daily interactions with them. Oregon's professional development system actually feels more complex with each passing year as my empathy for early childhood educators increases and as Oregon rolls out new policies and initiatives that are increasingly complex and multi-faceted. It might be assumed that my position as the Oregon Registry Coordinator influenced not only which participants volunteered to come forward, but also impacted study findings. Individuals may have come forward hoping for a problem to be solved in navigating the Oregon Registry or Oregon's professional development system.

Conversely, other possible participants may have elected not to participate because contact with the Oregon's professional development system might have implied a heighten monitoring of individuals or their programs. However, I worked to minimize my position's influence the existing participants' revelation of their experiences. Their experiences remained their own and presented through collage and narrative focused on the past to the present.

My positioning carries an implication for the validity of my research as an employee of an Oregon's professional development system program. In each contact 
with participants, I clearly outlined my role in Oregon's professional development system and my role as a doctoral student. I offered alternative pathways to accessing supports and services of the professional development system, especially the Oregon Registry. I did have strong personal beliefs about the ease of use of statewide systems that I took care to address by providing semi-structured impartial questions to encourage responses from the participants. I do think that my empathy for their experiences and interest in their stories through hermeneutic phenomenology extracted a richer narrative from the participants than a transcendental phenomenology approach would have achieved, even though a transcendental phenomenological researcher presumes to remove all bias from data interpretation. In my role as researcher-participant, I do not believe such removal is possible or desirable.

In contrast, the personal connection and honoring of the four participants' experiences were identified as being highly valued. Further, I believe that the use of collage as an a/r/tographic tool for meaning making provided significant depth in the narrative. My own collage experiences were foundational in bridling participants' experiences and creating the "elbow-room" (Dahlberg \& Dahlberg, 2003, pg. 47) for meaning to emerge. My own learning from this study served to expand my thinking greatly about the multiplicity of early childhood education. More than anything, collage helped me to shift my own tendency to bifurcate the issues. By engaging in a creative process, I explored the possible meanings that emerged from participants' experiences and determine themes and meanings. Collage illustrated my own learning and reinforced the framework on which to make the participants' experiences visible. 
Finally, I called upon Carolina, Linda, Nora, and Mira's voices frequently in Chapters 4 and 5. As I expressed in Chapter 1, one of my personal stances was the importance of the early childhood educator's voice in Oregon's professional development system and policy decisions. The deliberate choice to use Carolina, Linda, Nora, and Mira's names, block quotes, and images was an act of advocacy to represent participants' experience in research. This choice spoke directly to my desire, expressed in Chapter 1, to "prioritize the meanings that early childhood educators attach to their experiences." I also sought to "recognize the effects of institutional discourses on early childhood educators on their interpretation of accessibility of the professional development system." The use of their names, although pseudonyms, kept their narratives and collages at the heart of the research.

\section{Implications and Recommendations for the Future Action}

New questions arise out of this research study. I begin to wonder about the unintended consequences for early childhood education in Oregon, when early childhood educators identify themselves as professionals in a field that is not identified as a profession. The disconnect between the policy level and the participants, whose experiences were naturally limited by the exposure and access to system level decisions, had a profound impact on their perceptions of Oregon's professional development system. Given what we know about the structure of early childhood education, it might be more realistic to have the system make adjustments to create points of access to hear early childhood educators' experiences than to ask the early childhood educators to conform to the system. 
It may be argued that structures are in place to accept feedback, but from Carolina, Linda, Nora, and Mira's perspectives, these systems are hidden or inaccessible to them. Further, the very lack of perceived accessibility seemed to reinforce a general sense of distrust and frustration with Oregon's professional development system. Additionally, intertwining personal and professional-self has led to emotional vulnerability that is rarely if ever acknowledged by those working in Oregon's professional development system.

Further, Carolina, Linda, Nora, and Mira - whose educational attainment is in the top fifth of the early childhood field-articulate their views in informal language. This language in no way connects to the institutional definitions enacted by professional development systems that use complex vocabulary to define their meaning in a type of "speak" that is unintelligible to the outsider. In fact, in an effort to develop cross-sector understanding of early childhood education, the Early Learning Council has just requested a dictionary in "real word" to describe early childhood education programs and practices (personal communication, B. Webber, March 5, 2014) in an effort to translate institutional discourse. If these requests are coming from within the very agencies which developed the institutional discourse, we have to wonder what barriers early childhood educators must overcome to distill the meaning of the professional development system.

In Chapter 1, I highlighted my own experience with Oregon's professional development and the experiences of those with whom I speak daily on the phone. I wondered how and why early childhood educators have difficulty in finding their way in the system entry points provided by the state. The absence of studies of early childhood 
educators' experiences in navigating professional development systems was noted as a risk of broadcasting a message that a particular professional development system is unresponsive to the needs of the early childhood community (Osgood, 2012). The very absence of studies of early childhood educators' experiences with navigating professional development systems, led me to expand how I asked the question about early childhood educators' experiences of Oregon's professional development system. If I were to ask early childhood educators about their professional development journey, I knew that I would receive a rich narrative response. Building on experiences of professional development as an overarching theme of, and a fundamental requirement for, working in licensed early childhood settings, I knew that there would be a foundation to create detailed connections.

Issues relating to the intersection of participants' professional engagement and the Oregon's professional development system reflect the national debate about early childhood education as a profession. Oregon is actively engaged in professionalizing the field of early childhood education through a series of state initiatives. From universal enrollment in the Oregon Registry Online of Office of Child Care licensed programs to the implementation of the Quality Rating Improvement System, Oregon is structuring professional engagement activities for early childhood educators. Many initiatives are being driven by federal funding and are implemented in prescribed formats that limit conversations between early childhood educators and policy makers. Participants clearly expressed their lack of faith in policy makers or professional development system initiatives to understand the multiplicity of their profession. Participants also raised the 
question about the intersection of seeing oneself as a professional in a field that is not identified as a profession by policy makers, but rather simply as a workforce.

Many implications can be derived from or expanded upon from the essential themes discovered in this study. A significant number of educators indicated that they wanted to participate in the study, from individuals in family child care to directors in center-based programs. From the early childhood education field's perspective, this study offered a unique opportunity to offer insight into their experiences and have those experiences presented as part of a research project.

An expansion of the current study could be conceived in two formats. First, experiences in Oregon's professional development system could be expanded to impressions of early childhood educators in all four of Katz's (1995) professional stages, survival, consolidation, renewal, and maturity. The second expansion of the study would incorporate experiences of early childhood educators in the three types of licensed care, registered family, certified family, and center-based programs. These expansions would provide insight into expansion or change of essential themes across professional stages and program type.

Another important area that warrants further investigation is the experiences of policy makers and project managers of Oregon's professional development system program and services. Do these professionals see or recognize the disconnection between the intent of their policies and programs and early childhood educators' experiences? Another question that could be asked is: What are the experiences of policy makers or project managers of Oregon's professional development system in enacting programs and 
services? These two questions create a counterpoint to the question of early childhood educators' experiences. A comparison between the early childhood educators' experiences and policy and program managers in Oregon's professional development system would yield a holistic view of the experiences and perceptions of the enactment Oregon's professional development system.

\section{Conclusions}

The intent of this study was to provide a platform for participants as early childhood educators to express in their own words their experiences with Oregon's professional development system. Much of early childhood education is provided with one or two educators in a classroom in isolation from decision-making hubs of the school, community, or the professional development system. It is rare that early childhood educators who spend their day teaching young children have an opportunity to become involved in the numerous decision making entities of Oregon's professional development system. The gap that exists between the early childhood classroom and policy leads to assumptions about practices that become the formation of policy decisions.

At a recent state policy meeting, policy makers expressed shock at the education attainment levels of Oregon's early childhood education community. It was shown that a full third of early childhood educators are college educated as reported by the Oregon Child Care Research Partnership (B. Webber, personal communication March 5, 2014). Over 6,000 early childhood and school age educators have submitted degrees into the state database ORO to document their education (OCCD, 2014). 
As I found this revelation, I also came across these sentiments in my journal. I wrote about my feelings of early childhood education in Oregon.

It's so important to me because I worry so much that early childhood is so fractured as a professional and if we're not working to come together and understand everybody then when these large state movements happen so much of who we are and how we are and what we believe gets left behind. And it's so important not to let that happen.

At the end of the day, the purpose of this study was to illuminate early childhood educators' experiences with Oregon's professional development system. Through collage and interviews, participants shared their feelings, beliefs, and perceptions of Oregon's professional development system. In doing so, they offered insight in what it means to be an early childhood educator who must juggle the classroom and grapple with the enactment of policy in their early childhood education environments. Through the emergence of essential themes, early childhood educators demonstrated that their experiences were unique and also shared common characteristics of what it means to be an early childhood educator in Oregon living with policy in the classroom. It is now the turn of policy makers and program managers of Oregon's professional development system to recognize the strength and wisdom of the voices in the early childhood classroom. 
ECE PERCEPTIONS OF OREGON'S PDS

\section{REFERENCES}

Ailwood, J. (2003). Governing early childhood education through play. Contemporary Issues in Early Childhood, 4(3), 286-298.

Ailwood, J. (2008). Mothers, teachers, maternalism and early childhood education and care: Some historical connections. Contemporary Issues in Early Childhood, 8(2), 157-165. doi: 10.2304/ciec.2007.8.2.157

Ajjawi, R., \& Higgs, J. (2007). Using hermeneutic phenomenology to investigate how experienced practitioners learn to communicate clinical reasoning. The Qualitative Report, (12)4, 612-638.

Anderson-Nathe, B. (2008a). Contextualizing not-knowing: Terminology and the role of professional identity. Child \& Youth Services, 30(1-2), 11-25. doi:10.1080/01459350802156532

Anderson-Nathe, B. (2008b). Investigating not-knowing: Research methodology. Child \& Youth Services, 30(1-2), 27-42. doi:10.1080/01459350802156557.

Arnold, C. (2002). Kitty and horse [photograph]. Retrieved from coreyfishes.com

Apple, M. W., \& King, N. R. (1977). What do schools teach? Curriculum Inquiry, 6(4), 341-358.

Apple, M. W. (1993). The politics of official knowledge: Does a national curriculum make sense? Teachers College Record, 95(2), 222-241.

Bamberger, J., \& Schön, D.A. (1983). Learning as reflective conversation with materials: Notes from work in progress. Art Education, 36(2), 68-73.

Barnett, W. S. (2011). Minimum requirements for preschool teacher educational qualifications. In E. Zigler, W. Gilliam, \& W. S. Barnett (Eds.), The prek debates: Current controversies \& issues (pp. 48-54). Washington, DC: NAEYC.

Bown, K., \& Sumsion, J. (2007). Voices from the other side of the fence: Early childhood teachers' experiences with mandatory regulatory requirements. Contemporary Issues in Early Childhood Education, 8(1), 30-49. doi:10.2304/ciec.2007.8.1.30

Brown, R. (2012). Daring greatly: How the courage to be vulnerable transforms the way we live, love, parent, and lead. New York: Gotham Books. 
Brownlee, J., \& Berthelsen, D. (2005). Personal epistemology and relational pedagogy in early childhood teacher education programs. Early Years: An International Journal of Research, 1-14.

Cadwell, L. B. (2003). Bringing learning to life: The Reggio approach to early childhood education (Vol. 86). New York: Teachers College Press.

Camp, D. G. (2009). Where do standards come from? A phenomenological study of the development of National Board Early Childhood/Generalist Standards. Journal of Research in Childhood Education. 21(4), 420-437. doi:10.1080/0256854070954605

Case, J. (2012). Best of the city: Best of family [drawing]. Retrieved from portlandmonthlymagazine.com

Caulfield, R. (1997). Professionalism in early care and education. Early Childhood Education Journal, 24(4), 261-263. doi: 10.1007/BF02354843

Copple, C., \& Bredekamp, S. (Eds.). (1991). Developmentally appropriate practice in early childhood programs serving children from birth through age 8. Washington, DC: NAEYC.

Cohen, L. E. (2008). Foucault and the early childhood classroom. Educational Studies, $44,7-21$.

Cochran-Smith, M., \& Lytle, S. L. (1990). Research on teaching and teacher research: The issues that divide. Educational Researcher, 19(2), 2-11.

Curtis D., \& Carter, M. (2000). The art of awareness: How observation can transform your teaching. St. Paul, MN: Red Leaf Press.

Curtis, P., Saxton, L., Adarkar, S., McClintock, M. L., Stewart, B., Waller, N., \& Willis, D. (2011). Early Childhood and Family Investment Transition Report. Retrieved from http://www.ucancap.org/_files/Early_Childhood_Transition_Report.pdf

Dahlberg, K. (2006). The essence of essence-The search for meaning structures in phenomenological analysis of lifeworld phenomena. International Journal of Qualitative Studies On Health and Well-Being, 1(1), 11-19. doi:10.1080/17482620500478405

Dahlberg, K. (2011). Lifeworld phenomenology for caring and for health care research. Qualitative Research in Midwifery and Childbirth: Phenomenological Approaches. G. Thomson, F. Dykes, S. Downe, (Eds). London: Routledge, 17-34 
Dahlberg, H., \& Dahlberg, K. (2003). To not make definite what is indefinite: A phenomenological analysis of perception and its epistemological consequences in human science research. The Humanistic Psychologist, 31(4), 34-50.

Dahlberg, G., Moss, P., \& Pence, A. R. (2007). Beyond quality in early childhood education and care: Languages of evaluation $\left(2^{\text {nd }} e d.\right)$. London: Routledge.

Dalli, C. (2008). Pedagogy, knowledge and collaboration: Towards a ground-up perspective on professionalism. European Early Childhood Education Research Journal, 16(2), 171-185.

Dalli, C. \& Urban. M. (Eds.). (2010). Professionalism in early childhood education and care: International perspectives. New York: Routledge.

Dana, N. F., \& Yendol-Hoppey, D. (2005). Becoming an early childhood teacher leader and an advocate for social justice: A phenomenological interview study. Journal of Early Childhood Education, 26, 191-206. doi:10.1080/10901020500369647

Darling-Hammond, L. (2012). Powerful teacher education: Lessons from exemplary programs. New York: John Wiley \& Sons.

Day, C., Kington, A., Stobart, G., \& Sammons, P. (2006). The personal and professional selves of teachers: Stable and unstable identities. British Education Research Journal, 32(4), 601-616.

Demma, R., \& LeMoine, S. (2010). Issue brief: Building an early childhood professional development system. Washington, DC: National Governors Association Center for Best Practices.

Dewey, J. (1934). Art as experience. New York: The Berkley Publishing Group.

Dumbrajs, S., \& Keinonen, T. (2011). Three pedagogs: A comparison of professional life stories. The International Journal of Learning, 18, 551-564.

Early Learning Council SB 909 Report. (2011). Retrieved from http://www.oregon.gov/gov /oeib/docs/earlylearningcouncilsb909report1211.pdf

Ellett, J. (2011). Narrative and Phenomenology as Methodology for Understanding Persistence in Art Teachers: A Reflective Journey. Marilyn Zurmuehlen Working Papers in Art Education, 2011(1), 2.

Ernst, P. (1994). Varieties of constructivism: Their metaphors, epistemologies and pedagogical implications. Hiroshima Journal of Mathematical Education, 2, 1-14. 
Ettling, D. (2006). Ethical demands of transformative learning. New Directions for Adult \& Continuing Education, 109, 59-67.

Executive Order No. 11-02: Oregon Education Investment Team. (2011). Retrieved from http://www.oregon.gov/Gov/OEIT/docs/oeit-eo-1102.pdf?ga=t

Feeney, S. (2012). Professionalism in early childhood education: Doing our best for children. Boston: MA Pearson.

Feeney, S., \& Freeman, N. K., Pizzolongo, P. (2012). Ethics and the early childhood educator: Using the NAEYC Code (2nd ed.). Washington, DC: National Association for the Education of Young Children.

Fenech, M. (2010). Promoting early childhood teacher professionalism in the Australian context: A place of resistance. Contemporary Issues in Early Childhood, 11(1), 89-105. doi:10.2304/ciec.2010.11.1.89

Fenech, M., \& Sumsion (2007). Early childhood teacher and regulation: Complicating power relations using a Foucauldian lens. Contemporary Issues in Early Childhood Education, 8(2), 109-122. doi: 10.2304/ciec.2007.8.2.109

Fenech, M., Sumsion, J., Robertson, G., \& Goodfellow, J. (2008). The regulatory environment: a source of job (dis)satisfaction for early childhood professionals? Early Child Development and Care, 178 (1), 1-4. dio:10.1080/03004430600597222

Fenech, M., Sumsion, J., \& Shepard, W. (2010). Promoting early childhood teacher professionalism in the Australian context. Contemporary Issues in Early Childhood, 11(1), 89-97.

Fleet, A., \& Patterson, C. (2001). Professional growth reconceptualized: Early childhood staff searching for meaning. Early Childhood Research and Practice, 3(2), 1-14.

Fosnot, C. T. (1996). Constructivism: A psychological theory of learning. In C.T. Fosnot (Ed.), Constructivism: Theory, perspective and practice (pp. 8-33). New York: Teachers College Press.

Gable, S., \& Halliburton, A. (2003). Barriers to child care providers' professional development. Child \& Youth Forum, 32(3), 175-193.

Gadamer, H. G. (1975). Truth and method. New York: Seabury.

Gee, J. P. (2011). How to do Discourse Analysis: A Toolkit. New York, NY: Routledge. 
Goelman, H., \& Guo, H. (1998). What we know and what do we don't know about burnout among early childhood care providers. Child \& Youth Forum, 27(3), 175199.

Goffin, S. G. (1996). Child development knowledge and early childhood teacher preparation: Assessing the relationship-a special collection. Early Childhood Research Quarterly, 11, 117-133.

Goodfellow, J. (2004). Documenting professional practice through the use of a professional portfolio. Early Years, 24(1), 63-74.

Groenewald, T. (2004). A phenomenological research design illustrated. International Journal of Qualitative Methods, 3(1), Article 4. Retrieved from http://www.ualberta.ca/ iipm/backissues/3_1/pdf/groenewald.pdf

Hardwood, D., Klopper, A., Osanyin, A, Vanderlee, M. (2012). It's more than care: Early Childhood Educators' concepts of professionalism. Early Years 33(1), 4-17.

Hargreaves, A. (1998). The emotional practice of teaching. Teaching and Teacher Education, 14(8), 835-854.

Heidegger, M. (1962). Being and time. New York: Harper and Row.

Hooks, B. (2010). Teaching critical thinking: Practical wisdom. New York: Routledge.

Hsu, C. (2008). Taiwanese early childhood educators' professional development Early Child Development and Care, 178(3), 259-272. doi:10.1080/03004430600767932

Husserl, E. (1913). Logical investigations. (J. N. Findlay, Trans.). London: Routledge [1900/01; 2nd, revised edition 1913], 1973.

Kagan, S. L., \& Kauerz, K. (Eds.). (2012). Early childhood systems: Transforming early learning. New York: Teachers College Press.

Kakkori, L. (2009). Hermeneutics and phenomenology problems when applying hermeneutic phenomenological method in educational qualitative research. Paideusis, 18, 19-27.

Katz, L. (1977). Talks with teachers: Reflections on early childhood education. Washington, DC: National Association for the Education of Young Children. 
ECE PERCEPTIONS OF OREGON'S PDS

Katz. L. (1995). The developmental stages of teachers. Talks with teachers of young children: A collection. Stamford, CT: Ablex.

Katz, L. (1996). Child development knowledge and teacher preparation: Confronting assumptions. Early Childhood Research Quarterly, 11, 135-146.

Katz, L. (2008, November). Challenges and dilemmas of educating teachers of young children, S.D. Chairperson (Chair) in NAECTE-NAEYC Symposium. Symposium conducted at the meeting of NAECTE, Dallas, TX.

Kelchtermans, G. (2005). Teachers' emotions in educational reforms: Self-understanding, vulnerable commitment and micropolitical literacy. Teaching and Teacher Education, 21, 995-1006.

Krieg, S. (2010). Novice teachers' work: Constructing “different' children"? Asia-Pacific Journal of Teacher Education, 38(1), 57-68. doi:10.1080/13598660903474148

Kwong, M., \& Kwong, M. W. (July 2000). Making Sense of teaching and learning: Kindergarten teachers as researchers. Paper presented at the Inaugural Pacific Early Childhood Education Research Association Conference, Kobe, Japan.

La Jevic, L., \& Springgay, S. (2008). A/r/tography as an ethics of embodiment: Visual journals in preservice education. Qualitative Inquiry, 14(1), 67-89. doi: $10.1177 / 1077800407304509$

Langford, R. (2007). Who is a good early childhood educator? A critical study of differences within a universal professional identity in early childhood education preparation programs. Journal of Early Childhood Teacher Education, 28, 333352. doi:10.1080/10901020701686609

Langford, R. (2008). Making a difference in the lives of young children: A critical analysis of a pedagogical discourse for motivating young women to become early childhood educators. Canadian Journal of Education, 31(1), 78-101.

Laverty, S. M. (2003). Hermeneutic phenomenology and phenomenology: A comparison of historical and methodological considerations. International Journal of Qualitative Methods, 2(3), 21-35.

Lazzari, A. (2012). Reconceptualizing professionalism in early childhood education: Insights from a study carried out in Bologna. Early Years, 32(3), 252-265.

Leavy, P. ( 2009). Method meets art. New York: The Guilford Press. 
LeMoine, S. (2008). NAEYC policy report: Workforce designs, a policy blueprint for state early childhood professional development systems. Washington, D.C.: National Association for the Education of Young Children.

Lobman, C., \& Ryan, S. (2007). Differing discourses on early childhood teacher development. Journal of Early Childhood Teacher Education, 28, 367-380.

Lubeck, S. (1996). Deconstructing "child development knowledge" and "teacher Preparation.” Early Childhood Research Quarterly, 11, 147-167.

Malchiodi, C. A. (Ed.). (2011). Handbook of art therapy. New York: Guilford Press.

McCabe, L. A., \& Sipple, J. W. (2011). Colliding world: Practical and political tension of prekindergarten implementation in public schools. Educational Policy, 25(1), e1e26. doi:10.1177/0895904810387415

Menmuir, J., \& Huges, A. (2012). Early education and childcare: The developing professional. European Early Childhood Education Research Journal, 12(2), 3341. doi:10.1080/13502930485209411

Merleau-Ponty, M. (1962). Phenomenology of perception. New York: Humanities Press.

Merriam, S. B. (2009). Qualitative research: A guide to design and implementation. San Francisco, CA: Jossey-Bass.

Mevawalla, Z., \& Hadley, F. (2012). The advocacy of educators: Perspectives from early childhood. Australasian Journal of Early Childhood, 37(1), 74-80.

Mignot, P. (2000). Using visual methods in careers education and guidance. Pastoral Care in Education, 18(2), 8-16.

Moloney, M. (2010). Professional identity in early care and education: Perspectives of pre-school and infant teachers. Irish Educational Studies, 29(2), 167-187. doi:10.1080/03323311003779068

Moustakas, C. (1994). Phenomenological research methods. Thousand Oaks, CA: Sage Publications, Inc.

Mozére, L. (2012). Is experience on an immanent level possible in RACE (reconceptualizing early childhood education)? Indo-Pacific Journal of Phenomenology, 12, 1-9. 
National Association for the Education of Young Children. (1997). Position statement: NAEYC developmentally appropriate practices for early childhood programs severing birth through age 8. Retrieved from http://www.naeyc.org/files/naeyc/ file/positions/position\%20statement\%20Web.pdf

National Association for the Education of Young Children. (2009). Position statement: NAEYC standards for early childhood teacher preparation. Retrieved from http://www.naeyc.org/positionstatements/ppp

National Association for the Education of Young Children. (2011). Early childhood workforce systems initiative. Retrieved from http://www.naeyc.org/policy/ecwsi

National Association for the Education of Young Children. (2012a). About NAEYC. Retrieved from http://www.naeyc.org/content/about-naeyc

National Association for the Education of Young Children. (2012b). Strategic directions: Technical assistance professionals in state early childhood professional development systems. Retrieved from http://www.naeyc.org/files/naeyc/ TA_Professionals.pdf

National Association for the Education of Young Children, \& National Association of Child Care Resource and Referral Agencies. (2011a). Early Childhood Education Professional Development: Training and Technical Assistance Glossary. Washington, D.C.: NAEYC.

National Association for the Education of Young Children, \& National Association of Child Care Resource and Referral Agencies. (2011b). Early Childhood Education Professional Development: Adult Education Glossary. Washington, D.C.: NAEYC.

National Child Care Information Center. (2009). Elements of a professional development system simplified framework and definitions. Retrieved from http://occ-archive.org/pubs/goodstart/pd_section2b.html

National Registry Alliance. (2012). Partnership Eligibility Review Overview. Retrieved from http://www.registryalliance.org/resources-briefs/partnership-eligibilityreview

Norcutt, T. (n.d.). Remote control [photograph]. Retrieved from gettyimages.com.

Novinger, S., \& O'Brien, L. (2003). Beyond 'boring, meaningless shit' in the academy: Early childhood teacher educators under the regulatory glaze. Contemporary Issues in Early Childhood, 4(1), 3-31. 
ECE PERCEPTIONS OF OREGON'S PDS

Office of the Governor. (2011a). Oregon's early learning challenge grant. Retrieved from http://www.oregon.gov/Gov/OEIB/OregonEducationInvestmentBoard.shtml

Office of the Governor. (2011b). Oregon learns: SB909 report to the legislature December 15,2011 . Retrieved from http://www.oregon.gov/Gov/OEIB/OregonEducationInvestmentBoard.shtml

Ord, K. (2010). Bodies of knowledge: Early childhood teachers' experiences of their initial teacher education programme and sense of preparedness for teaching. Retrieved from http://mro.massey.ac.nz

Oregon Administrative Rules. (2011). Child care administrative rules. (Chapter 657A child care). Salem, OR: State of Oregon.

Oregon Center for Career Development in Childhood Care and Education. (2008). Core body of knowledge for Oregon's childhood care and education professionals. Retrieved from http://www.pdx.edu/occd

Oregon Center for Career Development in Childhood Care and Education. (2009). Oregon Registry Steps for the Oregon Registry: Pathways to professional recognition in childhood care \& education. Retrieved from http://www.pdx.edu/occd

Oregon Center for Career Development in Childhood Care and Education. (2012). December 2012 Data Report. Portland, OR: Portland State University.

Oregon Center for Career Development in Childhood Care and Education. (2013). July 2013 Data Report. Portland, OR: Portland State University.

Oregon Center for Career Development in Childhood Care and Education. (2014). March 2014 Data Report. Portland, OR: Portland State University.

Oregon Employment Department Child Care Division. (2008). Registered Family Child Care Providers 2008 Customer Survey Report. Retrieved from http://library .state.or.us/repository/2009/200905221427095/index.pdf

Oregon Employment Department Child Care Division. (2009). Certified Family Child Care Providers 2009 Customer Survey Report. Retrieved from http://www .claritywriting.com/samples/State\%20agency\%20survey\%20report.pdf

Oregon Employment Department Child Care Division. (2010). Certified Child Care Centers 2010 Customer Survey Report. Retrieved from http://www.oregon.gov /EMPLOY/CCD/docs/forms/2011oedccdcenterssurveyreprev4web.pdf 
ECE PERCEPTIONS OF OREGON'S PDS

Oregon Employment Department Child Care Division. (2011). About us. Retrieved from http://www.oregon.gov/EMPLOY/CCD/Pages/about_us.aspx

Ortlipp, M., Arthur, L., \& Woodrow, C. (2011). Discourse of the early childhood learning framework: Constructing the early childhood professional. Contemporary Issues in Early Childhood, 12(1), 56-70. doi:10.2304/ciec.2011.12.1.56

Osgood, J. (2006). Deconstructing professionalism in early childhood education: Resisting the regulatory glaze. Contemporary Issues in Early Childhood Education, 7(1), 5-14. doi: 10.2304/ciec.2006.7.1.5

Osgood, J. (2009). Childcare workforce reform in England and "the early years Professional": A critical discourse analysis. Journal of Education Policy, 24(6), 733-751. doi:10.1080/02680930903244557

Osgood, J. (2010). Reconstructing professionalism in ECEC: The case for the "critically reflective emotional professional." Early Years, 30(2), 119-133. doi:10.1080/09575146.2010.490905

Osgood, J. (2012). Narratives from the nursery: Negotiating professional identity in early childhood. New York: Routledge.

Parnell, W. (2010). Image of the teacher in educational leadership. National Council of Professors of Educational Administration. Retrieved from: http://cnx.org/content/m34806/latest/

Parnell, W. (2011). Experiences of teacher reflection: Reggio inspired practices in the studio. Journal of Early Childhood Research 10(2), 117-133. doi:10.1177/1276718X11407982

Parnell, W. (2012a). Investigating the Reggio Emilia study tour experience: From conversation to insights. Networks, 14(1).

Parnell, W. (2012b). Reconstruction: Meltdown in the midst of beauty. The Indo-Pacific Journal of Phenomenology, 12, 1-8.

Parnell, W., \& Iorio, J. M. (In press). A/r/tography and action research: Crisis, empowerment and learning in early childhood. In Narrative, arts-based and postapproaches to research. Thousand Oaks, CA: Sage.

Patton, M. Q. (2002). Qualitative research and evaluation methods ( $3^{\text {rd }}$ ed.). Thousand Oaks, CA: Sage. 
Pham, R., \& DeMoe, L. (2012, July). Overview of the tiered quality rating improvement system (TQRIS). PowerPoint presentation at the Qualifications Credentials and Pathways Committee of the Child Care Division. Gladstone, OR.

Phillips, D. C. (1995). The good, the bad and the ugly: The many faces of constructivism. Educational Researcher, 24(7), 5-12.

Ricoeur, P. (1976). Interpretation theory: Discourse and the surplus of meaning. Fort Worth, TX: The Texas Christian University Press.

Rinaldi, C. (1998). The space of childhood. In G. Ceppi \& M. Zini (Eds.). Children, spaces, relations: Metaproject for an environment for young children (pp. 114120). Milan, Italy: Domus Academy Research Center.

Sachs, J. (2001). Teacher professional identity: Competing discourses, competing outcomes. Journal of Education Policy, 16(2), 149-161. doi:10.1080/02680930116819

Saracho, O. N., \& Spodek, B. (1993). Professionalism and preparation of early childhood education practitioners. Early Childhood Development and Care, 89, 1-17.

Schön, D. A. (1983). The reflective practitioner: How professionals think in action. New York: Basic Books.

Seamon, D. (2012, June). Challenges for Qualitative Approaches in EnvironmentBehavior Research: Ideology, Ethics, and Understanding Phenomena," Paper presentation at the annual meeting of the Environmental Design Research Association (EDRA), Seattle, WA.

Sfard, A. (1998). On two metaphors for learning and the dangers of choosing just one. Educational Researcher, 27(2), 4-13.

Sims, D. (2005). The road less traveled [photograph]. Retrieved from www.simspix.com

Skattebol, J. (2010). Affect: A tool to support pedagogical change. Discourse: Studies in the Cultural Politics of Education, 31(1), 75-91. doi:10.1080/015963009033465435

Smith, D. W. (2011). Phenomenology. In E. N. Zalta (Ed.). The Stanford Encyclopedia of Philosophy (Fall 2011 Edition), Retrieved from http://plato.stanford.edu /archives/fall2011/entries/phenomenology 
Springgay, S., Irwin, R. L. \& Kind, S.W. (2005). A/r/topography as living inquiry through art and text. Qualitative Inquiry, 11(6), 897-911. doi:10.1177/107780040528096

Sumsion, J. (2001). Becoming, being and unbecoming an early childhood educator: A phenomenological case study of teacher attrition. Teaching and Teacher Education, 18, 869-885.

Sumsion, J. (2003). Rereading metaphors as cultural texts: A case study of early childhood teacher attrition. The Australian Educational Researcher, 30(3), 67-87.

Taggart, G. (2011). Don't we care? The ethics and emotional labour of early years professionalism. Early years, 31(1), 85-95. doi: 10.1080/09575146.2010.536948

Taguchi, H. L. (2007). Deconstructing and transgressing the theory - Practice dichotomy in early childhood education. Educational Philosophy and Theory, 39(3), 275290. doi:10.1111/j.1469-5812.2007.00324.x

Tennant, M., \& Pogson, P. (1995). Learning and change in the adult years. San Francisco: Josse-Bass.

The Reggio Emilia Australia Information Exchange. (2011). Pedagogical Documentation. Retrieved from http://www.reaie.org.au/component /content/article/61

Torquati, J. C., Raikes, H., \& Huddleston-Casas, C. A. (2007). Teacher education, motivation, compensation, workplace support, and links to quality of center-based child care and teachers' intention to stay in the early childhood profession. Early Childhood Research Quarterly, 22, 261-275.

Vagle, M. D. (2009). Validity as intended: "Bursting forth toward" bridling in phenomenological research. International Journal of Qualitative Studies in Education, 22(5), 585-605.

Van Manen, M. (1990). Researching lived experience: Human science foe an action sensitive pedagogy. New York: State University of New York Press. Van Manen, M. (1982). Phenomenological pedagogy. Curriculum Inquiry, 12(3), 283-299.

Van Manen, M. (2011a). Thematic reflection. Phenomenology Online: A resource for phenomenological inquiry. Retrieved from www.phenomenologyonline.com 
Van Manen, M. (2011b). Orientation in phenomenology. Phenomenology Online: resource for phenomenological inquiry. Retrieved from www.phenomenologyonline.com/inquiry/orientations-in-phenomenology/

Van Manen, M. (2011b). Thematic reflection. Phenomenology Online: A resource for phenomenological inquiry. Retrieved from www.phenomenologyonline.com /inquiry/orientations-in-phenomenology/hermeneutical-phenomenology/

Warash, B., Curtis, R., Hursh, D., \& Tucci, V. (2008). Skinner meets Piaget on the Reggio playground: Practical synthesis of applied behavior analysis and developmentally appropriate practice orientations. Journal of Research in Early Childhood Education, 22(4), 441-453.

Webster-Wright, A. (2009). Reframing professional development through understanding authentic professional learning. Review of Educational Research, 79(2), 702-739. doi:10.3102/00346554308330970

Western Oregon University (2013a). Oregon's quality rating and improvement standards for center-based child care programs. Retrieved from http://www.wou.edu /tri/QRIS/Family-Based.pdf

Western Oregon University (2013b). Oregon's quality rating and improvement standards for family child care providers. Retrieved from Chapter 1-5 on 5-2414.docxhttp://www.wou.edu/tri /QRIS/Family-Based.pdf

Wheatley, M. J., \& Kellner-Rogers, M. (1996). A simpler way. San Francisco: BerrettKoehler Publishers.

Woodrow, C. (2007). W(H)Ither the early childhood teacher: Tensions for early childhood professional identity between the policy landscape and the politics of teacher regulation. Contemporary Issues in Early Childhood, 8(3), 233-243. doi:10.2304/ciec.2007.8.3.233

Woodrow, C., \& Press, F. (2007). (Re)Positioning the child in the policy/politics of early childhood. Educational Philosophy and Theory, 39(3), 312-325.

Zigler, E., Gilliam, W. S., \& Barnett, W. S. (Eds.). (2011). The pre-k debates: Current controversies and issues. Washington, DC: NAEYC.

Zigler E., \& Styfco, S. J. (2003). The federal commitment to preschool education: Lessons from and for Head Start. In A. J. Reynolds, M.C. Wang, \& H. J. Walberg (Eds.), Early childhood programs for a new century (pp. 3-33). Washington, DC: CWLA Press. 


\section{APPENDIX A \\ RECRUITMENT MATERIALS}

\section{Website Recruitment Posting}

Do you have experiences with Oregon's Childhood Care and Education Professional Development System, you would like to share? My name is Ingrid Anderson. I a doctoral Candidate at Portland State University seeking to understand early childhood educator's experiences in working in Child Care Division/Office of Child Care Licensed Child Care Centers with children from three to five years of age for a minimum of 3 years.

In fall 2013 and winter of 2014, you are invited to participate in a research study investigating early childhood educator's experiences with Oregon's Professional Development System. The purpose of this study is capture early childhood educator's experiences in their own professional journey and explore how interactions with the Professional development system can intersect professional practice. The study includes a preliminary phone interview and a 60 to 90 minute interview session. During the interviews you will have an opportunity to create a collage of their experiences as part of the interview process.

If you are interested in learning more about the study, please contact Ingrid Anderson at 503-866-0454. 
$\underline{\text { Recruitment Flyer }}$
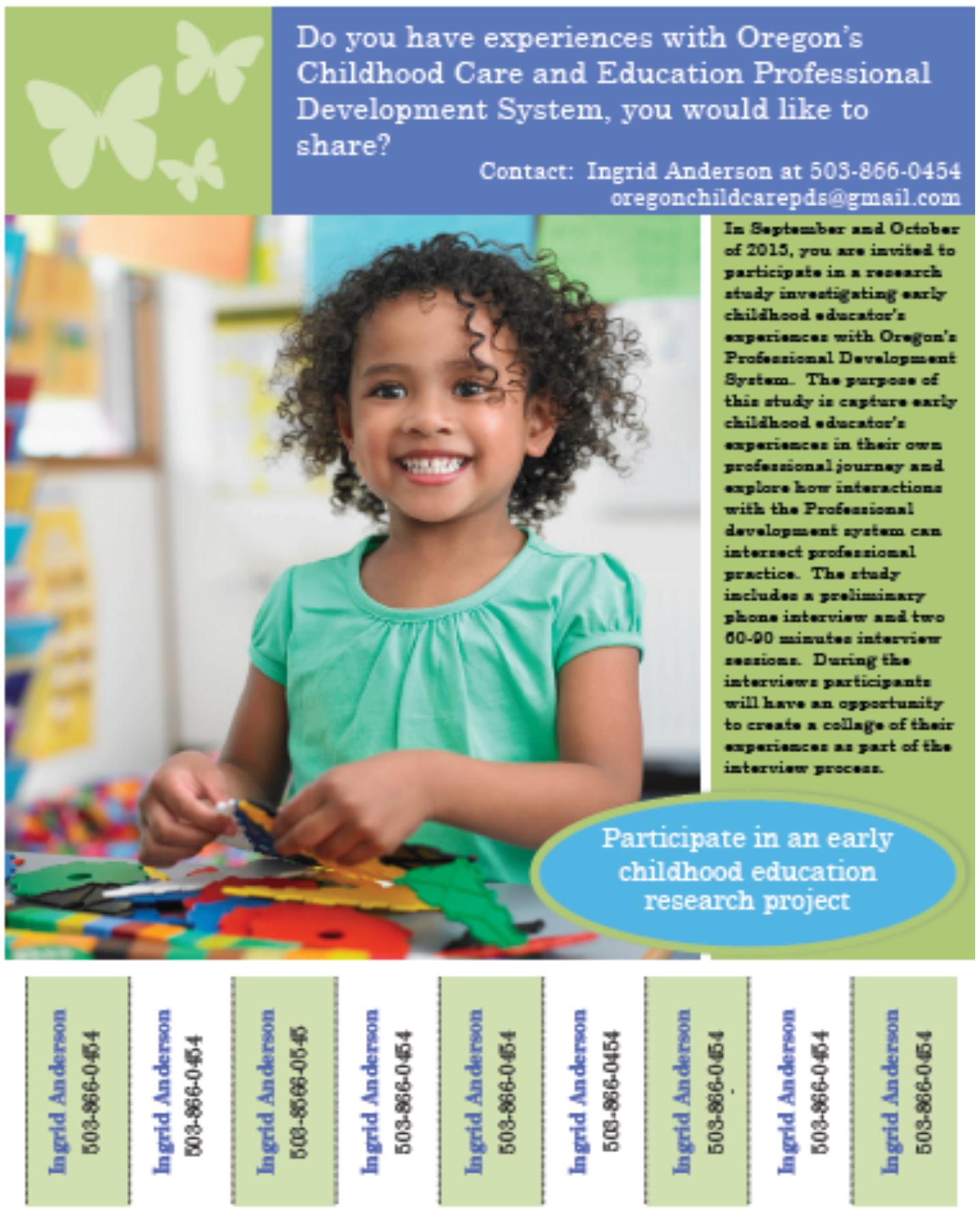


\title{
APPENDIX B
}

\section{SUPPORT FOR NAVIGATING OREGON'S PROFESSIONAL DEVELOPMENT SYSTEM}

\author{
Resource List for Support in Navigating Oregon's Professional Development \\ System \\ Additional information for Oregon Professional Development System for childhood care \\ and education professionals is available from Child Care Resource and Referral \\ Programs.
}

\section{What is Child Care Resource and Referral?}

Child Care Resource and Referral Agencies (CCR\&Rs) are grass roots programs that provide child care referrals and parenting information to parents, training and technical assistance to child care providers, information and support for employers and for the community. There are currently 13 community-based $C C R \& R s$ in Oregon receiving state funding. All are members of the Oregon Child Care Resource and Referral Network.

$C C R \& R$ programs work with parents seeking child care, as well as parents with questions about what is important in child care, or perhaps with questions about their child's development. CCR\&R programs work with providers, connecting them with parents needing child care, providing access to child care trainings, and providing information and technical assistance. CCR\&R programs work directly with employers who help employees with child care and other family needs. Child care resource and referral programs also work with state agencies and local communities to address the growing demand for good, affordable child care. Funded through a combination of public and private resources, $C C R \& R$ programs reflect the diversity and needs of the communities in which they serve.

\begin{tabular}{|c|c|}
\hline $\begin{array}{l}\text { What CCR\&R does for providers } \\
\text { - Refer families who need child care } \\
\text { - Offer training in child development, health } \\
\text { and safety, and business practices } \\
\text { - Provide ongoing support and links to } \\
\text { resources }\end{array}$ & $\begin{array}{l}\text { What CCR\&R does for employers } \\
\text { - Conduct work-life effectiveness training for } \\
\text { managers, supervisors and employees } \\
\text { - Offer workplace resource and referral programs } \\
\text { - Consult on work-life strategies to boost } \\
\text { recruitment, retention and productivity }\end{array}$ \\
\hline $\begin{array}{l}\text { What CCR\&R does for communities } \\
\text { - Provide data for planning and policy } \\
\text { making } \\
\text { - Maintain a directory of community } \\
\text { resources for families } \\
\text { - Improve the quality and supply of child care } \\
\text { - Advocate for a high quality child care } \\
\text { system }\end{array}$ & $\begin{array}{l}\text { What CCR\&R does for families } \\
\text { - Offers personalized assistance on choosing } \\
\text { quality child care. } \\
\text { - Makes referrals to local child care providers and } \\
\text { school age programs } \\
\text { - Connects families with resources to help with the } \\
\text { cost of care } \\
\text { - Finds care options for non-traditional work } \\
\text { schedules and children with special needs }\end{array}$ \\
\hline
\end{tabular}


Child Care Resource and Referral of Clackamas County

Toll-free Phone: 1-866-371-4373

Website:

www.clackesd.k12.or.us
Child Care Resource and Referral of Multnomah County*

Toll-free Phone: 1-866-227-5529

Website: www.ccrr-mc.org

*Serves Spanish, Russian,

Vietnamese language speakers

across tri-county area
Child Care Resource and Referral of Washington and Columbia County

Toll-free Phone: 1-800-6249516

Website:

www.communityaction $4 u$.org 
APPENDIX C

INITIAL PHONE SCREENING

Interviewee:

Time:

Date:
Interview \#:

Thank you for calling to find out more about my research study. This call should take approximately 15 minutes.

Before you decide to participate in this study, it is important to understand that Ingrid Anderson works with the Oregon Center for Career Development in Childhood Care and Education, home of the Oregon Registry. If you participate in the Oregon Registry or any of the programs supported by the Oregon Center for Career Development, there are no benefits or drawbacks to participating in this study connected to OCCD. If you are interested in the programs of OCCD, a contact will be provided to support you in navigating OCCD programs as part of Oregon's Professional Development System from the Child Care Resource and Referral in your county.

In addition to working for OCCD, I am a doctoral study at Portland State University in the Graduate School of Education. The purpose of this research study is seeking to explore early childhood educator's experiences in Oregon childhood care and education professional development system.

The study involves one 60-90 minute interview. Through the use of collage, you will reflect on their professional experiences in working in the childhood care and education profession, and will share their insights into navigating Oregon's professional development system.

As part of the dissertation study, I am asking individuals interested in participating in the study to identify some basic personal and professional demographic information. Do you think you would be interested in in participating in this study?

$\{$ If No: $\}$ Thank you very much for calling.

\{If Yes: $\}$ Before enrolling individuals in this study, I need to determine if you are eligible. I would now like to ask you a series of questions about your personal and professional demographical information. There is a possibility that some of these questions might make you uncomfortable. If so, please let me know. You don't have to answer any of those questions if you do not want to. You also need to understand that all 
information I receive from you by phone, including your name and any other identifying information, will be strictly confidential and will be kept locked in a file cabinet on the PSU campus. The purpose of these questions is only to determine if you are eligible for the larger study. Remember your participation is voluntary; you do not have to complete these questions.

Do I have your permission to ask you these questions?

\{If No: $\}$ Thank you very much for calling.

\{If Yes:\} I have several of personal demographic questions to ask you.

- Are you at least 21 years of age?

- Do you identify as female?

- Do you live in the Portland Metro area?

Thank you. Additionally, I have a series of five professional questions to ask you.

- Are you currently working in a Child Care Division/Office of Child Care licensed center-based program?

- Are you currently working with children, ages 3-5 years of age?

- How long have you worked with this age group?

- Are you familiar with Oregon Professional Development system for childhood care and education professionals?

- Can you name two or more agencies or programs in Oregon's professional development system that you participate in?

\{If No to one or more questions: \} Thank you very much for calling. I sincerely appreciate the time you took to talk with me today. Would you like phone number or website address to obtain additional information for Oregon Professional Development system for childhood care and education professionals?

Child Care Resource and Referral of Clackamas County

Toll-free Phone: 1-866-371-4373

Website: www.clackesd.k12.or.us

Child Care Resource and Referral of Multnomah County*

Toll-free Phone: 1-866-227-5529

Website: www.ccrr-mc.org

*Serves Spanish, Russian, Vietnamese language speakers across tri-county area

Child Care Resource and Referral of Washington and Columbia County

Toll-free Phone: 1-800-624-9516

Website: www.communityaction4u.org 
\{If Yes:\} Thank you for answering the questions. You are eligible to participate in the interview study in exploring early childhood educator's experiences in Oregon childhood care and education professional development system.

This interview is designed in two-parts. Through the use of collage, you will reflect on your professional experiences in working in the childhood care and education profession, and then you will share your insights in regard to navigating Oregon's professional development system.

For the purpose of this study, a collage is defined as an art medium that uses various forms materials and objects pasted over a surface. Collage is often used to help people tell their stories. The purpose of a collage in this research project is to support you in telling your story of your experiences in your professional journey. There are no expectations about the 'look' of the collage. It is a tool for telling your story.

In this research study, the collage materials will use different types of paper and images to tell your story of your professional journey in early childhood education. You are welcome and encouraged to bring any pictures, photos, quotes or other materials that help you to tell your story of your journey as an early childhood educator.

The interview format will include an introduction and a review of the Informed Consent document, telling you about the study and laying out guidelines of what to expect. Then photos will be taken of any materials you choose to bring to the interview. A tour of the room and the tools available will be next, followed by private time to work on your collage. Next an interview will take place, where we will discuss your journey as an early childhood educator and experiences in Oregon's professional development system, using the collage as support. The last part of the interview will be to take photos of your collage.

Are you interested in participant in the study?

\{If No: $\}$ Thank you very much for calling. I sincerely appreciate the time you took to talk with me today. Would you like phone number or website address to obtain additional information for Oregon Professional Development system for childhood care and education professionals?

\{If Yes:\} The study is conducted during the months September 2013 through February 2014 at a local private art studio in the Portland metro area. Thank you for agreeing to a location.

What times and dates work best for you for an interview? 
What would be the best way to contact you to confirm the times and dates of your interviews?

Thank you for agreeing to participate in this study. I will contact you within 48-hours with the times and locations of you interview.

My contact information is Ingrid Anderson ingrid2@pdx.edu or you can call me at 503866-0454. 
APPENDIX D

RESEARCH LOG

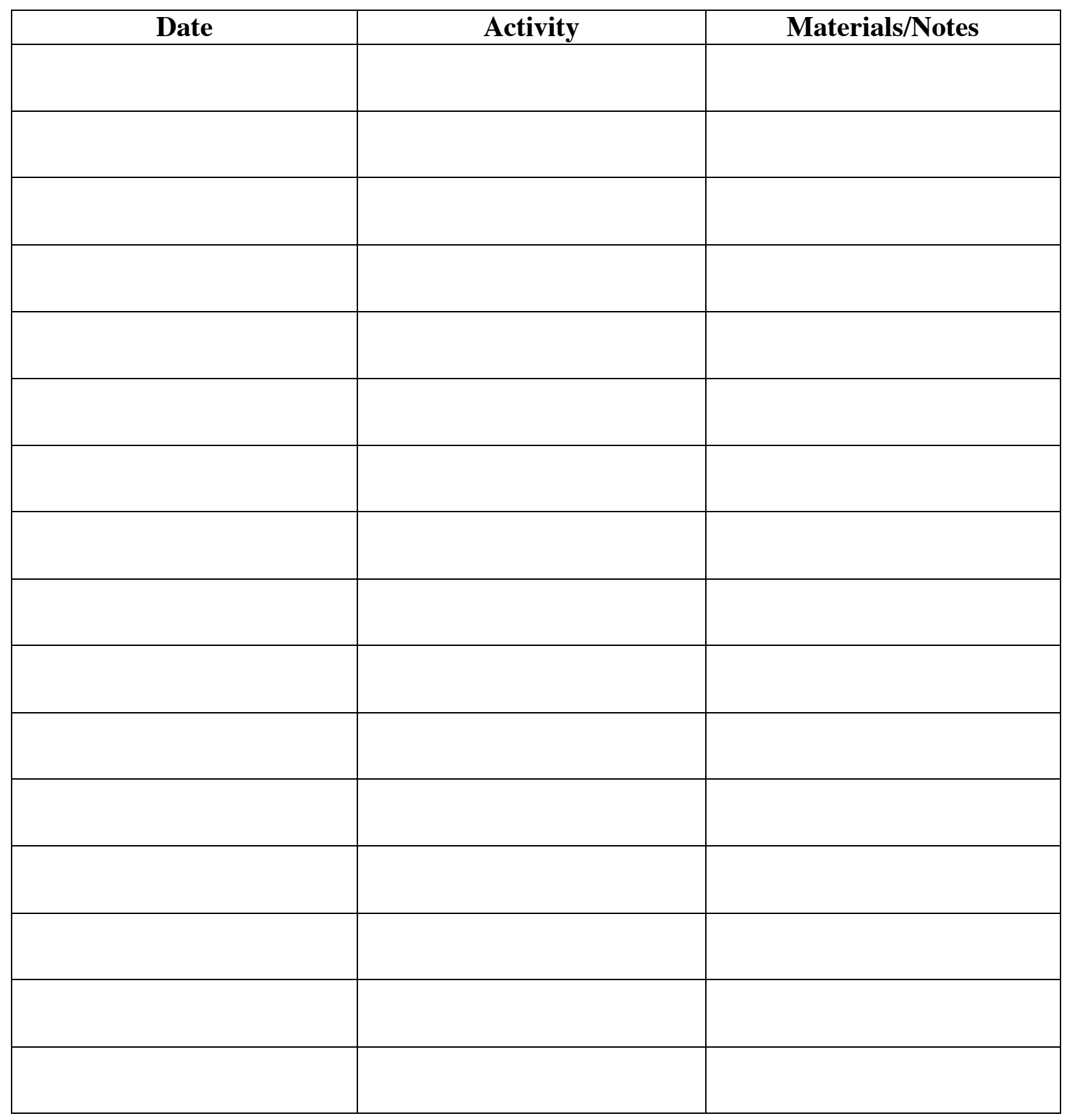




\section{APPENDIX E}

\section{DATA COLLECTION TIMELINES AND PROCEDURES}

\section{Dates of Project}

August 2013 to

February 2014

September 2013 to

February 2014

November 2013 to

February 2014

November 2013 to

February 2014

November 2013 to

February 2014

November 2013 to

April 2014

\section{Activity}

Participant Recruitment at OregonAEYC and CCR\&R

- Posting web announcements

- Distributing flyers

Initial Phone Screening using phone screening scrip

Email confirmation of interview

Interviews using interview script

Researcher-participant reflective writing following interviews

Researcher-participant Reflections on collages

\section{Data Collected}

Activities entered into

Research Log

Researcher-participant

Notes

Research Log

Response

Audio recording

Transcripts

Artifacts

Research-participant Log

Transcripts

Artifacts

Research-participant Log

Artifacts

Research-participant Log 


\section{APPENDIX F \\ INTERVIEW PROTOCOL}

Interviewee:

Time:

Date:

\section{Introduction to Interview and Collage}

My name is Ingrid Anderson and I am a doctoral study at Portland State University in the Graduate School of Education and work for the Oregon Center for Career Development in Childhood Care and Education. It is good to meet you in person. Here is my contact information if you need to get ahold of me during the process. My contact information is Ingrid Anderson ingrid2@pdx.edu or you can call me at 503-866-0454.

Thank you for your interest participating in the interview portion of the research study. We will spend 60-90 minutes together. The purpose of this research study is seeking to explore early childhood educators' experiences in the Oregon childhood care and education professional development system.

This interview is designed in two-parts. Through the use of collage, you will reflect on their professional experiences in working in the childhood care and education profession and then will share your insight in navigating Oregon's professional development system.

I would like to start our time together by reviewing the Informed Consent Document. An informed consent document provides you with information as to what will happen during the interviews, and will provide information about what you can expect during our time together, and speak to the collection and use of data. I brought a copy for you to keep for your records today. At any point that you feel uncomfortable, then please feel free to let me know. If you wish to leave at any time, please feel free to do so.

What questions do you have?

Let us review the informed consent form. Review Form.

Do you have any questions?

Thank you for participating in this study.

\section{Introduction to Collage as Part of Interview}


Collage is often used to help people tell their stories. The purpose of this collage is support you in telling your story of your experiences in your professional journey. There are no expectations about the "look" of the collage. It is a tool for telling your story.

As part of the interview process, we will be working on a collage to facilitate some of your thoughts about your professional journey. A professional journey can be defined in many ways... how you came to work in early childhood, the experiences that you have had along the way, a memorable moment... and can describe your professional journey. The collage is a way to capture some of your memories of your professional journey.

Let's look at the materials. For the base of your collage, I have several pieces of heavy cardstock or watercolor paper that you can use for the base. For the collage, you can use any of material provided. There are magazines, newspaper, sharpie markers, scissors, printed paper, and glue.

So, in collage, you can look at materials and think about what materials would help you tell your story about your professional journey. One advantage of collage is that you can move objects around. So, all of these materials you use can come together, and you can organize them in a way you find tells your story. On the table, I have left a piece of paper with the prompts about professional journeys.

- $\quad$ Tell the story about your journey in early childhood education.

- Think about your interactions with Oregon's professional development system as part of your journey.

- How do you see yourself as part of the early childhood education community?

You can take as much or little time as you need to tell your story about your professional journey. Once you are ready to start, I will leave the room. Please take as much time as you wish. I will be outside the room if you have any question. When you are ready, please come get me to begin the interview.

I would like to start by taking photos of the artifacts you brought for the collage. Is that all right with you?

Thank you. I will now leave you. Please take your time. When you are ready I will be outside the door.

Participant works on collage.

When resuming the interview: Thank you, would you like to take a break?

When you are ready, we can start on the second part of the interview. I have a digital recorder set-up to capture our conversation. Also, during the interview, you might see me 
take notes from time-to-time, which is just to help me remember when I look at our interview later.

When we are done with the interview, I would like to take photos of your collage.

\section{Semi-Structured Interview Question}

1. How is the process of collage for you?

2. Was there anything that surprised you?

3. Can you tell me about your collage? Follow-up if needed, can you tell me about your professional journey?

- Can you share what made you choose these particular experiences?

- What feelings did these experiences bring up for you?

- How did these experiences impact your practice?

If needed: Think about your interactions with Oregon's professional development system as part of your journey.

- Can you share what made you choose these particular experiences?

- What feelings did these experiences bring up for you?

- How did these experiences impact your practice?

How do you see yourself as part of the early childhood education community?

- Can you share what made you choose these particular experiences?

- What feelings did these experiences bring up for you?

- How did these experiences impact your practice?

Prompts

- "Can you tell me more about..." and,

- "How did that make your feel" or

- "Thinking back, are there particular experiences that changed your thinking?"

Thank you for sharing your experiences with me. Before I take photographs of your collage, is there anything else you would like to share?

I want to express my appreciation for your participation in this study. Would you like me to send you photos of your collage, your interview and, or a copy of the completed study? You have my contact information and, if I have any questions, may I follow-up with you? 
Materials List

Collage Base

- Heavy watercolor paper

- Paper in rectangle, square and circles

- Color - cream

- $\quad$ Size - variety, minimum size $11 \times 17$, max size $16 \times 22$

Tools

- Regular and crafty scissors

- Glue sticks and Adhesives
Options for collage materials

- $\quad$ Paper with print -newspaper and/or magazine

- $\quad$ Paper with pattern - printed patterns with variety of color

- $\quad$ Plain paper variety of colors
- $\quad$ Markers, pencils, and pens

- Rubber stamps
- Paper cutter

- Die-cutting machine

- Crafty hole punches

- Stencils and rulers 


\section{APPENDIX G}

\section{INFORMED CONSENT FORM}

Study title:

Early Childhood Educators' Perception of Oregon's Professional Development System: A Hermeneutic Phenomenological Study.

\author{
Principle investigator: \\ Will Parnell \\ Graduate School of Education \\ Education \\ Curriculum and Instruction \\ PO Box 751 \\ 300 Portland, OR 97207-0751 \\ 503-725-3091 \\ parnellw@pdx.edu
}

\author{
Co-Investigator: \\ Ingrid Anderson \\ Graduate School of \\ Curriculum and Instruction \\ 527 SW Hall Street, Suite \\ Portland, OR 97201 \\ 503-866-0454 \\ ingrid2@gmail.com
}

\section{Introduction to the study:}

You are being invited to take place in a research study. Before you decide to participate in this study, it is important to understand that Ingrid Anderson (me) works with the Oregon Center for Career Development in Childhood Care and Education, home of the Oregon Registry. If you participate in the Oregon Registry or any of the programs supported by the Oregon Center for Career Development, there are no benefits or drawbacks to participating in this study connected to OCCD. If you are interested in the programs of OCCD, a contact will be provided to support you in navigating OCCD programs as part of Oregon's Professional Development System from the Child Care Resource and Referral in your county.

In addition to working for OCCD, I am a doctoral study at Portland State University in the Graduate School of Education. The purpose of this research study is seeking to explore early childhood educator's experiences in Oregon childhood care and education professional development system.

The study involves one 60-90 minute two-part interview. In the first part, you will have a chance to reflect on professional experiences in working in the childhood care and education profession and share their insight in navigating Oregon's professional development system through the use of collage. In the second part, you will sit with the researcher and talk about your collage and experiences in Oregon's professional development system. 
It is important that you understand why the research is being done and what it will involve. Please take the time to read the following information carefully. Please ask me if there is anything that is not clear or if you need more information.

\section{What will happen during the study:}

The study will require you to agree to an initial phone interview. The initials phone interview will be approximately 15 minutes. You will participate in an interview ranging from 60-90 minutes. The study is conducted during the months September 2013

through February 2014 at a location in a local private art studio in the Portland metro area. The interview has two-parts, a self-reflective process using collage to think about the research question as it relates to the your professional life and an interview about your experiences, using the collage as a reference.

Data will be gathered from your collage and interview. The data collected includes an audio recording of our conversation, photos of your collages, interview notes, and research reflections following the interview and from the collage and interviews. The audio will be used to transcribe the conversation and check for concepts and themes from the interview. The collage is yours to take at the end of the interview. A copy of your interview transcription, photos of your collage, and final dissertation will be available on request.

\section{Risks:}

The risk of this study is minimal. These risks are similar to those you experience when you share work-related information with others. If the topics challenge you beyond your comfort level, you may choose to decline to answer any questions in the study and you may terminate your involvement at any time if you choose.

\section{Benefits:}

There will be no direct benefit to you from this study beyond the pleasure of sharing your experiences. However, I hope that the information from this study will bring early childhood educators' voice to the state policy makers

\section{How is the participant's (your) privacy protected:}

For the purpose of this research project, your interview will be confidential unless you give permission for the use of your identity. Every effort will be made by the researcher to preserve your confidentiality including the following:

Assigning code names and numbers to all participating individuals that will be used on all researcher notes and documents:

- Notes, audio, transcriptions, transcribed notes, and any other identifying participant information will be kept in a locked file cabinet in the personal possession of the researcher. When no longer necessary, all materials will be destroyed. Collages will be returned to you if desired. 
- Information from this research study will be used solely for the purpose of this study and any publications that may result from this study. Any final publications will remain confidential unless you have agreed to waive confidentiality.

- You have the opportunity to obtain a transcribed copy of their interview and photos of their collage. Please tell the researcher if a copy of the interview and photos of the collage are desired.

You should be aware that the researcher is a mandated reporter by Oregon law and confidentiality is not protected if the researcher is legally required to make a report on an incident involving a child.

\section{Contact:}

Should you have any questions about the research or any related matters, please contact co-investigator Ingrid Anderson at ingrid2@pdx.edu or at 503-866-0454. If you have any questions about the co-investigator, please contact principle investigator, Will Parnell at 503-725-3091or parnellw@pdx.edu.

\section{Institutional Review Board:}

If you have any questions regarding your rights as a research subject, or if problem arise which you do not feel like you can discuss with the principle investigator, please contact the Institutional Review Board at hsrre@pdx.edu.

\section{Voluntary Participation:}

Your participation in this study is voluntary. It is up to you to decide whether or not to take part in this study. If you decide to take part in this study, you will be asked to sign a consent form. If you decide to take part in this study, you are still free to withdraw at any time and without giving a reason. You are free to answer or not answer any question or questions if you choose. This will not affect any relationship you have with the researcher or have any impact on your participation in any programs of Oregon's Professional Development System.

\section{Unforeseen risk:}

There may be risks that are not anticipated. However, every effort will be made to minimize any risks.

\section{Cost to participate:}

There is no cost for your participation in this study.

\section{Compensation:}

There is no compensation for this study.

\section{PLEASE READ THE FOLLOWING STATEMENT AND SIGN BELOW IF YOU AGREE.}


I have had the chance to ask any questions I have about this study and my questions have been answered. I have read the information in this consent form and I agree to participate. Select One:

$\square$ I give permission for my real identity to be used in the research (please initials)

$\square$ I wish for my identity to remain confidential (please initial)

Signature of the participant

Date

Printed name of the participant 
APPENDIX H

\section{ARTIFACT CATALOGUE}

Artifact

Date Received:

Number:

Artifact Type:

$\square$ Photo

Personal representation

$\square$ Other :

Location:

Description of Artifact:

Event or Contact associated with artifact:

Presentation of artifact:

Personal representation for collage

Other:

Brief Summary of artifact: 